University of South Florida

DIGITAL COMMONS Digital Commons @ University of @ UNIVERSITY OF SOUTH FLORIDA South Florida

$7-1-2012$

\title{
A Summary of Design, Policies and Operational Characteristics for Shared Bicycle/Bus Lanes
}

CUTR

Follow this and additional works at: https://digitalcommons.usf.edu/cutr_nctr

\section{Recommended Citation}

"A Summary of Design, Policies and Operational Characteristics for Shared Bicycle/Bus Lanes," National Center for Transit Research (NCTR) Report No. CUTR-NCTR-RR-2011-07, Center for Urban Transportation Research, University of South Florida, 2012.

DOI: https://doi.org/10.5038/CUTR-NCTR-RR-2011-07

Available at: https://scholarcommons.usf.edu/cutr_nctr/119

This Technical Report is brought to you for free and open access by the National Center for Transit Research (NCTR) Archive (2000-2020) at Digital Commons @ University of South Florida. It has been accepted for inclusion in Research Reports by an authorized administrator of Digital Commons @ University of South Florida. For more information, please contact digitalcommons@usf.edu. 


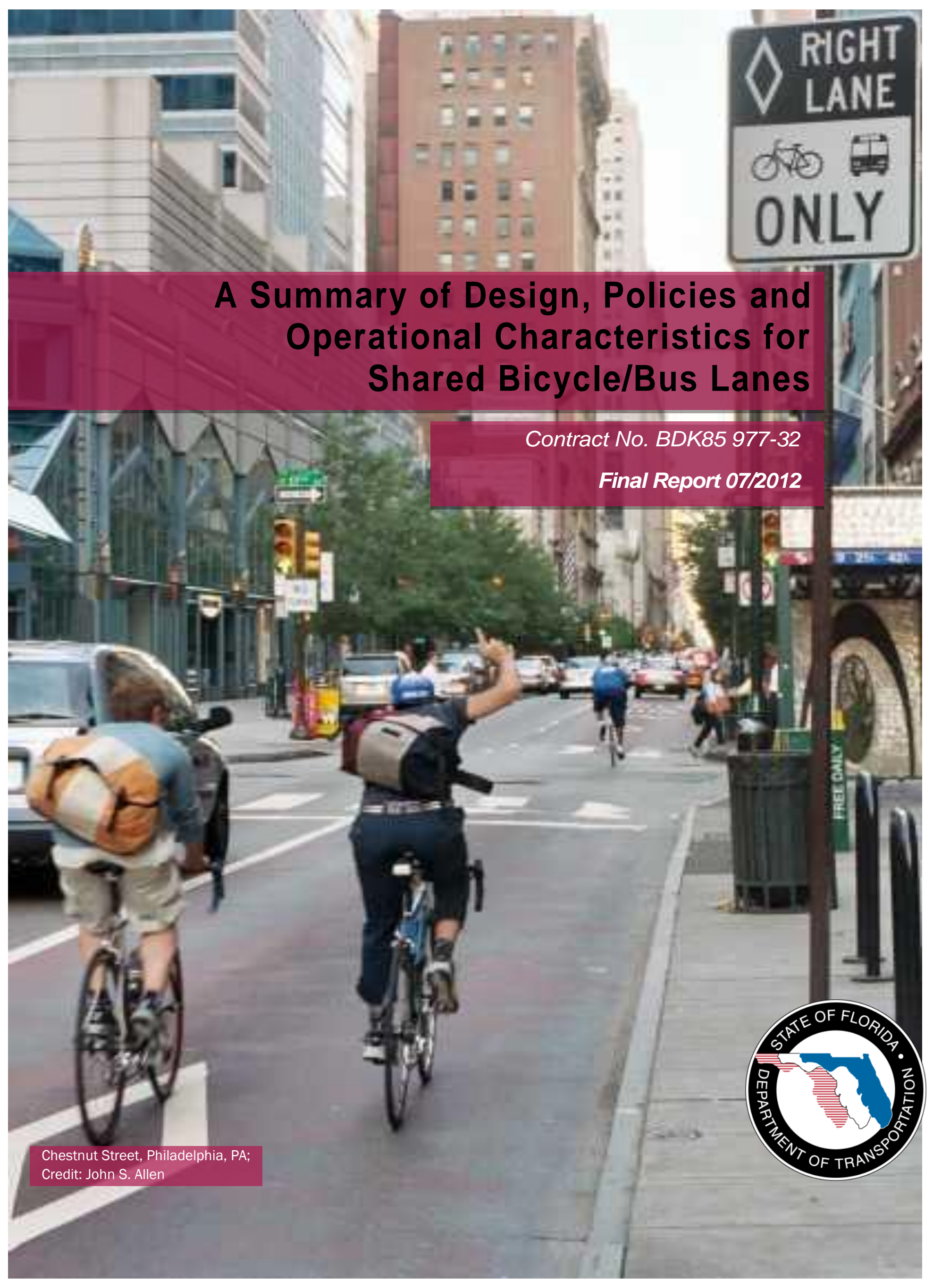




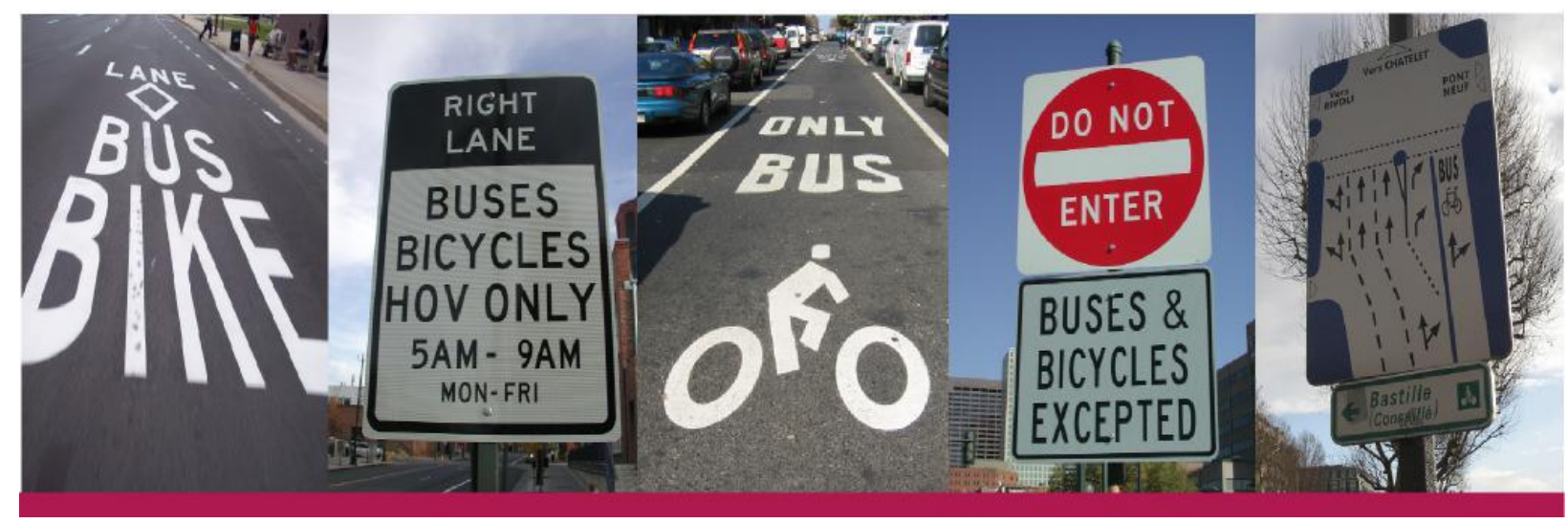

A Summary of Design, Policies and Operational Characteristics for Shared Bicycle/Bus Lanes Project No. BDK85 977-32

Prepared By

Edward L. Hillsman, Ph.D., Senior Research Associate, Transportation Demand Management Sara J. Hendricks, AICP, Senior Research Associate, Transportation Demand Management JoAnne K. Fiebe, MUCD, LEED AP, Research Assistant Center for Urban Transportation Research University of South Florida 4202 East Fowler Avenue, CUT100 Tampa, FL 33620-5375
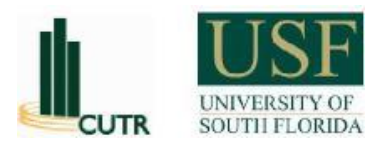

Joel Volinski, National Center for Transit Research Program Director Philip L. Winters, Transportation Demand Management Program Director

Prepared For The Florida Department of Transportation Research Center 605 Suwannee Street, MS 30 Tallahassee, FL 32399 Project Manager: David C. O'Hagan, P.E. Co-Project Manager: Mary Anne Koos

July 2012

Final Report 


\section{Disclaimer}

The contents of this report reflect the views of the authors, who are responsible for the facts and the accuracy of the information presented herein. This document is disseminated under the sponsorship of the Department of Transportation University Transportation Centers Program and the Florida Department of Transportation, in the interest of information exchange. The U.S. Government and the Florida Department of Transportation assume no liability for the contents or use thereof. 


\section{Metric Conversion}

SI* Modern Metric Conversion Factors as provided by the Department of Transportation, Federal Highway Administration http://www.fhwa.dot.gov/aaa/metricp.htm

\section{Length}

\begin{tabular}{|l|l|l|l|l|}
\hline SYMBOL & WHEN YOU KNOW & MULTIPLY BY & TO FIND & SYMBOL \\
\hline in & inches & 25.4 & millimeters & $\mathrm{mm}$ \\
\hline $\mathrm{ft}$ & feet & 0.305 & meters & $\mathrm{m}$ \\
\hline $\mathrm{yd}$ & yards & 0.914 & meters & $\mathrm{m}$ \\
\hline $\mathrm{mi}$ & miles & 1.61 & kilometers & $\mathrm{km}$ \\
\hline
\end{tabular}

\section{Area}

\begin{tabular}{|l|l|l|l|l|}
\hline SYMBOL & WHEN YOU KNOW & MULTIPLY BY & TO FIND & SYMBOL \\
\hline $\mathrm{in}^{2}$ & square inches & 645.2 & square millimeters & $\mathrm{mm}^{2}$ \\
\hline $\mathrm{ft}^{2}$ & square feet & 0.093 & square meters & $\mathrm{m} 2$ \\
\hline $\mathrm{yd}^{2}$ & square yard & 0.836 & square meters & $\mathrm{m} 2$ \\
\hline $\mathrm{ac}$ & acres & 0.405 & hectares & $\mathrm{ha}$ \\
\hline $\mathrm{mi}^{2}$ & square miles & 2.59 & square kilometers & $\mathrm{km}^{2}$ \\
\hline
\end{tabular}

\section{Length}

\begin{tabular}{|l|l|l|l|l|}
\hline SYMBOL & WHEN YOU KNOW & MULTIPLY BY & TO FIND & SYMBOL \\
\hline $\mathrm{mm}$ & millimeters & 0.039 & inches & in \\
\hline $\mathrm{m}$ & meters & 3.28 & feet & $\mathrm{ft}$ \\
\hline $\mathrm{m}$ & meters & 1.09 & yards & yd \\
\hline $\mathrm{km}$ & kilometers & 0.621 & miles & $\mathrm{mi}$ \\
\hline
\end{tabular}

Area

\begin{tabular}{|l|l|l|l|l|}
\hline SYMBOL & WHEN YOU KNOW & MULTIPLY BY & TO FIND & SYMBOL \\
\hline $\mathrm{mm}^{2}$ & square millimeters & 0.0016 & square inches & $\mathrm{in}^{2}$ \\
\hline $\mathrm{m} 2$ & square meters & 10.764 & square feet & $\mathrm{ft}^{2}$ \\
\hline $\mathrm{m} 2$ & square meters & 1.195 & square yards & $\mathrm{yd}^{2}$ \\
\hline $\mathrm{ha}$ & hectares & 2.47 & acres & $\mathrm{ac}$ \\
\hline $\mathrm{km}^{2}$ & square kilometers & 0.386 & square miles & $\mathrm{mi}^{2}$ \\
\hline
\end{tabular}

*SI is the symbol for the International System of Units. Appropriate rounding should be made to comply with Section 4 of ASTM E380. 


\section{Technical Documentation Page}

\begin{tabular}{|c|c|c|c|c|}
\hline 1. Report No. & \multicolumn{2}{|l|}{ 2. Government Accession No. } & \multicolumn{2}{|l|}{ 3. Recipient's Catalog No. } \\
\hline \multirow{2}{*}{\multicolumn{3}{|c|}{$\begin{array}{l}\text { 4. Title and Subtitle } \\
\text { A Summary of Design, Policies and Operational Characteristics for } \\
\text { Shared Bicycle/Bus Lanes }\end{array}$}} & \multicolumn{2}{|l|}{$\begin{array}{l}\text { 5. Report Date } \\
\text { July } 2012\end{array}$} \\
\hline & & & \multicolumn{2}{|c|}{ 6. Performing Organization Code } \\
\hline \multicolumn{3}{|c|}{$\begin{array}{l}\text { 7. Author(s) } \\
\text { Edward L Hillsman, Sara J Hendricks, AICP, JoAnne Fiebe }\end{array}$} & \multicolumn{2}{|c|}{$\begin{array}{l}\text { 8. Performing Organization Report No. } \\
\text { NCTR 77937/BDK85 977-32 }\end{array}$} \\
\hline \multirow{2}{*}{\multicolumn{3}{|c|}{$\begin{array}{l}\text { 9. Performing Organization Name and Address } \\
\text { National Center for Transit Research } \\
\text { Center for Urban Transportation Research } \\
\text { University of South Florida } \\
4202 \text { E Fowler Avenue, CUT 100, Tampa, FL 33620-5375 }\end{array}$}} & \multicolumn{2}{|l|}{ 10. Work Unit No. (TRAIS) } \\
\hline & & & \multicolumn{2}{|c|}{$\begin{array}{l}\text { 11. Contract or Grant No. } \\
\text { FDOT BDK85 } 977-32 \\
\text { U.S. DOT DTRS98-G-0032 }\end{array}$} \\
\hline \multirow{2}{*}{\multicolumn{3}{|c|}{$\begin{array}{l}\text { 12. Sponsoring Agency Name and Address } \\
\text { Research and Innovative Technology Administration } \\
\text { U.S. Department of Transportation, Mail Code RDT-30 } \\
\text { 1200 New Jersey Ave, SE, Room E33, Washington, DC 20590-0001 }\end{array}$}} & \multicolumn{2}{|c|}{$\begin{array}{l}\text { 13. Type of Report and Period Covered } \\
\text { Final Report } \\
02 / 17 / 11-04 / 31 / 12\end{array}$} \\
\hline & & & \multicolumn{2}{|c|}{ 14. Sponsoring Agency Code } \\
\hline \multicolumn{5}{|l|}{ 15. Supplementary Notes } \\
\hline \multicolumn{5}{|c|}{$\begin{array}{l}\text { 16. Abstract } \\
\text { This report contains the results of an investigation of the design and operation of shared bicycle/bus lanes } \\
\text { in municipalities in the United States and other countries. These lanes are designated for use by public } \\
\text { transit buses, bicycles, and usually also for right-turning vehicles. Some municipalities may also allow use of } \\
\text { these lanes by taxis and delivery vehicles. The purpose of such lanes is to provide a time advantage to } \\
\text { public transit service by taking the buses out of the general traffic flow and into a designated lane. Where } \\
\text { constrained right-of-way prevents provision of a separate bicycle lane, the intent is to allow bicycles to use } \\
\text { the designated bus lane. This is to provide a more direct route for bicyclists, provide greater level of service } \\
\text { to bicyclists and provide some degree of space separation between general traffic and bicyclists for their } \\
\text { greater safety and comfort. However, this combined use raises many issues of compatibility of bicycles and } \\
\text { buses sharing the same road space. The limited available research on the subject of shared bicycle/bus } \\
\text { lanes includes informative investigations from the Minneapolis Public Works Department, Minnesota; the } \\
\text { Delaware Valley Regional Planning Commission, Pennsylvania; the City of Ottawa, Canada, the Department } \\
\text { for Transport of the United Kingdom and from Austroads, Sydney, Australia. Investigators compiled a list of } \\
\text { shared bicycle/bus lanes in cities in the United States and Canada, including facility attributes that are } \\
\text { presented in an appendix. Researchers found very few examples of state-level guidance on shared } \\
\text { bicycle/bus lanes but more examples at the local and regional levels. These are provided in the report. } \\
\text { Through surveys and interviews, the shared bicycle/bus lanes from four cities in the United States were } \\
\text { selected for in-depth examination and were developed into case studies: Ocean City, Maryland; } \\
\text { Minneapolis, Minnesota; Philadelphia, Pennsylvania; and Washington, D.C. As a result of this investigation, } \\
\text { an identification and discussion of the contextual factors, design variables, and tools for planning and } \\
\text { implementing shared bicycle/bus lanes is presented. The report provides recommendations for further } \\
\text { needed research. }\end{array}$} \\
\hline \multicolumn{2}{|c|}{$\begin{array}{l}\text { 17. Key Words } \\
\text { Bicycle, Bus, Congestion, Public transportation, Shared } \\
\text { bicycle/bus lanes, Bicycle safety, Preferential lanes }\end{array}$} & \multicolumn{3}{|c|}{ 18. Distribution Statement } \\
\hline $\begin{array}{l}\text { 19. Security Classif. (of this report) } \\
\text { Unclassified }\end{array}$ & $\begin{array}{r}\text { 20. Security Classif. ( } \\
\text { Unclassi }\end{array}$ & page) & $\begin{array}{r}\text { 21. No. of Pages } \\
167\end{array}$ & 22. Price \\
\hline
\end{tabular}




\section{Acknowledgments}

This report was prepared by the National Center for Transit Research at the Center for Urban Transportation Research, College of Engineering, University of South Florida, through the sponsorship of the Florida Department of Transportation.

\section{FDOT Project Manager}

David C. O’Hagan, P.E., State Roadway Design Engineer

FDOT Co-Project Manager

Mary Anne Koos, Special Projects Coordinator, Roadway Design Office

\section{Contributors and Reviewers}

Study authors would like to thank several transportation professionals from the U.K. for their kind assistance, including lain Macbeth, Alex Sully, Richard Armitage, John Lee, Adrian Lord, Derek Lawlor, and Tony Russell. At the beginning of the study, John Ciccarelli provided the research team with a spreadsheet that listed shared bicycle/bus lanes, which the research team checked, augmented, and expanded into the inventory that appears as Appendix A. Tony Garcia of the Street Plans Collaborative and Transit Miami blog in Miami also provided helpful comments and suggestions at the beginning of the study. Diane Quigley and Amy Datz from FDOT also conducted a detailed review of the report. Finally, the study authors interviewed and surveyed numerous persons in cities where there are shared bicycle/bus lanes. The authors greatly appreciate the time and information made available by these persons, who are identified in footnotes throughout the report.

Joel Volinski, Program Director for the National Center for Transit Research at CUTR, Jay Goodwill, Senior Research Associate at CUTR, and Philip L. Winters, Director of CUTR's Transportation Demand Management Program, reviewed a draft of this report and provided useful advice for improving it. Nevine Georggi provided helpful assistance in report formatting. 


\section{Executive Summary}

A shared bicycle/bus lane (SBBL) is a traffic lane dedicated for exclusive use by buses, bicyclists, and, usually, right-turning vehicles. SBBLs have been implemented in municipalities where there are street right-of-way constraints and where municipalities seek ways to accommodate buses and bicycles for better multimodal service. There were three objectives of this study, conducted for the Florida Department of Transportation (FDOT):

- Identify and describe the state of the art and practice in the design, implementation, operation, and use of shared bicycle/bus lanes (SBBL)

- Evaluate the benefits and barriers to implementing SBBLs

- Develop recommendations for Florida to consider the use of SBBLs on the State Highway System.

Through the literature review, surveys of chief contacts within municipalities that have SBBLs, and follow-up telephone interviews, information was collected about SBBL design, operation, and functional effectiveness. For four municipalities with SBBLs, there was sufficient information to develop and present case study narratives. These were Ocean City, Maryland; Minneapolis, Minnesota; Philadelphia, Pennsylvania; and Washington, D.C. For the other host municipalities, additional comparative data about SBBLs were collected, where available. The main report summarizes findings of relevant previous research, available SBBL planning and design guidelines of localities, states, and other nations, identification of those background conditions that remain fixed that provide the context for the SBBL, and the planning and engineering variables that can be manipulated to guide design and implementation of an SBBL.

The study identified 27 SBBLs in municipalities throughout the United States. Among the identified SBBLs that are currently in use, Coastal Highway in Ocean City, MD, was the earliest. It began operation as an SBBL in the late 1980s; however, 12 of the identified SBBLs in the U.S. were established in the past ten years. SBBLs can be grouped into three main types, according to their length and setting. These include SBBLs that serve as connector segments to bicycle lanes, over bridges, highway overpasses, or intersections. These are generally shorter than one half mile. Urban SBBLs located within or connecting to downtown areas represent a second type of SBBL. These are generally shorter than two miles. Urban SBBLs experience large swings in traffic volumes that may be related to commuter traffic. The third type is suburban/low density SBBLs, found generally on busy arterials or state highways. These extend for distances greater than two miles and generally operate under conditions of higher speeds than the connector or urban SBBLs. A total of 18 SBBLs, or 72 percent of the identified SBBLs, operate within travel lanes that are 13 feet or less, with posted speed limits ranging between 25 and $45 \mathrm{mph}$ (median is $30 \mathrm{mph}$; mean is $32 \mathrm{mph}$ ).

Bus stop spacing for urban and suburban SBBLs are of three general types. Buses may stop at every block, every intersection, or every other block. Just two of the SBBLs identified in this study have used colored pavement. These include Chestnut Street, Philadelphia, and Hennepin Avenue, Minneapolis. Two locations have a parking lane adjacent to the SBBL. These are $7^{\text {th }}$ Street NW and $9^{\text {th }}$ Street NW in Washington, D.C., and Washington Street in Boston. Stewart Street and Elliot Avenue W/15th Avenue $W$ in Seattle, as well as $19^{\text {th }}$ Street in Denver, Colorado, are SBBLs only during peak traffic hours and convert to parking lanes with bicycles using the remaining portion of the lanes during the off-peaks.

Brief references to SBBLs were found in design guidelines for three state departments of transportation, including Illinois, Maryland, and Washington State. In Illinois, “...Where roadway width is limited, bicycles and buses may share an outside lane with a minimum of 16.5 feet $(5 \mathrm{~m})$ to the 
curb face" (Illinois DOT 2011, 17-2.5). In Maryland, “...Shared bus/bicycle lanes are typically wider than the standard 11-foot lane. Bus/bicycle lanes have been used in Maryland (in Ocean City), the District of Columbia, and other parts of the country; however, due to the conflicts inherent in the type of facility, it shall only be considered in consultation with SHA's (State Highway Administration) Bicycle and Pedestrian Coordinator" (MSHA n.d., 4-4). In Illinois and Maryland, no guidance is provided regarding speed limits or bus and bicycle volumes that would warrant the establishment of an SBBL. In Washington State, "When buses and bicyclists share the same roadway, consider the following: where bus speeds and volumes are high, separate facilities for buses and bicyclists are desirable. Where bus speeds and volumes are low, consider a shared-use bus/bicycle lane" (WSDOT 2012, 1520-5). No guidance is given regarding values for high and low volumes, nor are values given for lane widths or speed limits.

Further brief guidance about SBBLs from four municipalities also was found. These include the City of Tucson/Pima County, Arizona; San Francisco, California; Albuquerque, New Mexico; and Minneapolis, Minnesota. Table ES.1 below lists recommended widths for SBBLs and for separate bicycle and bus lanes. Tucson developed pavement marking details for SBBLs and provides that use of bike lane symbols in SBBLs are optional. If used, the frequency should be every $1 / 2$ mile in Tucson, every $1 / 4$ mile in Pima County, and after every major intersection. Bike lane markings are to be located 65 feet from road intersections to avoid excessive wear by turning vehicles and to avoid placing them where buses stop and dwell (Pima County DOT 2008, 6-1.1). San Francisco's design guidelines provide that SBBLs should be used where width is available for a bus lane but not a separate bus lane and bike lane, and describes transit stop striping for SBBLs (Alta Planning + Design and Parisi Associates 2003, 8). Albuquerque's design guide describes several innovative bicycle facility treatments, including SBBLs briefly: "The lane should be used where width is available for a bus lane, but not a bike lane. The dedicated lane attempts to reduce conflicts between bicyclists, buses, and automobiles. Various cities have experimented with different designs, and there is currently no evidence of one design being more effective than the others. SBBLs can be appropriate in the following applications: on autocongested streets with moderate or long bus headways, moderate bus headways during peak hour, or where there is no reasonable alternative route" (Alta Planning + Design and Gannett Fleming West 2010, 2). Moderate and long headways are not defined. The design guide for Minneapolis identifies considerations for the implementation of SBBLs: bicycle volumes, bus frequency and peak hour volumes, available lane width, including space to pass on the left, placement and frequency of bus stops, and potential time restrictions (City of Minneapolis 2010a, 259). Although the guidance in these cities specified lane widths, analyses justifying these lane widths could not be found.

Table ES.1 - Municipal Guidance on Lane Widths

\begin{tabular}{|c|c|c|c|}
\hline \multirow[b]{2}{*}{ Municipality } & \multirow[b]{2}{*}{ Reporting Agency } & \multicolumn{2}{|c|}{ Lane Widths (feet) } \\
\hline & & SBBL & $\begin{array}{l}\text { Separate but Adjacent } \\
\text { Bike and Bus Lanes }\end{array}$ \\
\hline Tucson, AZ & $\begin{array}{l}\text { Pima County DOT, } \\
\text { City of Tucson DOT }\end{array}$ & $\begin{array}{l}10 \text { minimum } \\
12 \text { standard }\end{array}$ & $\mathrm{n} / \mathrm{a}$ \\
\hline $\begin{array}{l}\text { San } \\
\text { Francisco, CA }\end{array}$ & City of San Francisco & $10-13$ & $14-17$ \\
\hline $\begin{array}{l}\text { Albuquerque, } \\
\text { NM }\end{array}$ & City of Albuquerque & $10-13$ & 14 - 17 (preferred alternative) \\
\hline $\begin{array}{l}\text { Minneapolis, } \\
\text { MN }\end{array}$ & City of Minneapolis & $\begin{array}{c}12 \text { minimum } \\
15-18 \text { recommended }\end{array}$ & $\mathrm{n} / \mathrm{a}$ \\
\hline \multicolumn{4}{|c|}{$\begin{array}{l}\text { Sources: } \\
\text { Pima County DOT and City of Tucson DOT } 2008 . \\
\text { Alta Planning + Design, and Parisi Associates } 2003 . \\
\text { Alta Planning + Design, and Gannett Fleming West } 2010 . \\
\text { City of Minneapolis 2010a, } 259 .\end{array}$} \\
\hline
\end{tabular}


Authorities providing bus operator training or guidance for operating buses in the presence of bicycles include the City of Chicago Department of Transportation (Chicago Bike Program 2010), Delaware Department of Transportation (DelDOT Bicycle Program n.d.), and the Washington Area Metropolitan Transit Authority (WMATA 2011). To help bus operators predict bicyclist behavior, all programs teach bus operators what bicyclists are taught regarding proper riding placement in the lane and related bicycle law in the state. The Chicago guidance instructs bus operators to anticipate that bicyclists may be to the right of the bus, may suddenly swerve left to avoid an opening car door, may change lanes upon approaching an intersection, and may not hear a bus approaching from behind. Operators are instructed to make a mental note after passing a bicyclist that if a bus passenger shortly thereafter requests to stop, the bicyclist may be approaching from behind and to the right of the bus as the operator intends to slow and swerve to the right. Operators are instructed to adjust mirrors to ensure that a bicyclist passing three feet or more from the bus will be visible in the mirrors. They are instructed to check mirrors whenever they are about to pull to the curb to stop, or to turn right, or change lanes. Delaware guidance advises against using a bus horn to communicate with bicyclists. The Washington Metro guidance to bus operators advises to move at least partially into the adjacent lane to pass, and to maintain at least one bus-length's distance behind a bicyclist when following. Bus operators are advised to pull as close as possible to the curb to discourage bicyclists from passing a stopped bus to the right.

A key question of interest to FDOT is the determination of the minimum width of the SBBL that ensures safety and satisfactory level of service for all roadway users. Figure ES.1 illustrates that the necessary width for an SBBL is estimated to be 16 feet, seven inches, where all the following conditions exist.

- Curb and gutter

- Posted speed limit $30 \mathrm{mph}$ or less, operating speed of buses is $30 \mathrm{mph}$ or less

- Lateral clearance of at least three feet between a bicyclist and a passing motor vehicle, (required by state law in Florida and 19 other states (Bisbee 2012)

- Sufficient width for a public transit bus of standard width (eight feet, six inches) to pass a bicyclist while staying within the SBBL

This width includes a three feet, four inches of width of bicyclist operating space, per AASHTO guidelines (AASHTO 1999, 5), measured from the longitudinal joint of the gutter pan. Another three feet measured from the edge of the bicyclist operating space to the bus body is added per requirements of Florida State law (Section 316.083, F.S.). An additional eight feet, six inches represents the width of a standard public transit bus (TI 1996, 36). An additional width of one foot, nine inches is added, measured from the left edge of the bus to the middle of the eight-inch-wide solid white stripe that separates the SBBL from the adjacent general traffic lane. This additional width was computed by positioning the bus in the center of 12 feet of operating space-the recommended width of a lane for public transit buses (Sando and Moses 2010, 44). These four widths, labeled A + B + C + $D$ in figure ES.1, total 16 feet, seven inches when added together. As discussed throughout this report, this width is not a necessary condition for an SBBL to operate.

SBBLs are in common use in the United Kingdom, where bicyclists are permitted to use bus lanes unless signed otherwise. Evidence also has been found indicating SBBLs exist in Austria, Australia, Belgium, Canada, Denmark, France, Germany, Ireland, and Switzerland. Where width of the SBBL is constrained, buses move into the adjacent general use lane to pass a bicyclist. However, this study found few research results justifying the available guidance and standards used by other nations.

Variables of interest include lane width, operating speed, volumes of buses, bicycles, and right turning traffic, and general traffic in adjacent lanes. These elements appear to interact within a variety of 
contexts and the functional relationships among these variables, if they had been measured, might define safe thresholds for effective operation of SBBLs. There also has been little evaluation of SBBLs, before and after their implementation, for safety and level of service for all roadway users.

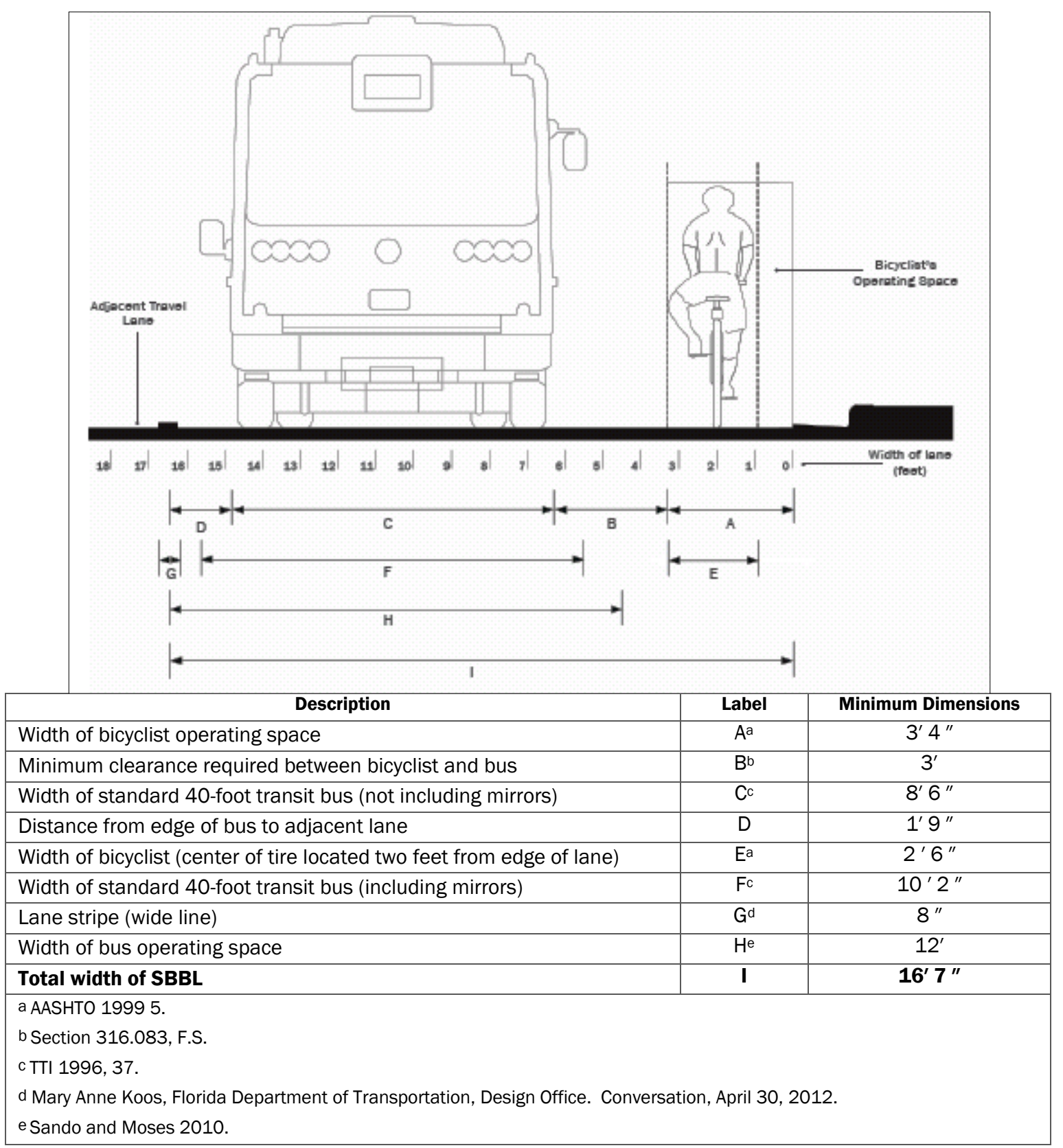

Figure ES.1 - Dimensions to accommodate passing within shared bike/bus lanes

A key consideration in the success or failure of SBBLs is whether and how to accommodate right turns by general traffic coming from the lane to the left of the SBBL. Three of the four case study SBBLs examined in detail have experienced serious degradation of performance for buses and bicyclists arising from (1) allowing right turns from the SBBL in areas where heavy pedestrian traffic delays right turns or (2) an inability to prevent cars from using the SBBL as a through lane instead of just as a rightturn lane. One of the cities, Washington, D.C., is considering removing the SBBLs, and a second city, Minneapolis, would probably not consider another one in similar conditions. Any municipality that 
wishes to implement an SBBL must consider whether it has the resources to provide the education and enforcement necessary to maintain functioning of the SBBL.

Researchers concluded that SBBLs have merit for further evaluation. It is recommended that future research focus upon the following topics.

1. Effect of SBBLs on encouraging bicycling

2. Better ways to collect bicycle traffic count data

3. Mobility impacts of an SBBL upon all modes

4. Bicycle level of service measurement refinements

5. Crash analysis of SBBLs compared to other bicycle facility types

6. Crash analysis of SBBLs of different designs, including determination of the maximum safe posted speed limit and characteristics of gaps in traffic that are necessary to provide safe passing opportunities

7. Use of intersection red light cameras to enforce SBBL restrictions

8. Evaluation of alternative bus stop treatments

Four alternative bus stop treatments were identified. The first of these bus stops is served by lanes that can accommodate passing (width of 16 feet, seven inches or greater) and the bus stops in the lane. The second of these may be along narrow lanes (width less than 16 feet, seven inches) and the bus stops in the lane. A third type of bus stop is along a narrow-width SBBL, but a partial bus bay is provided at the bus stop. A fourth type of bus stop treatment is typically of narrow width, in which the bicyclist is routed through a separate channel to the right of the pedestrian waiting area at the bus stop. 


\section{Table of Contents}

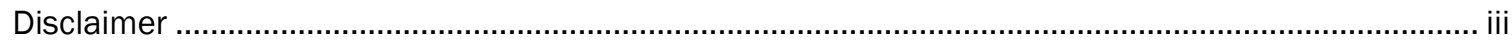

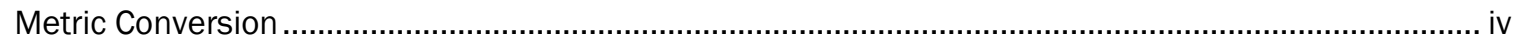

Technical Documentation Page ................................................................................................

Acknowledgements........................................................................................................... vi

Executive Summary .................................................................................................................... vii

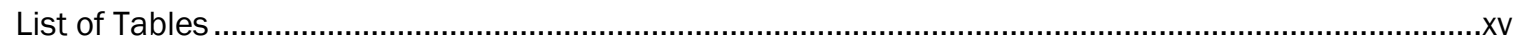

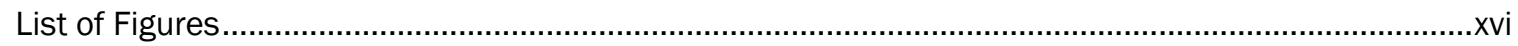

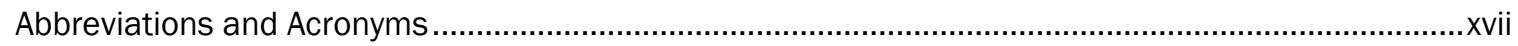

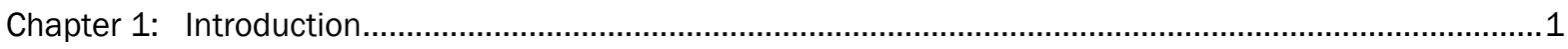

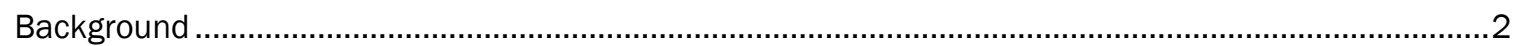

Study and Planning of SBBLs in Florida

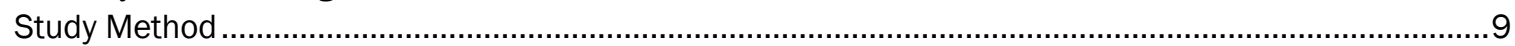

Relevant Previous Research about SBBLs or Related Topics........................................................... 10

Hennepin Avenue and 1st Avenue Two-Way Conversion, Minneapolis, Minnesota .......................... 11

Bicycle-Bus Conflict Area Study, Delaware Valley Regional Planning Commission ........................... 15

Design Treatments for Bicycles and Buses on Arterial and Collector Roads, City of Ottawa............. 16

Cycling in Bus Lanes, Department for Transport, United Kingdom ................................................ 18

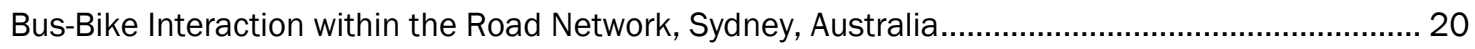

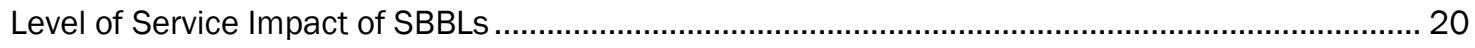

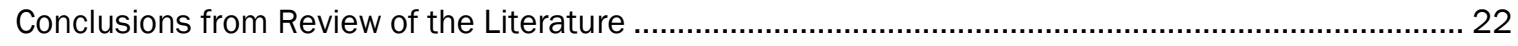

Chapter 2: Survey of Current Practices .............................................................................................. 24

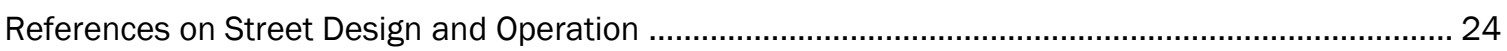

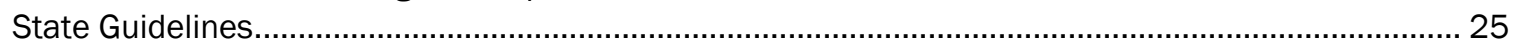

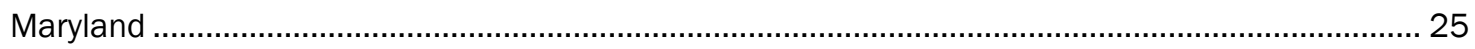

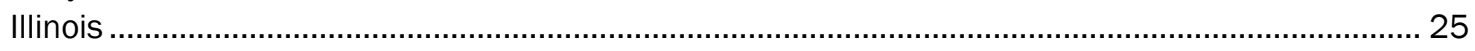

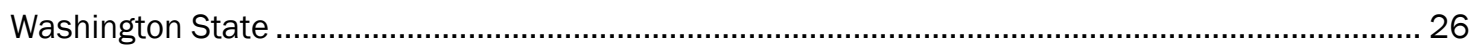

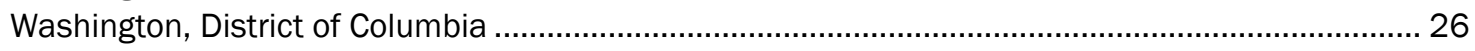

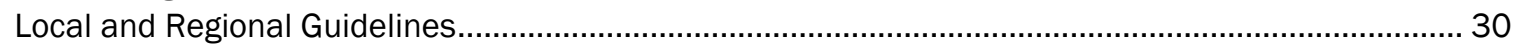

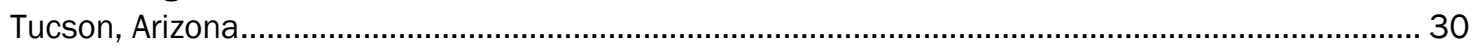

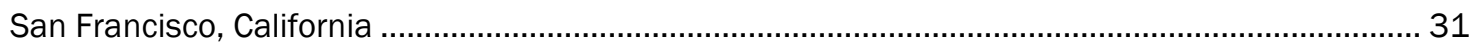

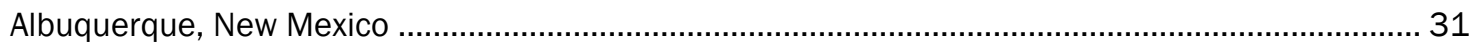

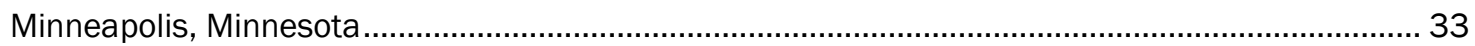

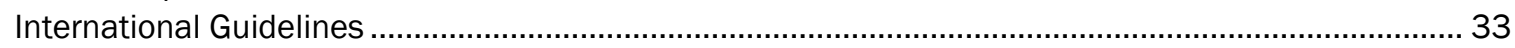

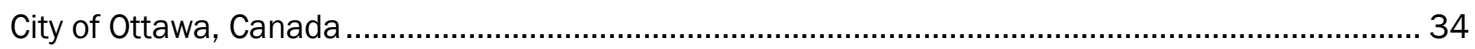

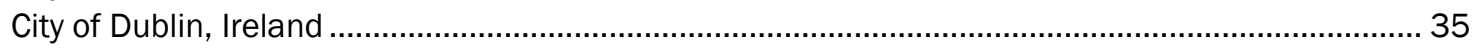

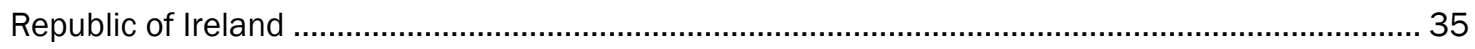

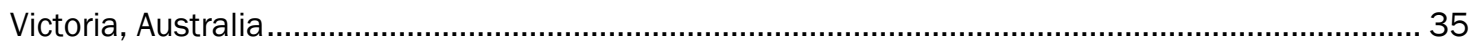

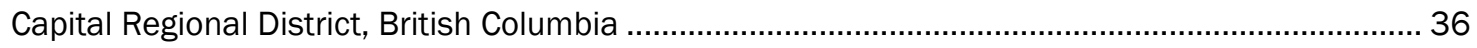

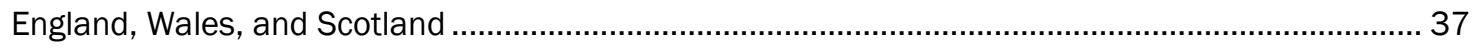

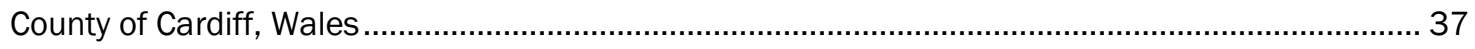

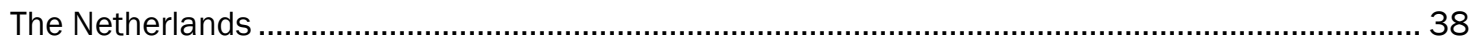

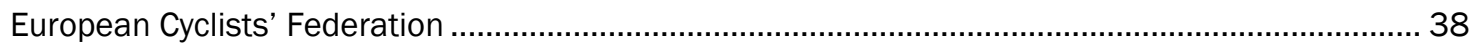

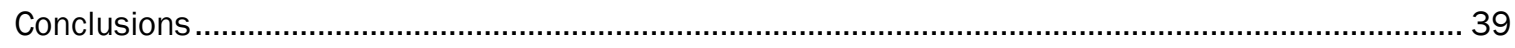

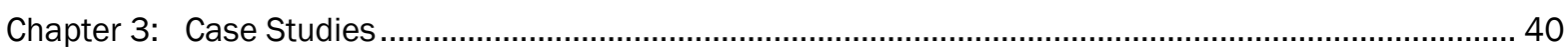

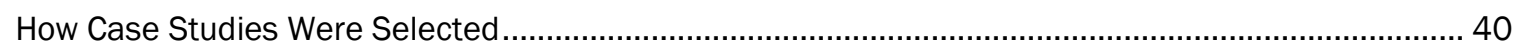

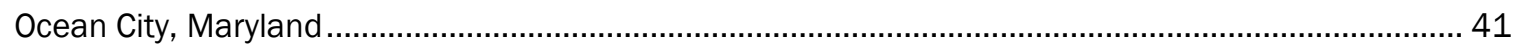

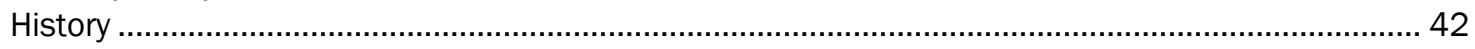

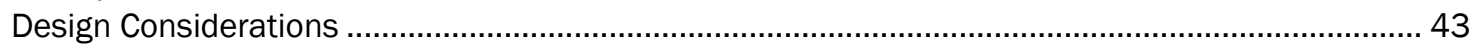

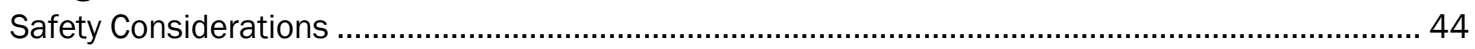




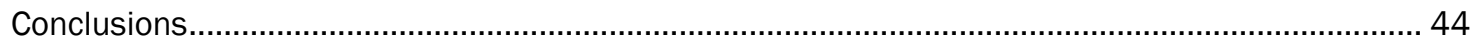

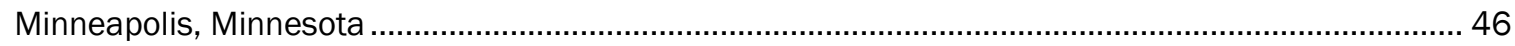

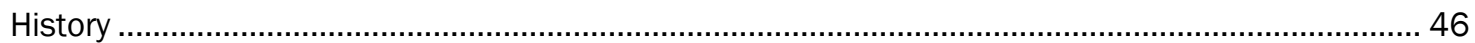

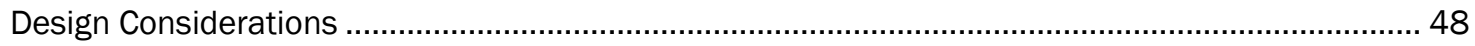

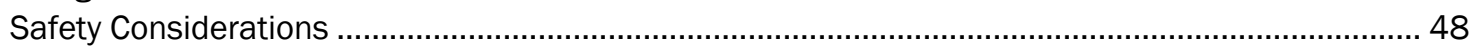

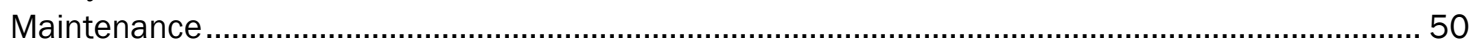

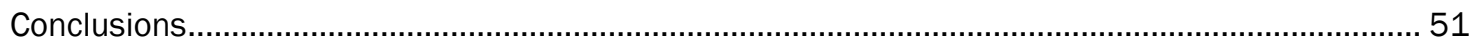

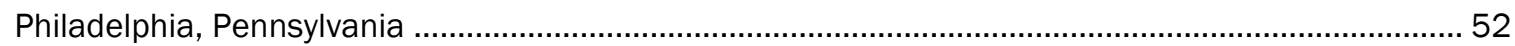

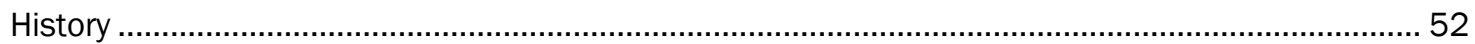

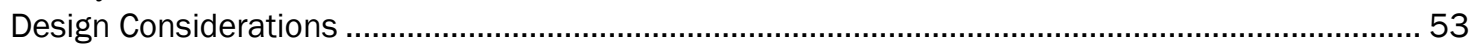

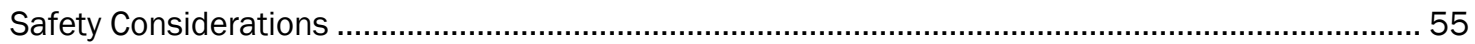

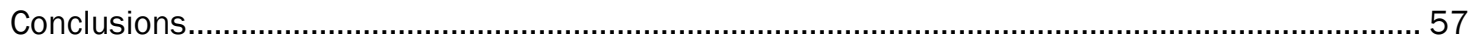

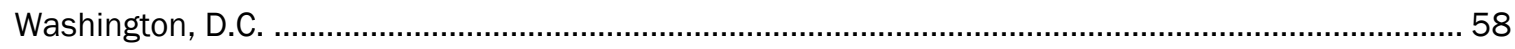

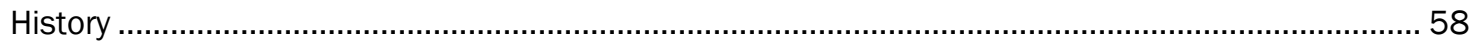

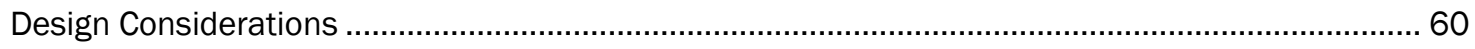

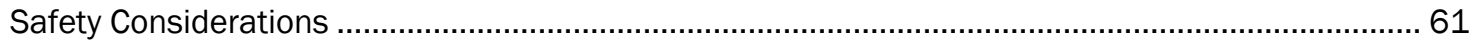

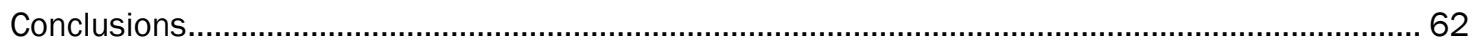

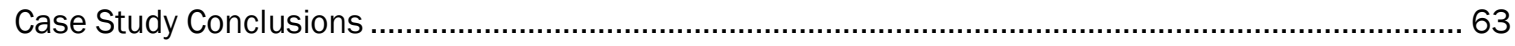

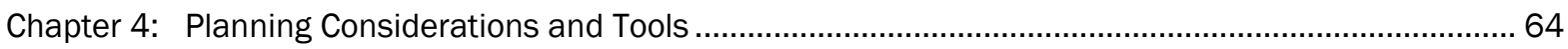

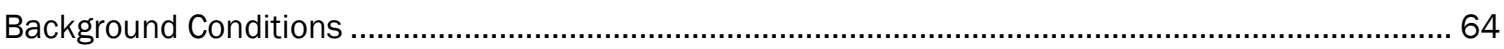

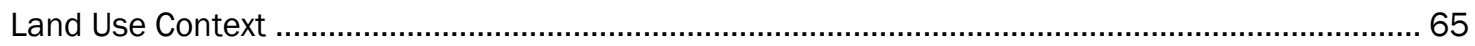

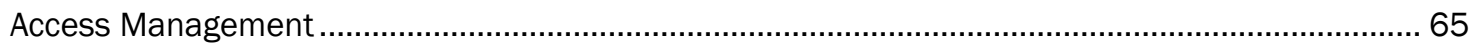

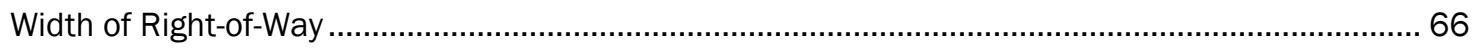

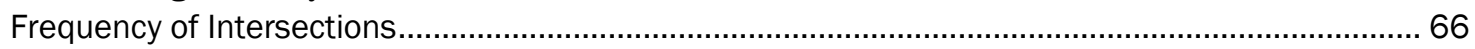

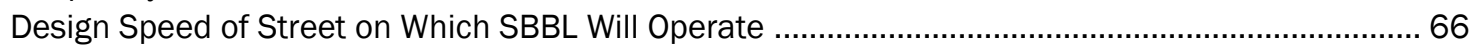

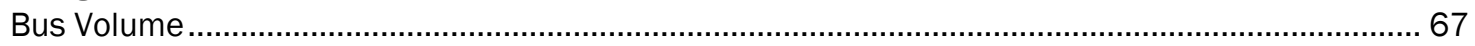

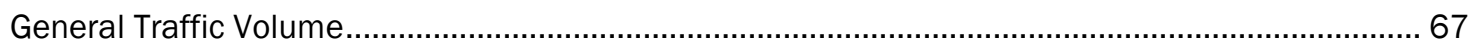

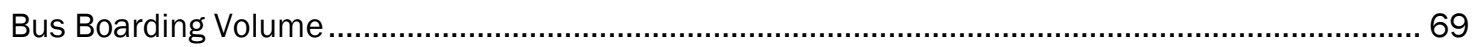

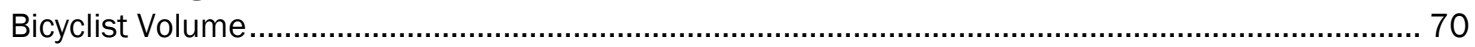

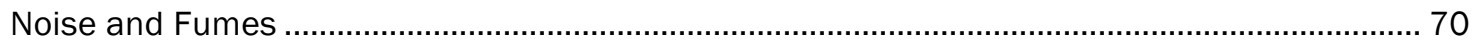

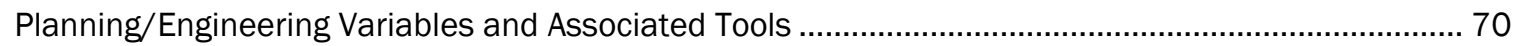

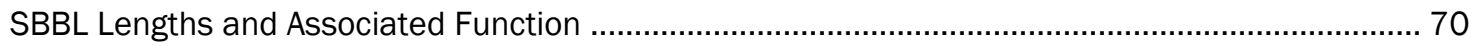

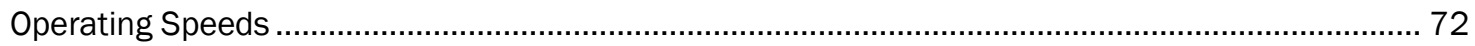

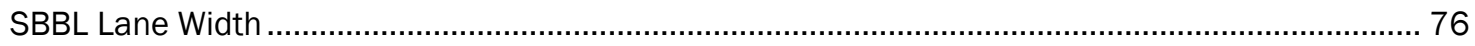

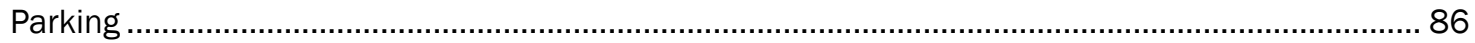

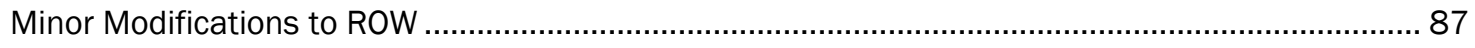

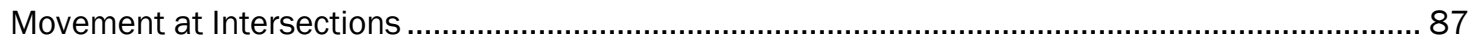

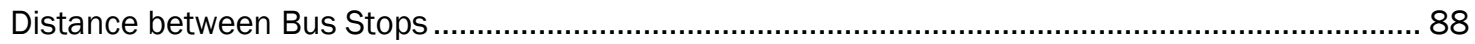

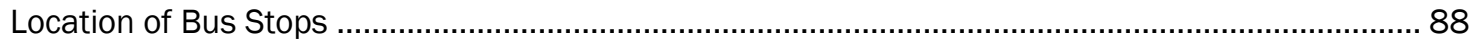

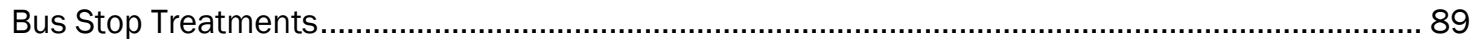

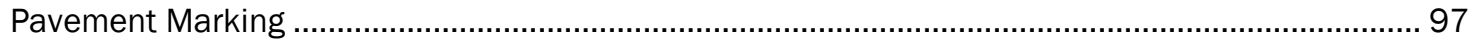

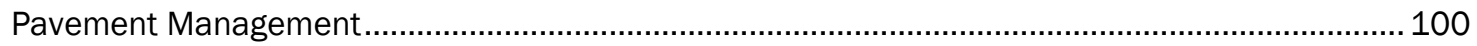

Behavior of Bicyclists, Bus Operators, and Other Road Users ..................................................... 101

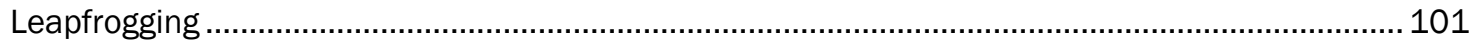

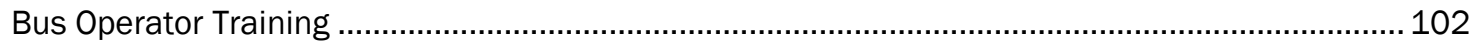

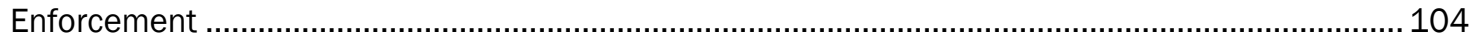

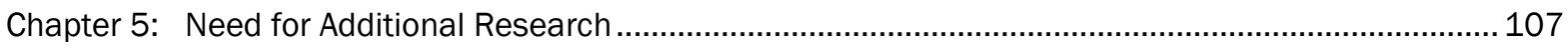

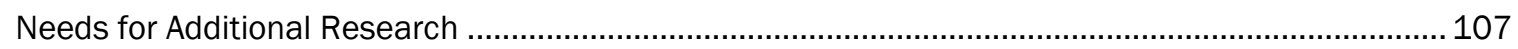

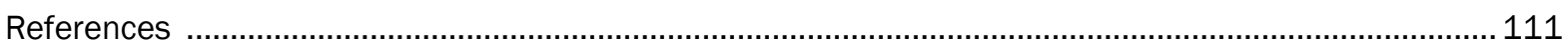

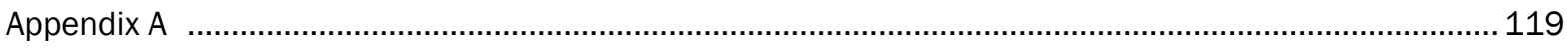

Database of United States and International Cases of Shared Bike/Bus Lanes .............................. 119 
Inventory of U.S. Cities with Shared Bike/Bus Lanes................................................................. 120

Examples of Facilities: Proposed, Removed, or Uncommon Design/Operation ..............................128

Inventory of International Cities with Shared Bike/Bus Lanes .................................................131

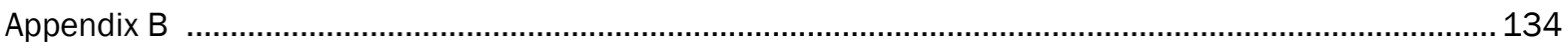

Minneapolis, MN, Educational Brochure of Lane Changes on Hennepin and First Avenues.............. 134

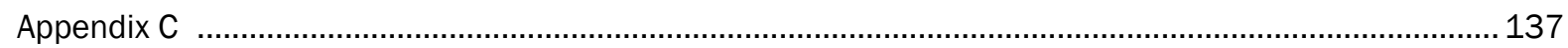

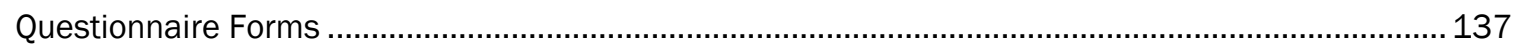

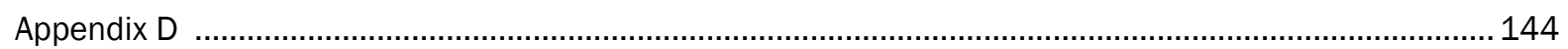

Pavement Marking Construction Details ................................................................................ 144

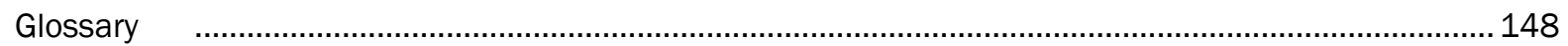




\section{List of Tables}

Table ES.1 - Municipal Guidance on Lane Widths ...................................................................................... viii

Table 1.1 - Number of Interactions Observed near Intersections on Hennepin Avenue .....................................14

Table 1.2 - Preferred Design Treatments (Ottawa) - Summary of Criteria ........................................................17

Table 1.3 - Recommended Specifications for Design Treatments (Ottawa) ......................................................18

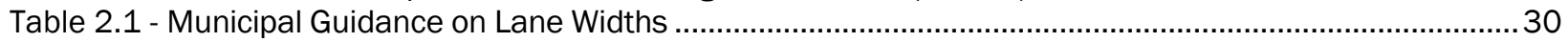

Table 2.2 - Survey of Lane Width Recommendations from Other Governments ................................................34

Table 2.3 - Clearance Recommendations between Bicyclists and Barriers/Obstacles (Cardiff) ..........................38

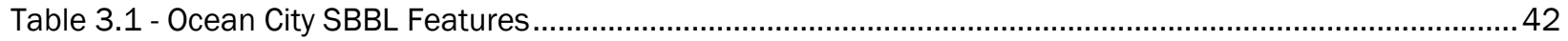

Table 3.2 - Ocean City Bus Schedule and Frequency (2011) ......................................................................43

Table 3.3 - Hennepin Avenue SBBL Features ...................................................................................... 47

Table 3.4 - Hennepin Avenue Traffic Counts before and after Lane Modification ..............................................48

Table 3.5 - Chestnut Street SBBL Features .......................................................................................... 53

Table 3.6 - 2011 Bus Service Frequency, Chestnut Street, Philadelphia, PA..................................................53

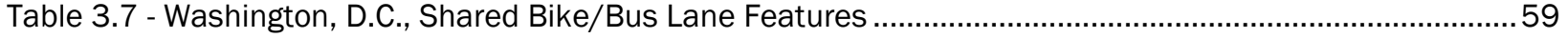

Table 4.1 - Florida Access Management Standards for Controlled Access Facilities .........................................65

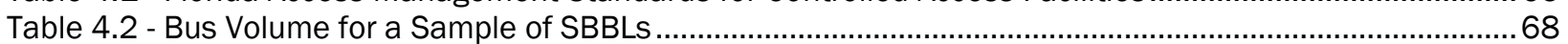

Table 4.3 - General Traffic Volume on Urban Arterial and Collector Roadways ...................................................68

Table 4.4 - Comparative SBBL Roadway Posted Speed Limits .................................................................... 73

Table 4.5 - Florida Statutes Standards for Maximum Speed Limits .................................................................. 75

Table 4.6 - Example Cities by SBBL Type and Width ............................................................................. 76

Table 4.7 - Minimum Lane Widths for Transportation Design for Livable Communities Projects (Florida) ......... 82

Table 4.8 - Summary of Lane Width Recommendations from Studies or Official Guidance or Actual Widths ... 85

Table 4.9 - Examples of Colored Lane Paint Options .........................................................................101 


\section{List of Figures}

Figure ES.1 - Dimensions to accommodate passing within shared bike/bus lanes ..........................................

Figure 1.1 - SBBL located at the intersection of 9th Street NW and G Street NW, Washington, D.C.................... 1

Figure 1.2: - Dimensions to be considered in planning SBBLs ..................................................................... 4

Figure 1.3 - Existing and proposed lane configuration for West Tennessee Street .......................................... 5

Figure 1.4 - Map of Panama City Beach proposed SBBL.......................................................................... 7

Figure 1.5 - Photograph taken on Front Beach Road.................................................................................. 7

Figure 1.6 - Rendering of proposed redesign of Front Beach Road ............................................................. 7

Figure 1.7 - Existing and proposed lane configuration for Front Beach Road ................................................ 8

Figure 1.8 - Change in bicycle volumes and crash rates 2007-2011, Hennepin Avenue ............................12

Figure 1.9 - Hatch marks were used to measure lane position of bicyclists and motor vehicles, .....................13

Figure 2.1 - Hennepin Avenue, Minneapolis, MN .......................................................................................24

Figure 2.2 - Intersection example of a combined bike lane/turn lane ................................................................25

Figure 2.3 - Mid-block bicycle lane striping adjacent to a bus stop.....................................................................2 27

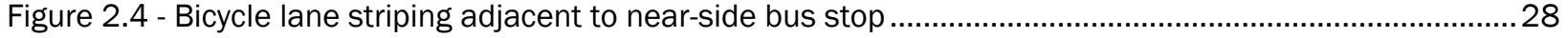

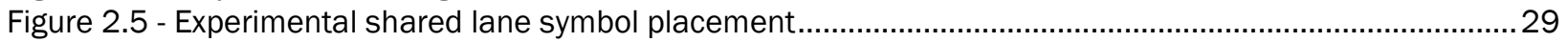

Figure 2.6 - Albuquerque's minimum and preferred SBBL design.................................................................. 32

Figure 2.7 - Shared lane pavement markings (British Columbia) ................................................................... 36

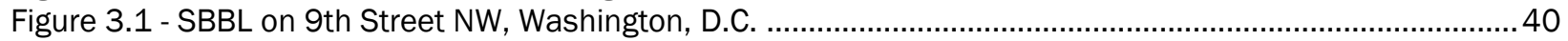

Figure 3.2 - Location of Ocean City SBBL.................................................................................................. 41

Figure 3.3 - SBBL on MD 528, Ocean City, MD ……................................................................................... 43

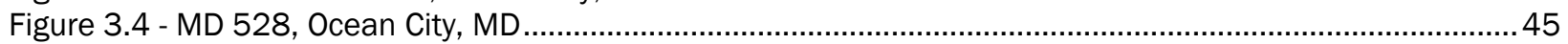

Figure 3.5 - MD 528, Ocean City, MD Near the intersection of 70th Street................................................... 45

Figure 3.6 - Location of Hennepin Avenue SBBL ……................................................................................ 46

Figure 3.7 - Hennepin Ave changes in lane configuration .......................................................................... 49

Figure 3.8 - Hennepin Avenue prior to lane reconfiguration in 2009 ..........................................................50

Figure 3.9 - Hennepin Avenue after redesign in 2010 .............................................................................5

Figure 3.10 - Hennepin Avenue, Green Shared Lane Study, 2010 ................................................................... 51

Figure 3.11 - Hennepin Avenue signage ............................................................................................... 51

Figure 3.12 - Location of Chestnut Street SBBL ....................................................................................... 52

Figure 3.13 - SBBL on Chestnut Street, Philadelphia, PA ............................................................................5

Figure 3.14 - Chestnut Street lane configuration ................................................................................................. 55

Figure 3.15 - Location of Washington, D.C. SBBLs.................................................................................... 58

Figure 3.16 - Washington, D.C. 9th Street NW - lane configuration: type 1 ..................................................60

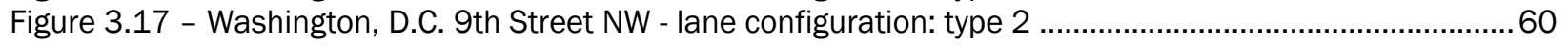

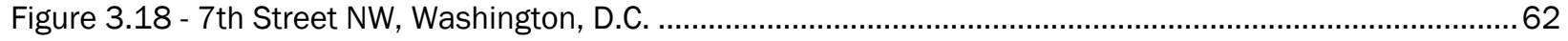

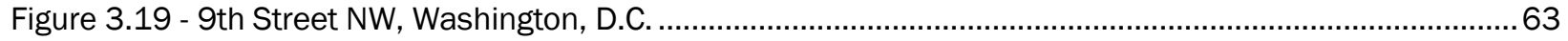

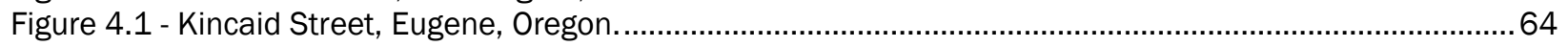

Figure 4.2 - Dimensions to accommodate passing within shared bike/bus lanes...........................................79

Figure 4.3 - Wide curb lane, SR 61/Thomasville Road, Tallahassee, FL ........................................................ 83

Figure 4.4 - Aerodynamic forces caused by heavy motor vehicles passing bicyclists .......................................... 84

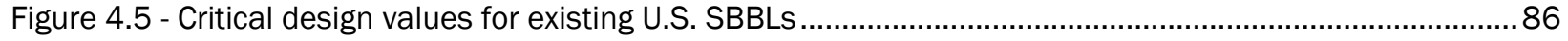

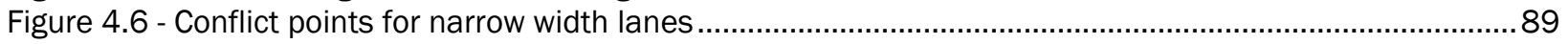

Figure 4.7 - Narrow width SBBL with advisory cycle lane and stop bar ......................................................91

Figure 4.8 - Conflict points for wide width lanes........................................................................................... 92

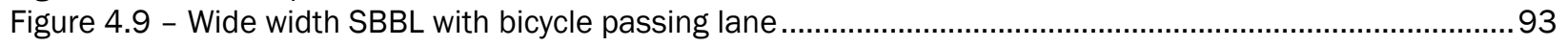

Figure 4.10 - Conflict points: bus stop island with advisory cycle lane ..............................................................94

Figure 4.11 - Conflict points: partial bus bay with advisory cycle lane ..............................................................95

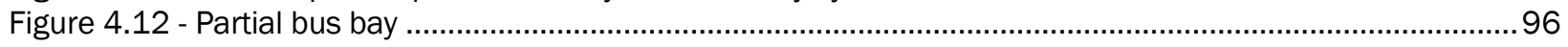

Figure 4.13 - Example of advisory cycle lane, United Kingdom ....................................................................97

Figure 4.14 - Example of pavement markings around a bus stop, United Kingdom .............................................97

Figure 5.1 - Paris, France ................................................................................................................................ 


\section{Abbreviations and Acronyms}

\begin{tabular}{|c|c|}
\hline AADT & Average annual daily traffic \\
\hline AASHTO & American Association of State Highway and Transportation Officials \\
\hline ADT & Average Daily Traffic \\
\hline BDE & Bureau of Design and Environment (Illinois DOT) \\
\hline BRT & Bus Rapid Transit \\
\hline CBD & Central Business District \\
\hline CLTL & Center left turn lane \\
\hline CNG & Compressed natural gas \\
\hline CORSIM & CORridor SIMulation \\
\hline CRA & Community Redevelopment Agency \\
\hline CROW & $\begin{array}{l}\text { Centre for Research and Contract Standardization in Civil and Traffic } \\
\text { Engineering (The Netherlands) }\end{array}$ \\
\hline CTC & Cyclists' Touring Club \\
\hline DDOT & District (of Columbia) Department of Transportation \\
\hline DelDOT & Delaware Department of Transportation \\
\hline DETR & (U.K.) Department of the Environment, Transport and the Regions \\
\hline DfT & Department for Transport \\
\hline DHSMV & Department of Highway Safety and Motor Vehicles (Florida) \\
\hline DOT & Department of Transportation \\
\hline DULA & Dense Urban Land Area \\
\hline DVRPC & Delaware Valley Regional Planning Commission \\
\hline EDB & Estimated daily bicyclists \\
\hline EDT & Estimated daily traffic \\
\hline FAMU & Florida Agricultural and Mechanical University \\
\hline FDOT & Florida Department of Transportation \\
\hline FHWA & Federal Highway Administration \\
\hline FSU & Florida State University \\
\hline GART & $\begin{array}{l}\text { Groupement des Autorités Responsables de Transport (Association } \\
\text { of Transport Authorities) }\end{array}$ \\
\hline GRACQ & $\begin{array}{l}\text { Groupe de Recherche et d'Action des Cyclistes Quotidiens (Everyday } \\
\text { Cyclists' Research and Action Group) }\end{array}$ \\
\hline $\mathrm{HCM}$ & Highway Capacity Manual \\
\hline $\mathrm{HOV}$ & High occupancy vehicle \\
\hline ITE & Institute of Transportation Engineers \\
\hline LOS & Level of service \\
\hline LTOL & Left turn only lane \\
\hline MUTCD & Manual on Uniform Traffic Control Devices \\
\hline MMUTCD & Minnesota Manual on Uniform Traffic Control Devices \\
\hline MSHA & Maryland State Highway Administration \\
\hline NACTO & National Association of City Transportation Officials \\
\hline NCHRP & National Cooperative Highway Research Program \\
\hline OECD & Organization for Economic Cooperation and Development \\
\hline PD\&E & Project Development \& Environment \\
\hline PennDOT & Pennsylvania Department of Transportation \\
\hline PPM & Plans Preparation Manual \\
\hline Q/LOS & Quality/Level of Service \\
\hline RRR & Resurfacing Restoration Rehabilitation \\
\hline RTOL & Right turn only lane \\
\hline SBBL & Shared bicycle/bus lane \\
\hline SEPTA & Southeastern Pennsylvania Transportation Authority \\
\hline
\end{tabular}




$\begin{array}{ll}\text { SFMTA } & \text { San Francisco Municipal Transportation Agency } \\ \text { SWOV } & \text { Dutch Institute for Road Safety Research } \\ \text { TBEST } & \text { Transit Boardings Estimation and Simulation Tool } \\ \text { TCQSM } & \text { Transit Capacity and Quality of Service Manual } \\ \text { TCRP } & \text { Transit Cooperative Research Program } \\ \text { TDLC } & \text { Transportation Design for Livable Communities } \\ \text { TRID } & \text { Transport Research International Documentation } \\ \text { TRB } & \text { Transportation Research Board } \\ \text { TRL } & \text { Transport Research Laboratory } \\ \text { TRRL } & \text { Transport and Road Research Laboratory } \\ \text { TTI } & \text { Texas Transportation Institute } \\ \text { UNF } & \text { University of North Florida } \\ \text { VPLPD } & \text { Vehicles per lane per day } \\ \text { WSDOT } & \text { Washington State Department of Transportation } \\ \text { WMATA } & \text { Washington Metropolitan Area Transit Authority }\end{array}$




\section{Chapter 1:Introduction}

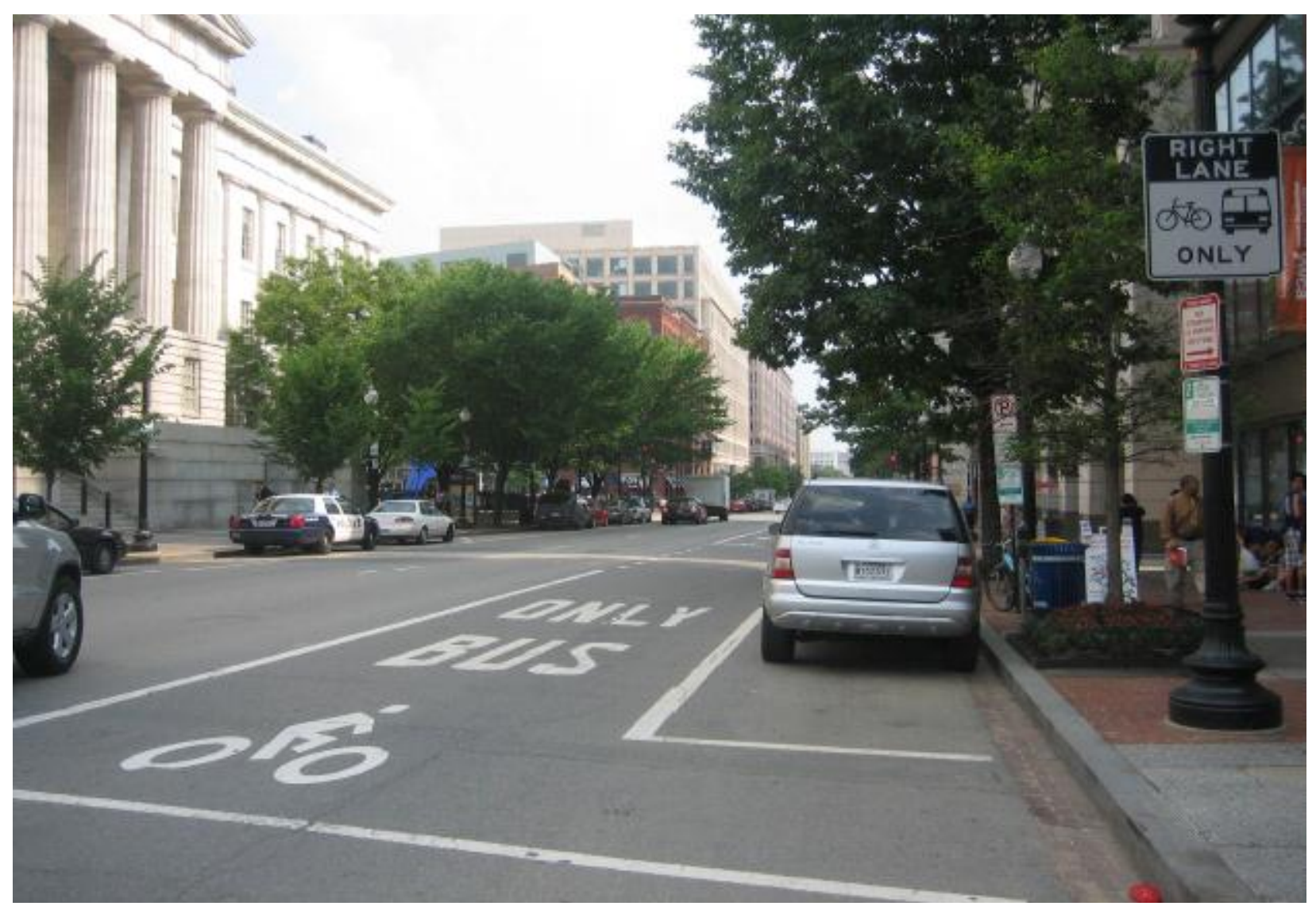

Figure 1.1 - SBBL located at the intersection of 9th Street NW and G Street NW, Washington, D.C.

Credit: JoAnne Fiebe

This study examines the design and operation of lanes intended for use both by bicycles and by buses. These shared bicycle/bus lanes (referred to throughout the report as SBBLs) are uncommon in the United States. Staff of the Florida Department of Transportation (FDOT) has observed increasing interest by municipalities to consider implementing SBBLs along state roadways. There are presently no national or Florida state standards for such facilities. Municipalities with design guidelines for SBBLs do not necessarily have SBBLs in operation. Conversely, municipalities with SBBLs do not necessarily have explicit design guidelines. FDOT requested an examination of how SBBLs are used in cities of other states. The study accomplished three objectives: 
1. Identify and describe the state of the art and practice in the design, implementation, operation, and use of SBBLs.

2. Evaluate the benefits and barriers to implementing SBBLs.

3. Develop recommendations for Florida to consider the use of SBBLs on the State Highway System.

This introductory Chapter 1 provides a review of relevant research and a summary of recent municipal efforts to consider SBBLs in Florida. Chapter 2, Survey of Current Practices, provides available state, local, and international references of guidelines on SBBL street design and operation. Chapter 3, Case Studies, presents four detailed case studies of SBBLs in the United States. Chapter 4, Planning Considerations and Tools, describes conditions under which an SBBL would operate and are not easily changed, as well as variable conditions that can be tools in the development of an SBBL. Chapter 5 provides recommendations for future research.

\section{Background}

Bus lanes are desirable to encourage use of public transit by providing a time advantage. Bicycle lanes encourage bicycling by providing separate roadway space for the greater safety and comfort of bicyclists. Generally, fewer buses and bicycles use the roadway than other types of vehicles. In concept, buses and bicycles could then share a lane, thereby maintaining the advantages to both groups while better using the lane capacity and freeing other roadway space for general purpose lanes that might otherwise have been used for bicycle lanes.

SBBLs have been considered and implemented for various, sometimes overlapping reasons. Through the course of this research, six primary motivations for considering SBBLs were found:

- A jurisdiction adopts a policy to improve transit service as a strategy to increase transit ridership, and a policy to increase bicycle ridership, as ways to reduce traffic congestion, reduce emissions, or otherwise improve the quality of life. Providing an SBBL is one way to do this.

- Existing right-of-way on a street is too narrow to provide separate lanes for bicycles and buses as well as for cars, and the financial or political cost rules out widening the street.

- A street already may have a preferential bus lane, and there is interest from the bicycling community and from local government transportation planners in allowing bicycles to use it.

- A street already may have a preferential bus lane, and bicyclists are already using it illegally, even though it has not been designed with bicycle safety in mind.

- There is a desire by the bicycling community and government bicycle and pedestrian coordinators to improve safety on a street that has substantial bus or bicycle traffic.

- A road diet, or reduction in the number of vehicle lanes within a given right-of-way, with space being reallocated to parking, bicycle lanes, or sidewalks (Rosales 2006), is being considered as a way of improving safety, livability, or the performance of transit and bicycling. The reduction of lanes available for general traffic forces consideration of how to allocate what has effectively now become a more limited right-of-way.

Researchers found 27 SBBLs in the United States. One SBBL featured as a case study in this report has been in operation since the late 1980s and one existed in Madison, WI prior to 1984, when the street was reconfigured to provide parallel bicycle and bus lanes. Twelve of the SBBLs were established in the past ten years, so the concept of SBBLs is still relatively new in the U.S. Some are in the planning process and not yet in operation, such as the shared bike/tram lanes in the City of Panama City Beach, Florida. The SBBLs in Fort Worth, Texas, just opened in December 2011. 
There are numerous planning considerations in the development and design of an SBBL including the following.

- What are the transportation goals and policies of the municipality? In the consideration of an SBBL, explicit local government planning priorities will be useful in guiding decisions regarding modal trade-offs.

- What are the land development plans and transportation plans for the surrounding area?

- What transportation capital improvements are scheduled for this area? The development, design, and staging of an SBBL should be done within the context of existing and planned activities.

- Does the state or municipality have laws requiring lateral clearance between bicyclist and a passing motorist? As of spring 2012, 20 U.S. states, including Florida, and several cities in other states, have adopted legislation requiring that motor vehicle operators provide clearance (noted as dimension B in Figure 1.2) of at least three feet when passing a bicyclist (Bisbee 2012). This affects requirements for planning and operating SBBLs. If an SBBL is not wide enough to provide required clearance, then the SBBL and the adjacent general purpose traffic lane must jointly accommodate the need for such clearance where law requires it.

- Are there local policies that prohibit sharing of bus lanes with other vehicles, including bicyclists?

- Is a bus lane already in place with current consideration for opening it to bicycle traffic? If so, certain traffic patterns will already be established. Useful observations can be made regarding the level of law abidance. Are cars entering the bus lane? Are bicyclists illegally using the bus lane? What has been the impact of this illegal use? Crash history of the facility and characteristics of traffic flow in adjacent general use lanes provide important information to guide decisions whether to establish an SBBL and how the facility should be designed and operated.

- Is a bus lane currently not in existence? If a new SBBL is planned, then a larger set of considerations are required. For example, should additional users be allowed, such as rightturning vehicles, taxis and delivery vehicles?

- How should the SBBL be designed and operated to make it safe for those who use it? One transit planner noted that buses make frequent stops and tend to be faster than bicycles. Conversely, bicycles tend to make infrequent stops and travel more slowly than buses. ${ }^{1}$ For an SBBL to serve its intended purpose, bicyclists need to perceive the SBBL as safe. Perceptions of safety vary greatly among bicyclists. If enough bicyclists avoid an SBBL, this defeats one of the objectives in creating it. Variables such as lane width, cross traffic, the volume and speed of motor vehicles and the presence of large heavy vehicles (including buses) can affect bicyclist perception of safety.

${ }_{1}^{1}$ Mike Cechvala, King County Metro, Seattle, WA. Survey response, July 1, 2011. 


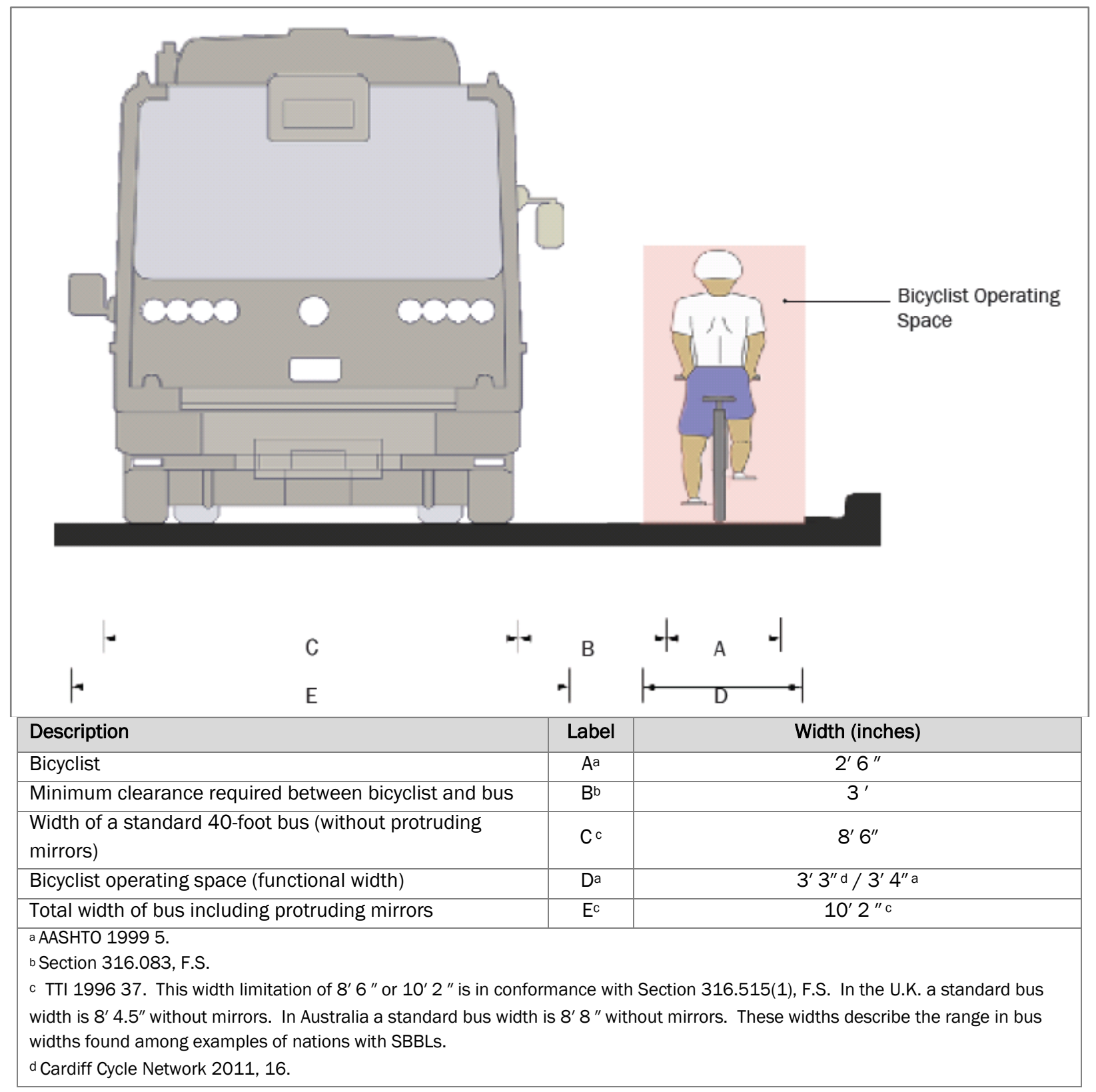

Figure 1.2: - Dimensions to be considered in planning SBBLS

\section{Study and Planning of SBBLs in Florida}

Two cities in Florida, Tallahassee and Panama City Beach, have recently undertaken studies to explore the use of SBBLs. These two efforts are summarized briefly here.

\section{West Tennessee Street (US 90/SR 10), Tallahassee}

In Tallahassee, Florida, West Tennessee Street (US 90/SR 10) between Ocala Road and Monroe Street was studied to determine potential benefits and impacts of replacing the outside general purpose traffic lanes with SBBLs. The study provided recommendations for the facility's design and 
implementation (Genesis Group 2009). The proposal for SBBLs on W. Tennessee Street is purely conceptual and has not been verified as being feasible.

W. Tennessee Street is a six-lane road located on the northern edge of Florida State University's (FSU) campus. It separates the university from many off-campus student amenities. Adjacent to the student activity center, W. Tennessee Street is a main east-west corridor for the city and a major traffic route during home football games. The study area incorporated the university road network in order to address university concerns that removing motor vehicle capacity from W. Tennessee Street would push traffic onto campus streets. Meetings were held with local business owners as well as stakeholders on the FSU campus. According to the transportation planner for the Tallahassee-Leon County Planning Department, "There were misconceptions about the project that led to some initial public resistance for the redesign. The most common issue was that business owners thought that right turns would be prohibited in the new configuration."2

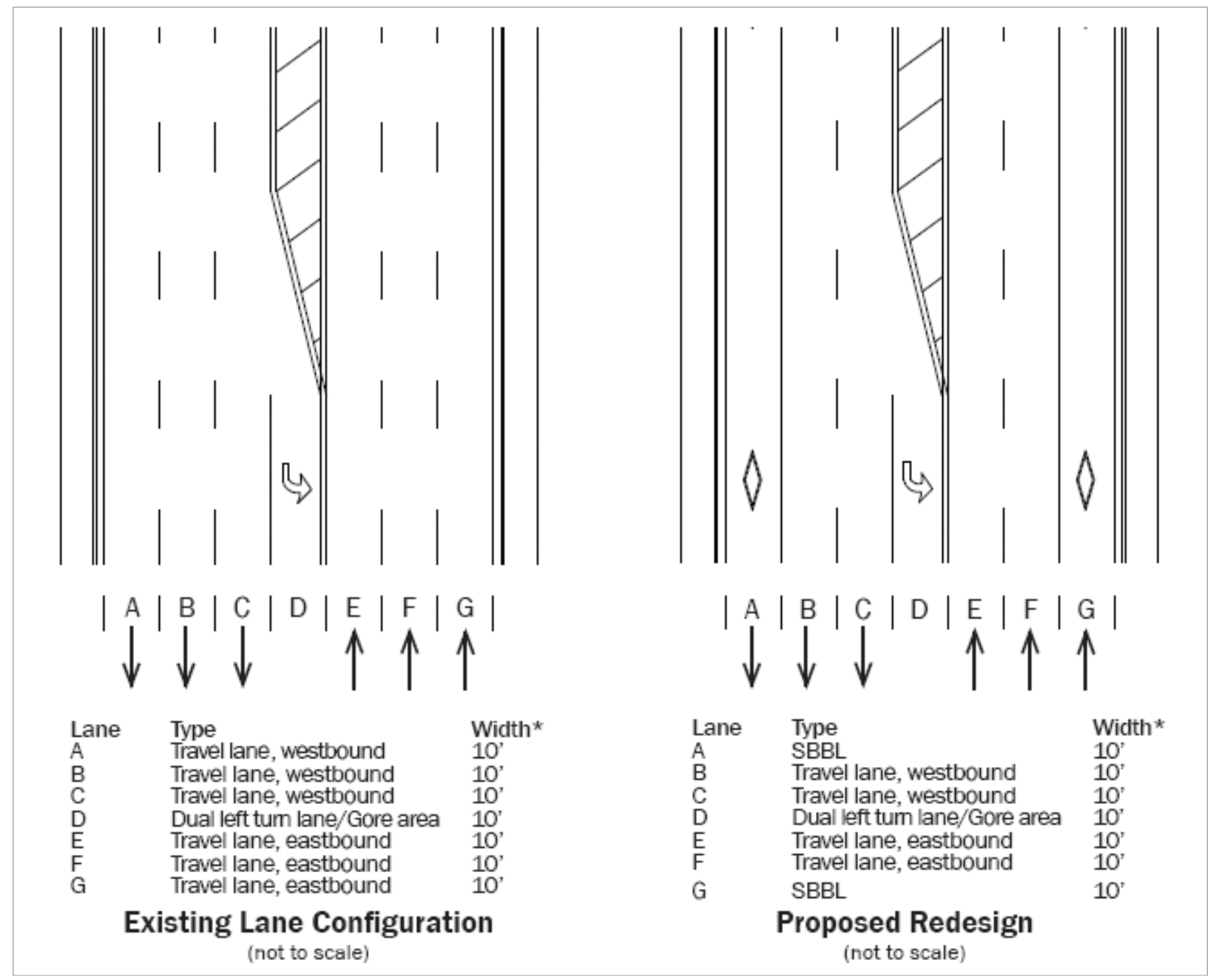

Figure 1.3 - Existing and proposed lane configuration for West Tennessee Street

* Availability of lane width throughout the study corridor, as illustrated in this concept of existing and proposed lane configuration, has not been verified.

2 Megan Doherty, Tallahassee-Leon County Planning Department, Personal correspondence, November 25, 2011. 
Analysis of roadway level of service (LOS) examined signalized intersections on the W. Tennessee corridor and streets within the study area. Two scenarios were analyzed.

W. Tennessee Street remains unchanged as a six-lane arterial roadway.

W. Tennessee Street becomes a four-lane road for motor vehicles and two lanes are converted to SBBLs with right-turning vehicles permitted in the dedicated lanes.

A multimodal LOS analysis indicated significant service improvements for pedestrians, bicyclists as well as transit capacity and quality of service for the four-lane revised roadway design of scenario 2 . The concept for the SBBLs included returning the SBBLs to general use lanes during times when there are major sporting events in the stadium, to increase motor vehicle capacity of the corridor during these events. Most recently, a public hearing on the project was held in March 2012.

\section{Front Beach Road, City of Panama City Beach}

Shared bike/tram lanes are proposed for Front Beach Road in Panama City Beach as a component of larger redevelopment plans for the Front Beach Road (US 98) corridor (Figure 1.4). The project was first introduced in 2002 as part of the establishment of the Panama City Beach Community Redevelopment Agency (CRA) and the development of a revitalization plan. The City identified the community's transportation system as, "inadequate, unsafe for pedestrians and bicyclists, and unable to sustain a growing population and beach tourism industry" (City of Panama City Beach CRA 2010, 1).

According to the Panama City Beach CRA, FDOT data acquired from 2004 through 2008 indicates that the Front Beach Road corridor had 650 crashes with six fatalities, 81 injuries, 42 crashes involving pedestrians, and ten involving bicyclists (City of Panama City Beach CRA 2010, 4-6). Subsequently, the City initiated a multimodal program to accommodate these present and future transportation needs. The series of projects that are currently in various stages of planning and construction address several common goals. These goals include livability, safety, establishing and maintaining quality infrastructure, and environmental sustainability through the application of technology and innovative solutions. The CRA describes the project as significantly enhancing user mobility and reducing the average user cost through the creation of more convenient transportation options. These include efficient transit senvice operating on a dedicated lane along the Front Beach Road corridor. As illustrated in the "before" and "after" representations of Front Beach Road in Figures 1.5 and 1.6, the proposed project will provide dual 11-foot shared bicycle/tram lanes that will carry trams in both directions and will be located adjacent to each curb (City of Panama City Beach CRA 2010, 2). Trams are different from transit buses in several ways. First, they have a lower operating speed than buses, making them more likely candidates for use in tourism. Trams are also narrower than buses. Trams are eight feet in width, including side mirrors and buses are ten feet, two inches in width, including mirrors. 


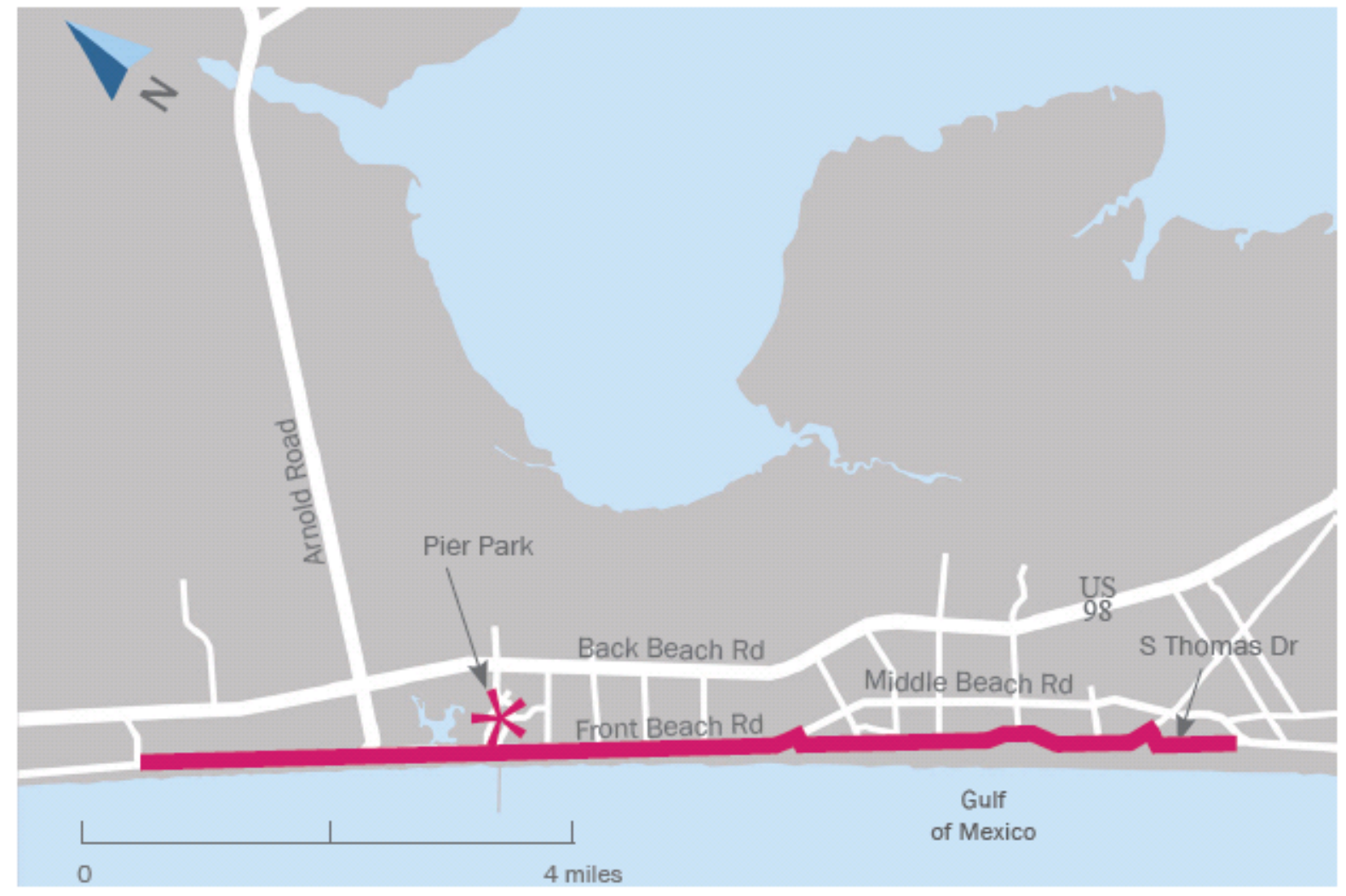

Figure 1.4 - Map of Panama City Beach proposed SBBL

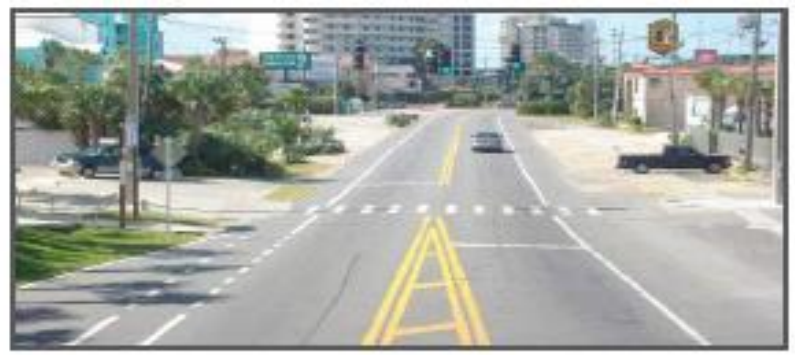

Figure 1.5 - Photograph taken on Front Beach Road Credit: Panama City Beach CRA, 2007

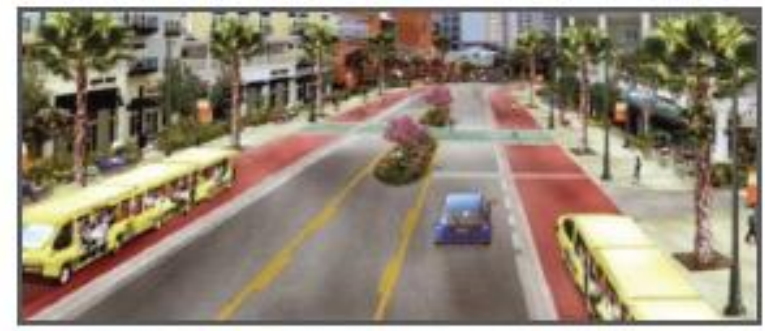

Figure 1.6 - Rendering of proposed redesign of Front Beach Road Credit: Panama City Beach CRA, 2008 
In 2006, and subsequently updated in 2008, Panama City Beach staff worked with a team of consultants to develop a Front Beach Road Streetscape Design Guidelines Manual. The document provides design specifications for Front Beach Road and its related amenities including transit facilities. Section 1 - Typical Roadways describes the current and proposed conditions for Front Beach Road. Right-of-way on the road varies from 66 feet to 100 feet in width. Existing buildings are adjacent to the right-of-way line with limited on-site parking capabilities. In many cases, private parking occurs within the public right-of-way. The manual proposes general purpose lanes that are ten feet in width, a nine-foot dual left center turning lane and 11-foot bike/tram lanes. Ten-foot tram pull out lanes are planned at all bus stops along the routes (Figure 1.7). The sidewalks and landscape areas vary according to the right-of-way widths with minimum six-foot sidewalks along the 66 feet of right-of-way and eight- to 12-foot sidewalks with four-foot by four-foot tree wells along sections of right-of-way that are 100 feet in width (HHI Design et al. 2008, 8-12).

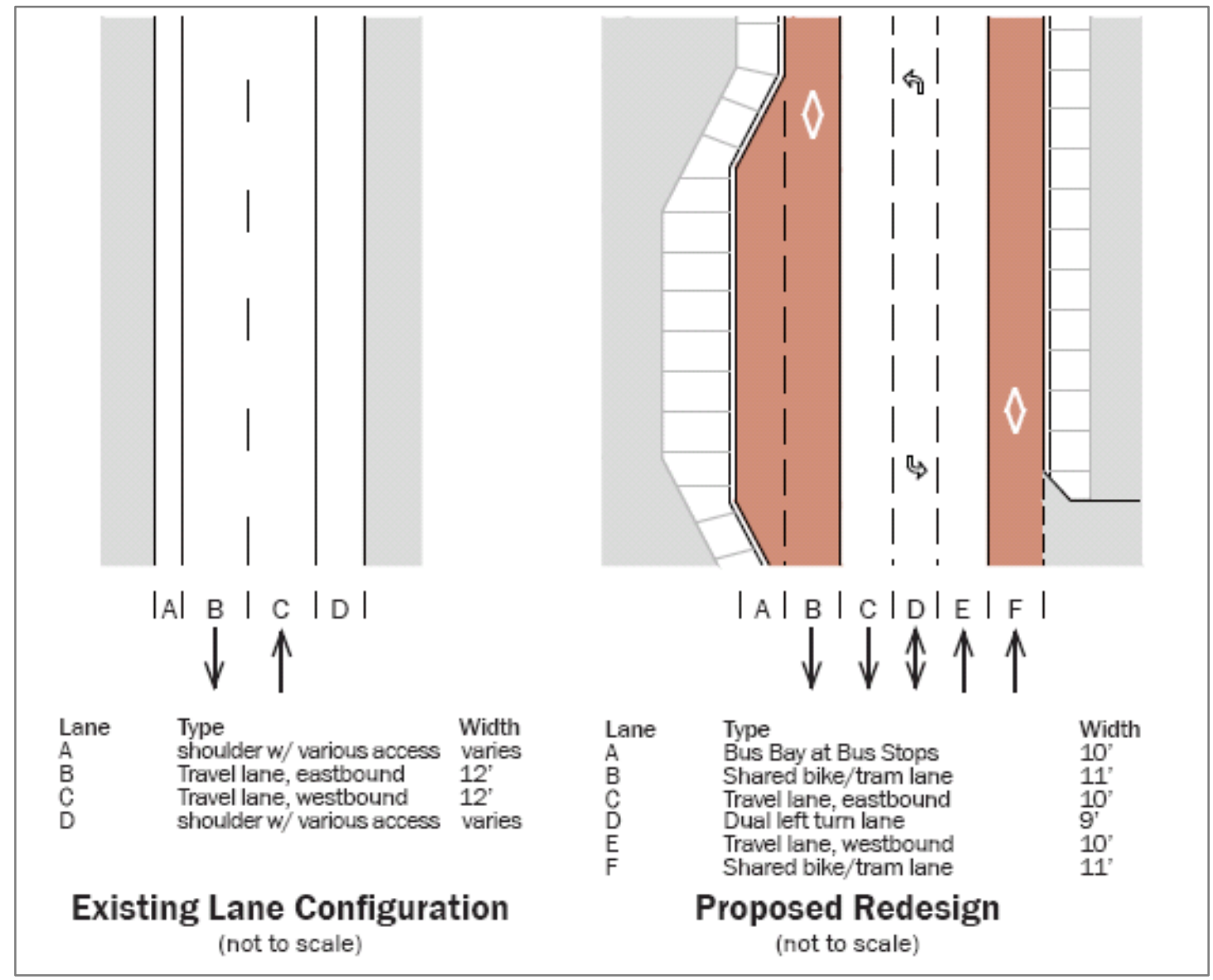

Figure 1.7 - Existing and proposed lane configuration for Front Beach Road

Section 13 - Transit System provides route information and general design criteria for dedicated bike/tram lanes:

- 11-foot bike/tram lanes

- Colored asphalt (Asphacolor Integral Color for Hot Mix - Brick Red color)

- Thermoplastic pavement striping with reflectors applied between the roadway and the bike/tram lane

- Details regarding the design of pull-out areas adjacent to tram stops (HHI Design et al. 2008, 56) 
Additional components of the bike/tram lanes not described in the Streetscape Design Manual include the following.

- Reduction of current roadway speed limits from 35 to $25 \mathrm{mph}$, with buses governed at a speed appropriate to be mixed with bicyclists

- No right-turning vehicles permitted

- Intelligent Transportation Systems communications for traffic signal prioritization of transit traffic at signalized intersections along the route (City of Panama City Beach CRA 2010, 4-6)

Tram pull-outs are provided at every stop along the Front Beach Road corridor for two primary purposes. Front Beach Road is the primary travel route through and within Panama City Beach. Tram pull-outs provide a clear path for emergency vehicles along the congested corridor. The pull-outs also create safer passage for bicyclists to pass a stopped tram. The pull-outs were viewed by the design team as a good alternative to wider lane widths which were not possible due to the lack of available right-of-way.

A Project Development and Environment (PD\&E) study has been done for Front Beach Road to determine type, location and design of roadway improvements. The boundaries of the study examined Front Beach Road from South Arnold Road (SR 79) at the west end, for a distance of approximately 6.5 miles, terminating at the eastern end of Hutchison Blvd. (SR 392A) where it intersects North Thomas Drive. The Draft Preliminary Engineering Report that presents the results of the PD\&E study described a part of the proposed design concept of the recommended Build Alternative thus.

This build scenario provides an exclusive transit/bike facility throughout the study area. Upon completion, the new facility will include curb and gutter and will have defined access points into driveways and parking lots. This will greatly enhance the safety of the bicyclists and pedestrians. Furthermore, the wide lane provides bicyclists with a buffer from vehicles in the adjacent lane. (PBS\& 2010, 2-2).

South Thomas Drive is a roadway segment known as Segment 1, which was not a part of the PD\&E study but connects to the eastern terminus of the roadway studied under the PD\&E. Segment 1 has recently been completed but is not yet opened to traffic, as of the date of this report. Segment 1 includes an 11-foot shared bike/tram lane on the westbound side of the road and a 4-foot bike lane and no tram lane on the eastbound side. Segment 2 is a portion of Front Beach Road that extends from Richard Jackson Blvd. to South Thomas Drive. Segment 2 is proposed to have 11-foot shared bike/tram lanes on both sides of the street. It is estimated that Segment 2 may take from 3-5 years before completion. ${ }^{3}$

\section{Study Method}

As part of this study, researchers conducted searches on Transport Research International Documentation (TRID), reviewed periodicals, conference proceedings, webinars, and publications of professional associations. These included the American Public Transportation Association, the Institute of Transportation Engineers, the Association of Pedestrian and Bicycle Professionals, and the National Association of City Transportation Officials. These also included the National Cooperative Highway Research Program, the Transit Cooperative Research Program and Transportation Research Records of the Transportation Research Board, and corresponding groups from the United Kingdom, Canada, Australia, and several countries in Europe. Researchers inventoried national, state, and

\footnotetext{
3 John Alaghemand, P.E., City of Panama City Beach, phone conversation, May 3, 2012.
} 
local reference manuals and plans, including the Uniform Vehicle Code, the FHWA Manual on Uniform Traffic Control Devices (MUTCD), A Policy of Geometric Design of Highways and Streets (AASHTO Greenbook), and AASHTO's Guide for the Development of Bicycle Facilities, and their international counterparts. Researchers also inventoried Florida State law and administrative code, FDOT Plans Preparation Manual, FDOT Design Standards, and related design guidance documents, such as Accessing Transit (Higgins and Audirac 2008). Researchers sought information from local public transit agencies and searched blogs and related websites.

A resource network of contacts in states, cities, consulting firms, and other organizations with experience and knowledge of SBBLs was developed. An inventory of SBBLs in cities throughout Florida, the United States, Canada, and abroad was developed. Questionnaires were developed and disseminated to bicycle organizations, bicyclists, municipal and FDOT district engineers and planners, transit agencies, and bicycle/pedestrian coordinators. The questionnaires were developed to address the design and operational characteristics of individual SBBLs. Detailed follow-up telephone interviews were conducted with representatives of two design firms, managers, planning staff and bicycle and pedestrian coordinators of regional planning commissions, municipalities, and bus transit agencies. Sufficient information was available for the development of instructive case studies from Ocean City, MD; Washington, D.C.; Philadelphia, PA; and Minneapolis, MN, with detailed information on particular topics provided by other cities with SBBLs. Researchers prepared case studies, synthesized planning and design considerations, and provided recommendations for further research.

\section{Relevant Previous Research about SBBLs or Related Topics}

A search for SBBL in TRID indicates that the body of literature on SBBLs is presently small. SBBLs have generally not been considered as an option to improve bus service. For example, the Transit Capacity and Quality of Service Manual (TCQSM) defines bus lanes as “...a range of techniques designed to speed up transit vehicles and improve overall system efficiency..." (Kittelson et al. 2003, 4-19-4-34) but the TCQSM does not address SBBLs. A review of TCRP Synthesis 83 on transit preferential treatments in mixed traffic summarizes treatments for both roadway segments and intersections but also does not address SBBLs (Danaher 2010). Bus lanes have received research attention in recent years but with more of a focus on impacts upon highway capacity, travel times for buses, and enforcement of exclusive use. The literature on bus crashes has focused more on school buses and intercity buses rather than city transit buses. Bus crash analysis has studied the role of weather rather than roadway characteristics. One review of bus crashes in the U.S. found that 40 percent of bus injury crashes were rear-end crashes, and that 80 percent of these occurred when the bus was stationary and rear-ended by automobiles (Chimba, Sando, and Kwigizile 2010). This finding suggests that bus lanes and by extension, SBBLs, should be safer from this type of crash because they exclude or reduce use by automobile traffic. Another study found increased risk of bus crashes (sideswipes, mirror crashes) when buses operate in narrow lanes. The authors of that study concluded that when possible, buses should operate in lanes at least 12 feet in width (Sando and Moses 2010, 44).

Other research not directly related to SBBLs, but informative to issues common to SBBLs, was also considered in this review. For example, the research on bicycle facilities is far more varied in its consideration of alternative treatments that function as shared use. These include the design and application of wider outside curb lanes, general purpose lanes with Shared Lane Markings for bicyclists, and paved shoulders (Jacobson et al. 2009; Furth et al. 2010; Duthie et al. 2010). Findings from these studies may have some application to SBBLs. SBBLs are more prevalent and have a longer history of use in the United Kingdom, Australia, Canada, and some European countries. However, evaluation of existing SBBLs in other nations has been minimal. Those references that do present an in-depth assessment of SBBLs and relevant topics are summarized below. 


\section{Hennepin Avenue and 1st Avenue Two-Way Conversion, Minneapolis, Minnesota}

In 2009, Hennepin Avenue and 1st Avenue in downtown Minneapolis were converted from a one-way pair to two-way streets. Initially, Hennepin Avenue operated as a one-way street with a contraflow bus lane and a two-way bicycle lane in between the bus lane and general traffic lanes. Hennepin Avenue was then changed to a two-way street with an SBBL along each curb. The Department of Public Works conducted two studies to evaluate the SBBLs. The first, an evaluation of the two-way conversion, was released in July, 2010 (City of Minneapolis 2010b). The second, an observational study of green pavement along the length of the SBBL, was completed in October, 2011 (City of Minneapolis, 2011). The summary below focuses on the results of these studies. The SBBL itself is discussed in more detail as one of the case studies in Chapter 3.

After consideration of several alternatives, the design for the two-way conversion of Hennepin Avenue and 1st Avenue was selected based on its ability to achieve several objectives of the City, including the following.

- Improve vehicle safety by minimizing lane changes and weaving around stopped buses.

- Improve transit service and operation by reducing motor vehicle conflicts.

- Provide continuity and consistent bicycle alignment along both directions of Hennepin Avenue in transitioning southwest of 12th Street and in transitioning across the Hennepin Avenue Bridge into northeast Minneapolis.

\section{Impact on Travel Activity}

After the two-way conversion was implemented, bicycle volumes along Hennepin Avenue decreased (Figure 1.8). However, volumes counted along adjacent facilities indicated that there was an overall increase in bicycling in this area by 43 percent. General traffic volumes indicated an overall increase when cross-street volumes were included, indicating that traffic was circulating to achieve the shortest trip route. It was found that Hennepin Avenue functioned more to provide access and not as a through street (City of Minneapolis 2010b, 14). 


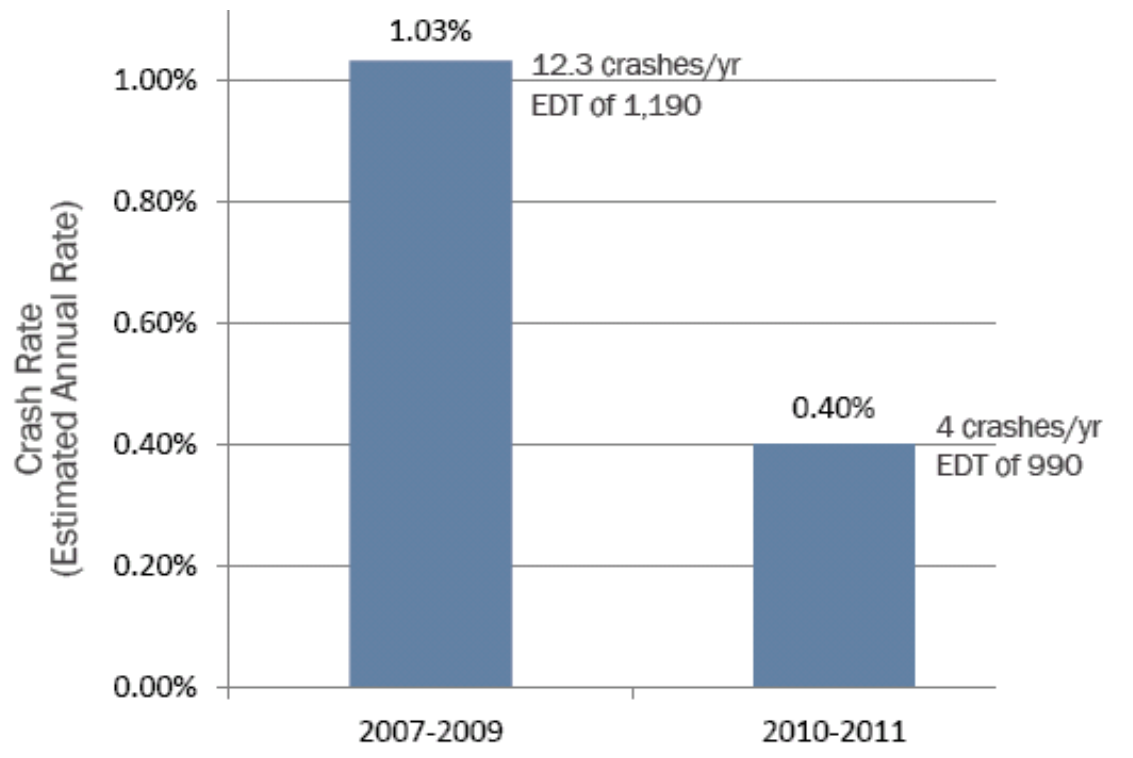

Estimated daily totals (EDT) based on 12-hr counts at 7th Street and Hennepin Avenue. Source: Hennepin Avenue Green Shared Lane Study, 2011.

Figure 1.8 - Change in bicycle volumes and crash rates 2007-2011, Hennepin Avenue

\section{Impact on Safety}

The conversion from one-way to two-way operation was initially anticipated to introduce added conflict points. Another key design concern was the ability to safely integrate a bicycle facility in the midst of two-way traffic. Prior to the two-way conversion, the existing Hennepin Avenue and 1st Avenue crashes were evaluated (2004-2008 data). The evaluation found that 31 bicycle crashes occurred on Hennepin Avenue between 1st and 12th Street. "Eighty-four percent of the 31 crashes were left turn related with over half of these being directly related to the left hook (i.e., bicycle approaching from behind the motorist out of their field of vision and the motorist turning left in front of the bicycle)" (City of Minneapolis 2010b, 5).

In evaluation of the design alternatives, and working with community stakeholders, a key bicycle safety concern of the proposed two-way traffic along Hennepin Avenue was anticipation of more right squeeze incidents at bus stops. Given the bus volume and number of bus stops, several stakeholders voiced this issue as a significant concern, if not fatal flaw to providing curb side bicycle lanes on Hennepin Avenue. However, after the two-way conversion, bicycle crashes decreased. Although the crash data that were evaluated in the study represented only 6 months of data after the two-way conversion, the trend was positive with zero bicycle crashes indicated during that time period. Due to experience with one-way streets and one-way bicycle lanes, Public Works staff had also expected the occurrence of wrong-way bicyclists to be a significant concern (City of Minneapolis 2010b, 5, 6, and 14). However, after the two-way conversion, the study evaluation of the green pavement documented four out of 442 cyclists riding against the flow of traffic during 36 hours of videotaped observations. Three of the cases occurred in segments with 18.5-foot lanes (City of Minneapolis 2011, 16). 


\section{Effect of Green Pavement}

Green pavement was added along the right side of the SBBLs on Hennepin Avenue. To observe the effects of the green pavement, the city installed video cameras at three sites along Hennepin Avenue to record the position of cyclists, motor vehicles, and buses in the SBBLs. Hatch marks were painted at one-foot intervals along the width of the SBBLs at each of the sites to accurately record the lane position of the bicycle or motor vehicle. Figure 1.9 illustrates where the hatch marks were painted.

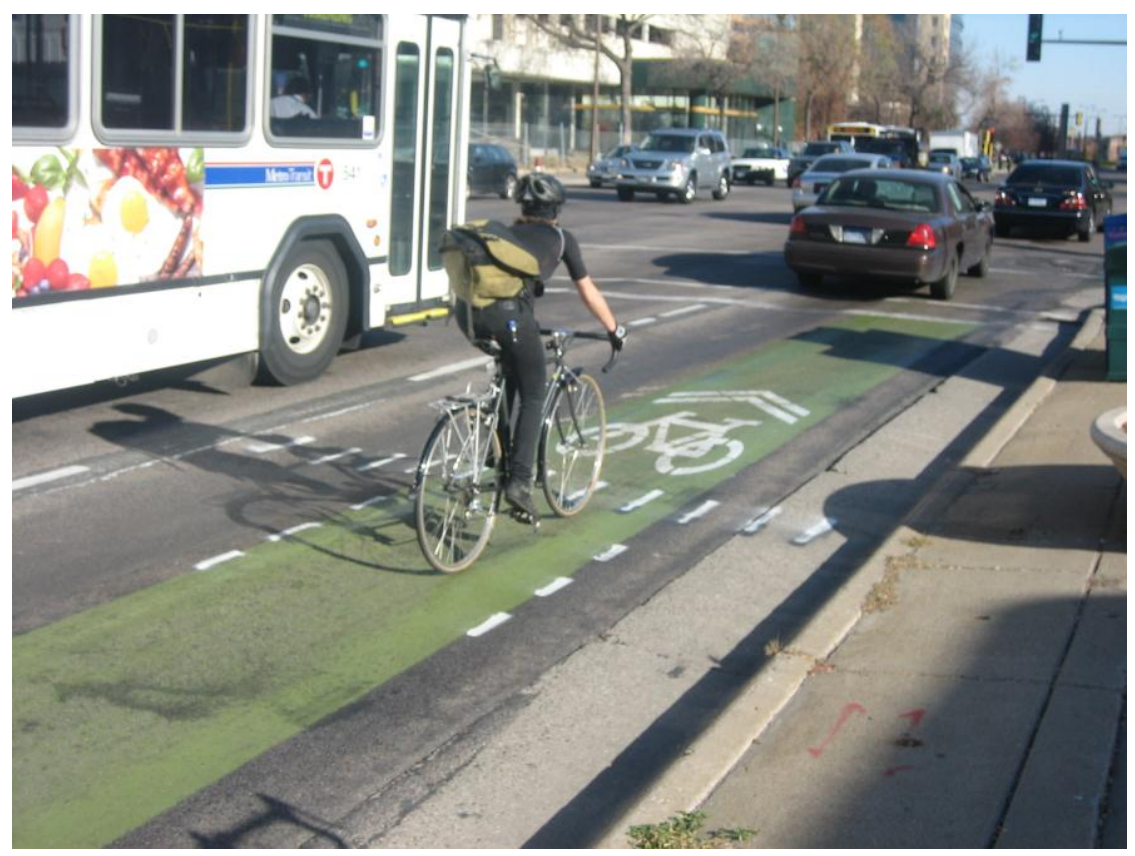

Figure 1.9 - Hatch marks were used to measure lane position of bicyclists and motor vehicles

Hennepin Avenue Green Pavement Study, Minneapolis Public Works

\section{Position of Bicyclists}

At all three locations, the majority of bicyclists rode in the painted lane area or to the right of it. Bicyclists rode closer to the curb in the narrower sections of the SBBLs than in the wider sections. While 80 percent of bicyclists in the narrower sections rode within the green lane, another 17 percent rode to the right of the green lane. Most (93 percent) of bicyclists in the wider sections rode within the green pavement and 3 percent of bicyclists rode to the right of the green pavement.

\section{Position of Motor Vehicles}

Motor vehicle driving position varied by location. The mean position of motor vehicles at each of the locations fell either over a portion of the painted lane or just to the left of it. Motor vehicles tended to travel to the left of the green pavement when traveling in the wider lanes (18.5 feet in width), but encroached on the green pavement when traveling where the lane narrowed (13.5 feet in width due to the presence of a left-turn lane).

\section{Position of Buses}

Similarly to other motor vehicles, bus driving position varied by location. Buses tended to drive closer to the curb when traveling in the narrower lanes than in the wider lanes. Buses tended to encroach on 
the green pavement for both lane widths, though less so for the wider lane. At the Washington Avenue observation location, where there is a narrower lane, the mean bus driving position was 2.3 feet from the curb, completely covering the green pavement. At the 4th Street location, where there is a wider lane, the mean bus driving position was 5.6 feet from the curb, covering approximately half the green pavement. At the 7th Street location, where there is a narrower lane, the mean bus driving position was 3.5 feet from the curb, completely covering the green pavement. The study researchers note that although the width of the lane may have something to do with the bus driving position relative to the green pavement, they also noted that the location of bus stops may have affected bus driving position. At the Washington Avenue and 7th Street locations, there were bus stops at the end of each of the blocks. At 4th Street, there was no bus stop along the block. Both buses and other motor vehicles encroached closer into the green pavement upon approaching an intersection, rather than when leaving an intersection (City of Minneapolis 2011, 14).

\section{Bicycle/Bus/Motor Vehicle Interaction}

The observational green-pavement study also attempted to evaluate interactions between bicyclists, buses, and other motor vehicles. Interactions of interest included four types.

- A bicyclist passes, or overtakes a stopped motor vehicle, such as at an intersection.

- A motor vehicle overtakes a moving bicyclist.

- A bicyclist overtakes a stopped bus, such as at a bus stop.

- A bus overtakes a moving bicyclist.

The sample sizes of particular types of interactions were too small to yield statistically significant results from which to draw conclusions. However, relative to the number of observations of motor vehicles, buses, and bicyclists along a heavily travelled downtown street that serves as a major bicycle route, researchers observed low numbers of interactions overall, as tallied in Table 1.1 The study recorded 36 hours of video observations (including one-hour time periods each at the morning peak, the evening peak, and mid-day between 11 a.m. to noon) over the course of three days at three SBBL locations along Hennepin Avenue. During this period, the study tabulated 3,506 motor vehicles, 480 buses, and 442 bicyclists (City of Minneapolis 2011, 15). However, only 21 interactions were recorded between buses and bicycles, and only 99 between bicycles and other motor vehicles. This is less than five interactions per hour. The safety of bicyclists improved after the green pavement was installed, although it is not clear if this is due to the two-way conversion of Hennepin Avenue, the green pavement, or some combination of both. Bicyclist crash rates decreased from 1.03 crashes per year per 100 estimated daily bicyclists (EDB) to 0.4 crashes per year per 100 EDB (City of Minneapolis 2011, 22).

Table 1.1 - Number of Interactions Observed near Intersections on Hennepin Avenue

\begin{tabular}{|l|c|c|c|c|}
\hline & $\begin{array}{c}\text { Washington Avenue } \\
\text { 13.5-foot lane } \\
\text { Near-side } \\
\text { intersection }\end{array}$ & $\begin{array}{c}7^{\text {th }} \\
\text { 13.5-foot lane } \\
\text { Far-side } \\
\text { intersection }\end{array}$ & $\begin{array}{c}\mathbf{4}^{\text {th }} \text { Street } \\
\text { 18.5-foot lane }\end{array}$ & Total \\
\hline $\begin{array}{l}\text { Bike overtaking stopped motor } \\
\text { vehicle }\end{array}$ & 18 & 1 & 53 & 72 \\
\hline $\begin{array}{l}\text { Motor vehicle overtaking } \\
\text { moving bike }\end{array}$ & 4 & 6 & 17 & 27 \\
\hline Bike overtaking stopped bus & 2 & 0 & 15 & 17 \\
\hline Bus overtaking moving bike & Not specified & Not specified & Not specified & 4 \\
\hline City of Minneapolis 2011, 15-16. & \multicolumn{4}{|l}{} \\
\hline
\end{tabular}




\section{Public Opinion Survey}

In addition, as part of the green lane evaluation, the City of Minneapolis Traffic and Parking Services Division administered a survey to determine public perception of the green lanes, comprehension of the new facilities, and changes to travel patterns before and after the changes to Hennepin Avenue and parallel corridors. The survey received 494 responses, primarily from bicyclists (City of Minneapolis 2011, 18). Despite the safety gains, survey respondents expressed dissatisfaction with the changes to Hennepin Avenue, citing lack of adequate space, the desire for a defined or separated facility, and lack of comprehension of the current configuration (City of Minneapolis 2011, 20).

\section{Bicycle-Bus Conflict Area Study, Delaware Valley Regional Planning Commission}

A study in Philadelphia (DVRPC and SEPTA 2009) did not specifically examine SBBLs but instead studied bike/bus conflicts that are nonetheless relevant to the consideration of the design and operation of SBBLs. With a research grant from Pennsylvania Department of Transportation (PennDOT), the Delaware Valley Regional Planning Commission (DVRPC) partnered with staff from Southeastern Pennsylvania Transportation Authority (SEPTA), the Philadelphia Streets Department, the Bicycle Coalition of Greater Philadelphia, the University District and others, to determine the nature of bike/bus conflicts, concentrating focus upon Walnut Street in University City (near the downtown), where there is both heavy bus and motor vehicle traffic and a bike lane serving heavy bicyclist traffic. The study collected and analyzed PennDOT crash data, conducted videotaping of bike/bus conflicts to better understand what conditions are causing the crashes, and conducted a survey of what other cities in the U.S. and internationally are doing to minimize bike/bus conflicts. The DVRPC study provides context for the SBBL case study for Chestnut Street in Center City, Philadelphia, presented in Chapter 3.

The study's analysis of crash data for years 2003-2007 in the City of Philadelphia indicated that 2.6 percent of all reported bus crashes involved bicycles, and 1.8 percent of all reported bicycle crashes involved buses (DVRPC and SEPTA 2009, 5 and 7). Ten out of the 46 bike/bus crashes that happened during this period occurred on streets with bike lanes, and the largest concentration of crashes occurred in downtown area. Forty-six percent of all bike/bus crashes were sideswipe and another 33 percent were angle crashes. DVRPC study authors also noted that in their experience, reported non-motorized crashes are only those that involve fatalities, injuries or major property damage and crash data is often mislabeled in the database, introducing some degree of uncertainty.

The video logs of Walnut Street were analyzed to identify incidents between buses and bicycles in which some type of conflict or "near miss" occurred. Two primary types of incidents were observed. The most frequent incident was that of a bicyclist attempting to pass to the right of a stopped bus that was dropping off and picking up passengers. Sometimes the bus was stopped in the bicycle lane. The second most frequent conflict was that of a stopped bus where there was insufficient width within the lane for a bicyclist to pass. The bicyclist then veered left into the adjacent traffic lane to pass the bus. There are many locations in Philadelphia where right-side bike lanes are adjacent to curbside bus zones. SEPTA policy is for buses to pull to the curb before letting off passengers; however, parked vehicles often block the curbside bus zone. Buses also conflict with bicyclists by having to pass across the bike lane to reach the curb.

The DVRPC study surveyed solutions used by other cities and found five main strategies. These are discussed in more detail in Chapter 4 of this report and include: discontinuing the bike lane at transit stops (Figure 4.6), use of colored pavement in bike lanes to highlight conflict areas such as transit stops (Figure 4.14), the use of cautionary pavement markings or signage, re-routing the bike lane 
around the right side of the bus stop (Figures 4.9 and 4.10), and establishing left side bicycle lanes for one-way streets.

The DVRPC considered each of these five SBBL strategies. For example, with regard to colored bike lanes, any colored lane treatment requires an FHWA experiment application. With regard to the discontinuance of a bike lane at a bus stop, it would require the bicyclist to either stop or to pass to the left of the bus and into general traffic. Examples of this from the U.K. and Denmark were considered. The DVRPC study found examples in the U.K., Australia and Denmark where bike lanes had been physically rerouted outside of bus stops. The main disadvantage of this approach is the additional right-of-way needed, although it might be considered the better option where there are very large numbers of bicyclists or where the right-of-way is available.

The study also found examples of bike lanes routed along the left side of one-way streets in Madison, WI, Minneapolis, MN, New York City and Seattle, WA. Left-side bike lanes eliminate conflict with buses in addition to reducing conflict with parked vehicles. Bike boxes are used at intersections to transition bicyclists in a left lane to cross over to a right side bike lane or to make a right turn onto a left-side bike lane. The study found examples of signage from Portland and Australia directing motor vehicles to yield to buses re-entering traffic. Some of these signs are attached to the rear panel of buses.

The DVRPC concluded that the left-side bike lanes under certain conditions might have the most potential to reduce bike/bus conflicts. Another recommendation was to educate road users to a "yield/courtesy pyramid," in which cars and trucks yield to buses, buses yield to bicyclists, and bicyclists yield to pedestrians. In addition, the study recommended a targeted campaign to discourage bicyclists from passing buses on the right through signage and education. An alternative to this is a light-up indicator on the rear of the bus to alert bicyclists that passengers are disembarking. Another alternative used in some European countries, such as Denmark, is to place a yield or stop sign at the bike lane prior to a bus stop.

\section{Design Treatments for Bicycles and Buses on Arterial and Collector Roads, City of Ottawa}

The City of Ottawa commissioned a study (Dillon Consulting 2009) to determine when sharing a lane between buses and bicycles might be appropriate and to establish policy and design guidelines to minimize conflicts between bicycle facilities and public transit movement. This study was conducted in four stages: (1) identify the range of existing design treatments that are in use in Ottawa; (2) conduct a scan of current industry practices; (3) identify and review policy and design elements; and (4) recommend a policy and a range of acceptable design treatments. The study also reported on a monitoring/data collection exercise.

The range of existing treatments that were examined included:

- Mixed traffic lane (no dedicated facilities for either bikes or buses);

- Dedicated bike lanes (buses in mixed traffic on the left);

- Dedicated bike lane, dedicated bus lane (mixed traffic lane on the left of the bus lane);

- Dedicated SBBL (mixed traffic on the left); and

- Dedicated bus-only lane (bikes in mixed traffic lane on the left).

The scan of industry practices included a webpage literature review providing guidelines and/or recommendations related to a number of design elements. These included suggested lane dimensions and design guidelines, suggested triggers for different design treatments, and safe 
practices for bus operators and cyclists. The study then identified five key design treatment factors to incorporate into a policy framework for the selection of design treatments for SBBLs:

1. Bus volume

2. Cyclist volume

3. Bus operating speed

4. Lane dimensions

5. Traffic safety

The Ottawa study concluded by providing guidance for recommended design treatments based upon thresholds for bus volumes, bicycle volumes, and bus operating speeds. These are provided in Tables 1.2 and 1.3. It is unknown how these indicator values were derived. The Dublin Transportation Office Cycle Track Design Guidelines Manual, 1997, that is the source for Ottawa's recommended thresholds, refers to research from the Dutch Institute for Road Safety Research "SWOV," but no specific citation was given. There is research from SWOV that resulted in rough estimations of the type of segregation between bicycles and buses needed in relation to different speeds and volumes. This research focused on "Sustainable Safety Principles," one of which is homogeneity, or the aim to minimize differences in mass, speed, and direction of vehicles using the same traffic space (SWOV 2010).

Table 1.2 - Preferred Design Treatments (Ottawa) - Summary of Criteria

\begin{tabular}{|c|c|c|}
\hline Criteria & Indicator & Recommended Design Treatment \\
\hline \multirow{2}{*}{ Bus Volumea } & $>20$ buses/hour & $\begin{array}{l}\text { - dedicated bike lane; or } \\
\text { - dedicated bus lane }\end{array}$ \\
\hline & $\leq 20$ buses/hour & $\begin{array}{l}\text { - dedicated SBBL, or } \\
\text { - mixed traffic lane }\end{array}$ \\
\hline \multirow{3}{*}{ Bicycle Volume ${ }^{b}$} & $>100$ cyclists $/ \mathrm{hr}$ & - physically segregated bike facility \\
\hline & 50 - 100 cyclists/hr & - dedicated bike lane \\
\hline & $<50$ cyclists $/ \mathrm{hr}$ & $\begin{array}{l}\text { - dedicated SBBL, or } \\
\text { - mixed traffic lane }\end{array}$ \\
\hline \multirow{2}{*}{ Bus Operating Speed $\mathrm{c}$} & $>60 \mathrm{~km} / \mathrm{hr}(37.2 \mathrm{mph})$ & - dedicated bus lane \\
\hline & $\leq 60 \mathrm{~km} / \mathrm{hr}(37.2 \mathrm{mph})$ & $\begin{array}{l}\text { - dedicated bus lane; or } \\
\text { - dedicated SBBL }\end{array}$ \\
\hline \multicolumn{3}{|c|}{$\begin{array}{l}\text { Dillon Consulting 2009, Table } 7 . \\
\text { a Bus volume thresholds were based on the Dublin Transportation Office Cycle Track Design Guidelines Manual, } \\
\text { 1997, and staff input from the City of Ottawa. } \\
\text { b Bicycle volume thresholds were based on the Dublin Transportation Office Cycle Track Design Guidelines Manual, } \\
\text { 1997, staff input from the City of Ottawa, and Vic Roads Bicycle and Pedestrian Programs. } \\
\text { c Bus operating speed thresholds were based on Dublin Transportation Office Cycle Track Design Guidelines Manual, } \\
\text { 1997, and staff input from the City of Ottawa. }\end{array}$} \\
\hline
\end{tabular}


Table 1.3 - Recommended Specifications for Design Treatments (Ottawa)

\begin{tabular}{|l|c|c|}
\hline \multicolumn{1}{|c|}{ Treatment } & $\begin{array}{c}\text { Minimum Specifications } \\
\text { (feet) }\end{array}$ & $\begin{array}{c}\text { Maximum Specifications } \\
\text { (feet) }\end{array}$ \\
\hline Mixed Traffic Lane & 13.1 & 14.8 \\
\hline Dedicated Bike Lane & & $\begin{array}{c}5.9 \\
\text { speed }\end{array}$ \\
\hline Dedicated Bike and Dedicated Bus Lane & 4.9 & $\begin{array}{c}6.6 \text { for maximum bus operating } \\
>60 \mathrm{~km} / \mathrm{hr}(37.2 \mathrm{mph})\end{array}$ \\
\hline Dedicated SBBL & 16.4 & $\begin{array}{c}18.0 \\
(5.9+12.1)\end{array}$ \\
\hline Dedicated Bus Lane & 13.1 & 14.8 \\
\hline Dillon Consulting 2009, Table 8. & 11.5 & 12.3 \\
\hline
\end{tabular}

\section{Cycling in Bus Lanes, Department for Transport, United Kingdom}

A study was undertaken by Reid and Guthrie (2004) of the Transport Research Laboratory (TRL) on behalf of the Department for Transport in the United Kingdom for the purpose of better understanding bicyclist and bus interaction in bus lanes and to provide guidance for increasing safety of bicyclists in SBBLs. The study conducted a survey of bicyclists who use the SBBLs and a survey of bus drivers who drive routes along SBBLs. Researchers also conducted interviews with bicyclists and conducted observations of bike/bus interaction in SBBLs. Researchers also reviewed crash statistics.

The study also summarized previous policy regarding SBBLs. Reid and Guthrie found that the Institution of Highways and Transportation and Cyclists' Touring Club and Bicycle Association published guidance (1996) on bicycle infrastructure. The guidance states that SBBLs can improve safety and convenience for bicyclists in town centers and on main urban roads. A minimum lane width of $4.0 \mathrm{~m}$, but preferably 4.25-4.6 m width, should be provided to enable buses to pass bicyclists without having to swerve into an adjacent general use travel lane. The U.K. does not specify a minimum separation between motor vehicles and bicyclists when passing.

The Department of the Environment, Transport and the Regions (DETR) issued policy (1997) that bicyclists will be allowed in bus-only lanes unless there is a good reason to prohibit their use. Technical guidance provided for a minimum preferred SBBL width of $4 \mathrm{~m}$, with $4.24 \mathrm{~m}$ preferable where right-of-way allows, for both with-flow and contraflow SBBLs. That same year, Ove Arup \& Partners and Sustrans developed guidelines (1997) for a preferable bus lane width of $4.25 \mathrm{~m}$ to $4.6 \mathrm{~m}$; however, they stated that busy bus lanes are not ideal for young or novice bicyclists and this could be addressed by SBBLs allowed only during non-peak hours.

The London Cycle Network Steering Group issued a design manual (1998) that advises that bicyclists should be permitted to use bus lanes and that such lanes should be $4.0 \mathrm{~m}$ at a minimum. In summary, three sources in the U.K. during the late 1990s advised that an SBBL should be $4.0 \mathrm{~m}$ at a minimum.

Reid and Guthrie compared bicycle crash rates in bus lanes to bicycle crash rates in general lanes during the same time period; however, bicycle exposure data as well as time series data were unavailable, making it not possible to draw conclusions about the relative safety of the facilities. Lower levels of bicycle crashes on SBBLs might reflect higher levels of discomfort of bicyclists and overall lower levels of bicycling within them.

The study also observed bike/bus interactions at three locations where there were SBBLs. The purpose of the observations was to assess the nature of the interactions, such as a bus passing a 
bicyclist, determine any delay experienced by bicyclists and/or bus as a result of the interaction, and note when a bicyclist or bus was forced to leave the shared lane into the general traffic lane. The study provided a report of observed bike/bus interactions in London, Hull, and Edinburgh. In Edinburgh, observations were made at a location where there was a $3.1 \mathrm{~m}(10.2 \mathrm{ft}$.) bus lane and also at a location where the bus lane was $3.8 \mathrm{~m}$ (12.5 ft.) wide. A total of 104 bike/bus interactions were observed, or on average, one interaction per bus every 8 minutes.

In Hull, an observer recording interactions from the front seat of a moving bus, observed interactions at various bus lane locations with lane widths up to $3.65 \mathrm{~m}(12.0 \mathrm{ft})$. A total of $25 \mathrm{bike} / \mathrm{bus}$ interactions were observed. Eight of these interactions caused the buses to be delayed for a period of between three and 30 seconds. The traffic flow in the main lane was congested in four of the interactions. In each of these four instances, the bus was delayed by the cyclist and could not overtake in the bus lane. In London, video footage was used to evaluate bike/bus interactions at two bus lane locations. During a 2-hour morning peak observation period, 20 out of a total of 264 buses experienced delay as a result of bicyclists using the bus lane. Time length of delay was not given.

The study authors had several recommendations, including the following.

- Traffic engineers should anticipate and plan for the use of bus lanes by bicyclists.

- Bus lanes should be designed also for use by bicyclists, with a minimum $4.0 \mathrm{~m}$ preferred width.

- Where there is $4.0 \mathrm{~m}$ width and over, advisory cycle lanes should be included within the bus lane, along the curb side of the bus lane. (Ove Arup \& Partners $(2008,36)$ define an advisory cycle lane as a bicycle lane marked by dashed lines, which guides bicyclists where they should ride in the lane and where other vehicles should not enter unless safe to do so. Figure 4.6 in Chapter 4 of this report illustrates an advisory cycle lane and it is further described within the discussion of the Cardiff Cycle Design Guide in Chapter 2.)

- Bus lanes should not deliberately be made narrow in order to prevent buses from overtaking bicyclists.

- Contraflow bus lanes should be wider than the equivalent with-flow bus lane.

- Bus lane pavement should be inspected more frequently because the heavier buses will cause more rapid deterioration of the pavement, creating unsafe conditions for bicyclists.

- Bus lane regulations require consistent enforcement to discourage illegal parking and other misuses.

- More research is needed to develop ways to reduce bike/bus conflict at bus stops.

The survey results of bicyclist attitudes taken at five locations suggested the following conclusions to the U.K. researchers.

- Bus lanes are popular with bicyclists.

- Bicyclists perceived safety benefits and a more direct travel route.

- Bicyclists did not like misuse of the bus lane by other vehicles, such as illegally parked cars.

- Bicyclists preferred wider bus lanes of $4.0 \mathrm{~m}$ to $4.2 \mathrm{~m}$ in width over narrower lanes.

- Bicyclists preferred a narrow bus lane to a general purpose traffic lane.

- Most bicyclists preferred a wide bus lane to a separate bicycle lane.

- Most bicyclists preferred a separate bicycle lane to a narrow bus lane.

- A majority of bicyclists preferred having an advisory cycle lane within the bus lane.

- A majority of bicyclists did not want motorcycles to use the bus lane. 


\section{Bus-Bike Interaction within the Road Network, Sydney, Australia}

A report prepared for Austroads documented interaction between buses and bicycles within the road network in Australia. It recommends suggestions to limit negative impacts on cyclists, bus operators, and transit passengers. The report identifies issues of bicycle/bus interaction (Ker, Moore, and Yapp 2005, 2-3).

- Bicycles are small and vulnerable. Buses are large and perceived as potentially threatening by bicyclists. Buses and bicycles represent almost the extremes of the user spectrum on roads in cities, yet they often operate in the same part of the roadway. State laws typically require that bicyclists use the outside lane of streets, except when making a vehicular left turn from the center of the road. Many bicyclists use the outside portion of the outside lane, even when not required. Buses also operate primarily in the outside lane because of the need to pick up and drop off passengers at stops.

- A bicyclist presents a small visibility profile. The design of buses may mean that the driver has poor visibility with respect to certain areas surrounding the bus, where a cyclist might be located. Additionally, the bus may block a bicyclist's view of cross-traffic at intersections or in adjacent lanes. A bus may block a car driver's view of a bicyclist, potentially placing the bicyclist at greater risk of a collision. For speed and perceived safety, car drivers often try to avoid following a bus and may change lanes abruptly to pass. Uncertainty about where a bicyclist is expected to be on the roadway and at intersections can cause problems for both bus operators and bicyclists.

- Bus drivers may underestimate the speed of a cyclist being passed and pull in towards the curb before there is sufficient clear space in front of the cyclist.

- Use of SBBLs by unauthorized vehicles may force bicyclists into faster-moving and more complex traffic.

- Some municipalities in Australia have incorporated financial penalties for late running into transit operator contracts or franchises. Such penalties can lead to more aggressive behaviors in shared lanes. (This is not common in the U.S.)

The report includes an overview of laws in Australia's states and territories that explicitly permit bicycles to use bus lanes and also identifies where SBBLs are in use. The study includes a crash analysis, identifies for what types of streets SBBLs are appropriate ("neighborhood connectors" and "integrator arterials", roughly equivalent to urban collectors and urban arterials in the U.S.), proposes guidelines to address various issues of bike/bus conflict and presents examples for roadway design. The report contains a toolkit of "Information Notes", one of which addresses the issue of whether SBBLs should be wide enough for overtaking (by bike or bus), or should overtaking be discouraged (Ker, Moore, and Yapp 2005, 47). The Information Note contains the recommendation that overtaking should be enabled by SBBLs of sufficient width, between 4.2-4.5 m where motor vehicle traffic speeds are up to $60 \mathrm{~km} / \mathrm{h}(37 \mathrm{mph})$ and 4.5-5.0 m where motor vehicle traffic speeds are up to $80 \mathrm{~km} / \mathrm{h} \mathrm{(50}$ $\mathrm{mph}$ ). The whole bicyclist design operating space should be accommodated within the roadway and not as part of the curb and gutter. As in the U.K., Australia does not specify a minimum passing distance when a motor vehicle passes a bicyclist.

\section{Level of Service Impact of SBBLs}

Most of the available research on SBBLs has addressed safety; however, there were a few attempts to address level of service. The study by The Genesis Group, summarized previously, attempted to calculate the LOS impact of SBBLs on West Tennessee Street in Tallahassee; however, this analysis is prospective. Reid and Guthrie evaluated the LOS impact of SBBLs in several towns in the U.K. as one 
component of their study for Transport Research Laboratory. They investigated whether bicyclists caused delays to buses in the SBBL as well as whether buses caused bicyclist delays. The study included static observations at various SBBL locations representing bus lanes of varying widths. The study also included fixed video camera surveys, on-bus observations of bus interaction with bicyclists, and interview surveys with both bicyclists and bus operators. The study concluded that bicyclists were generally not delayed by buses. Delay to buses was described thus:

Taking both lane widths together, fewer than one in four interactions resulted in the buses being noticeably slowed. This amounted to approximately one slight delay per two buses, or one slight delay per 18 bus-km. Nearly all of these were in the $3.1 \mathrm{~m}$ lanes. In the $3.8 \mathrm{~m}$ wide lanes, buses were rarely delayed. Cyclists tended to pull to the kerb and buses overtook without entering the main traffic flow. Where delays occurred, they were due to buses waiting behind cyclists when approaching bus stops or roundabouts.

and

In bus lanes of less than approximately $3.5 \mathrm{~m}$, buses might be delayed by cyclists, but that is only a significant problem if cycle flows are high. Wider bus lanes are, therefore, in the interests of bus users. At the sites studied, delays to buses as a result of cyclists using bus lanes were minimal. (Reid and Guthrie 2004, 8 and 20)

CUTR researchers attempted to collect information on impacts to roadway level of service as a result of the implementation of SBBLs in cities in the United States. Planners and transit agency representatives who responded to a survey indicated that the impact of the SBBL has been mixed. However, almost no formal evaluations of LOS were found to verify such observations.

- No information on LOS was reported for Tucson or Denver.

- The comments from one Ocean City respondent seemed to imply that the SBBL had no effect on LOS.

- A respondent from Washington, D.C. said there has been no LOS impact upon transit.

- A SEPTA representative from Philadelphia reported a reduction in transit LOS and attributed this to the City's decision to allow use of the SBBLs for right turns.

- A Baltimore survey respondent reported that LOS improved for transit and bicycles, and remained constant for other modes, but there was no indication how this had been assessed.

- A Seattle respondent reported that the SBBL has improved transit LOS on both Stewart Street and Elliot Avenue, although buses are occasionally delayed by cyclists and right turns. Elliot Avenue has relatively low bicycle volumes. An increase in bicycle use is reported for Stewart Street, but this is thought to reflect the general trend of increased bicycle use in the Seattle area.

- Minneapolis was the only city in which an evaluative study was conducted; however, this was a study of the impact of converting a one-way pair of streets into two-way streets. The installation of SBBLs was a part of that redesign. As a result, the impacts measured were the result of several changes that were made all at once and so it is not possible to separate the impact of the SBBLs from other changes.

With regard to evaluating roadway LOS for general traffic, transit buses and bicyclists, FDOT's 2009 Quality/LOS Handbook has been nationally recognized as the first planning application of the Highway Capacity Manual (HCM) for the evaluation of multimodal quality/level of service. With the recent update of the $2000 \mathrm{HCM}$, FDOT plans to implement the new $2010 \mathrm{HCM}$ in place of the FDOT 2009 Quality/Level of Service Handbook. Many evaluation procedures in the $2000 \mathrm{HCM}$ were changed in the 
$2010 \mathrm{HCM}$, including a new approach to evaluating LOS trade-offs among modes. The new approach was based upon research, much of which was conducted since 2000. The research included NCHRP Report 616: Multimodal Level of Service Analysis for Urban Streets (Dowling et al. 2008). Full transition to use of the 2010 HCM by FDOT is expected by the conclusion of 2012.

Volume 3 of the 2010 HCM offers separate LOS analysis methodologies for each mode. Used together, these methodologies allow a multimodal evaluation of urban streets, for each direction of travel, from the point of view of motorists, bus passengers and bicyclists. In general, changes that reallocate lane width to improve LOS to one mode may affect the LOS of other modes. The transit methodology is limited to the evaluation of public transit vehicles that stop along the street and are operating in either mixed traffic or exclusive traffic lanes. The HCM multimodal LOS analyses can be conducted iteratively to evaluate different right-of-way allocations and other conditions. However, the conditions of an SBBL may not be entirely represented using the input data elements summarized in Exhibit 17-6 of the $\mathrm{HCM}$ and the formulas provided in Chapter 17 of the HCM (HCM 2010, 16-17). It may be necessary to select a different combination of input data elements to evaluate an SBBL.

For example, on an SBBL, bicycle LOS may be affected by transit frequency, which is not a data input used in the computation of bicycle LOS. While mid-segment flow rate of motorized vehicles and percent heavy vehicles might be data inputs that could serve as proxies for transit frequency, these might not completely duplicate the nature of the impact of transit frequency upon bicyclist perception of SBBL LOS. As another example of capturing the range of conditions that might affect bicycle LOS, transit bus dwell time, transit stop location and transit stop position are all input data elements not identified in the computation of bicycle LOS; however, these would have an effect upon bicycle LOS in an SBBL. These effects might be adequately captured in the computed bicycle travel speed but this would have to be verified. The width of the outside through lane is a data input element for bicycle LOS but not for transit LOS. However, the outside through lane would likely serve as the SBBL, in which case this should be included in the calculation of transit LOS. Additionally, the SBBL cannot adequately be represented by including the width of a separate bicycle lane and the width of an outside through lane. This is because the manner in which lanes are striped has an impact on lane positioning by motorists, bus operators and bicyclists.

In conclusion, it is suggested that the HCM multimodal LOS methodology be used with caution if applied to evaluate design alternatives for a roadway that might include an SBBL. Future research should develop a LOS evaluative process for SBBLs as a separate modal alternative. In addition, the 2010 $\mathrm{HCM}$ categorizes all arterials into one class. FDOT is conducting research to determine the best way to evaluate arterials of different locations (suburban versus central business district), posted speed limits and densities of traffic signals.

\section{Conclusions from Review of the Literature}

This survey of research relating to SBBLs has included evaluative studies of how SBBLs are operating. These studies have used traffic and bicycle counts, observational studies of traveler behavior in the SBBL with the aid of videotaping, surveys of users and reviews of crash statistics. Such studies have drawn conclusions and recommendations for design and operation that are useful for Florida to consider. Other research has attempted to develop thresholds for determining the most appropriate type of facility for buses and bicyclists, using combinations of bus and bicycle traffic volumes, bus operating speeds and recommended lane widths where right-of-way is available. A study of SBBL safety, conducted by the Minneapolis Public Works Department, evaluated the number of crashes before and after a particular SBBL was implemented (City of Minneapolis 2010b). Because this SBBL is new, the data on crashes since implementation is too limited to draw conclusions with much confidence. The 
studies in Minneapolis and Philadelphia also used video logs to examine interactions between bicycles and buses or other motor vehicles (City of Minneapolis 2011; DVRPC and SEPTA 2009). These studies provided recommendations for steps to reduce some types of interactions, but the low frequency with which interactions were observed makes data collection and analysis for evaluation expensive. The study prepared by Transport Research Laboratory (TRL) in the United Kingdom (U.K.) examined SBBLs in several towns, including London. It dealt primarily with bicyclist comfort and perception of safety (Reid and Guthrie 2004). 


\section{Chapter 2: Survey of Current Practices}

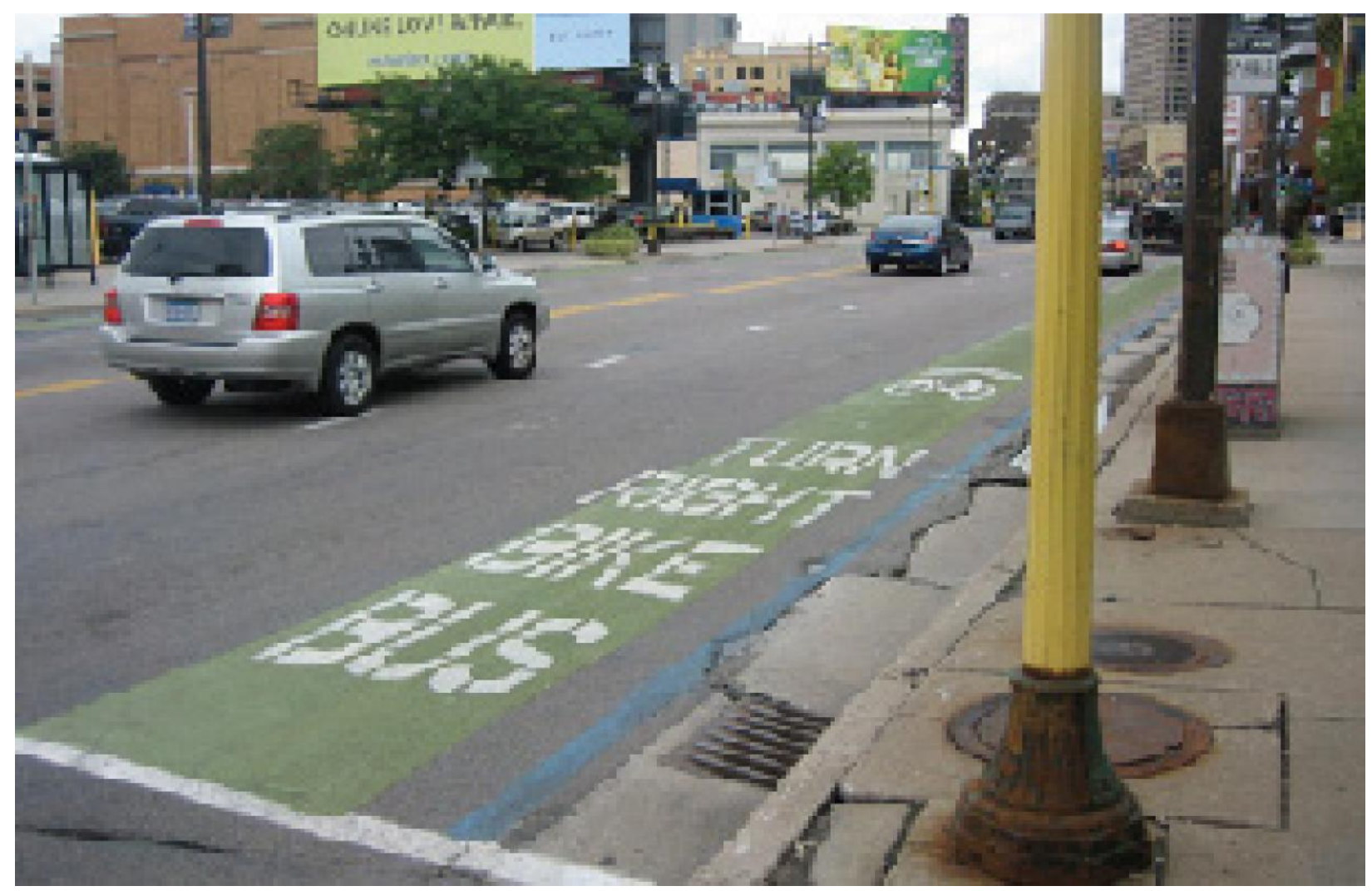

Figure 2.1 - Hennepin Avenue, Minneapolis, MN

Credit: Minneapolis Public Works

\section{References on Street Design and Operation}

Standard references for the United States and the State of Florida and studies of the Transportation Research Board were reviewed for guidance regarding SBBLs. No standards for SBBLs were found, but established standards and guidelines are available for separate bicycle lanes and for separate bus lanes (FHWA 2009; AASHTO 1999; FDOT 2012a; FDOT 2012b; Kittelson et al. 2003; Danaher 2010). However, active discussion has emerged with regard to shared use lanes, in which bicycles share the lane with motor vehicles. These include references to Shared Lane Markings in the Manual on Uniform Traffic Control Devices (MUTCD) (FHWA 2009, 810). The NACTO Urban Bikeway Design 
Guide (2011) references the FHWA-approved experimental use of Shared Lane Markings in right turn lanes. This is illustrated in Figure 2.2.

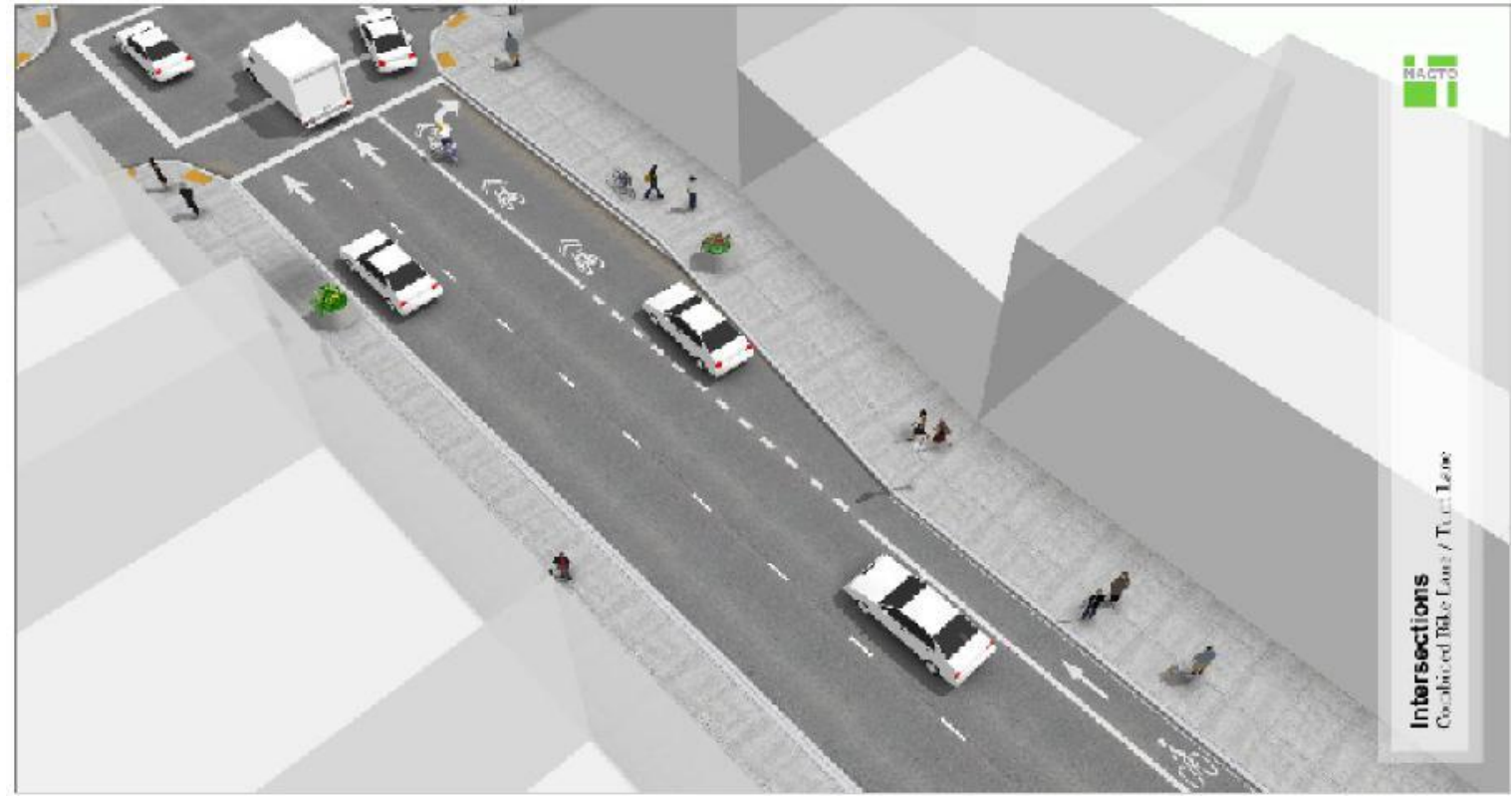

Figure 2.2 - Intersection example of a combined bike lane/turn lane

Source: National Association of City Transportation Officials, Urban Bikeway Design Guide. New York, NY, April 2011 Edition.

\section{State Guidelines}

A search for state design manuals for bicycle facilities and roadway design identified examples of guidance regarding SBBLs from Maryland, Illinois, Washington, and the District of Columbia.

\section{Maryland}

The Bicycle and Pedestrian Design Guidelines for the State of Maryland do not provide lane widths, thresholds for bicycle and bus volumes that would warrant establishing an SBBL, or recommended speed limits. However, there is a short section, entitled Shared Bus/Bicycle Lanes in Chapter 4 that reads:

Shared Bus/Bicycle lanes are typically wider than the standard 11-foot lane. Bus/bicycle lanes have been used in Maryland (in Ocean City), the District of Columbia, and other parts of the country, however due to the conflicts inherent in the type of facility, it shall only be considered in consultation with SHA's Bicycle and Pedestrian Coordinator. (MSHA n.d., 4-4)

\section{Illinois}

In a discussion of on-road marked bicycle lanes on urban roadways in the Illinois DOT Bureau of Design and Environment (BDE) Manual, guidance is provided on bicycles relative to buses: 
Locate one-way bicycle lanes that are on one-way streets on the right side of the street, except in areas where placing the bicycle lane on the left will decrease the number of conflicts (e.g., those caused by heavy bus traffic)... Place bicycle lanes that are adjacent to dedicated bus lanes between the vehicular traffic lane and the bus lane... Where roadway width is limited, bicycles and buses may share an outside lane with a minimum width of 16.5 feet ( $5 \mathrm{~m}$ ) to the curb face. (Illinois DOT 2011, 17-2.5).

\section{Washington State}

The Washington State Department of Transportation Design Manual briefly describes SBBLs thus:

When buses and bicyclists share the same roadway, consider the following: where bus speeds and volumes are high, separate facilities for buses and bicyclists are desirable. Where bus speeds and volumes are low, consider a shared-use bus/bicycle lane. (WSDOT 2010, 1520-5)

This manual does not specify threshold values for "high" or "low" volumes or speeds, and it does not specify widths for SBBLs. The most current revision, July 2011, clarifies that these guidelines are for use on state highway right-of-way or on city streets designated as state highways.

\section{Washington, District of Columbia}

No guidance is given regarding SBBLs but the Bicycle Facility Design Guide of the District Department of Transportation does contain diagrams that illustrate different configurations of bicyclist accommodation in constrained right-of-way with general traffic (Toole Design 2005, Figures 4, 15, and 23).

Figure 2.3 illustrates a 5-foot minimum width separate bicycle lane adjacent to a general traffic lane. Dashed white lines separate the bicycle lane from a bus stop located in the curb lane between onstreet parking. The curb lane is wide enough to completely contain the bus-at least eight feet, six inches. The dashed lines indicate potential conflict zone as the bus passes from the general traffic lane across the bicycle lane to the curb-side bus stop. (Figure has been reduced in size from the original. Scale given in figure is no longer correct).

Figure 2.4 illustrates a separate bicycle lane between a general traffic lane and on-street parking. The bicycle lane is marked with dashed lines as it passes next to the bus stop. The dashed lines end at the stop bar. The bicycle lane can vary in width from 3-5 feet if right turns are allowed from the bus stop. The curb lane is narrower than the width of the bus so that the bus must encroach upon the bicycle lane. The curb lane is also narrower than the general traffic lane. (Figure has been reduced in size from the original. Scale given in figure is no longer correct). Based upon the given information, total combined width of bike lane and bus stop would be less than 13 feet, 6 inches.

Figure 2.5 shows three diagrams. The top left diagram illustrates a wide outside lane for general traffic and no on-street parking. The outside lane is wide enough to completely contain a car passing to the left of a bicyclist. The bicyclist position is guided by the placement of Shared Lane Markings with their centers located a minimum of 4 feet from the curb face. The top right diagram illustrates a wide parking lane that is shared by bicyclists. The Shared Lane Markings mark the left side of the wide parking lane and are placed with their centers a minimum of 11 feet from the curb face. The bottom diagram illustrates a parking lane next to a wide general traffic lane. The bicyclist travels within and to the right side of the general traffic lane, as marked by the placement of Shared Lane Markings. These are located with their centers a 
minimum of 11 feet from the curb face. (Figure has been reduced in size from the original. Scale given in figure is no longer correct). Total width of wide outside lane is not given.

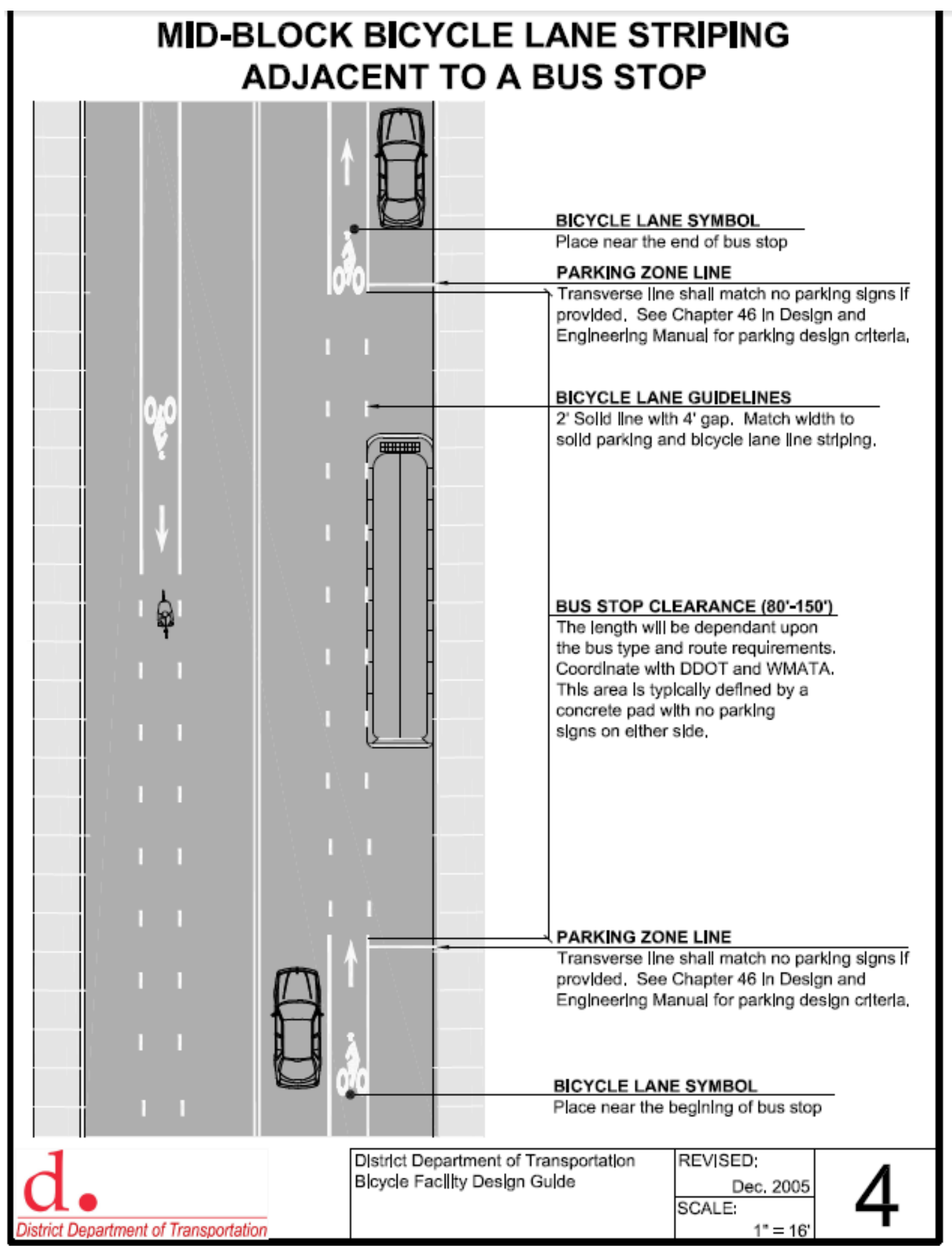

Figure 2.3 - Mid-block bicycle lane striping adjacent to a bus stop 


\section{BICYCLE LANE STRIPING ADJACENT TO NEAR SIDE BUS STOP}

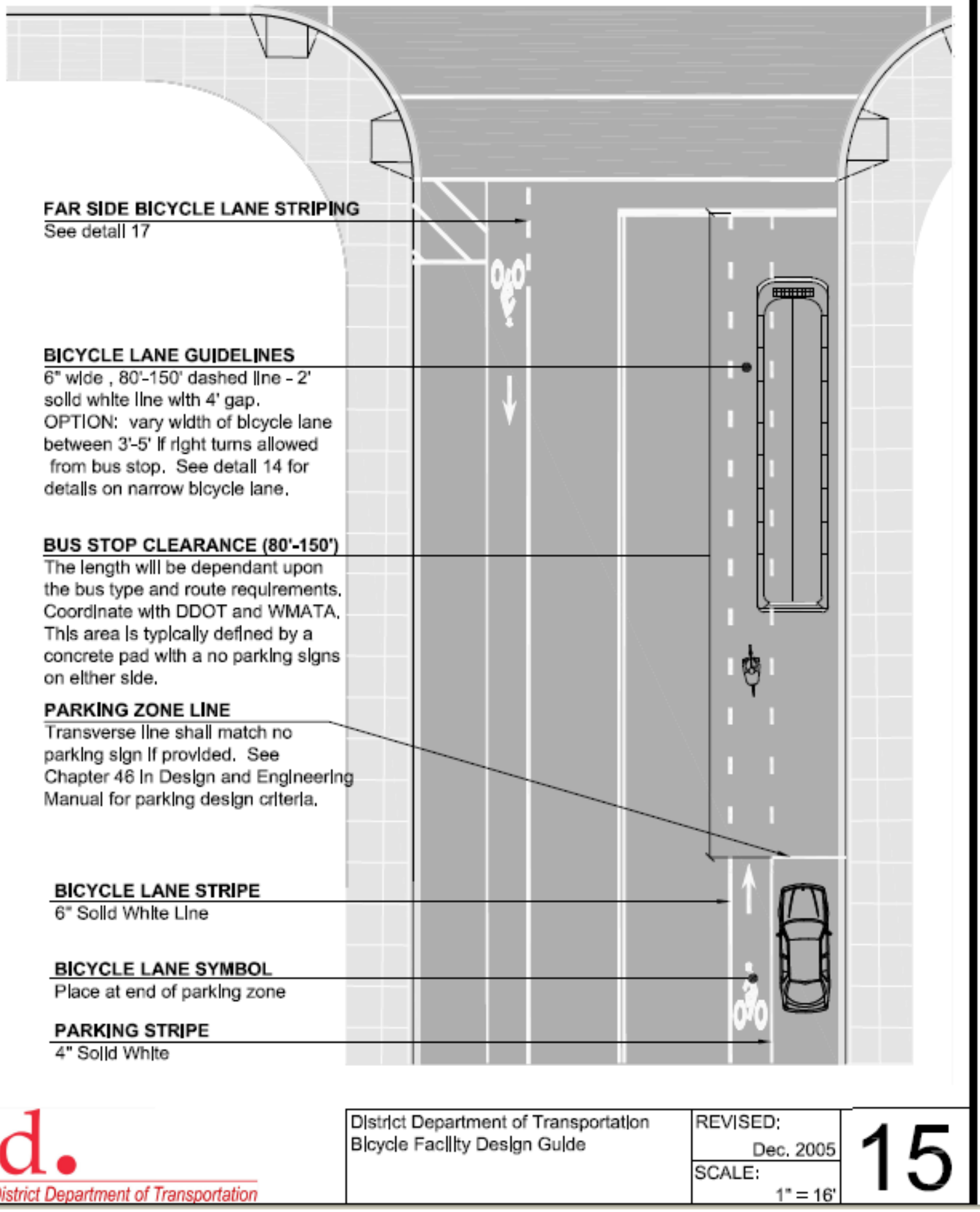

Figure 2.4 - Bicycle lane striping adjacent to near-side bus stop 


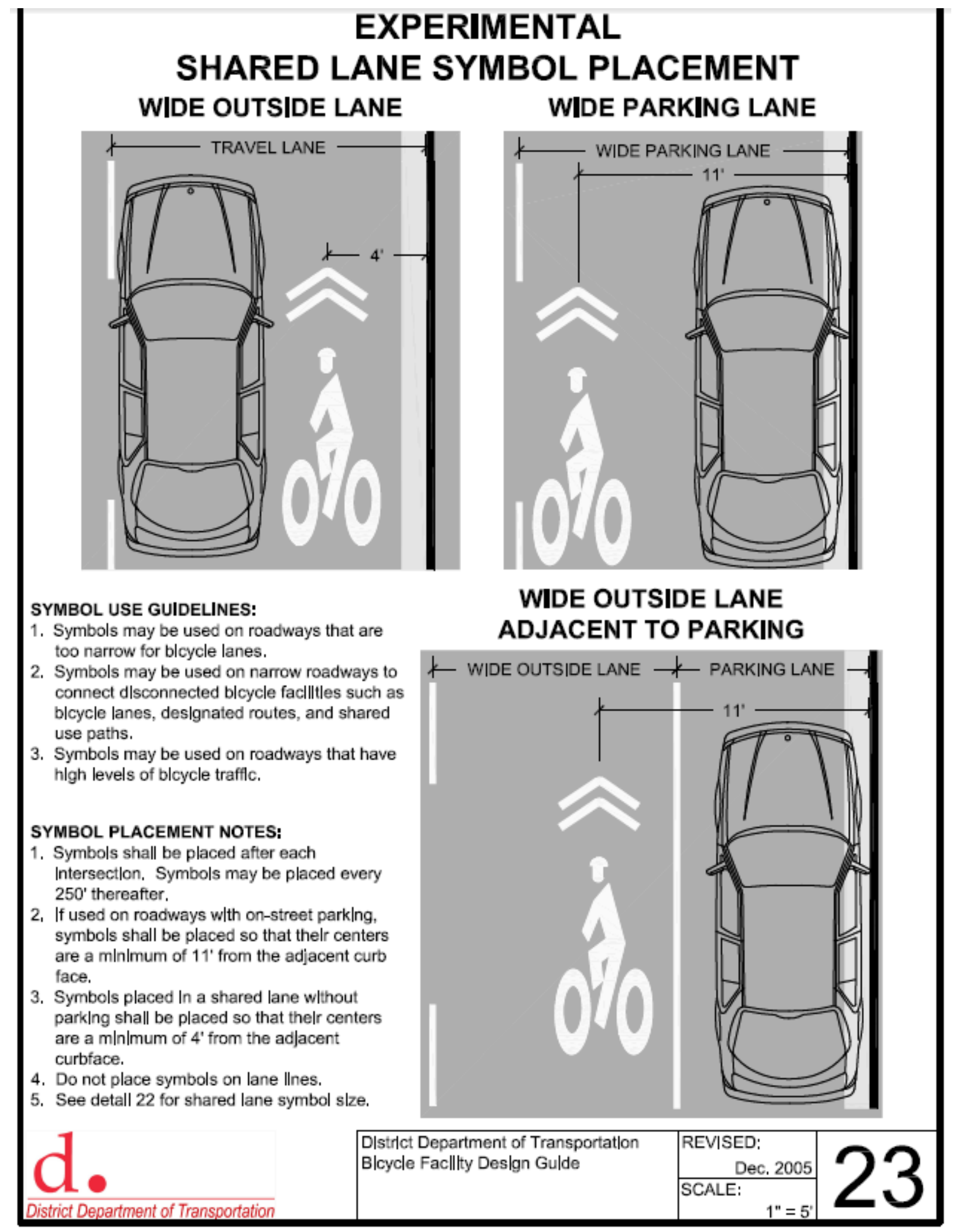

Figure 2.5 - Experimental shared lane symbol placement 


\section{Local and Regional Guidelines}

The majority of city and regional planning guides in the U.S. provide little information on how communities should plan for or design an SBBL. Cities with SBBLs were often required to design the lanes with existing constraints as the primary factor. Municipalities that describe SBBLs in their planning documents frequently provide little specific information but instead afford the possibility of using this type of facility as part of current or future planning efforts. Some cities do provide basic safety recommendations and minimum lane widths or width ranges for general guidance. Table 2.1 summarizes municipal guidance on lane widths.

Table 2.1 - Municipal Guidance on Lane Widths

\begin{tabular}{|c|c|c|c|}
\hline \multirow[b]{2}{*}{ Municipality } & \multirow[b]{2}{*}{ Reporting Agency } & \multicolumn{2}{|c|}{ Lane Widths (feet) } \\
\hline & & SBBL & $\begin{array}{l}\text { Separate but Adjacent } \\
\text { Bike and Bus Lanes }\end{array}$ \\
\hline Tucson, AZ & $\begin{array}{l}\text { Pima County DOT, } \\
\text { City of Tucson DOT }\end{array}$ & $\begin{array}{l}10 \text { minimum } \\
12 \text { standard }\end{array}$ & $\mathrm{n} / \mathrm{a}$ \\
\hline $\begin{array}{l}\text { San Francisco, } \\
\text { CA }\end{array}$ & $\begin{array}{l}\text { City of San } \\
\text { Francisco }\end{array}$ & $10-13$ & $14-17$ \\
\hline $\begin{array}{l}\text { Albuquerque, } \\
\text { NM }\end{array}$ & City of Albuquerque & $10-13$ & $14-17$ (preferred alternative) \\
\hline $\begin{array}{l}\text { Minneapolis, } \\
\text { MN }\end{array}$ & City of Minneapolis & $\begin{array}{l}12 \text { minimum } \\
15-18 \text { recommended }\end{array}$ & $\mathrm{n} / \mathrm{a}$ \\
\hline \multicolumn{4}{|c|}{$\begin{array}{l}\text { Sources: } \\
\text { Pima County DOT and City of Tucson DOT } 2008 . \\
\text { Alta Planning + Design, and Parisi Associates } 2003 . \\
\text { Alta Planning + Design, and Gannett Fleming West } 2010 . \\
\text { City of Minneapolis 2010a, } 259 .\end{array}$} \\
\hline
\end{tabular}

\section{Tucson, Arizona}

The City of Tucson has used SBBL treatments on several arterial roadways west of downtown. The City's Pavement Marking Design Manual is intended to provide guidance in the design of new reconstruction projects and resurfacing, restoration and rehabilitation projects. Detail 2 on sheet no. 6-1.1 illustrates the accepted configuration for SBBLs: minimum width of ten feet, standard width of 12 feet; use of bike symbols is optional; frequency of painted lane marking symbols is every one half mile for the City of Tucson, every one quarter mile for Pima County, and after every major signalized intersection (See Appendix D in this report). Bike lane markings should be located 65 feet from the road intersection to avoid excessive wear by turning vehicles and avoid placing markings where buses stop and dwell (Pima County DOT and City of Tucson DOT 2008).

A shared lane treatment is not described as an option in the design guidelines of the 2009 Tucson Regional Plan for Bicycling. The final chapter does provide recommendations and summarizes overall existing and planned miles of bikeway facilities including the plan to increase the use of SBBLs (lanes that accommodate buses, right-turns, and bicycles) from 7.5 to 50 miles by 2030 . It also discusses enforcement as a key goal and recommends five actions based on the documented most frequent bicyclist-motorist crashes. These are listed in Chapter 4 (Pima Association of Governments 2009). 


\section{San Francisco, California}

The City of San Francisco's Bicycle Plan Update (Alta Planning + Design and Parisi Associates 2003) describes transit stop striping for SBBLs. It explains that SBBLs should be used where width is available for a bus lane, but not a separate bus lane and bike lane, and that the SBBL attempts to reduce conflicts between bicyclists, buses, and automobiles. It provides recommended widths for both SBBLs and separate adjacent bike and bus lanes but little additional information on specific design recommendations.

The San Francisco Bicycle Plan produced by the San Francisco Municipal Transportation Agency (SFMTA) and adopted in 2009 provides an overall framework for the City's bicycle planning efforts and includes a recommended series of actions to effectively implement the adopted Plan. Chapter 1 discusses the city's bicycle route network, including a number of goals, objectives, and action items to improve the system. The chapter's Action 1.5 calls for studying the impacts of allowing bicycles in exclusive bus/taxi lanes. The document explains that state and local policy changes need to be made to permit bicycles to operate in bus lanes and that the laws governing these lanes are unclear. However, it states that the use of bus lanes by cyclists would be a tool to help complete the city's bicycle network. The document recommends that the safety of sharing bus lanes with bicycles be evaluated prior to implementing changes. The section references Action 4.8 that is a recommendation to develop a SFMTA bicycle safety workshop for transit vehicle operators and other large fleet vehicle operators to promote bicycle safety awareness and effective road sharing techniques.

\section{Albuquerque, New Mexico}

Recently updated, the Albuquerque Bikeways and Trails Master Plan Design Guidelines includes an accompanying text, "Innovative Design Treatments" (Alta Planning + Design, and Gannett Fleming West 2010). This includes best practices that are in use in other states as well as European cities to provide guidance for implementing high-quality bikeway facilities.

The document describes several innovative bike lane treatments commonly used on bicycle boulevards, including: bike boxes, SBBLs (Figure 2.6), shared bike/right turn lanes, colored bike lanes, buffered bike lanes, floating bike lanes, contraflow bike lanes and cycle tracks. Section 1.2 provides a design summary, discussion, and diagrams on SBBLs:

The lane should be used where width is available for a bus lane, but not a bus and bike lane. The dedicated lane attempts to reduce conflicts between bicyclists, buses, and automobiles. Various cities have experimented with different designs and there is currently no evidence of one design being more effective than the others. SBBLs can be appropriate in the following applications: on auto-congested streets with moderate or long bus headways, moderate bus headways during peak hour, or where there is no reasonable alternative route. (Alta Planning + Design, and Gannett Fleming West 2010 2-3) 


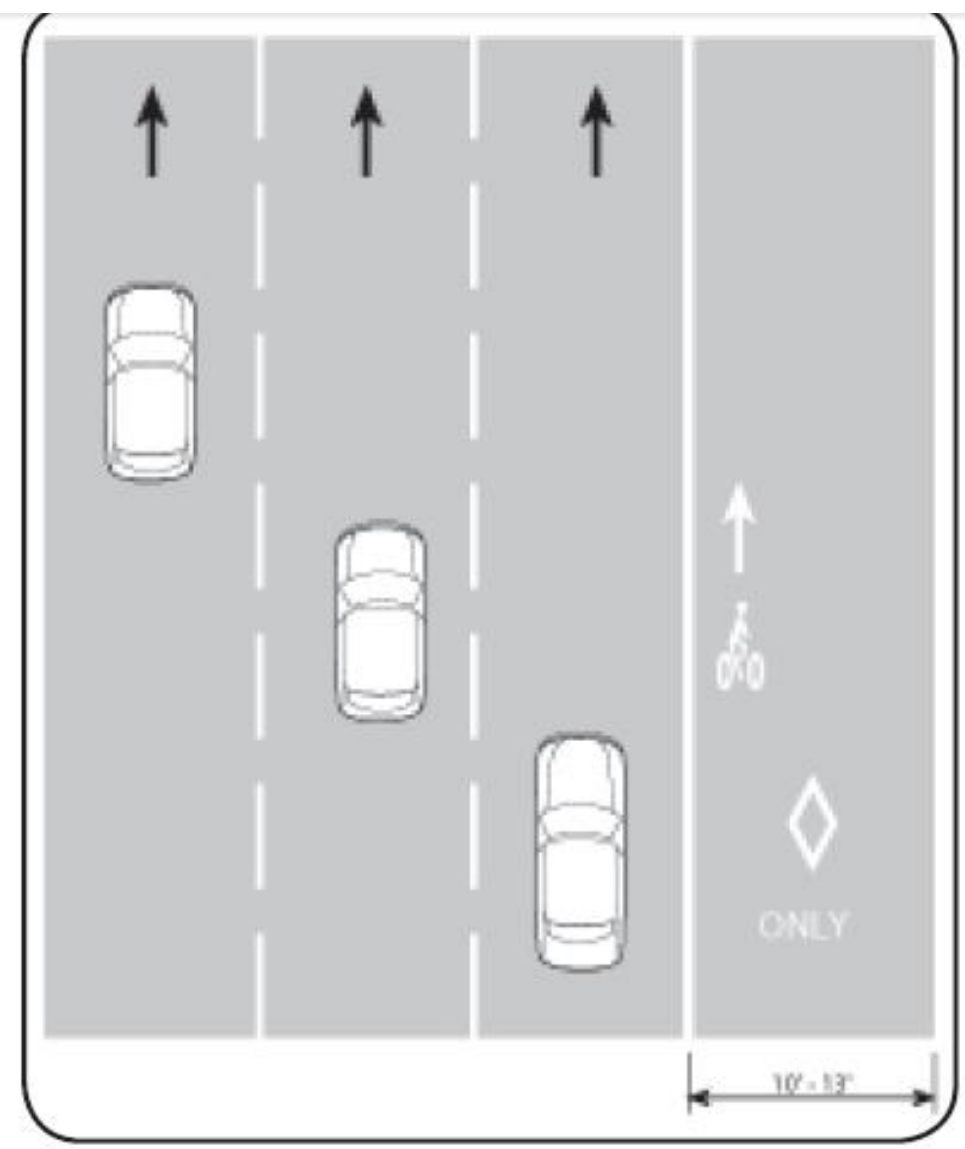

Minimum design: shared bicycle/bus lane.

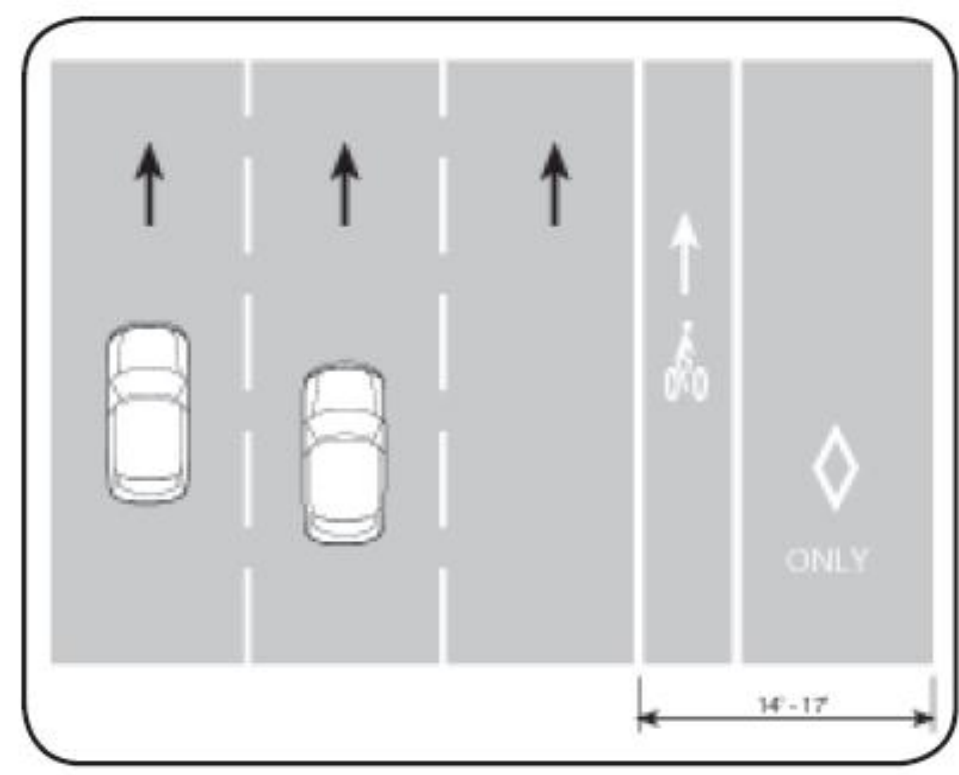

Preferred design: separated bike lane and bus lane.

Figure 2.6 - Albuquerque's minimum and preferred SBBL design

(In the original document, the two designs were not drawn to the same scale.) 


\section{Minneapolis, Minnesota}

Chapter 9 of the City of Minneapolis Bicycle Facility Design Guidelines describes innovative treatments that have been tested to solve a defined problem under an explicit set of circumstances. SBBLs along with a few variations on the lane type are described and examples are provided. The chapter describes considerations for SBBLs. Bicycle volumes, bus frequency, and available space typically dictate the need for an SBBL. Safety is a significant consideration when planning an SBBL. The placement and frequency of bus stops should be considered to minimize potential conflicts. Space to accommodate either buses or bikes passing on the left should be considered. Time restrictions may be necessary when peak hour bus volumes create too many potential conflicts. Separated bike lanes adjacent to a bus lane should be considered if there is enough roadway width (City of Minneapolis 2010a, 259-261).

\section{International Guidelines}

The use of SBBLs outside the United States is widespread and has been a common practice for some time. Notable countries include England, Ireland, France, Germany, Denmark, The Netherlands, Australia, and Canada. Dutch guidelines describe SBBLs as facilities provided only over short lengths of roadway such as over bridges (CROW 1993, 110). Some European cities such as London and Paris have extensive networks of SBBLs but are predominately found in the dense city core and were implemented as a result of the need for increased cycling and transit infrastructure where little space is available. These lanes are generally found on slow moving congested roadways with heavy bus traffic. They are often installed in conjunction with other bicycling and pedestrian infrastructure such as queue jumping, barrier separated lanes, heavy use of signage and special lane markings as well as colored pavement.

The United Kingdom has extensive experience with bus priority lanes in urban areas. During the 1990s, there was an increase in bus priority measures, such as the London Bus Priority Network. During this time, bus lanes were endorsed in the National Cycling Strategy as advantageous to bicyclists. Allowed users of bus lanes are established in a Traffic Regulation Order by the particular highway authority with jurisdiction. Users may include some combination of buses, bicyclists, taxis, high occupancy vehicles, and delivery vehicles. Use of bus lanes is considered the safer alternative for bicyclists than riding between a bus lane and a general traffic lane (Reid and Guthrie 2004, 3). In general, with the exception of a few guided bus ways, bicyclists are allowed to use bus lanes in the U.K. unless otherwise signed.

SBBLs are the default situation on streets in the U.K. due to lack of land in urban areas and are considered a compromise. There is much pressure for segregated bicycle facilities, but car traffic still gets priority in the design process. There are few areas in London where there is more than one lane of car traffic in each direction. The minimum width of a bus lane is $3.0 \mathrm{~m}$ (9.84 feet). In residential areas, the default speed limit is $30 \mathrm{mph}$, but with growing interest in creating $20 \mathrm{mph}$ zones. In central London, average speed is much lower than $30 \mathrm{mph}$. Bus drivers in London undergo extensive training. Bus services in London are regulated and procured by Transport for London (TfL). In London, "black cabs" are permitted in bus lanes but not private hire cars. Vehicles are permitted in the bus lane a short distance from an intersection to make a turn, as signified by dotted white lanes, painted arrows and signage. Crashes at intersections are a major concern, particularly where large delivery vehicles are turning and the bicyclist is in their blind spot. ${ }^{4}$

\footnotetext{
${ }^{4}$ lain Macbeth, Transport for London. Email communication, November 22, 2011.
} 
Municipalities outside the U.S. provide more specific guidance on how to plan for and design SBBLs. Generally they look at a wider variety of factors that impact design including roadway design speeds, traffic volumes, bus frequency, bus stop design, and bike/bus interaction. Table 2.2 provides examples of recommended lane widths provided in government guidance documents outside the U.S.

Table 2.2 - Survey of Lane Width Recommendations from Other Governments

\begin{tabular}{|c|c|c|c|c|}
\hline \multirow[b]{2}{*}{$\begin{array}{c}\text { International } \\
\text { District/Region }\end{array}$} & \multirow[b]{2}{*}{ Reporting Agency } & \multicolumn{2}{|c|}{ Lane Widths } & \multirow[b]{2}{*}{$\begin{array}{l}\text { Standard width } \\
\text { of Transit Bus } \\
\text { (feet) }\end{array}$} \\
\hline & & SBBLa & $\begin{array}{l}\text { Separate but } \\
\text { Adjacent Bike and } \\
\text { Bus Lanes }^{a}\end{array}$ & \\
\hline $\begin{array}{l}\text { City of Ottawa, } \\
\text { Canada }\end{array}$ & $\begin{array}{l}\text { A report commissioned by } \\
\text { the City of Ottawa, } \\
\text { "Design Treatments for } \\
\text { Bicycles and Buses on } \\
\text { Arterials and Collector } \\
\text { Roads" }\end{array}$ & $\begin{array}{l}\text { (Report } \\
\text { recommendation) } \\
13.1-14.8\end{array}$ & $\begin{array}{c}\text { (Report } \\
\text { recommendations) } \\
16.4 \text { minimum } \\
(4.9 \text { bike }+11.5 \text { bus } \\
\text { lane }) \\
18 \text { maximum ( } 5.9 \\
\text { bike }+12.1 \text { bus } \\
\text { lane) }\end{array}$ & $\begin{array}{l}8.5 \text { excluding } \\
\text { mirrors }\end{array}$ \\
\hline $\begin{array}{l}\text { City of Dublin, } \\
\text { Ireland }\end{array}$ & $\begin{array}{l}\text { Dublin Transportation } \\
\text { Office. Cycle Track Design } \\
\text { Guidelines Manual }\end{array}$ & $\begin{array}{l}11.5 \text { minimum } \\
13.1 \\
\text { recommended }\end{array}$ & $\mathrm{n} / \mathrm{a}$ & $\begin{array}{l}8.37 \text { excluding } \\
\text { mirrors }\end{array}$ \\
\hline $\begin{array}{l}\text { Republic of } \\
\text { Ireland }\end{array}$ & $\begin{array}{l}\text { National Transport } \\
\text { Authority } \\
\text { National Cycle Manual } \\
\text { 4.3.3 Cycling and Bus } \\
\text { Lanes }\end{array}$ & $\begin{array}{c}9.8 \text { (at } \max 50 \\
\mathrm{~km} / \mathrm{h}, 31.0 \mathrm{mph})\end{array}$ & $\begin{array}{c}14.8 \text { minimum } \\
16.4 \text { recommended } \\
(6.6 \text { bike }+9.8 \text { bus } \\
\text { lane })\end{array}$ & $\mathrm{n} / \mathrm{a}$ \\
\hline $\begin{array}{l}\text { Victoria, } \\
\text { Australia }\end{array}$ & $\begin{array}{l}\text { Victoria Department of } \\
\text { Transport. } \\
\text { Vic Roads Cycle Notes No. } \\
19\end{array}$ & $\begin{array}{c}12.1(\text { at } 60 \mathrm{~km} / \mathrm{h}, \\
37.2 \mathrm{mph}) \\
14.1(80 \mathrm{~km} / \mathrm{h} \\
50 \mathrm{mph})\end{array}$ & $\begin{array}{c}13.8(\text { at } 60 \mathrm{~km} / \mathrm{h}, \\
37.2 \mathrm{mph}) \\
16.7(\text { at } 80 \mathrm{~km} / \mathrm{h}, \\
50 \mathrm{mph})\end{array}$ & $\begin{array}{l}8.67 \text { excluding } \\
\text { mirrors, } 10.17 \\
\text { including } \\
\text { mirrors }\end{array}$ \\
\hline $\begin{array}{l}\text { British } \\
\text { Columbia }\end{array}$ & $\begin{array}{l}\text { Capital Regional District } \\
\text { District Pedestrian and } \\
\text { Cycling Master Plan } \\
\text { Design Guidelines }\end{array}$ & $14.8-16.4$ & $\begin{array}{l}16.0-17.7 \\
\text { (preferred } \\
\text { alternative) }\end{array}$ & $\begin{array}{l}8.5 \text { excluding } \\
\text { mirrors }\end{array}$ \\
\hline $\begin{array}{l}\text { England, } \\
\text { Wales and } \\
\text { Scotland }\end{array}$ & $\begin{array}{l}\text { Department for Transport, } \\
\text { Cycle Infrastructure } \\
\text { Design }\end{array}$ & $\begin{array}{l}13.1 \text { minimum } \\
13.9 \\
\text { recommended }\end{array}$ & $\mathrm{n} / \mathrm{a}$ & $\begin{array}{l}8.37 \text { excluding } \\
\text { mirrors }\end{array}$ \\
\hline $\begin{array}{l}\text { County of } \\
\text { Cardiff, Wales }\end{array}$ & $\begin{array}{l}\text { Cardiff Council, Cardiff } \\
\text { Cycle Design Guide }\end{array}$ & $\begin{array}{l}13.1 \text { minimum } \\
13.9 \\
\text { recommended }\end{array}$ & $\begin{array}{l}13.8 \text { minimum ( } 4.9 \\
\text { bike }+8.9 \text { bus lane) }\end{array}$ & $\begin{array}{l}8.37 \text { excluding } \\
\text { mirrors }\end{array}$ \\
\hline
\end{tabular}

\section{City of Ottawa, Canada}

A report was commissioned by the City of Ottawa (Dillon Consulting 2009) for the purpose of establishing policy and guidelines for design treatments for bicycles and buses on arterial and collector roads. The report provided recommendations for lane widths for SBBLs and for separate bike lanes and bus lanes. The guidelines were discussed in the review of previous research in Chapter 1. 


\section{City of Dublin, Ireland}

The City of Dublin has a manual that guides planning and designing cycling facilities in urban areas. The manual establishes that where public transport and cycling facilities meet, an integrated design must ensure that neither mode inconveniences the other. The requirements of an integrated design for both modes are safety, comfort, and directness. Neither user type should be unnecessarily delayed. The document provides design guidelines for four different facilities ranging from physically segregated to bike and bus only roads. Criteria are proposed for assessing the type of integration best suited for bikes and buses, including route function, bike and bus volumes, driving speed, car parking, space required by each mode and cost (Dublin Transportation Office 1997, 131-158).

\section{Republic of Ireland}

As part of the Irish Government's Smarter Travel Policy, alternative travel modes are supported:

We will implement more radical bus priority and traffic management measures....This may involve making some urban streets car-free, creating tram-like priorities in others and making greater use of roads/hard shoulders by buses....the design philosophy will be based on the "hierarchy of measures"...with the focus being on the reduction of vehicular speeds...We will ensure that designs are created with the principal aim of preserving cyclist momentum. We will also ensure that designs will provide for a safe passing distance of 1.5 metres ( $4.9 \mathrm{ft}$ ) between motorized vehicles and bicycles. To give practical effect to the above approach in urban areas a combination of measures need to be taken, not just new approaches in relation to design. One such measure is a reduction in general speed limits to $30 \mathrm{~km} / \mathrm{h}$ (18.6 mph). (National Transport Authority 2010, 2.2.8)

The National Cycle Manual provides lane widths for SBBLs and for separate but adjacent bicycle lanes and bus lanes (National Transport Authority 2010, 4.3.3).

\section{Victoria, Australia}

In Australia, bicyclists are generally permitted to use bus lanes. Vic Roads, the transportation authority in Victoria, summarizes issues in its "Cycle Notes No. 19", and provides design guidelines for three types of bicycle and bus facilities (Vic Roads 2007). These include designs that:

- allow cyclists to mix with buses in a minimum-normal width bus lane,

- provide a wide curb lane for cyclists and buses to share the bus lane, and

- $\quad$ provide a separate on-road bicycle lane to separate cyclists from buses.

A number of thresholds and recommendations are presented. Four main characteristics were highlighted with respect to shared and separated bicycle and bus facilities: bus headways, bicycle volumes, speed differential between both modes, and lane width. Thresholds are listed for determining appropriate treatments using cyclist volumes and bus headways criteria. In minimum width lanes, buses and cyclists may "mix" when there are fewer than 50 cyclists per hour and bus headways are greater than 30 minutes. In wide curb lanes, buses and cyclists may share the lane when there are 50-100 cyclists per hour and bus headways range from 15-30 minutes. Separated facilities are required when there are more than 100 cyclists per hour and bus headways are less than 15 minutes. The recommended lane widths listed in Table 2.2 are also provided in the Austroads 2010 Guide to Road Design (Table 4.22) and in the 2011 Cycling Aspects of Austroads 
Guides ( $p$ 29). Austroads is an association of eleven transportation authorities in Australia and New Zealand. Signage and road layouts are provided in diagrams and references Victorian road safety regulations. The Cycling Aspects of Austroads Guides explains that excluding cyclists from bus lanes may force them to travel in mixed traffic lanes. This could act as a deterrent to employing cycling as a mode of transportation and therefore should be avoided from a safety and mobility standpoint.

\section{Capital Regional District, British Columbia}

The District Pedestrian and Cycling Master Plan Design Guidelines for the Capital Regional District provide a brief summary of SBBLs. A portion of the section is written nearly identically to the Albuquerque, New Mexico guidelines. However, it does add design criteria with regard to striping, pavement markings, and conflict zones. The Transportation Association of Canada provides standards for breaking the inner line of the bicycle lane at bus stops where a bus crosses the bicycle line (Figure 2.7). This treatment is beneficial to indicate to bus drivers and cyclists that the area is a conflict zone. However, the treatment also assumes a continuous bicycle lane. Where bicycle and buses share the lane, shared lane markings are recommended over other treatments (such as a dotted bicycle lane line or colored pavement markings) because the shared markings provide sufficient information, and there is an expense of maintaining paint where buses cross over (Capital Regional District 2011, 36).

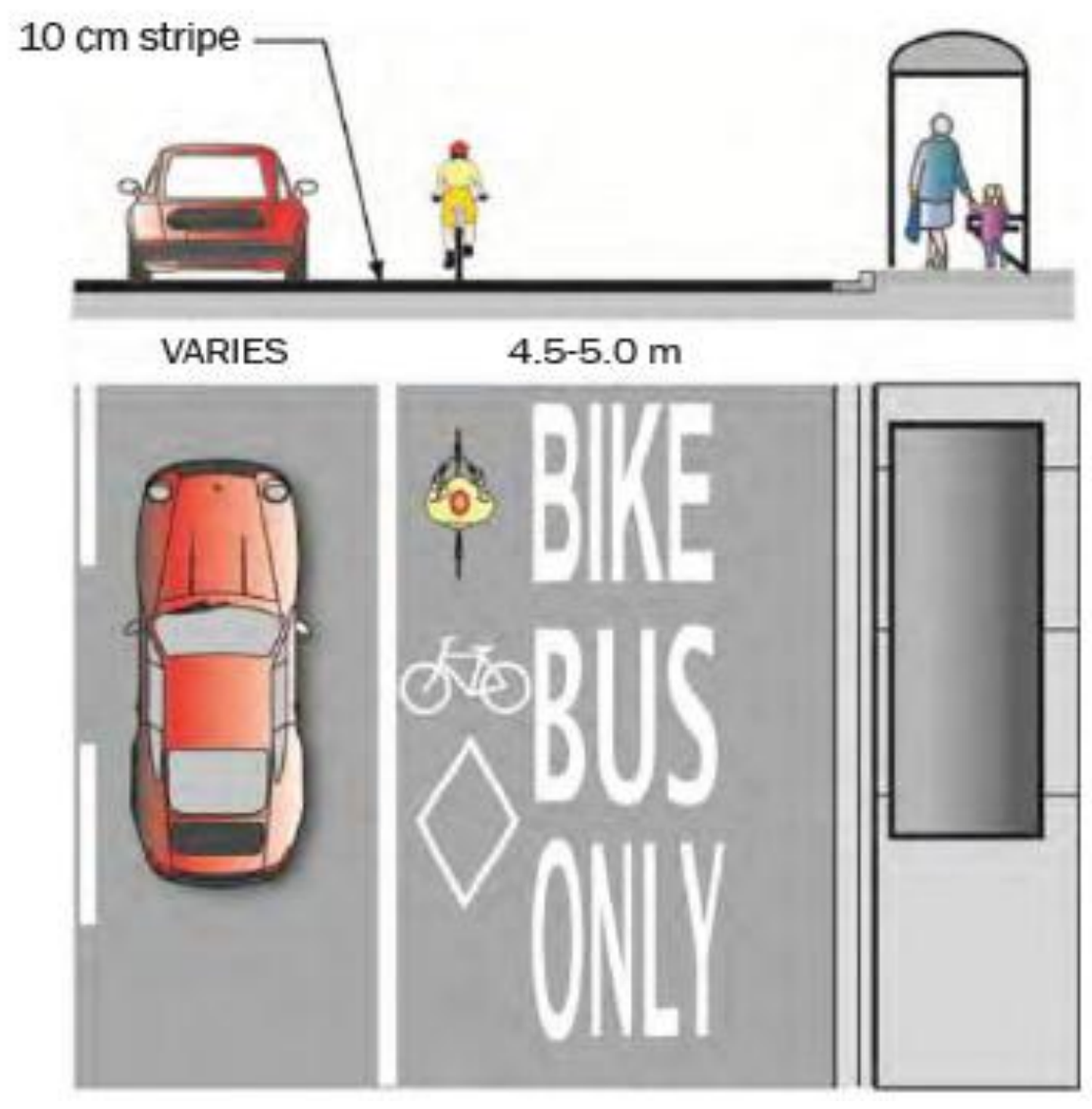

Figure 2.7 - Shared lane pavement markings (British Columbia)

Source: Capital Regional District.

District Pedestrian and Cycling Master Plan Design Guidelines. 2011. p. 36. 


\section{England, Wales, and Scotland}

The Department for Transport in the U.K. issued official guidance, Cycle Infrastructure Design, in October 2008. The design guide establishes that bicyclists are generally permitted in bus lanes. If a local authority prohibits bicyclist use of bus lanes, it must be signed as such. The ease with which a bus can pass a bicyclist depends on speed, volume of traffic, the width of the bus lane and the width of the adjacent lane for general traffic. The design guide recommends a bus lane width of $4.5 \mathrm{~m}$ (14.8 ft). Cycle lanes cannot be taken through a marked bus stop. The cycle lane is discontinued prior to the marked bus stop then continued after the bus stop. For narrow bus lanes, the design guide mentions the option of localized widening of the bus lane at the bus stop where there is room to do so. Where traffic speeds are high and/or there is heavy bus volume, another option illustrated in the design guide is to create a boarding island for bus passengers and route the bike lane behind the island. This prevents the bicyclist from having to move to the opposite side of the bus lane to pass the buses. The disadvantage is that it may create conflicts between pedestrians and bicyclists (Ove Arup \& Partners 2008, 32-34).

\section{County of Cardiff, Wales}

In the County of Cardiff, Wales, U.K., the Hierarchy of Provision (Cardiff Cycle Network 2011, 2 and 44) is applied when considering multiple options for on-road provision of bicycle facilities. A key point in the Cardiff Cycle Design Guide is that:

Consideration should always be given first to measures to reduce the speed and volume of traffic in preference to providing segregated facilities. Use the Hierarchy of Provision when considering multiple options for on-road provision:

- Reduce traffic speeds and/or volumes.

- Provide mandatory cycle lanes.

- Provide advisory cycle lanes.

- Provide parallel off road route.

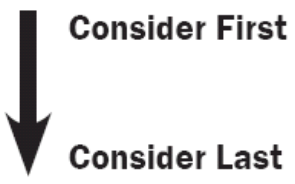

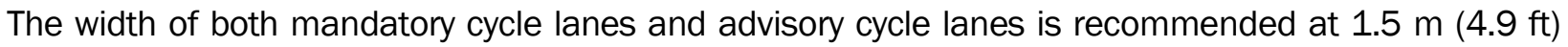
minimum and $1.8 \mathrm{~m}(5.9 \mathrm{ft})$ maximum. Mandatory cycle lanes are recommended for traffic speeds greater than $35 \mathrm{mph}$ (Cardiff Cycle Network 2011, 48). The minimum $1.5 \mathrm{~m}$ (4.9 ft) cycle lane width is considered sufficient for a car to safely pass at $30 \mathrm{mph}$ and a bus to safely pass at $20 \mathrm{mph}$. The typical width of a bicycle with a rider is $800 \mathrm{~mm}$ (2.6 ft) (Ove Arup \& Partners 2008, 32-34). The Design Guide also explains why bicyclists require more width than that defined by the width of their bicycles:

When moving, cyclists require additional space to cater for deviations in their path. At speeds in excess of $7 \mathrm{mph}$, cyclists can typically ride in a reasonably straight line, with a deviation of $200 \mathrm{~mm}(0.7 \mathrm{ft})$ being typical. Below this speed, deviation increases-at $3 \mathrm{mph}$ a deviation of $800 \mathrm{~mm}$ (2.6 ft) can be expected. This should be borne in mind when designing infrastructure at locations where lower cycling speeds are expected (e.g., islands for two-stage crossings, or feeder lanes for advance stop lines), as greater widths may be required to accommodate cyclists in these instances...For simplicity, the width required by a moving cyclist (the dynamic envelope) can be taken to

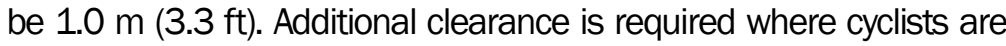


passing adjacent to vertical features. (Cardiff Cycle Network 2011, 16)

Table 2.3 - Clearance Recommendations between Bicyclists and Barriers/Obstacles (Cardiff)

\begin{tabular}{|l|c|c|}
\hline Object & $\begin{array}{c}\text { Clearance required from wheel } \\
\text { of bicycle (feet) }{ }^{a}\end{array}$ & $\begin{array}{c}\text { Clearance required from dynamic } \\
\text { envelope (feet) }{ }^{a}\end{array}$ \\
\hline Curb (<0.2 ft upstand) & 0.8 & 0.8 \\
\hline Curb (>0.2 ft upstand) & 1.6 & 1.6 \\
\hline Sign posts, lighting columns, etc & & 3.3 \\
\hline Walls, railings, parapets, etc. & & \\
\hline $\begin{array}{l}\text { Parked cars in short term parking } \\
\text { area with high turnover }\end{array}$ & & \\
\hline $\begin{array}{l}\text { Cardiff Cycle Network 2011. 16-17. } \\
\text { a All values converted from millimeters to feet }\end{array}$ & \\
\hline
\end{tabular}

\section{The Netherlands}

Dutch planning and design of bicycle infrastructure places greater emphasis on physically separating the bicyclist from faster-moving motor vehicle traffic. For example, it is general policy that bicycle lanes that are part of the street are used only where motor vehicles operate at $31 \mathrm{mph}$ or less. Above this speed, parallel but physically separate facilities, known as cycle tracks, are provided. Bicyclists may use bus lanes but only where buses travel no more than $18.6 \mathrm{mph}$ (CROW 2007).

\section{European Cyclists' Federation}

In France, a survey performed by GART (Groupement des Autorités Responsables de Transport) showed that 95 percent of towns that have implemented SBBLs favor this sharing system. The report explains that shared use of roadway facilities by buses and cyclists has advantages for the community:

- Good objective and subjective safety

- Consumption of a minimum area for the two categories of users

- Reduced cost for the community

Multiple towns/countries are referenced as having SBBLs, including Paris, France; Tilburg and Breda, the Netherlands; Bern, Switzerland; Berlin and Munster, Germany; Brussels, Belgium; and Odense, Denmark. A detailed discussion is included about the variations in lane width depending on European country and briefly how those decisions are made. The lane widths below are recommended by GRACQ $(2002,26)$

- France - Design Lane Widths

- $\quad$ SBBL: From $3.5 \mathrm{~m}(11.5 \mathrm{ft})$ to $4.5 \mathrm{~m}(14.8 \mathrm{ft})$. At $3.5 \mathrm{~m}(11.5 \mathrm{ft})$, the bus or the cyclist must change lanes to pass each other.

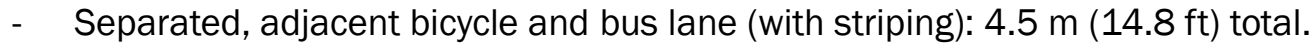

- Germany - Design Lane Widths

- $\quad$ SBBL: $4.0 \mathrm{~m}$ (13.1 ft) minimum for bus speeds $40 \mathrm{~km} / \mathrm{h}(25 \mathrm{mph})$ or less

- $\quad$ SBBL: $4.25 \mathrm{~m}$ (13.9 ft) for bus speeds up to $50 \mathrm{~km} / \mathrm{h}$ (31 mph). 


\section{Conclusions}

A review of standard references in the U.S. indicates that lanes for shared use are receiving more consideration, but very few states have incorporated SBBLs into guidance documents. More municipalities have begun to address the need for guidance regarding the design of SBBLs. More experience with SBBLs has come from locations like Australia, Wales, and Ireland where bus lanes are more common, constrained right-of-way is the rule, and bicyclists are generally allowed to ride in bus lanes, unless there is signage prohibiting it. This greater experience with SBBLs has provided other countries a background upon which to develop their design guidelines. 


\section{Chapter 3: Case Studies}

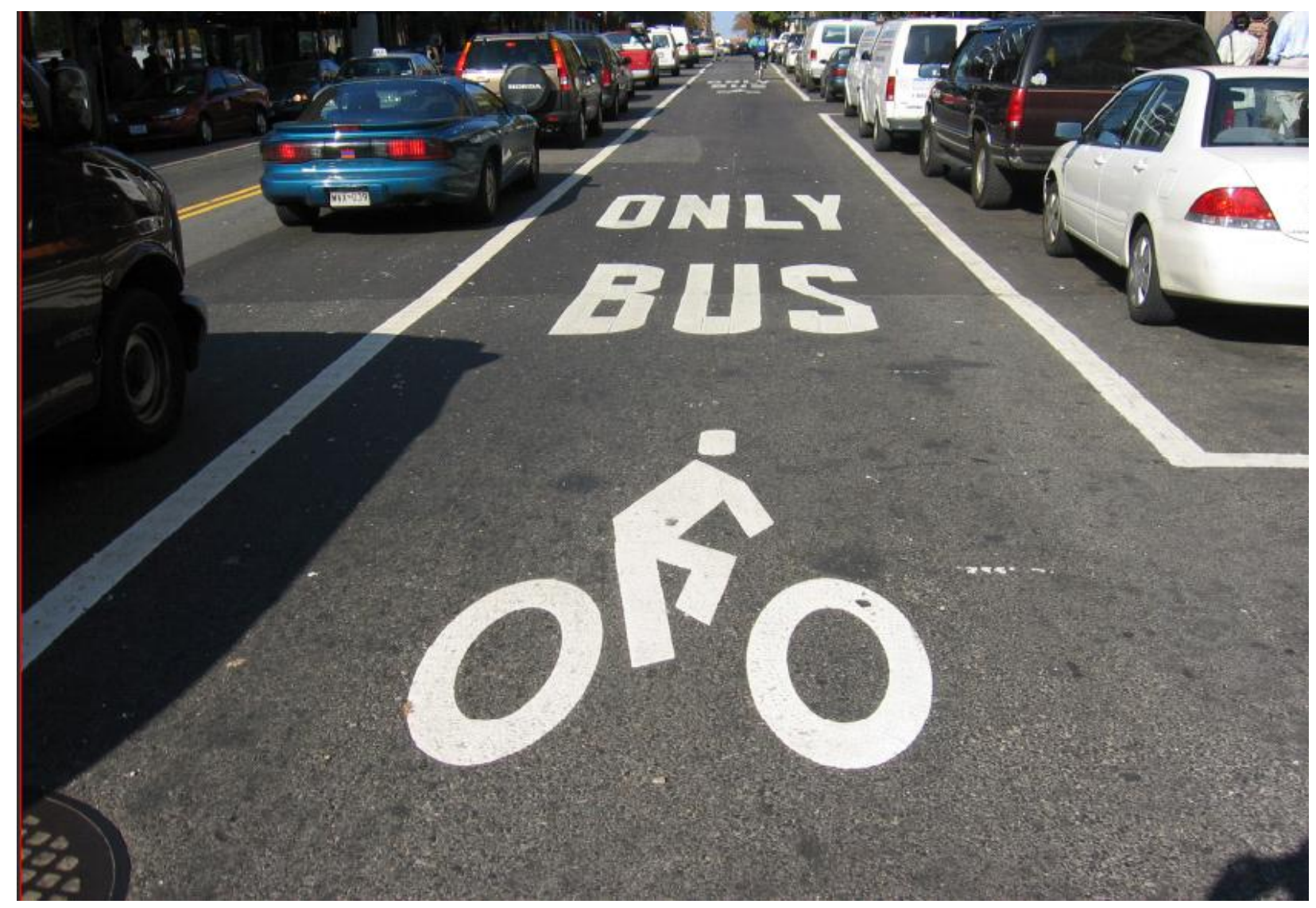

Figure 3.1 - SBBL on 9th Street NW, Washington, D.C.

Credit: JoAnne Fiebe

\section{How Case Studies Were Selected}

As described in the Introduction, a search for SBBLs in the United States identified 27 examples, which are listed in Appendix A, and which also include examples of variations of shared lane treatments. These represent examples of SBBLs in the states of Arizona, Colorado, Delaware, Washington, D.C., Florida (planned), Illinois, Massachusetts, Maryland, Minnesota, Oregon, Pennsylvania, Texas, and Washington State. Most examples of SBBLs did not have sufficient information for a comprehensive case study but several examples had informative aspects that are included in this report, for example, pavement treatments in Portland, OR, signage in Denver, CO, bus operator training in 
Chicago, IL, and the lane restriping experience in Ft. Worth, TX. Other SBBLs are in the planning stage, such as Front Beach Road in Panama City Beach, discussed earlier. Panama City Beach does not yet have results to evaluate but is nonetheless informative regarding reasons for pursuing SBBL and how the city is studying feasibility.

The case studies selected represent a variety of facility types, contexts, and operating conditions that will best inform the consideration of establishing SBBLs in Florida. These are Hennepin Avenue, Minneapolis, Chestnut Street, Philadelphia, 7th Street NW and 9th Street NW in Washington, D.C., and MD 528 (Coastal Highway) in Ocean City, MD. Both the Hennepin Avenue and Chestnut Street case studies were enriched by associated evaluative studies that had been conducted recently. The Chestnut Street case study is near a university. Hennepin Avenue, Chestnut Street, and 7th Street NW in Washington, D.C. are urban SBBLs in downtowns with peak hour buses running every 2 minutes, while the 9th Street NW Washington D.C. example functions as a short connector segment. The Ocean City, MD, example is a suburban SBBL in which many of the bicyclists are tourists. All the SBBL case studies are examples of constrained right-of-way with right-turning vehicles allowed to use the SBBL. The Chestnut Street, Philadelphia SBBL operates at $25 \mathrm{mph}$, both the Washington, D.C. and Hennepin Avenue SBBLs operate at $30 \mathrm{mph}$ and the Ocean City, MD SBBL operates at 35-40 mph.

\section{Ocean City, Maryland}

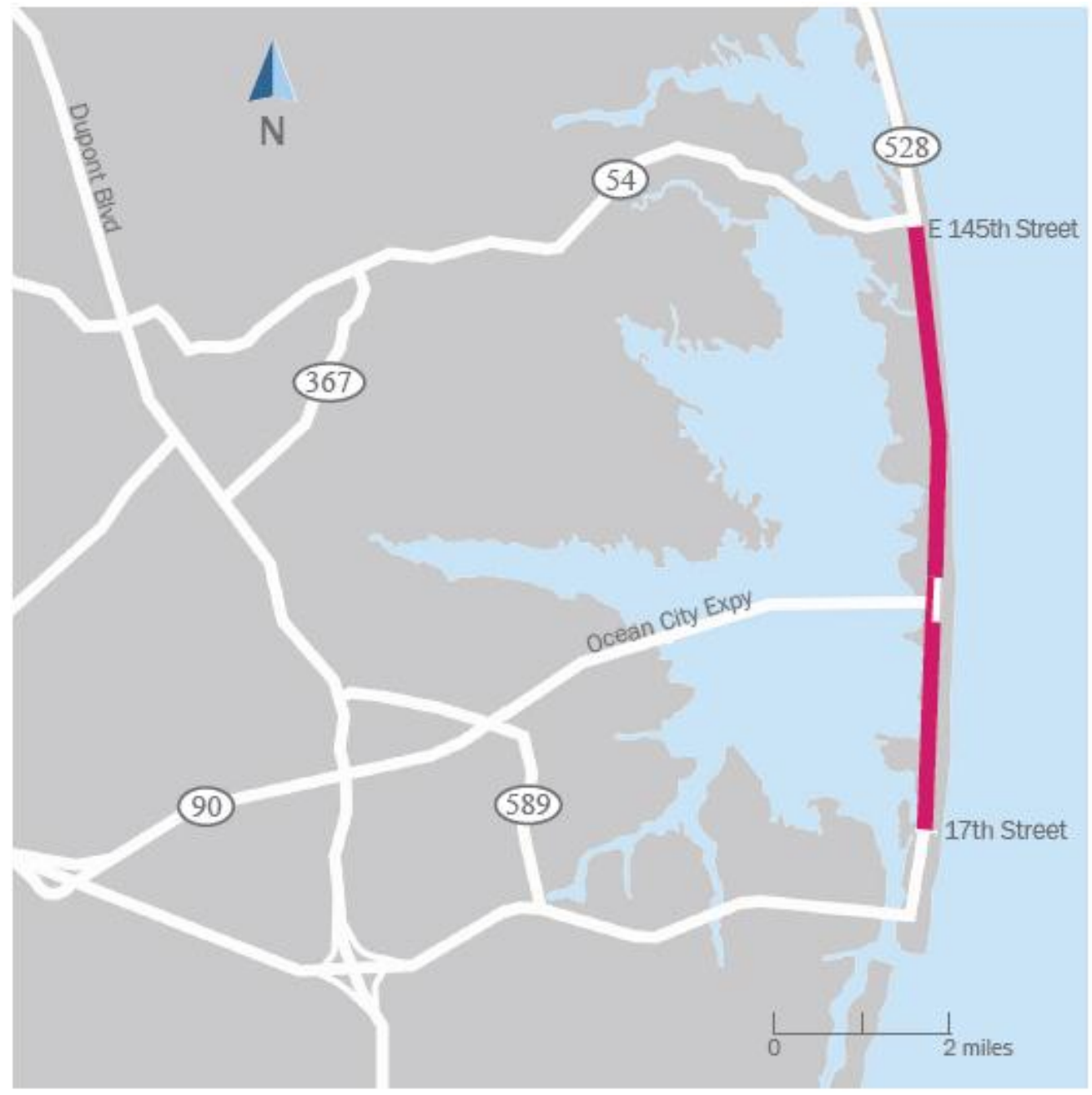

Figure 3.2 - Location of Ocean City SBBL 


\section{History}

Ocean City is a small town located on Maryland's coastal islands with year-round population of 7,100 and whose population swells during the summer tourist season to crowds that exceed 300,000. Located on a stretch of MD 528, also known as Coastal Highway, SBBLs have been in operation in Ocean City since the late 1980s (Figure 3.2). Table 3.1 provides information on the highway and how it functions. As shown in Figure 3.3, Coastal Highway is an eight-lane divided road with multiple access points between each block. Four- to six-feet-wide sidewalks are located immediately adjacent to the SBBLs. Transit buses operate year round, 24 hours a day, running both north and south along the city's main roadway (See Table 3.2 for bus schedule and frequency). Vehicle and bicycle traffic fluctuate depending on the season, with tourists making up the largest percentage of riders. Generally, Ocean City's commercial uses are located to the south, near the famous boardwalk, and its residential and hotel areas are to the north. During the summer busy season, tourists travel south to beach and commercial areas in the morning, and by late afternoon there is a rush of visitors returning northward.

Table 3.1 - Ocean City SBBL Features

\begin{tabular}{|c|c|}
\hline \multicolumn{2}{|r|}{ MD528 (Coastal Highway) } \\
\hline Location & $\begin{array}{l}\text { Ocean City, Maryland's SBBL is located on a } 7.4 \text { mile stretch of MD } 528 \\
\text { also known as Coastal Highway. The lanes extend from } 17 \text { th Street to E. } \\
\text { 145th Street. }\end{array}$ \\
\hline Date Opened & Operated as bus lanes prior to late $1980 \mathrm{~s}, \mathrm{SBBL}$ since \\
\hline Roadway Configuration & $\begin{array}{l}\text { Three general purpose travel lanes in each direction with an SBBL/right } \\
\text { turn lane adjacent to the curb. Four- to six-foot sidewalk adjacent to } \\
\text { road. }\end{array}$ \\
\hline Facility Type & $\begin{array}{l}\text { SBBL, northbound and southbound. Northbound SBBL is interrupted } \\
\text { for } 5 \text { blocks between 59th Street and 64th Street. }\end{array}$ \\
\hline Other Permitted Vehicles & $\begin{array}{l}\text { Right-turning vehicles, scooters, and ScootCoupes }{ }^{\mathrm{TM}} \text { (engine size under } \\
49 \mathrm{cc} \text { ) }\end{array}$ \\
\hline SBBL Width & $11-12.5^{\prime}$ \\
\hline Block Length & $300^{\prime}$ (varies) \\
\hline Bus Stop Frequency & Every other block (varies) \\
\hline Speed Limit & 35 - $40 \mathrm{mph} ; 30 \mathrm{mph}$ for scooters (Maryland state law) \\
\hline Colored Lane & no \\
\hline Curb and Gutter & yes \\
\hline $\begin{array}{l}\text { Barrier Separated from } \\
\text { Traffic }\end{array}$ & no \\
\hline Traffic Lights & The median spacing between traffic lights is $1000^{\prime}$ \\
\hline
\end{tabular}

Until the late 1980s, Coastal Highway's dedicated lanes legally operated as bus lanes. Because of a lack of available bicycle facilities, cyclists began using the lanes and the Maryland State Highway Administration (MSHA) added signage to permit legal bicycles to use the lanes. Recently, the city added bike route signs to the lanes to indicate that the lanes are part of a specific bicycling network. 


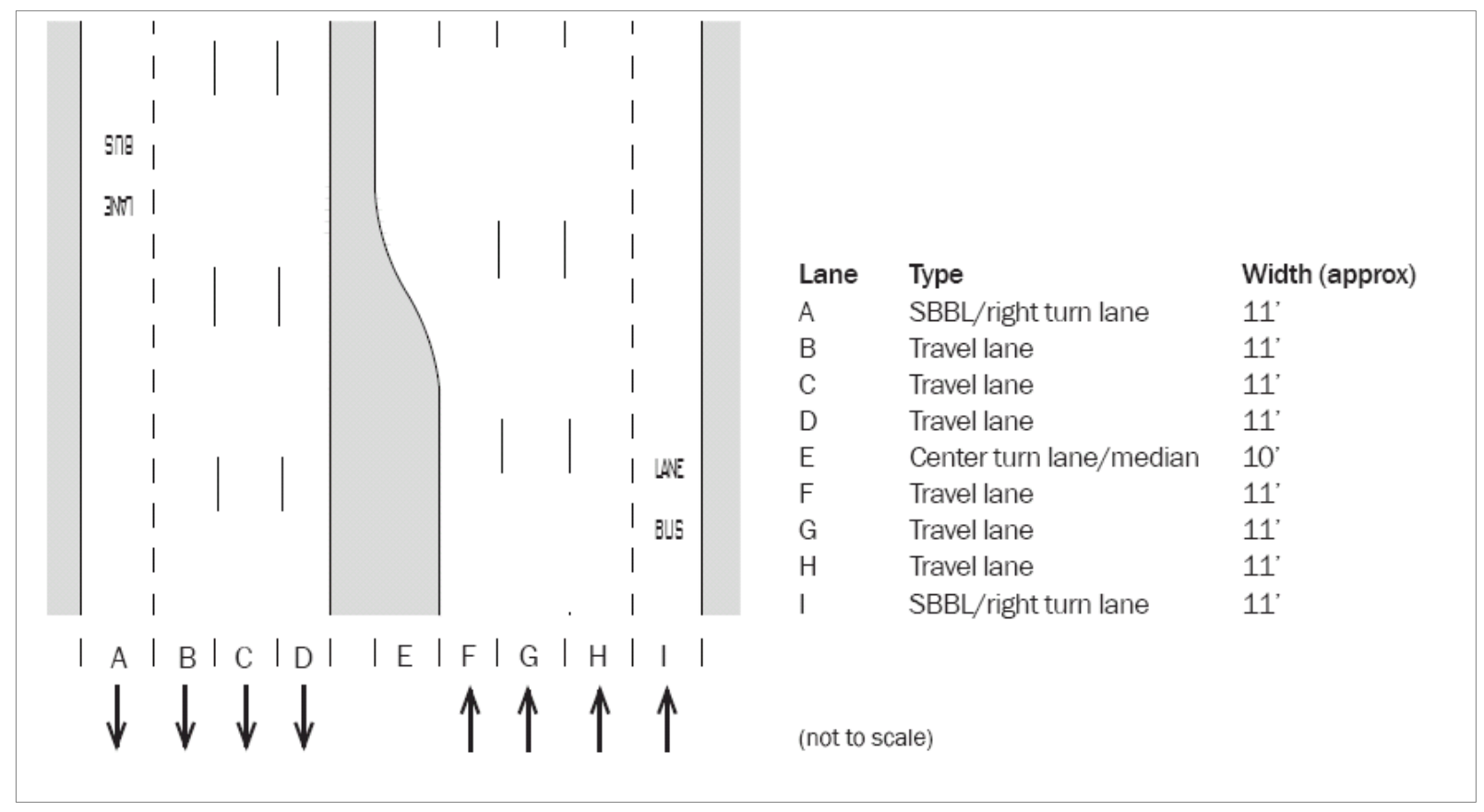

Figure 3.3 - SBBL on MD 528, Ocean City, MD

\section{Design Considerations}

SBBLs begin at the intersection of 17th Street and continue for 7.4 miles to E. 145th Street. The northbound lanes are interrupted for a five block section because of lack of adequate right-of-way at a major intersection with the Ocean City Expressway Bridge. Figure 3.4 is a photograph of the overhead signage which provides warning to buses, vehicles, and cyclists on the lane interruption. The lanes handle other users beyond bicyclists and transit buses including both legal and illegal uses. Rightturning vehicles are permitted in the lanes. Vehicles of engine size under $49 \mathrm{cc}$ such as some scooters and ScootCoupes ${ }^{\mathrm{TM}}$ (3-wheeled scooters) are also permitted to use the lanes and are required by state law to travel at speeds under $30 \mathrm{mph}$. Roller bladers and joggers use the lanes illegally and according to Ocean City Public Works have a negative effect on transit level of service. Figure 3.5 shows bicyclists and a vehicle operating together in the curb lane on the Coastal Highway.

Table 3.2 - Ocean City Bus Schedule and Frequency (2011)

\begin{tabular}{|l|l|}
\hline \multicolumn{2}{|c|}{ Ocean City Bus Schedule and Frequency (2011) } \\
\hline Winter Schedule (Nov-Mar): & headways every 40 minutes \\
\hline Spring and Fall Schedule: & $\begin{array}{l}\text { 6am-10pm, bus headways every } 15 \text { minutes } \\
10 p m-6 a m, \text { bus headways every } 30 \text { minutes }\end{array}$ \\
\hline Summer Schedule (Busy): & $\begin{array}{l}\text { 6am-3am, bus headways every } 10 \text { minutes } \\
\text { 3am-6am, bus headways every } 20 \text { minutes }\end{array}$ \\
\hline
\end{tabular}

Special events are another primary issue. As a result of Ocean City's cyclical population swings, special events factor into the performance of the lanes. Between May and September, major holidays create large amounts of traffic to Ocean City's boardwalk at the southern part of the city. Major holidays include Spring Fest, Memorial Day, Fourth of July, Summer Fest, and Labor Day. After events, heavy traffic on all eight lanes of Coastal Highway illegally crowds the SBBLs. 


\section{Safety Considerations}

Several years ago a number of complaints from transit operators prompted a review of the lanes and consideration to remove them altogether. There were several chief complaints. First, that the leapfrog effect, where bicyclist and bus repeatedly overtake each other was a problem as perceived by bus operators. Transit buses would pass cyclists and then buses would stop at a bus stop and the bicyclist would pass them. Second, there was a perception that the lanes were unsafe. There was also the problem of pedestrians walking out into the lane. ${ }^{5}$

Toward the conclusion of this study, researchers were contacted by the Maryland State Highway Administration (MSHA) and provided with summary data of the number of crashes along MD 528. During the time period, from January 1, 2009 through October 31, 2011, there were a total of 25 crashes involving bicycles that took place between 17th Street and 145th Street. Three of these 25 crashes involved both bicycles and buses. Probable crash cause for all three crashes was listed as unknown. These crashes took place at three separate locations along the corridor. One crash was intersection related. Injuries were involved in all three crashes. Two of the crashes took place in daylight under dry conditions. One crash took place at night under wet conditions.

It is not possible to interpret the significance of these crashes without the data to control for the level of bicycling along MD 528 relative to other streets in the area. Efforts to obtain the crash reports involving buses and/or bicycles along MD 528 were unsuccessful. Without examining the crash reports, it is not possible to determine whether the crashes were related to the design or operation of the SBBL. There is insufficient information to determine the contributory factors of the "bicycle involved crashes" and whether the rate of crash occurrence is higher relative to other streets. More research would be needed to evaluate the safety of the SBBL along MD 528.

\section{Conclusions}

The Ocean City case study of a tourist town presents unique issues and considerations. It is reported by the MSHA that the SBBL/right turn lanes function with a high LOS performance. However, dramatic population swings during the summer tourist season cause the lanes to function less successfully. This is due to increased motor vehicle use of the SBBL, particularly during annual events, as well as increased pedestrian activity along the edge of the street that can spill into the SBBL.

${ }^{5}$ Dustin Kuzan, Bicycle and Pedestrian Coordinator, Maryland State Highway Administration, Phone Interview, July 12, 2011. 


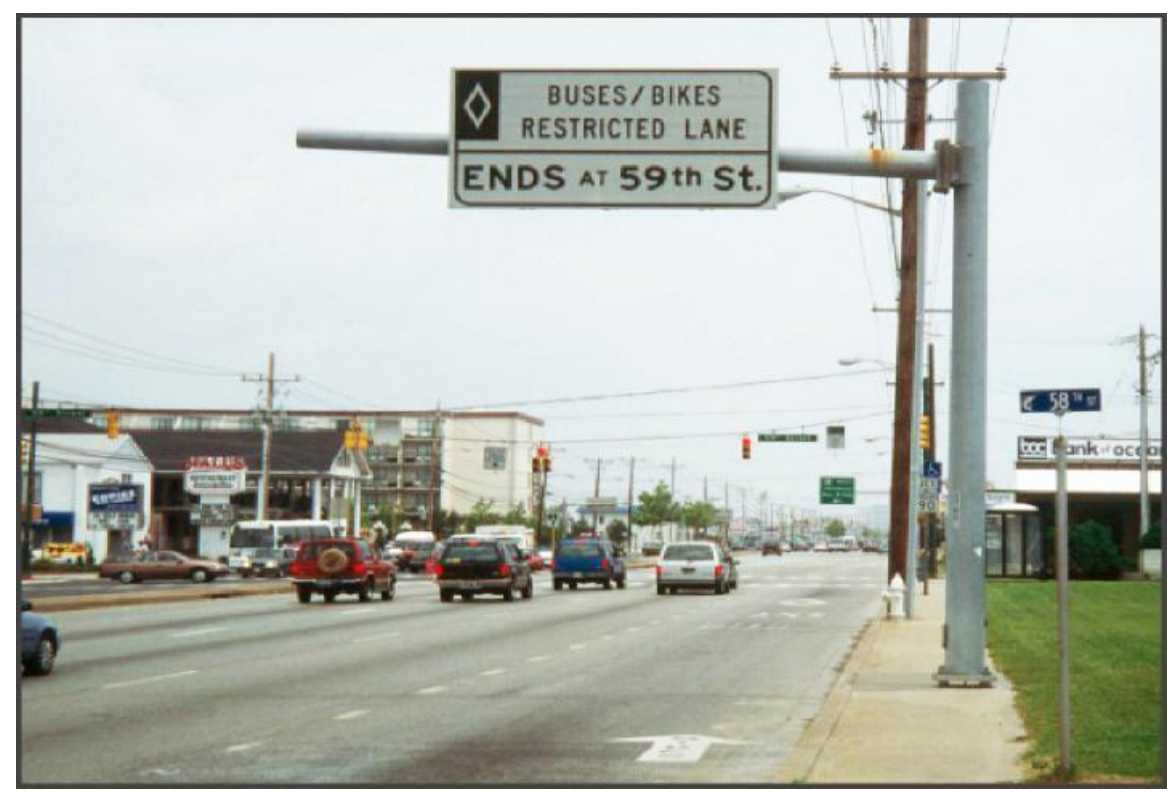

Figure 3.4 - MD 528, Ocean City, MD

Signage at 58th Street indicates interrupted section of SBBL due to major intersection with the Ocean City Expressway Bridge. Credit John Ciccarelli

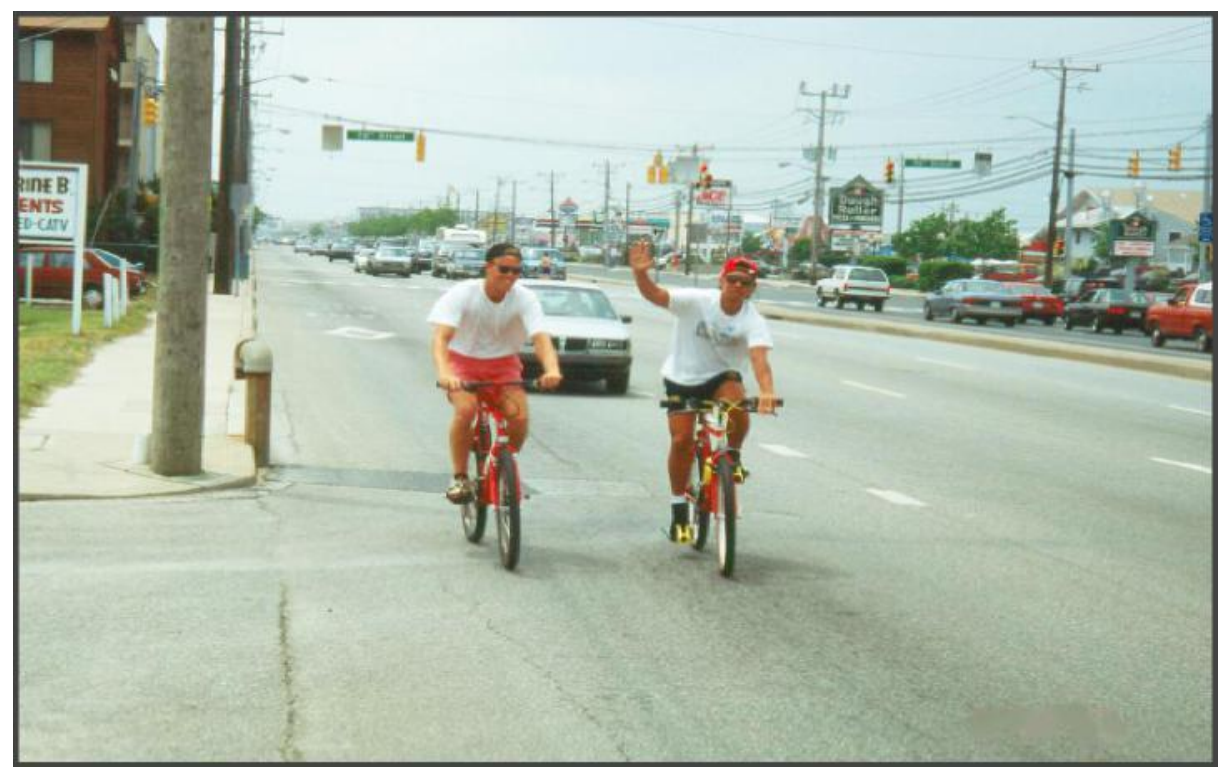

Figure 3.5 - MD 528, Ocean City, MD Near the intersection of 70th Street Credit: John Ciccarelli 


\section{Minneapolis, Minnesota}

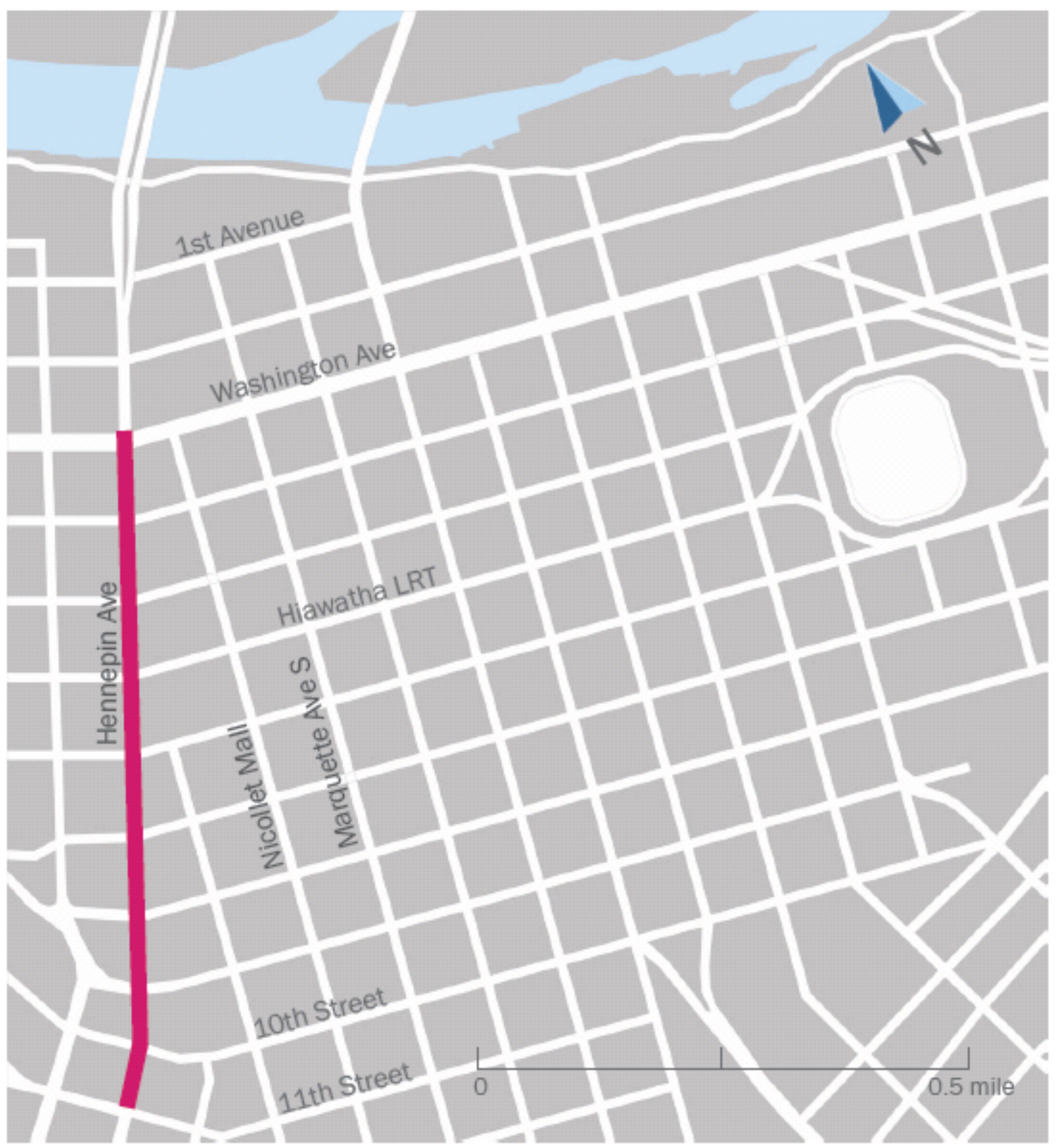

Figure 3.6 - Location of Hennepin Avenue SBBL

\section{History}

Hennepin Avenue, located in downtown Minneapolis (Figure 3.6) has undergone a number of recent modifications. Two research studies about Hennepin Avenue are discussed in the Relevant Previous Research section of Chapter 1 of this report. Since 1994, the heavily travelled street had been operating as a three-lane, one-way street with a contraflow bus lane and a two-way bicycle lane in the center of the street, between the bus lane and general traffic lanes. As part of the 2007 Access Minneapolis Downtown Action Plan, several projects were implemented to increase the mobility of downtown travelers, including the conversion of Hennepin Avenue into a two-way street in 2009. Table 
3.3 provides information on the roadway and how it operates. Between Washington Avenue S and 11th Street, bicycle facilities along Hennepin Avenue were changed from center-running lanes to SBBLs along both curbs. Figures 3.7, 3.8, and 3.9 show the lane configuration, both before and after changes were made.

Table 3.3 - Hennepin Avenue SBBL Features

\begin{tabular}{|l|l|}
\hline \multicolumn{2}{|c|}{ Hennepin Avenue from Washington Avenue S to 11th Street } \\
\hline Location: & $\begin{array}{l}\text { Hennepin Avenue is a main thoroughfare through the west side of } \\
\text { downtown Minneapolis. }\end{array}$ \\
\hline Date Opened: & $\begin{array}{l}\text { October 2009. Previously, Hennepin Avenue operated as a one-way pair } \\
\text { with 1st Avenue from 1994-2009. The one-way street included a two-way } \\
\text { bike lane in between the general traffic lanes and a contraflow bus lane. In } \\
\text { 2009, the street became bidirectional with SBBLs at both curbs. }\end{array}$ \\
\hline Roadway Configuration & $\begin{array}{l}\text { The new roadway configuration includes one general traffic lane in each } \\
\text { direction plus a center left turn lane every other block and SBBL/right turn } \\
\text { lanes at each curb side. Total roadway width is 59' from curb face to curb } \\
\text { face. }\end{array}$ \\
\hline Other Permitted Vehicles & $\begin{array}{l}\text { Right-turning vehicles in the SBBLs. Exclusive use of the SBBLs by } \\
\text { permitted vehicles is not enforced. }\end{array}$ \\
\hline SBBL Width & Alternating 18.5' and 13.5 ' on blocks with left turn lanes \\
\hline Block Length & $400^{\prime}$ \\
\hline Bus Stop Frequency & Every other block \\
\hline Speed Limit & 30 mph \\
\hline Colored Lanes & $\begin{array}{l}\text { In 2010, a green lane of four feet in width and additional lane markings } \\
\text { were painted to increase visibility. The paint has since faded. }\end{array}$ \\
\hline
\end{tabular}

In total, 23 design alternatives were considered for Hennepin Avenue and 1st Avenue. Design options included the combination of integrating various roadway lane typical section alternatives (3-lane, 4lane, and 5-lane) with various bicycle lane options (center running, curb side, one-way pair, and shared lane). An assessment of each option was measured against the following objectives:

- bicycle safety

- motor vehicle traffic operations/safety

- transit delivery loading/unloading conflicts

- pedestrian conflicts

- traffic laws and ordinances

- continuity/consistency of bike routing

- skill level

- accessibility to bike lane from cross streets

- directness of bike route, municipal state aid streets standards/city design guidelines maintenance (City of Minneapolis 2010b, 3) 
Table 3.4 - Hennepin Avenue Traffic Counts before and after Lane Modification

\begin{tabular}{|c|c|c|}
\hline & Before Modification & After Modification \\
\hline Traffic Volume & $\begin{array}{l}20,000 \text { estimated vehicles per } \\
\text { day }\end{array}$ & 20,000 estimated vehicles per daya \\
\hline Bicycles & $\begin{array}{l}\text { 1,190 estimated bicyclists per } \\
\text { day (2007) }\end{array}$ & $\begin{array}{l}990 \text { estimated bicyclists per day (2011) } \\
\text { bicycle facility improvements to adjacent } \\
\text { streets may have captured some of the } \\
\text { decrease }\end{array}$ \\
\hline Bus Frequency & $\begin{array}{l}\text { Peak: } 20-30 \text { buses/hour } \\
\text { Off-peak: } 10-20 \text { buses/hour } \\
\text { Weekends: }+/-10 \text { buses/hour }\end{array}$ & $\begin{array}{l}\text { Peak: } 20-30 \text { buses/hour } \\
\text { Off-peak: } 10-20 \text { buses/hour } \\
\text { Weekends: }+/-10 \text { buses/hour }\end{array}$ \\
\hline
\end{tabular}

\section{Design Considerations}

Changing widths in the SBBL, depending on available right-of-way in each block segment, can provide both opportunities and cause difficulties for buses and cyclists. The 13.5-foot sections along block segments with left turn lanes do not provide adequate width for a cyclist to pass a stopped bus, whereas the 18.5-foot sections along block lengths with no left turn lanes provide ample space for safely passing a stopped bus. Confusion of where to ride in the SBBL by both transit operators and cyclists, as well as whether or not there is adequate passing space, may cause challenges for both types of users. The SBBLs change into five-foot bike lanes after both SBBLs terminate. Dashed lines through the intersections guide motorists to the alignment of the offset lanes. At each end of the SBBL on Hennepin Avenue, bicycle lanes continue the facility for cyclists for two blocks north and one block to the south.

\section{Safety Considerations}

The 2009 lane modification included new pavement markings in the SBBLs similar to Shared Lane Markings with pavement text stating "BIKE BUS RIGHT TURN ONLY." The "ONLY" was later removed from the pavement markings after Minneapolis police determined that it was not possible to enforce the "ONLY" aspect of the lane. According to the police, traffic volumes were too high and turning movements too complex to hold drivers accountable for not using the lane properly. However, according to the Minneapolis Public Works Department, the right lane is still encouraged to be used only by right-turning motorists. ${ }^{6}$

In 2010, concerns were raised over visibility and effectiveness of the lane markings. Feedback came primarily from bicyclists. Public comments described the lane markings as too small, not scaled to the size of the roadway, and not visible when vehicles were stopped over the markings. They appeared similar to Shared Lane Markings rather than markings for dedicated lanes, which may have contributed to unauthorized use of the lanes. As a result, the SBBLs were enhanced to include a painted background, after approval from the Federal Highway Administration in August 2010. A green lane of four feet in width and offset from the curb by 3.5 feet was installed the length of each block (Figure 3.9). The placement of Shared Lane Markings was adjusted and placed at each block, with enlarged pavement text stating "BUS BIKE RIGHT TURN" (Figure 3.10). Paint does not extend across the intersections. Painted lane case studies in Salt Lake City, UT, and Long Beach, CA, were used as

${ }_{6}^{6}$ Simon Blenski, Minneapolis Public Works Department, Questionnaire completed on November 25, 2011. 
precedents for the installation. A variable message sign with the message "Share the Road" is also located along Hennepin Avenue (Figure 3.11).

In October 2010, an observational study performed by the Minneapolis Public Works Department using video cameras was conducted to determine riding and driving position relative to the green lanes. In addition, a survey was administered to determine public perception of the green lanes, comprehension of the new facilities, and changes to travel patterns before and after the changes to Hennepin Avenue and parallel corridors. The survey received 494 responses, primarily from bicyclists (City of Minneapolis 2011, 18). The evaluation of the SBBLs indicated increases in bicycling in the downtown, better access by motor vehicles, and decreases in crashes of both bicyclists and motor vehicles. Despite this, most survey respondents expressed dissatisfaction with the changes to Hennepin Avenue, citing lack of adequate space, the desire for a defined or separated facility, and lack of comprehension of the current configuration.

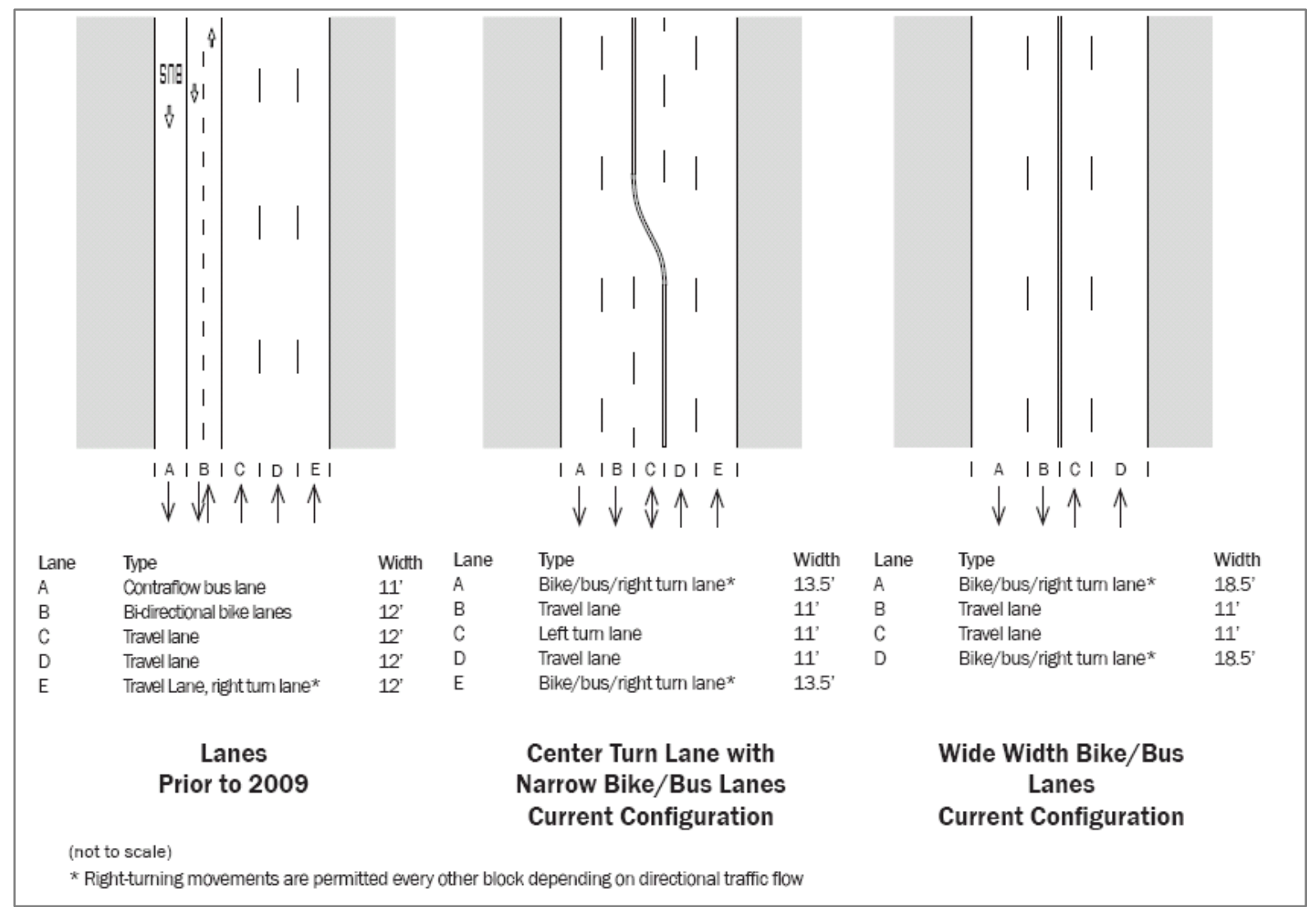

Figure 3.7 - Hennepin Ave changes in lane configuration 


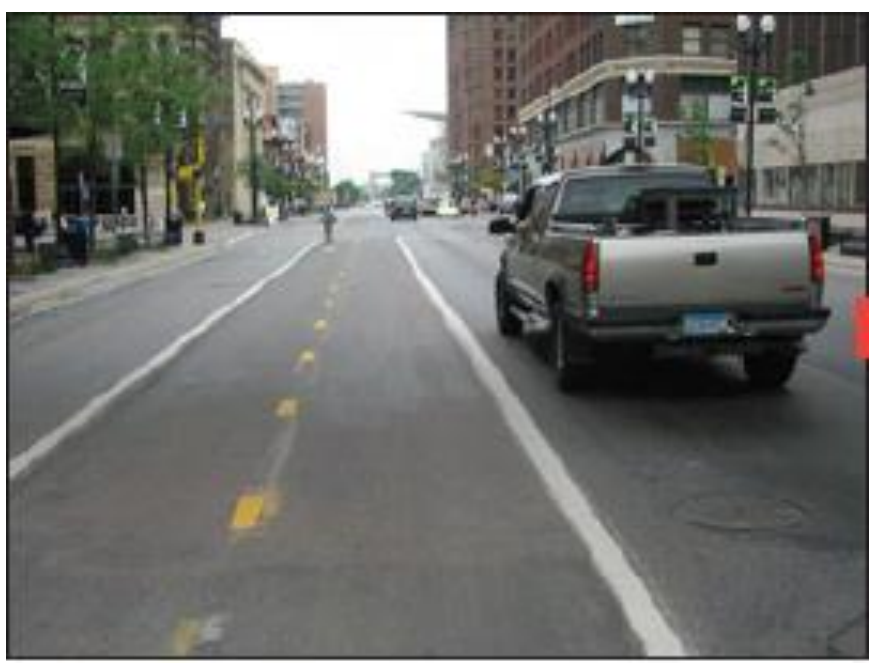

Figure 3.8 - Hennepin Avenue prior to lane reconfiguration in 2009

Credit: Minneapolis Public Works

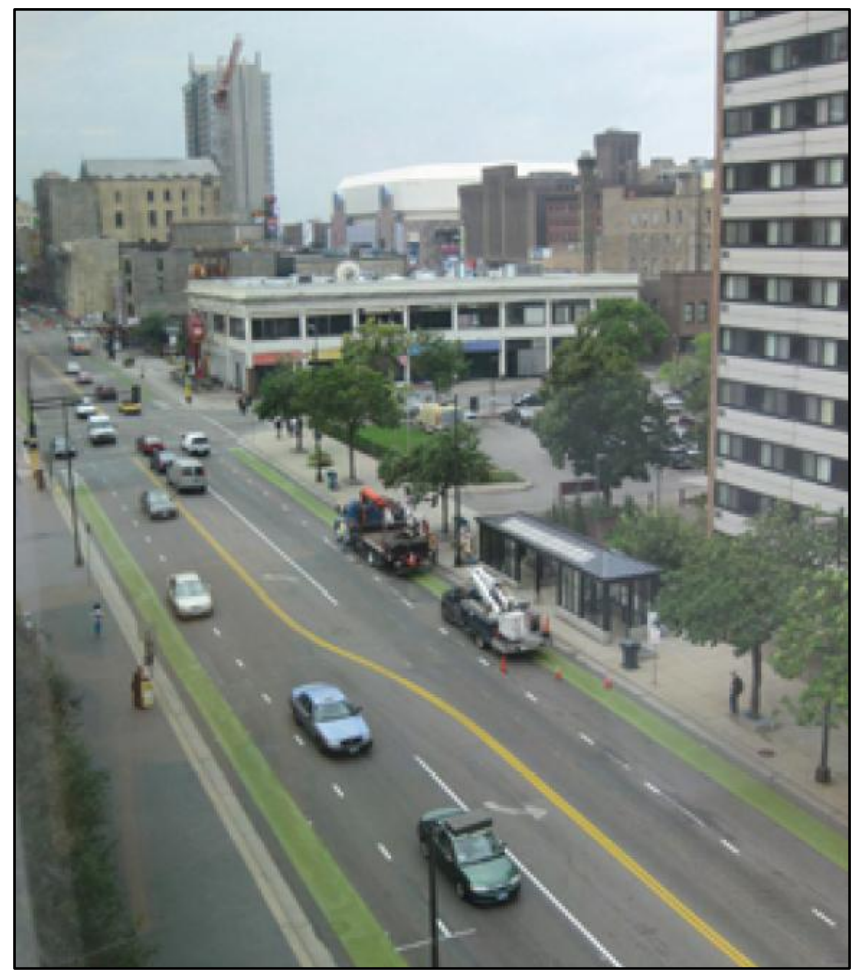

Figure 3.9 - Hennepin Avenue after redesign in 2010

Credit: Minneapolis Public Works

\section{Maintenance}

The green lanes were initially painted in August 2010 with standard latex road paint. After one winter season, the paint experienced significant wear and was almost completely worn away in some areas. Bus traffic, plowing, deicing, and freeze-thaw cycles were considered by Minneapolis Public Works as the likely contributing factors to the rapid wearing of the paint surface and deterioration of the roadway surface (City of Minneapolis 2011, 48-50). 


\section{Conclusions}

Few cities have both collected and evaluated data on shared lanes. Minneapolis Public Works has obtained data on several important factors, which they have used to determine the appropriate bicycle and transit bus facility type, and to modify the Hennepin Avenue SBBL after its initial installation. Bicycle counts, vehicle traffic, bus frequency, as well as public input are key factors that have been identified as contributing to the level of service of Hennepin Avenue. Other contributing factors included roadway width constraints, improving downtown access, and balancing uses of the curb lanes.

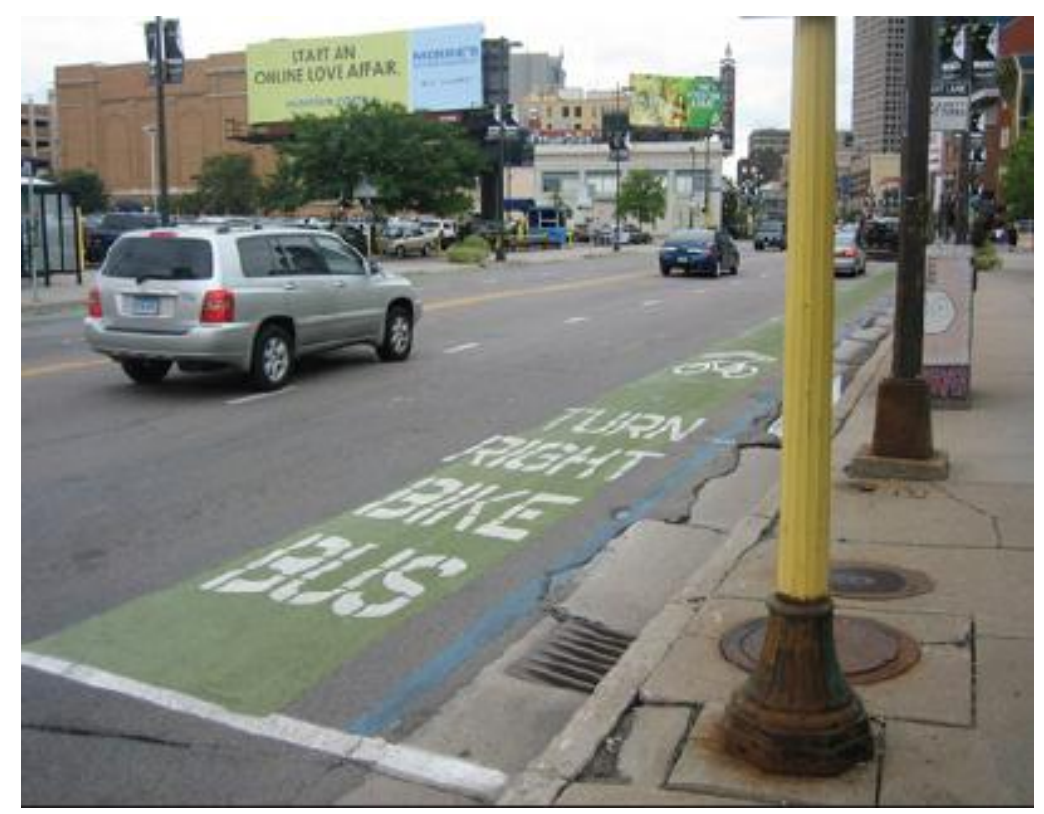

Figure 3.10 - Hennepin Avenue, Green Shared Lane Study, 2010

Credit: Minneapolis Public Works

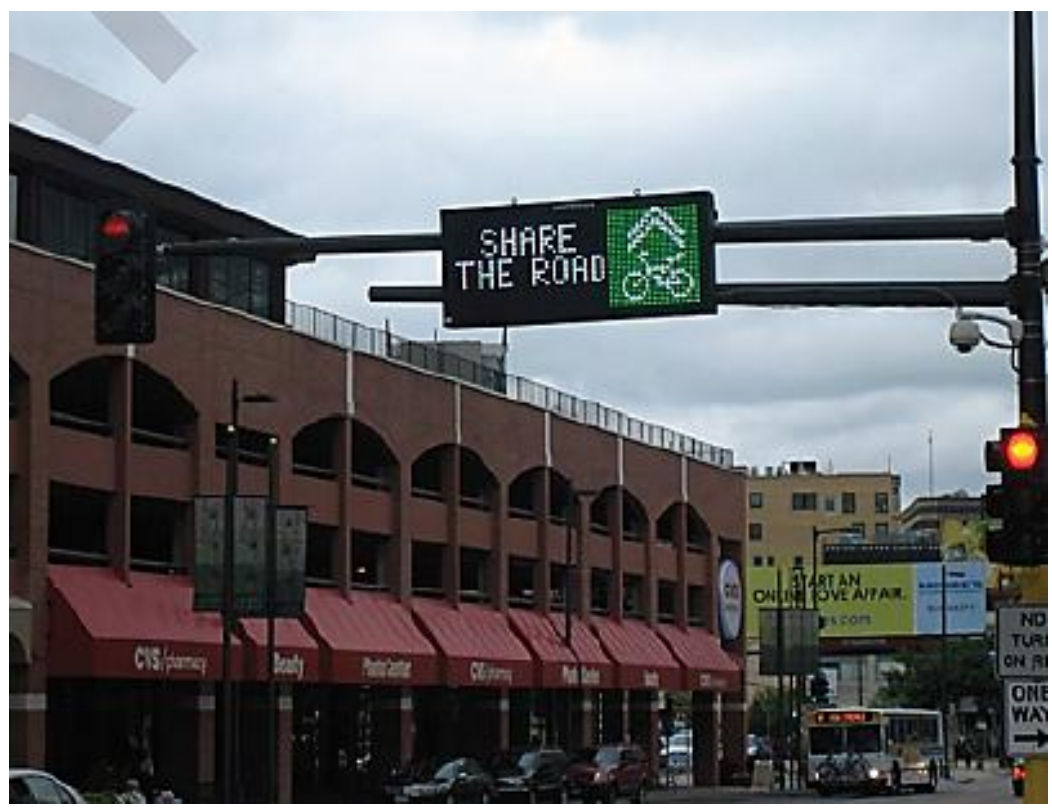

Figure 3.11 - Hennepin Avenue signage

Credit: Minneapolis Public Works 


\section{Philadelphia, Pennsylvania}

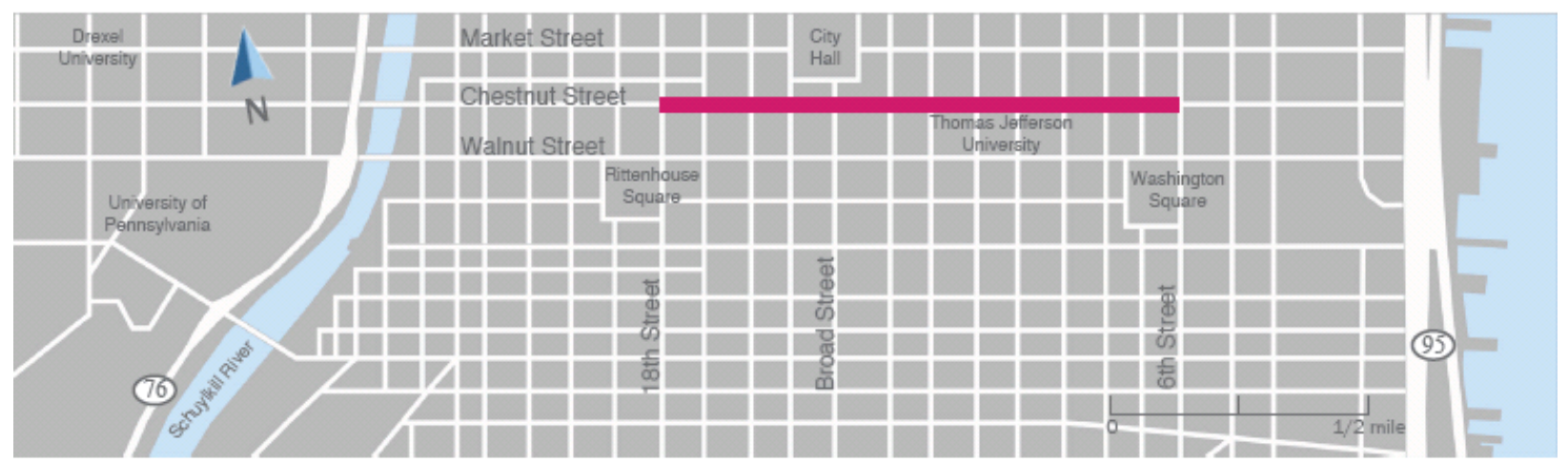

Figure 3.12 - Location of Chestnut Street SBBL

\section{History}

Philadelphia has several examples of bike lanes and an SBBL adjacent to heavily travelled bus routes. These include, but are not limited to, bike lanes on portions of Walnut Street in University City and along Market Street, and an SBBL along Chestnut Street. Figure 3.12 shows a map of a portion of downtown Philadelphia and labels the three university campuses which are in proximity to the Chestnut Street SBBL. Chestnut Street is a one-way eastbound street with two travel lanes. The south curb lane is an SBBL, designated for buses, bicycles, and right-turning vehicles only. The adjacent travel lane is open to all vehicles. Metered parking is located adjacent on the north side of the general traffic lane (Figures 3.13 and 3.14). Table 3.5 provides information on the street and how it operates. Table 3.6 provides information on bus service frequency along Chestnut Street. Walnut Street is a one-way westbound street with three travel lanes and a bike lane with an adjacent parking lane. Frequent bus traffic operates in the lane adjacent to the bicycle lane and is required to move across the bicycle lane into the parking lane at bus stops.

Until the mid 1990s, Chestnut Street had previously been used as a bidirectional busway with use by all other vehicles prohibited. The high volume of buses on the street was found to be a detriment to pedestrian quality of service because of noise and diesel exhaust. In response to business complaints, the busway was eliminated and replaced with a single, general purpose traffic lane and an SBBL/right turn lane. The SBBL was painted red along the entire length and included lane markings and signage.

Questionnaires and interviews were completed with staff at SEPTA that runs the bus system, as well as the bicycle and pedestrian coordinator for the Mayor's Office. According to both, lack of enforcement against unauthorized motor vehicles is the largest issue reducing the LOS for both bus transit and cyclists in the SBBL. It is also the primary safety issue affecting the SBBL. In addition, SEPTA staff explained that the level of transit service was reduced when Philadelphia City Council decided to allow right turns again in the SBBL in Center City, slowing buses because the right-turning vehicles must yield to pedestrians. .7,8

\footnotetext{
${ }^{7}$ Charles Carmalt, Bicycle and Pedestrian Coordinator, Philadelphia Mayor's Office, Interview completed on August 5 , 2011.

8 Joshua Gottlieb, Director of Administration - Bus Transportation, Southeastern Pennsylvania Transportation Authority (SEPTA), Phone interview, August 5, 2011.
} 
Table 3.5 - Chestnut Street SBBL Features

\begin{tabular}{|l|l|}
\hline \multicolumn{2}{|c|}{ Chestnut Street } \\
\hline \multirow{2}{*}{ Location } & $\begin{array}{l}\text { Located in a heavily congested area of downtown Philadelphia, known as } \\
\text { Center City, an SBBL was installed on Chestnut Street just south of Market } \\
\text { Street. A number of universities are located nearby including Thomas } \\
\text { Jefferson University, the University of Pennsylvania and Drexel University to } \\
\text { the west across the Schuylkill River. }\end{array}$ \\
\hline Date Opened & $\begin{array}{l}\text { In 1976, Chestnut Street was converted into a bidirectional busway. It was } \\
\text { then changed in the 1990s to reintroduce general traffic and bicycles, } \\
\text { including an SBBL. }\end{array}$ \\
\hline Roadway Configuration & $\begin{array}{l}\text { One general purpose traffic lane (eastbound), SBBL adjacent to curb on } \\
\text { south side of the street, on-street parking lane on north side. }\end{array}$ \\
\hline Facility Type & SBBL \\
\hline Other Permitted Vehicles & Right-turning vehicles \\
\hline SBBL Width & $9^{\prime}$ \\
\hline Block Length & $400^{\prime}$ \\
\hline Bus Stop Frequency & Every block \\
\hline Speed Limit & 25 mph \\
\hline Colored Lane & $\begin{array}{l}\text { Originally colored red, however, the paint had faded and will not be repainted } \\
\text { (according to the Mayor's Office, 2011). }\end{array}$ \\
\hline
\end{tabular}

The city is conducting 24-hour bicycle counts on key streets in downtown, but information has not been released. According to an earlier report produced by the Bicycle Coalition of Greater Philadelphia, 126 bicycles were counted in a one-hour period at the SBBL intersection of Chestnut Street and Broad Street (Bicycle Coalition of Greater Philadelphia 2006-08 Comparison). The bicycle and pedestrian coordinator for Philadelphia estimates bicycle counts for Chestnut Street to be between 50-100 cyclists per hour. Motor vehicle volumes range from 8,000 to 15,000 Average Daily Traffic (ADT).

Table 3.6 - 2011 Bus Service Frequency, Chestnut Street, Philadelphia, PA

\begin{tabular}{|l|c|}
\hline Morning Peak & $\mathbf{2 - 5}$ minutes \\
\hline Midday & $4-8$ minutes \\
\hline Afternoon Peak & $4-6$ minutes \\
\hline Weekends & 10-15 minutes \\
\hline $\begin{array}{l}\text { Source: SEPTA Bus Schedules for Routes 9, 21, and 42, effective September 4, } 2011 . \\
\text { http://www.septa.org/schedules/bus/index.html }\end{array}$ \\
\hline
\end{tabular}

\section{Design Considerations}

Chestnut and Walnut Streets manage a number of competing interests in a very limited amount of right-of-way. Volumes of motor vehicle, bus, bicycle, and pedestrian traffic are high. Traffic from nearby universities compounds these demands. A large number of retail establishments require parking and space for delivery trucks. Although there are several loading and unloading zones on Chestnut Street, delivery trucks frequently stop in either the SBBL or the adjacent travel lane. This blocks and requires lane shifting. Originally, right-turning movements were not permitted; however, public objections caused City Council to eliminate that restriction.

The high demands placed on the lanes yield enforcement issues and have led to several design adjustments over time. Initially the SBBL on Chestnut Street was painted red to alert motorists of the special uses and minimize unauthorized use. The paint has since faded, and there is no intent to repaint the lane due to its high maintenance requirements. 


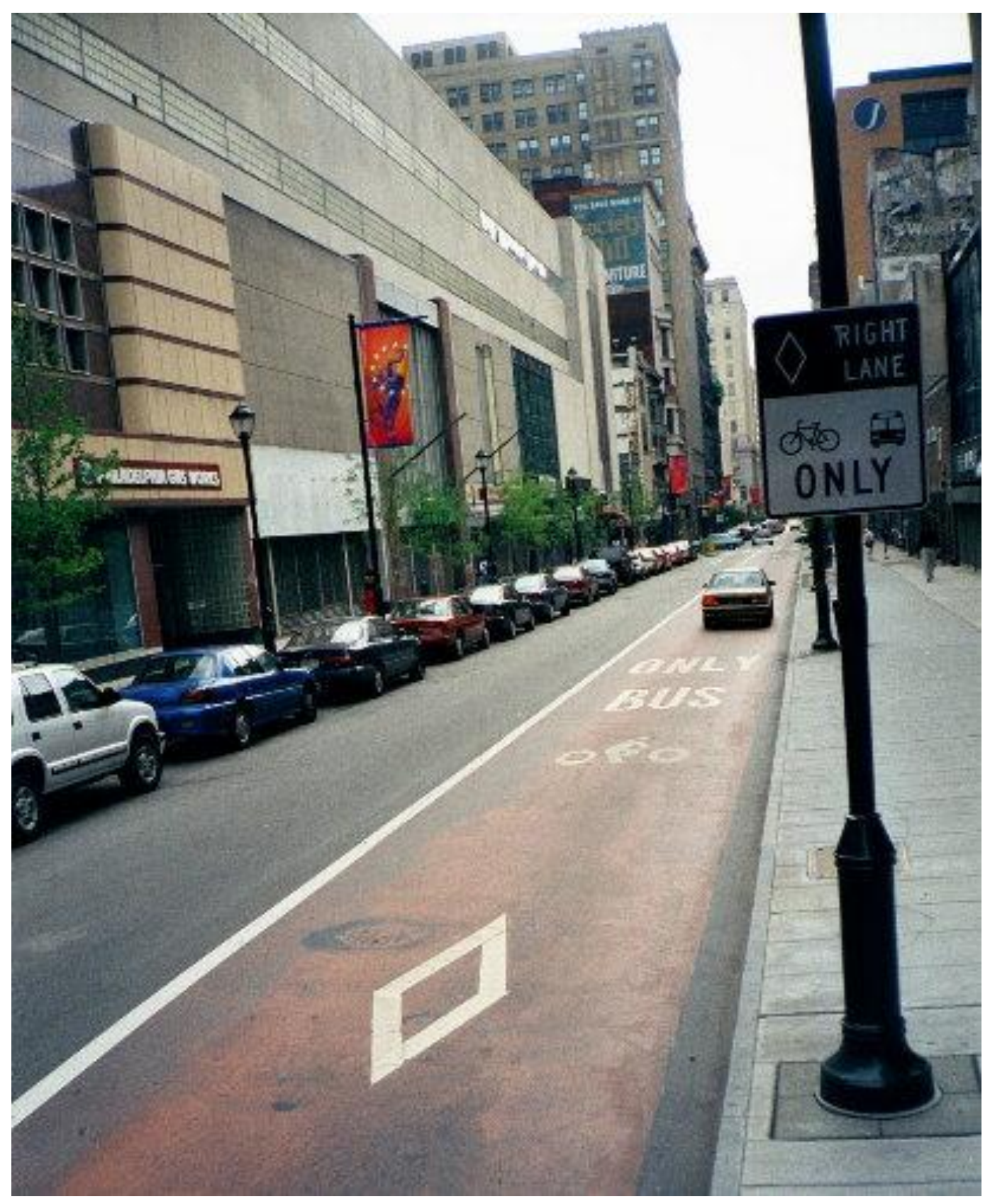

Figure 3.13 - SBBL on Chestnut Street, Philadelphia, PA

Credit: Michelle Derobertis 


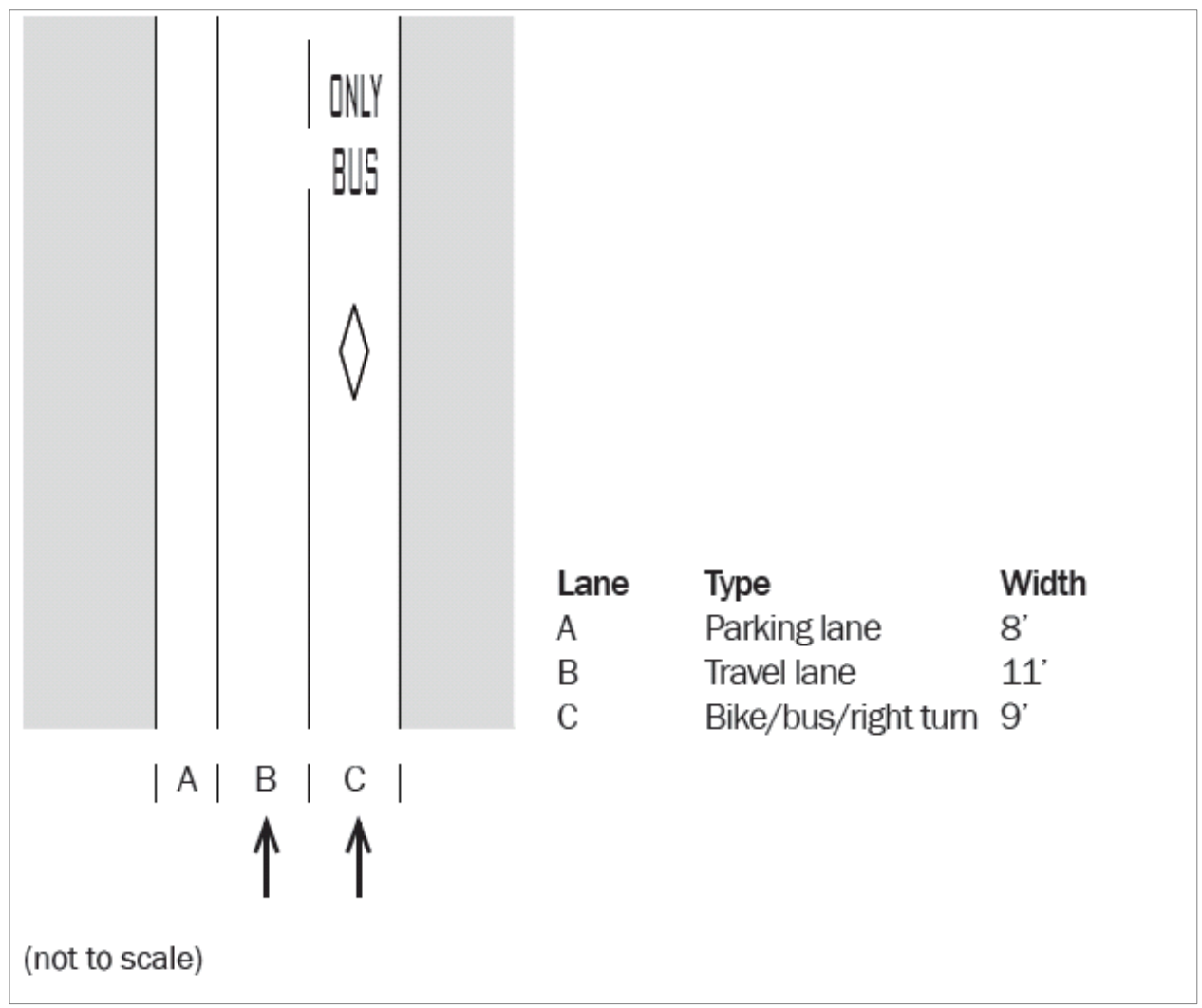

Figure 3.14 - Chestnut Street lane configuration

\section{Safety Considerations}

The DVRPC produced a report in 2009 reviewing crash data and video logs documenting the specific types of bus and bicycle conflicts in downtown Philadelphia. A discussion of study findings is included in the Relevant Previous Research section of Chapter 1. The report indicated that in downtown Philadelphia between 2003 and 2006, there were a total of 46 reported crashes involving both bikes and buses. These included three fatalities, two major injuries, and at least 52 other injuries.

A more detailed study was performed on Walnut Street (one block south of the Chestnut Street SBBL) that documented bus/bike conflicts using video logs at three intersections along Walnut Street: 33rd Street, 34th Street, and 38th Street in University City. The video was used to capture near misses or other incidents of conflict where either bicyclists or buses need to take action to avoid collisions. According to the report:

...the three locations had a total of almost 1,000 bicyclists and approximately 130 buses stopped during the selected time period (roughly 6 hours per intersection). The intersection of 33rd and Walnut saw the highest numbers, with almost 550 bicycles and 55 buses stopping. This accounts for a sizable volume of right-turning bicyclists moving north on 33rd Street towards Drexel University. Almost 300 bicycles and 40 buses were recorded at 34th Street. 38th Street saw the lightest activity, with roughly 130 bicycles and 40 buses being counted during the filming. There were 47 total incidents noted at the three intersections. Almost every occasion when a bicycle and bus were at an intersection at the same time, it resulted in an incident or conflict. It is important to note that not all of the incidents necessarily reflected unsafe passing. 
The study indicated two main types of incidents. Most of the incidents were of the bicyclist moving to the right of the curbed bus, conflicting with bus passengers attempting to get on or off the bus. The second most frequent incident type was of the bicyclist having to move quickly to the left of the stopping bus, and into the general traffic lane in order to pass the bus. (DVRPC and SEPTA 2009, 8-9)

DVRPC conducted a survey of best practices and identified five strategies that have been implemented across the U.S. and abroad to address the specific bike/bus/passenger conflict issue.

Strategy 1: Colored bike lanes in conflict hot spots, including transit stop areas

Strategy 2: Discontinue bike lanes at transit stops, allowing bicyclists to stop and wait while bus loads/unloads passengers, or allowing bicyclists to move to the left side of the SBBL and pass the bus.

Strategy 3: Physical re-routing of bike lane around stop location

Strategy 4: Left-side bicycle lanes

Strategy 5: Unique pavement markings and/or signage (DVRPC and SEPTA 2009, 14-25)

DVRPC determined that it could use Strategy 4, but that use of the other strategies would require it to file an FHWA experiment application and receive approval before proceeding with the test. Other states or cities may already have received the necessary approvals. FDOT staff indicates that they have received permission to experiment with strategies $1-4 .{ }^{9}$

According to the Director of Administration-Bus Transportation for SEPTA, "Bicyclists don't follow the rules as often as we'd like. From the transit agency's perspective, it's hard to keep track of cyclists in places where we share a lane. Bus operators are not always sure where they are because they don't ride in the same place in the lane. You cannot see a cyclist if they are directly behind the bus." 10

A subsequent report collected data for bus lane violations on Chestnut Street to assess the frequency of motor vehicles (non-bus) using the bus lane. The count showed that during the peak 15minute period, 58 non-buses used the SBBL on Chestnut Street at Broad Street. Of these 58 vehicles, $27(47 \%)$ were illegally using the lane for through movements and 31 (53\%) were legally using the lane to make a right turn (Schack and Mason 2010, 5).

According to the Bicycle and Pedestrian Coordinator, "The Chestnut Street SBBL continues to function better than the street would function without the lane restrictions. But without enforcement, it is not as effective as it could be. Abuse of the lane by taxis is a continuing problem. Cab drivers know that the lane restrictions are not enforced and routinely use the street to jump intersection queues. Most city bicyclists will use the lane because it gets them to where they need to go, but they don't like using it and we hear complaints about the street."11

The following comments by a bicyclist who uses the SBBLs in Philadelphia highlight a number of issues identified from interviews, comments, and blog posts by bicyclists in reference to other SBBLS.

\footnotetext{
9 Mary Anne Koos, Florida Department of Transportation, Roadway Design Office, February 16, 2012.

10 Joshua Gottlieb, Phone interview, August 5, 2011.

11 Charles Carmalt, Interview completed on August 5, 2011.
} 


\section{Shared Bike/Bus Lanes from the Perspective of a Commuter Cyclist12}

My impression of the SBBL on Chestnut Street is that to have the lane is a good thing but enforcement of cars in the lane is an issue. Cars frequently travel into the lane and l've never seen one ticketed by the police. Trucks also stop in the lane and use it as an uploading spot. In general, Chestnut Street is one of the most congested streets in Philadelphia. In cities, bicyclists travel faster than buses and this lane is not wide enough for a cyclist to go around the bus without having to move into the next lane.

Two years ago the City gave up an entire vehicle lane for a bike only lane (bike lane with a three-foot buffer) on Spruce Street. However, I still chose to bicycle on Chestnut for several reasons: 1) it is smoother than Spruce St, 2) it is more visually stimulating, and 3 ) it is more convenient.

\section{How well does the lane operate from your perspective?}

On a scale of 1-10, l'd give it a 5. It's not a great solution but it's much better than having to bicycle in typical lanes with cars.

Do you have a problem interacting with the buses? Do the bus drivers pay attention? Is the lane wide enough for you to go around the bus without you moving out of the lane or do you frequently have to move into the other travel lanes?

No, my negative interactions with bus drivers are not particular to Chestnut Street. The lane is not wide enough to go around a stopped bus without moving into the next lane. I'm not sure if it's illegal or not for me to travel into the adjacent traffic lane, but that is definitely a problem.

What I appreciate about the lane is that you know what to expect. You know to expect the occasional car, and that a bus is in front of you and that the bus will stop at the light and that it's going to stop frequently at bus stops. It's easy to anticipate.

From the perspective of this bicyclist, riding on SBBLs is more predictable than mixing with general traffic. This is in direct contrast to answers provided by transit operators who complain that cyclists in the lanes are much more unpredictable than when riding in a bike lane.

\section{Conclusions}

The Philadelphia example presents a similar context and similar issues to the Washington, D.C. example, discussed next. Enforcement and predictability are consistent themes that affect the safety and LOS. Adjacent land uses along the SBBLs in both Philadelphia and Washington D.C also add to the

\footnotetext{
12 Michael Garden, Philadelphia cyclist who commutes on the Chestnut Street SBBL 2-3 times per week, Phone interview, August 1, 2011.
} 
potential conflicts. Very high bus volumes during peak periods in both cities present challenges for cyclists to safely and efficiently use the lanes.

\section{Washington, D.C.}

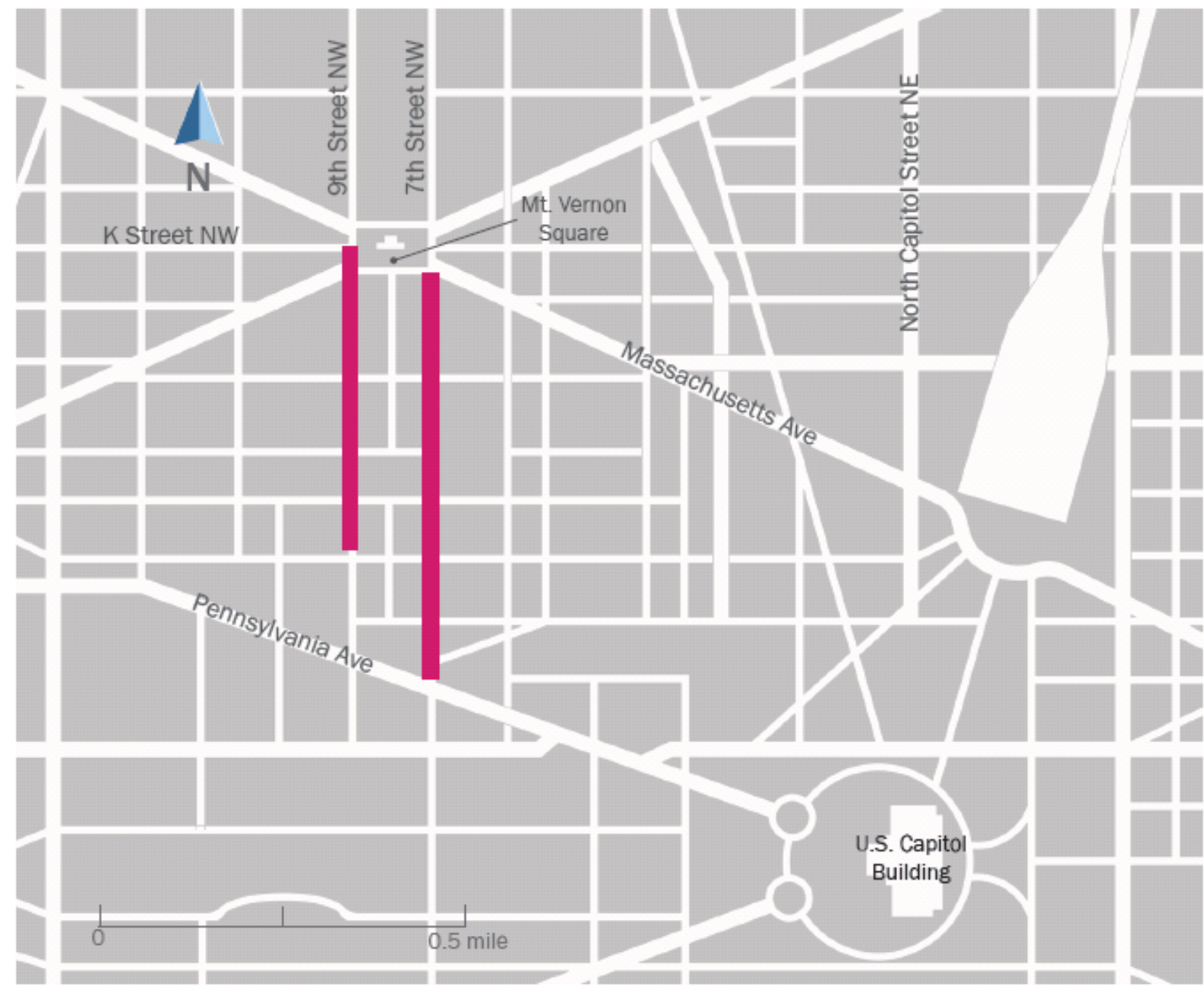

Figure 3.15 - Location of Washington, D.C. SBBLs

\section{History}

Paired SBBLs are located on 7th and 9th Streets NW in downtown Washington, D.C. between Pennsylvania Avenue to the south and Mount Vernon Square to the north (Figure 3.15). The streets are heavily travelled and are adjacent to a variety of uses, including federal buildings, corporate offices, museums, and other tourist sites. In addition to these uses, the area has long been known as the District's China Town and is now emerging as the city's theater district with the Verizon Center, a large event and sports complex, on 7th Street NW. These adjacent uses in combination with commuter traffic place high demands on 7th and 9th Streets NW for extended periods of the day, not just during peak times. Visitors unfamiliar with the area compound the traffic problem. ${ }^{13}$

13 Charlie Denney, Senior Planning Associate for Alta Planning + Design, Phone interview, July 21, 2011. 
In 2003, 7th and 9th Streets were redesigned to incorporate a new circulator bus route. According to the District Department of Transportation (DDOT) and the Washington Metropolitan Area Transit Authority (WMATA), the circulator required a dedicated bus lane to operate. During DDOT's design process they incorporated a bicycle lane into the bus lane. ${ }^{14}$ In addition to the lane reallocation, lane markings were placed regularly at the beginning, midpoint, and end of each block and are delineated with wide, solid white lines that become dashed to identify where there are conflict zones. Signs were added to distinguish the restricted SBBLs from general purpose traffic. Signs are placed at the beginning of most intersections and state "BUS ONLY" with a bicycle symbol. Signs are generally affixed to streetlight posts approximately 12 feet from the ground. Right-turn-on-red restrictions were also placed on the streets. Table 3.7 provides information on the paired streets and how they operate.

Table 3.7 - Washington, D.C., Shared Bike/Bus Lane Features

\begin{tabular}{|c|c|c|}
\hline & 7th Street NW & 9th Street NW \\
\hline Location & \multicolumn{2}{|c|}{$\begin{array}{l}\text { Two parallel SBBLs are located in downtown Washington, D.C. between the } \\
\text { United States Capitol Building and the White House on 7th and 9th Streets } \\
\text { NW. The portion of street which includes an SBBL facility runs between } \\
\text { Pennsylvania Ave to the south and Mount Vernon Square to the north. }\end{array}$} \\
\hline Date Opened & 2003 & 2003 \\
\hline $\begin{array}{l}\text { Roadway } \\
\text { Configuration }\end{array}$ & $\begin{array}{l}\text { Two bidirectional traffic } \\
\text { lanes, SBBL, and on-street } \\
\text { parking on both sides }\end{array}$ & $\begin{array}{l}\text { Two traffic lanes one-way southbound, } \\
\text { southbound SBBL, northbound and on- } \\
\text { street parking on one or both sides (varies) }\end{array}$ \\
\hline Facility Type & $\begin{array}{l}\text { SBBL with adjacent on- } \\
\text { street parking }\end{array}$ & $\begin{array}{l}\text { Alternates between SBBL for portions of the } \\
\text { street and parking, with separate and } \\
\text { adjacent bus lane and bike lane }\end{array}$ \\
\hline $\begin{array}{l}\text { Other Permitted } \\
\text { Vehicles }\end{array}$ & Right-turning vehicles & Right-turning vehicles \\
\hline SBBL Width & $11^{\prime}$ & $\begin{array}{l}\text { 11-foot SBBL, } 18 \text {-foot separate but adjacent } \\
\text { bus lane and bike lane }\end{array}$ \\
\hline Block Length & $330-430$ ' (varies) & $330-430$ ' (varies) \\
\hline $\begin{array}{l}\text { Bus Stop } \\
\text { Frequency }\end{array}$ & $\begin{array}{l}\text { Multiple routes every } \\
\text { block (average) }\end{array}$ & Multiple routes every block (average) \\
\hline Speed Limit & $30 \mathrm{mph}$ & $30 \mathrm{mph}$ \\
\hline Colored Lane & no & no \\
\hline
\end{tabular}

On 9th Street NW, the lane configuration shifts each block between two different designs. It begins as an SBBL/right turn lane with two travel lanes and on-street parking adjacent to both curbs. The subsequent block does not have on-street parking between the bus lane and the curb. This permits more room for the SBBL to become separated into a 12-foot bus lane and a six-foot adjacent bike lane. Figures 3.16 and 3.17 show how the lanes change configurations depending on whether onstreet parking is present on both sides of the roadway.

\footnotetext{
$14 \mathrm{Jim}$ Sebastian, Coordinator of Bike, Pedestrian, and TDM Programs for the District Department of Transportation, Interview, June 10, 2011.
} 


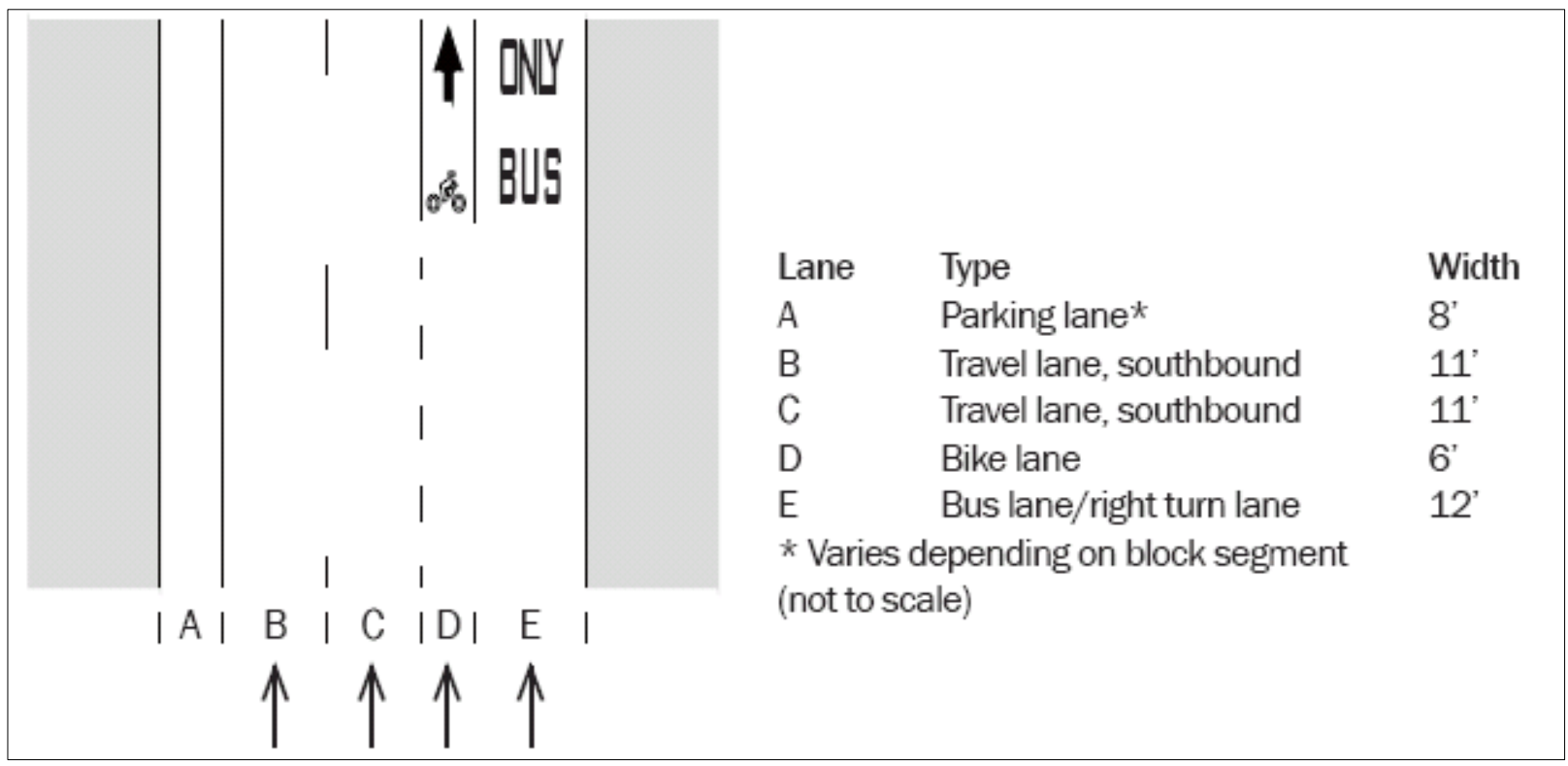

Figure 3.16 - Washington, D.C. 9th Street NW - lane configuration: type 1

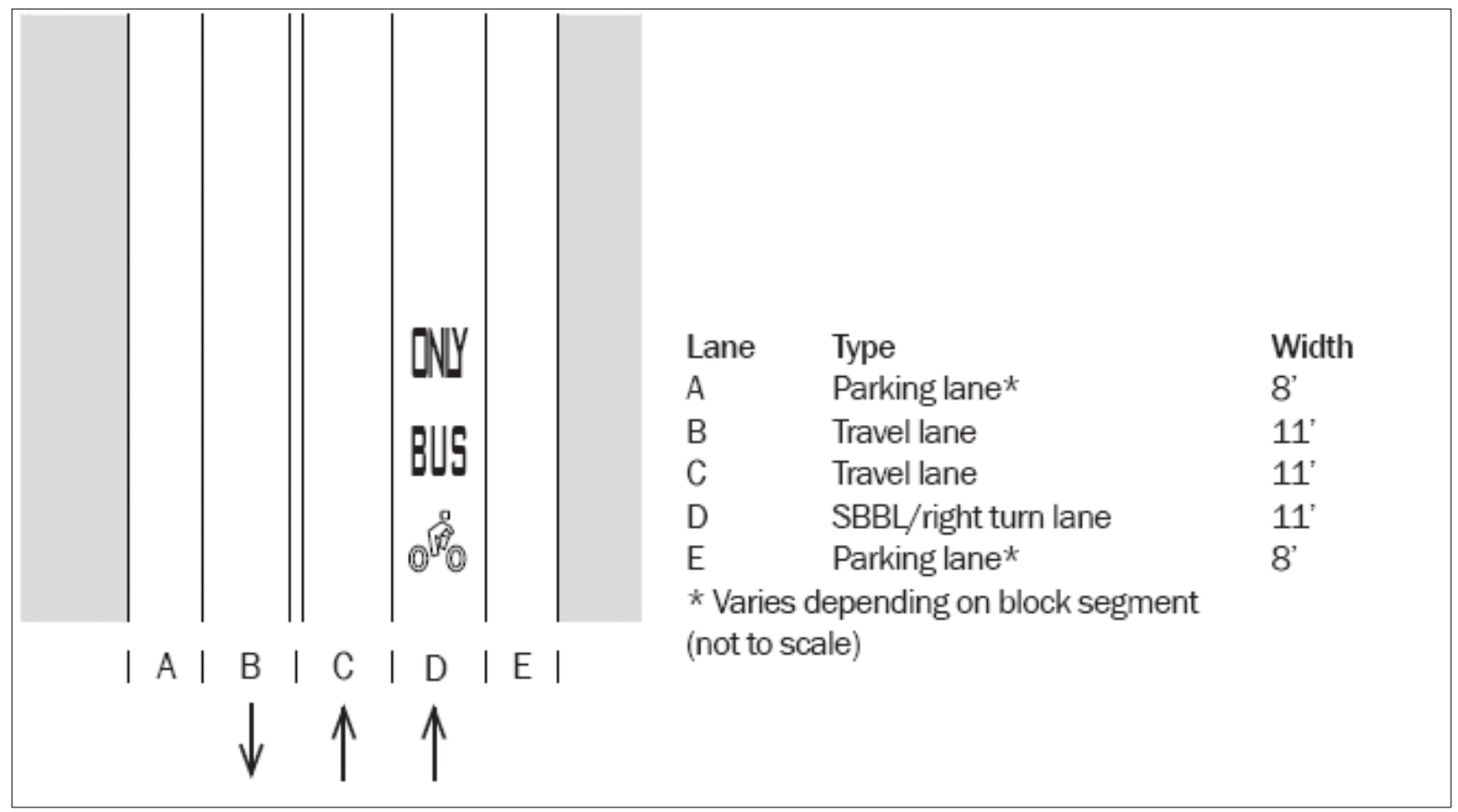

Figure 3.17 - Washington, D.C. 9th Street NW - lane configuration: type 2

\section{Design Considerations}

Figures 3.18 and 3.19 illustrate high demand for street space. In addition to the circulator, a number of other bus routes use 7th and 9th Streets NW, including an express route. Although bicycle counts were not available, DDOT estimates the level of use to be on par with other downtown streets. The two streets were observed by a researcher at several times during one day in the summer of 2011. At 
least one bus and one cyclist passed by every two minutes. Four Capitol Bike Share kiosks are adjacent to or near the two streets.

It is widely agreed by WMATA, DDOT, and local bicycle organizations that the lanes do not function well. The root cause of this is that too many motor vehicles use the lane unlawfully. The Coordinator of Bike, Pedestrian, and TDM Programs for DDOT argues that this problem cannot be pinned on enforcement. Enforcement is futile because of design. In order for the lanes to function as designed, several changes would need to be made, according to the Coordinator:

- The lanes must be a minimum width of 14 feet so that bicyclists and buses can pass each other safely.

- The lanes would need to be located against the curb, removing the adjacent on-street parking.

- They need to be a different color. It would be hard for a vehicle to argue that they didn't know the lane was for special use if it was green or red or blue. Then it becomes obviously special.

- They should be separated from the adjacent lane by a physical barrier.

\section{Safety Considerations}

Safety concerns for bicyclists in the SBBLs were acknowledged by WMATA. ${ }^{15}$ A WMATA bus operator who regularly drives routes on 7th and 9th Streets NW described situations specific to SBBLs which can lead to incidents between buses and cyclists:

\section{Blind Spots and Predictability}

Bus operators have to know where to look when bicyclists are riding nearby. Buses have many blind spots and bicyclists tend to weave when they have the room. Bus operators are trained to stay in their lane. When they are driving on a street with a dedicated bicycle lane, they know to look for bicyclists in the bicycle lane before they move over at a stop. In the case of an SBBL, bicyclists can potentially be anywhere within the lane.

\section{Safe Passing Distance}

WMATA trains bus operators for this type of condition primarily through a manual dedicated to pedestrian and bicycle awareness, safety, and alertness. Specific training on SBBLs may be added to future updates of training manuals. The WMATA bus operator training manual, Street Smart: Pedestrian Awareness \& Operator Alertness, lists common errors of bus operators around cyclists:

- Overtaking with too little clearance, leaving the bicyclist too little room to avoid obstacles without the risk of colliding with the side of the bus

- Turning or merging (toward the bicyclist) before having finished overtaking

- Merging into the path of a bicyclist when pulling out from a bus stop

- Not pulling close to the curb at a bus stop, thereby encouraging bicyclists to overtake between the bus and the curb and in the path of customers alighting from or getting onto the bus (WMATA 2011, 23)

\footnotetext{
15 Kristin Haldeman, Long Range Planner for Washington Metropolitan Area Transit Agency (WMATA) and Ruth Solomon, Curriculum Training Instructor for WMATA, Interview, June 9, 2011.
} 


\section{Conclusions}

Despite police ticketing campaigns, well-signed and marked lanes, and high use of the lanes by buses, the SBBLs are constantly violated by motorists. This decreases multimodal safety and level of service. The function of 7th and 9th Streets NW is currently under reevaluation. A study of Mt. Vernon Square (District of Columbia Office of Planning and DDOT 2010) was initiated to analyze the best circulation design around the Square for buses, bicycles, pedestrians, and a future streetcar, as well as improvements to the use of the Square. Changes have been made to 7 th Street within the last year. Pavement markings were not replaced on three blocks subsequent to a DDOT construction project as part of the circulation and redesign work at Mt. Vernon Square. According to DDOT's Coordinator of Bike, Pedestrian and TDM Programs, the goal was to change the configuration of the roadway along with a number of changes on the Square.

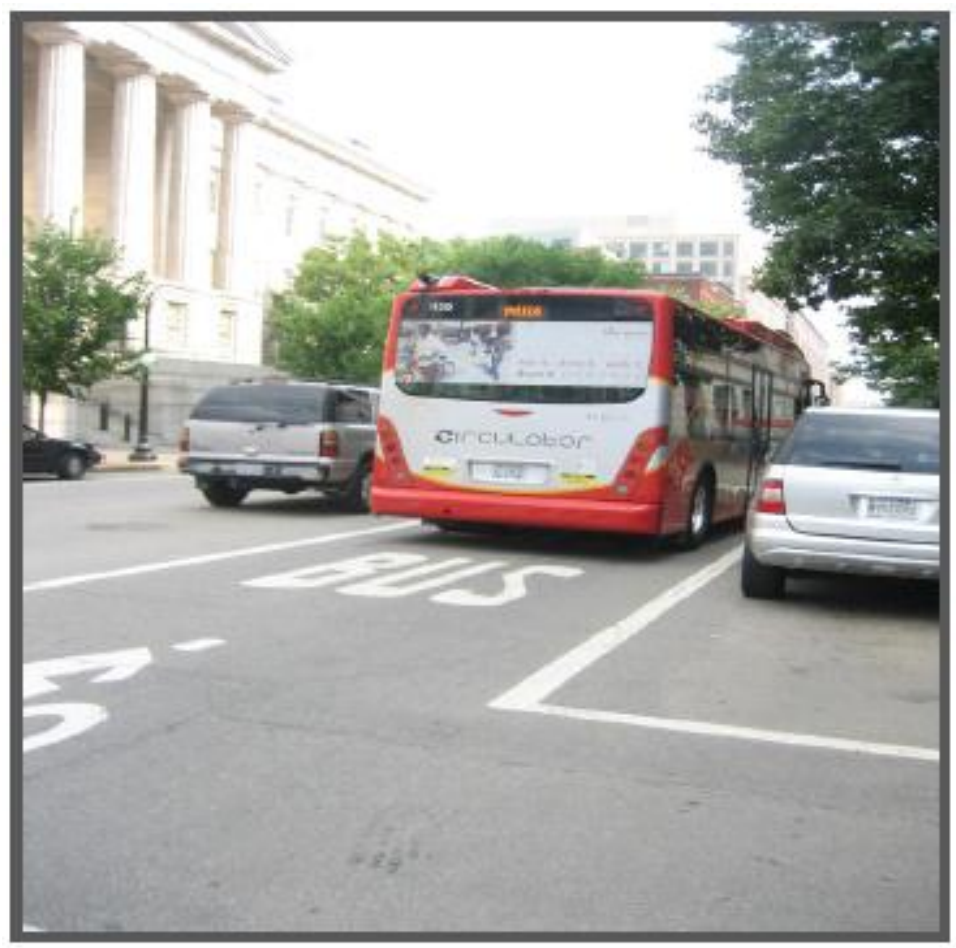

Figure 3.18 - 7th Street NW, Washington, D.C.

Credit: JoAnne Fiebe 


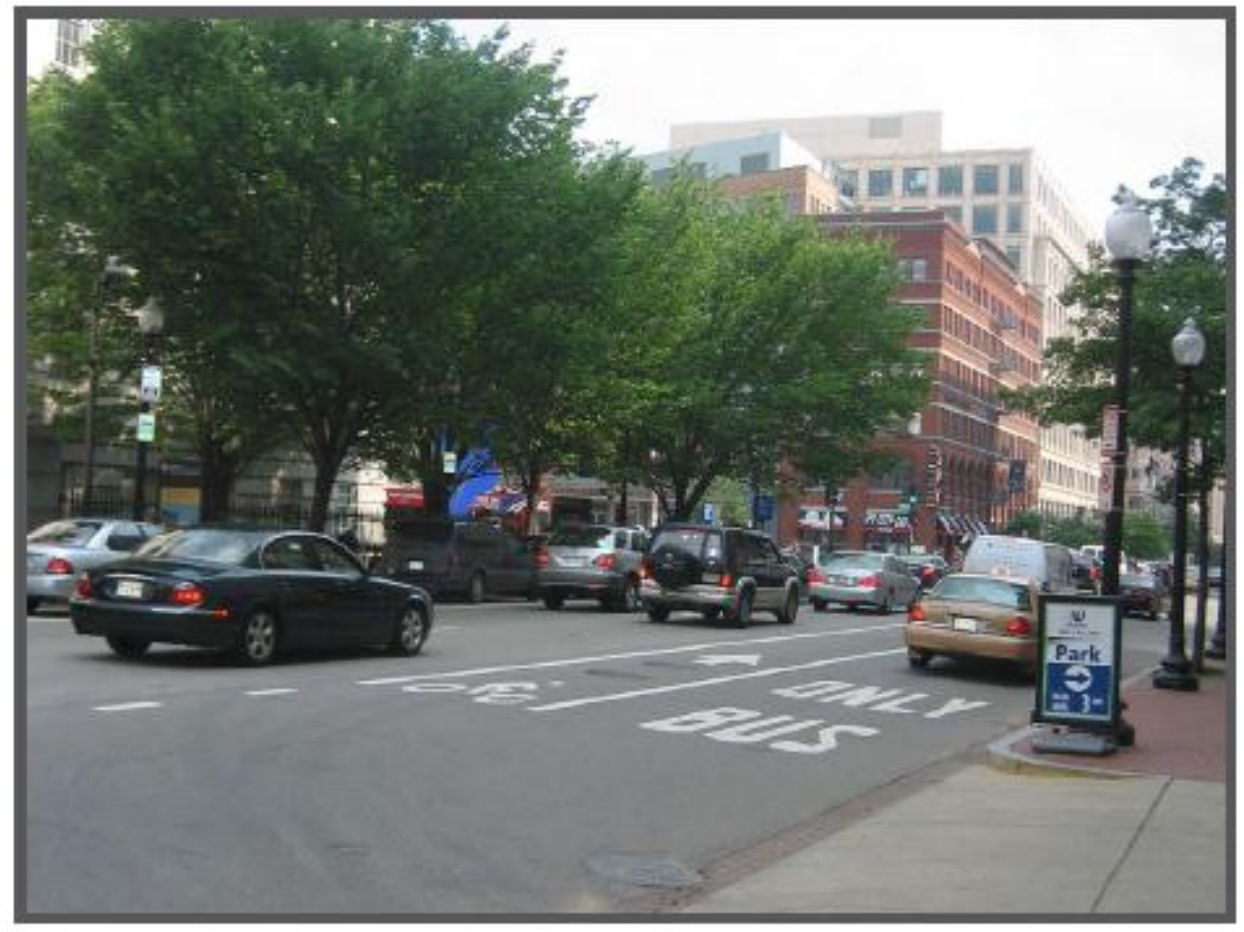

Figure 3.19 - 9th Street NW, Washington, D.C.

Credit: JoAnne Fiebe

\section{Case Study Conclusions}

The four preceding case studies provide illustrations of SBBLs operating under a variety of conditions. The SBBLs along Hennepin Avenue, Minneapolis, MN, Coastal Highway, Ocean City, MD, and Chestnut Street in Philadelphia, PA operate under challenges of constrained right-of-way, high volumes of rightturning vehicles, and high volumes of illegal road users. The Washington, D.C. SBBLs are an example of SBBLs that do not perform well and that may be removed because of a combination of competing demands for use of the roadway, on-street parking, design issues, and unresolved bike/bus conflicts. 


\section{Chapter 4:Planning Considerations and Tools}

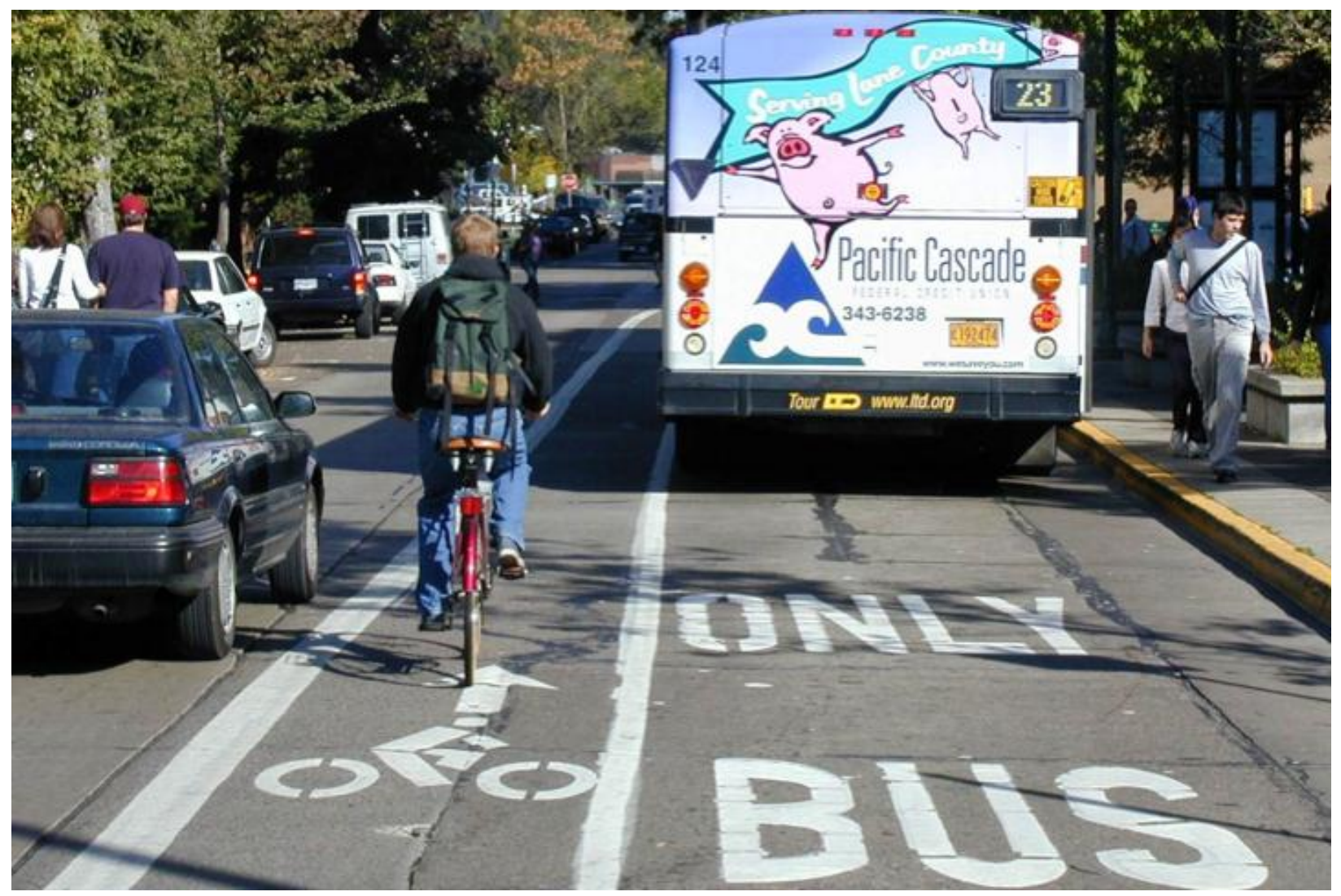

Figure 4.1 - Kincaid Street, Eugene, Oregon.

Transitions to an SBBL

along portions of the street between $11^{\text {th }}$ and $13^{\text {th }}$ Avenues

Credit John Ciccarelli

\section{Background Conditions}

Background conditions are characteristics of the street or corridor that are largely unchangeable or changeable only with great difficulty and/or expense. Where an SBBL is to be retrofitted onto an existing street, these conditions are given. If an SBBL is designed to be part of a new roadway, or part of widening an existing street, then some of these conditions become engineering variables, discussed in the following section. Background conditions include the surrounding land use context, existing access management, width of the right-of-way, frequency of intersections along the corridor, design speed of the 
street, bus volumes, general traffic volumes, bus boarding volumes, bicyclist volumes and aspects of bus vehicles that can affect bicyclists. These are discussed next.

\section{Land Use Context}

The land uses adjacent to and near an SBBL will strongly influence the lane's utility and performance. For example, university campuses may attract large numbers of bus passengers and bicyclists, for whom an SBBL would provide travel priority. Land uses adjacent to an SBBL, which are major destinations within a community, such as employment centers, also may bolster use of an SBBL. On the other hand, higher-speed facilities located outside major activity centers and serving as routes between major destinations also might characteristically serve strip commercial/retail development along the route. These developments are set behind large parking lots and are not part of major destinations in their own right. In this setting, an SBBL might attract fewer local bus patrons, and the resulting higher bus and motor vehicle speeds may be hazardous to bicyclists.

\section{Access Management}

To consider a bus lane, there must be initially at least two lanes provided for traffic in each direction to accommodate one lane for general traffic. The likely locations for bus lanes, where there is the possibility that bicycle use of bus lanes can be safe, are along controlled access facilities. These are non-limited access arterial facilities where access connections, median openings, and traffic signals are highly regulated (Rule 14-94.002, F.A.C.). The State Highway System Access Control Classification System and Access Management Standards in the Florida Administrative Code, and as provided in the FDOT PPM, defines roadway facilities of different access classes and specifies spacing for median openings, signals, and driveway connections for each access class (Chapter 14-97, F.A.C.). Access Classes 2 through 7 are controlled access facilities. The most restrictive is Class 2 and the least restrictive is Class 7 . The abridged table from Rule 14-97.003(1), reproduced below as Table 4.1, provides different standards for different classes based upon facilities that have a posted speed limit of $45 \mathrm{mph}$ and less. Roadway access Classes 5 through 7 might be most appropriate for SBBL facilities, based upon the lower posted speed limits. Class 7 may be best suited, based upon its definition. Access Class 7 roadways are controlled access facilities where adjacent land is generally developed to the maximum feasible intensity (thereby generating more transit patrons) and where roadway widening potential is limited. This classification is assigned only to roadway segments where there is little intent or opportunity to provide high speed travel. These roadways can have either restrictive or non-restrictive medians.

Table 4.1 - Florida Access Management Standards for Controlled Access Facilities

\begin{tabular}{|l|l|l|l|l|l|}
\hline $\begin{array}{c}\text { Access } \\
\text { Class }\end{array}$ & \multicolumn{1}{|c|}{ Median } & \multicolumn{2}{|c|}{$\begin{array}{c}\text { Median Opening spacing } \\
\text { Standard (feet) }\end{array}$} & \multicolumn{1}{|c|}{$\begin{array}{c}\text { Signal Spacing } \\
\text { Standard (feet) }\end{array}$} & $\begin{array}{c}\text { Connection } \\
\text { Spacing Standard } \\
\text { (feet) }\end{array}$ \\
\hline & Full & Directional & & $\begin{array}{l}\text { Posted Speed of } \\
45 \text { mph or less }\end{array}$ \\
\hline 5 & Restrictive & $\begin{array}{l}1,320 \\
(1 / 4 \text { mile) Posted } \\
\text { Speed of } 45 \mathrm{mph} \text { or } \\
\text { Less }\end{array}$ & 660 & $\begin{array}{l}1,320 \\
(1 / 4 \mathrm{mile}) \text { Posted } \\
\text { Speed of } 45 \mathrm{mph} \\
\text { or Less }\end{array}$ & 245 \\
\hline 6 & Non-Restrictive & - & - & $\begin{array}{l}1,320 \\
(1 / 4 \mathrm{mile})\end{array}$ & 245 \\
\hline 7 & Both Median Types & 660 & 330 & $1,320(1 / 4 \mathrm{mile})$ & 125 \\
\hline FDOT 2012b, Table 1.8.2. & & & & \\
\hline
\end{tabular}


Access Class 5 roadways are controlled access facilities where adjacent land has been extensively developed and where the probability of major land use change is not high. These roadways are distinguished by existing or planned restrictive medians. Access Class 6 roadways are controlled access facilities where adjacent land has been extensively developed, and the probability of major land use change is not high. These roadways are distinguished by existing or planned non-restrictive medians or centerlines (Rule 14-97.003(2)(b), F.A.C.).

\section{Width of Right-of-Way}

All of the examples found of SBBLs in the U.S. were retrofitted into an existing right-of-way. The total width available for lanes had been determined by previous planning and construction, and widening the right-of-way was not an option. In most cases, the initial consideration of an SBBL was motivated by the desire to enhance multimodal mobility within a constrained right-of-way. The objective was to reduce the portion of right-of-way used by general motor vehicle traffic, and allocate more lane width to buses and bicyclists, while providing an adequate LOS and safety to each mode. A major question encountered by roadway designers is how to accommodate bicyclists and buses safely within a limited right-of-way. This study has found many examples of SBBLs of varying widths but no research that determines this minimum width.

\section{Frequency of Intersections}

The frequency of intersections along a street affects safety, speed, and convenience for all users of the right-of-way. Intersections may be with other streets, or with driveways and service roads. Frequent intersections provide greater access for travelers and when these intersections are with streets in a traditional grid, they provide more route options and tend to distribute traffic volumes more evenly. A dense grid provides the possibility of placing a bus lane on one street and a bicycle lane on a parallel street one block over. The shorter block lengths associated with a denser grid also provide an easier pedestrian environment, and they may result in shorter distances between bus stops. However, each intersection creates points of conflict between users on a street and those entering or crossing it. This requires more instances of traffic control (signals, signs, and pavement markings). It also can reduce operating speeds for buses and other motor vehicles. Lower intersection density with longer block lengths generally serves mobility over access, and it may result in higher traffic speeds. However, depending on access management and adjacent land development policies, longer block lengths may also contain more driveways and curb cuts, which increase intersection density and reduce speeds.

\section{Design Speed of Street on Which SBBL Will Operate}

The greater the design speed, the greater the potential difference in operating speed between buses, bicycles, and other permitted users of an SBBL, such as right-turning vehicles and taxis. To increase safety, the goals in designing an SBBL should include reducing this difference in speed. Some options exist to reduce operating speeds by small amounts, such as making travel lanes narrower, but their effectiveness is limited by the design speed of the street in which the lanes operate.

The FDOT Plans Preparation Manual (PPM) provides guidance for the design speed for general use lanes on roadways of the State Highway System. For resurfacing, restoration and rehabilitation (RRR) projects, regardless of the original design speed, the minimum design speed for urban facilities on the State Highway System is 30 mph or less if lower design speeds can be justified (FDOT 2012b, 25-16-18 ). In general, for new construction and reconstruction projects, the recommended range for design speeds on non-FIHS/SIS facilities is 40-60 mph for urban arterials, 35-50 mph for urban collectors and 30-40 $\mathrm{mph}$ for projects developed under Transportation Design for Livable Communities (TDLC) (FDOT 2012b, 
Table 1.9.1). Based on these ranges, an SBBL might have to be limited to urban collectors and TDLC facilities, in most cases.

According to the PPM, "Most highway features are based on design speed. Design speed is a principal design control that regulates the selection of many of the project standards and criteria used to design a roadway project" (FDOT 2012b, 25-16.). Considering that SBBLs have not been part of the original design of most roadway facilities, this might limit the number of state roadways that would be considered appropriate for an SBBL.

\section{Bus Volume}

In planning for an SBBL, bus volumes might be considered as an existing background condition. In some cases, the decision whether to establish a bus lane might precede consideration of its use as an SBBL. For the designation of a bus preferential lane, attempts have been made to quantify numerical warrants for various facility types. Decision makers might justify the establishment of a bus lane based upon serving some minimum number of bus passengers transported during the peak hour. Various sources provide bus frequencies on bus lanes ranging from ten to 80 buses per peak hour (OECD Road Research Group 1977; Oldfield, Bly, and Webster 1977; Danaher et al. 2007; Turnbull and Capelle 1998). This gives an idea of the potential bus frequencies and volumes associated with an existing bus lane.

Where an SBBL is to be created on a street where buses now operate in general traffic lanes, then the transit agency might consider increasing the number of routes or frequency of services that use the street, to benefit from the operating conditions improved by the SBBL. The Ottawa design guidelines, summarized previously in Table 1.2, suggest an upper limit on bus volumes. The guidelines recommend that an SBBL not be considered where there are 20 or more buses per hour. High bus volumes do not necessarily preclude the establishment of an SBBL. For example, the Minneapolis Bicycle Facility Design Guidelines suggest considering restricting the times when bicycles may use an SBBL, if peak hour bus volumes create too many potential conflicts (City of Minneapolis 2010a, 259261).

Table 4.2 provides a survey of bus volumes for a sample of SBBL facilities in the U.S. Some survey respondents reported only headways and others reported only bus volumes per hour. Many of the streets are shared by multiple routes. Some of the SBBLs that have been implemented in the U.S. have much higher bus volumes than the Ottawa guidelines in Table 1.2 suggest. These include SBBLs in Minneapolis, Seattle, and Philadelphia.

\section{General Traffic Volume}

Traffic volumes in the general use lanes often are an important consideration of establishing a bus lane as well as separate facilities for bicyclists. Traffic volumes in mixed traffic lanes affect bicyclist perception of safety (Dowling et al. 2008, 82-85).

Gan et al. (2002, 76-81) developed a simulation model, the results of which suggested that in mixed traffic, motor vehicle speeds decrease as bus volume and general traffic volume increases. The model results also suggested that in mixed traffic, bus speed decreases as general traffic volumes increase. Gan et al. demonstrated the use of a CORSIM (CORridor SIMulation) simulation model as a decision tool to evaluate whether a bus lane is justified, based upon its effect on travel time for people traveling in buses as well as in vehicles in general travel lanes. A combination of inputs can be used to compute estimated person travel time under specific sets of conditions, including through vehicle volume, 
right-turn volume and bus volume. Where level of travel delay is the planning criterion of highest priority, the design alternative that provides the lowest computed total average person travel time is considered to be the recommended design alternative. The study also recognized the use of bus lanes for other vehicle types, such as carpools and taxis, and incorporated motor vehicle occupancy rates as model inputs but did not include bicycle volumes as a preferential use type and model input. The study did not evaluate the effects of different designs of preferential lanes, such as SBBLs, on safety but recommended this topic for further research (Gan et al. 2002, 76-81).

Table 4.2 - Bus Volume for a Sample of SBBLs

\begin{tabular}{|c|c|c|c|c|}
\hline City & Street & Peak & Off-peak & Weekend \\
\hline Seattle, WA & Elliot Ave & $\begin{array}{l}\text { 9-23 buses/hr, } \\
\text { depending on } \\
\text { segment of lane }\end{array}$ & $\begin{array}{l}\text { 3-9 buses/hr, } \\
\text { depending on } \\
\text { segment }\end{array}$ & $\begin{array}{l}\text { 3-9 buses/hr, } \\
\text { depending on } \\
\text { segment }\end{array}$ \\
\hline Seattle, WA & Stewart Street & 77 buses/hr & 16 buses/hr & 6 buses/hr \\
\hline Washington, D.C. & 7th/9th Streets NW & $\begin{array}{l}<10-\text { minute } \\
\text { headway }\end{array}$ & Not reported & Not reported \\
\hline Baltimore, MD & $\begin{array}{l}\text { Lombard/Pratt } \\
\text { Streets }\end{array}$ & $\begin{array}{l}\text { 10-minute } \\
\text { headway }\end{array}$ & $\begin{array}{l}\text { 8-minute } \\
\text { headway }\end{array}$ & 10-minute headway \\
\hline Denver, CO & 19th Street & $\begin{array}{l}\text { 3.5-minute } \\
\text { headway }\end{array}$ & none & none \\
\hline Ft. Worth, TX & $\begin{array}{l}\text { Throckmorton/ } \\
\text { Houston Streets }\end{array}$ & medium & low & $\begin{array}{l}\text { very low (reported as } \\
\text { frequency of buses) }\end{array}$ \\
\hline Minneapolis, MN & Hennepin Ave. & 30/lane/hr & $\begin{array}{l}\text { between } 10 \text { and } \\
20 \\
\text { buses/lane/hr }\end{array}$ & 10 buses/lane/hr \\
\hline Ocean City, MD & MD 528 & $\begin{array}{l}\text { 10-40-minute } \\
\text { headway }\end{array}$ & $\begin{array}{l}\text { 20-40-minute } \\
\text { headway }\end{array}$ & $\begin{array}{l}\text { 20-40-minute } \\
\text { headway (varies by } \\
\text { time of year) }\end{array}$ \\
\hline Philadelphia, PA & Chestnut St. & 26 buses/hr & 16 buses/hr & 14 buses/hr \\
\hline
\end{tabular}

The FDOT PPM defines low volume and high volume highways as criteria for some roadway design elements. Table 4.3 includes those highway types that might more likely be considered as a candidate SBBL, according to general traffic volume. Based upon a rough approximation of the number of vehicles per lane per day (vplpd), roads that are considered to be low volume appear to have less than 10,000 vehicles per lane. The roads that are considered to be high volume appear to have more than 10,000 vehicles per lane.

Table 4.3 - General Traffic Volume on Urban Arterial and Collector Roadways

\begin{tabular}{|c|c|c|c|c|}
\hline Highway Type & $\begin{array}{c}\text { Low Volume } \\
\text { AADT }\end{array}$ & Approx. vplpda & $\begin{array}{l}\text { High Volume } \\
\text { AADT }\end{array}$ & Approx. vplpda \\
\hline \multicolumn{5}{|c|}{ Arterials-Urban } \\
\hline 4-lane facility & 37,000 & 9250 per lane & 43,000 & 10,750 per lane \\
\hline 6-lane facility & 55,000 & 9167 per lane & 64,000 & 10,667 per lane \\
\hline 8-lane facility & 69,000 & 8625 per lane & 80,000 & 10,000 per lane \\
\hline \multicolumn{5}{|c|}{ Collectors-Urban } \\
\hline 4-lane facility & 37,000 & 9250 per lane & 45,000 & 11,250 per lane \\
\hline \multicolumn{5}{|c|}{$\begin{array}{l}\text { FDOT } 2012 b, 1-9 . \\
\text { a Rough approximation of the number of vehicles per lane per day, computed by dividing the AADT by the number } \\
\text { of lanes in the facility. }\end{array}$} \\
\hline
\end{tabular}


Relative to general traffic volume, Wilkinson et al. conducted a study resulting in recommended roadway treatments to accommodate bicyclists under certain conditions. Regarding level A bicyclists (advanced skill), for a high volume road (over AADT 10,000) on an urban section with no parking, where the average motor vehicle operating speed is $40 \mathrm{mph}$ or less, a wide curb lane of 14 feet in width was recommended. For speeds over $40 \mathrm{mph}$, a wide curb lane of 15 feet in width was recommended, then a separate six-foot shoulder for speeds over $50 \mathrm{mph}$. Regarding level B/C bicyclists (basic skilled adults and children), under similar roadway conditions, a separate bike lane of five feet in width was recommended where average motor vehicle operating speed is $40 \mathrm{mph}$ or less. For speeds over $40 \mathrm{mph}$, a separate bike lane of 6 feet in width was recommended (Wilkinson et al. 1994, Tables 1 and 4).

If an SBBL were considered to be functionally comparable to a wide curb lane, then according to the Wilkinson study, an SBBL of 15 feet in width might be sufficient for A level bicyclists for motor vehicle operating speeds less than $50 \mathrm{mph}$, but for B/C bicyclists, a separate bike lane of 5 feet in width might be required, even for the lowest motor vehicle operating speed range of $40 \mathrm{mph}$ or less. This might suggest that in the design of an SBBL, bicyclists of basic skill level might not be well served by an SBBL. However, such a facility would also serve only buses and probably right-turning vehicles, representing less AADT than a "high volume" road. Presently, there are tools, such as the model developed by Gan et al. for calculating whether a separate bus lane would result in less average passenger travel time, but no research to suggest general traffic volume thresholds for selecting an SBBL, based upon safety.

The volume of right-turning vehicles at intersections also needs to be considered in the design and placement of an SBBL. If the decision is made to create both an SBBL and a right-turn-only lane, then bus operators and bicyclists will have to contend with right-turning vehicles weaving through the SBBL. If the decision is made to allow general traffic to use the SBBL as a right-turn lane, then right-turning vehicles may reduce the effectiveness of providing preference to buses and bicycles. General traffic also may abuse the SBBL by using it as a general through-lane, as reported in all four of the case studies in Chapter 3. Survey respondents in the Washington and Minneapolis case studies reported that abuse of the SBBLs by general traffic was so frequent that they are considering removing the SBBLs or considering not creating new ones in similar settings. In areas with high pedestrian volumes, the decision to allow any right turns from an SBBL can degrade service when turning vehicles must wait for breaks in pedestrian crossings before completing their turns. Respondents in the Philadelphia case study reported this problem.

\section{Bus Boarding Volume}

The greater the passenger boarding volume at a bus stop, the longer a bus will dwell at the stop and the greater the likelihood that a bicyclist riding in the same lane will overtake a bus that has stopped to board or discharge passengers. This presents greater possibility of conflict between bicycles and buses. Tools are available for planners to estimate bus boarding volume as one consideration in the placement of an SBBL. For example, the Transit Boardings Estimation and Simulation Tool (TBEST) is a travel demand forecasting tool for public transportation. TBEST provides bus stop-level predictive capability with interactive spatial tools to help transit planners define and develop their transit route and stop configuration (Polzin et al. 2011). The impact of passenger boarding volumes also will depend upon the distribution of passenger boardings among bus stops during a particular bus route run, as well as the distribution of passenger boardings during the day. It is possible that boarding volumes may increase if a new SBBL improves transit service. However, increased boarding volumes may offset some of the improvement by increasing boarding times. The relationship between SBBL functional effectiveness and bus boarding volumes by magnitude, time of day, and stop location is not known. 


\section{Bicyclist Volume}

The greater the volume of bicyclists traveling on a roadway, the greater the need to provide safe accommodation for bicyclists. Additionally, it is suspected that the greater the bicycle volumes, the more opportunity for bike/bus interaction and potential conflict in an SBBL. Conversely, the lower the bicycle traffic volumes on an SBBL, the smoother the operation may be. While bicycle traffic volumes were available for the Minneapolis and Philadelphia case studies discussed earlier in this report, bicycle traffic volumes for streets are often unavailable. Such data can be expensive for municipalities to collect. No studies were found that explores the relationship between bicycle traffic volumes or their impact upon bus operation on a shared facility. This is a useful topic for further research. While bicycle facility improvements to the connectivity of a street network have been shown to increase the amount of bicycling (Cleveland and Douma 2008; Birk and Geller 2006), an SBBL that closes a gap in the bicycling network could encourage more bicycling once the SBBL is opened. This may be a motivation for considering an SBBL in the first place.

\section{Noise and Fumes}

Finally, a given condition in the consideration of establishing an SBBL is the aspects of bus vehicles that bicyclists must contend with. Potential conflicts between buses and bicyclists include noise and fumes generated by buses. Buses generally are equipped with engine compartments toward the back end. This makes a bus more difficult to hear if it is approaching a bicyclist from behind, raising the potential for a bicyclist to be startled and risk loss of control. Bicyclists must also contend with loud noise of the bus engine when they follow closely behind a bus. If trailing behind a bus, bicyclists may also breathe more bus exhaust fumes. Ongoing conversion of U.S. bus fleets from diesel fuel to compressed natural gas (CNG) and hybrid electric technology may make this less of a problem over time.

\section{Planning/Engineering Variables and Associated Tools}

Unlike the background conditions discussed above, other changeable conditions or variables can be considered as part of the design and operation of the facility. These include operating speeds, lane width, vehicular movement at intersections and bus stops, vehicular movement between intersections and bus stops, location of bus stops, distance between bus stops, behavior of cyclists, bus operators and other roadway users, parking, minor modifications of the right-of-way, and other considerations.

\section{SBBL Lengths and Associated Function}

The majority of SBBLs do not extend for the entire length of a roadway. Shared facilities may terminate at either end into bicycle lanes, general purpose traffic lanes, other special use lanes, or any combination of these.

\section{SBBL Termini}

An important consideration is the design of the start and the terminus of the SBBL to prevent confusion. For example, signage indicating that the SBBL is beginning and terminating could be placed prior to the intersections that bound the SBBL at both the beginning and end of the facility, to provide the bicyclist with the option to turn off the facility. Signage would be placed far enough in advance that a bicyclist who is new to the route can plan what to do. For example, simply placing a "bike lane ends" sign ten feet from the end of a bicycle lane or SBBL is not sufficient. Safe riding conditions, such as a separate bicycle lane, could continue after the SBBL terminates, or signage 
indicating alternative routes could be provided. Pavement markings and signage could provide clear instructions about where in the roadway the bicyclist should ride after the SBBL terminates. This also serves to remind motorists to continue to share the road with bicyclists. The Hennepin Avenue SBBL begins and terminates with separate bicycle lanes, marked with standard bicycle lane markings. Due to a lack of sufficient right-of-way, a five-block section interrupts the SBBL in Ocean City and is for bicycles only. A large overhead custom sign has been placed to advise the change from SBBL to bicycles only. The Larimer Street SBBL in Denver uses a sign advising "Restricted Lane Ends".

\section{SBBL Length}

Length is determined by local setting, and there is no minimum or maximum length for an SBBL. A survey respondent in Washington, D.C. suggested that one reason that general users ignore the restrictions on the SBBLs along $7^{\text {th }}$ and $9^{\text {th }}$ Streets NW, is because they are very short, making it more difficult to keep general users of the street aware that the SBBLs exist and are different from general purpose lanes. ${ }^{16}$ However, there is too little experience with SBBLs, in too few settings, to confirm or disprove this hypothesis. SBBLs lanes can be grouped into three types of categories based on their length and setting. A survey of SBBLs found in the U.S. suggests that facility length may serve different purposes.

\section{Short Connector Segments}

These are generally shorter than one half mile and frequently are used to connect two nearby facilities or to extend a bicycle lane for the remaining length of road. Several identified examples are located over bridge spans that are likely the result of limited available right-of-way across the bridge.

\author{
Location \\ State Road 865, Ft Myers Beach, FL \\ Milwaukee Avenue, Chicago, IL \\ Larimer Street, Denver, CO \\ 19th Street, Denver, CO \\ Kincaid Street, Eugene, OR \\ Vancouver Ave., Portland, OR \\ SW 5th Avenue, Portland OR \\ $9^{\text {th }}$ Street NW, Washington, D.C
}

\author{
Condition \\ Bridge over waterway \\ Highway overpass \\ Intersection \\ Extension of highway HOV lane into downtown \\ Short segment along university edge \\ Intersection overpass (over Interstate 5) \\ Highway overpass \\ Downtown Circulator route
}

\section{Urban SBBLs}

These examples are found within or connecting to a major downtown area. They are generally shorter than two miles and are terminated at either end by bicycle lanes or shared general traffic lanes. These examples experience large swings in traffic patterns which may be related to commuter traffic and are frequently congested with vehicles and pedestrians.

\section{Location}

Washington Street, Boston, MA

W Lombard, Pratt Streets, Baltimore, MD

Hennepin Avenue, Minneapolis, MN

Chestnut Street, Philadelphia, PA

Throckmorton, Houston Streets, Ft Worth, TX

\section{Condition}

Transit route and connector into downtown

Paired one-way streets

Transit route and connector into downtown

Downtown street

Paired one-way streets

16 Kristin Haldeman, Interview, June 9, 2011. 
7th Street NW, Washington D.C.

Elliot Ave. W/15 Ave. W

Stewart Street, Seattle, WA
Part of Downtown Circulator Loop

Collector between CBD and suburbs

Transit route and connector into downtown

\section{Suburban/Low Density SBBLs}

These instances of SBBL are located in suburban or lower density urban areas and are generally on busy arterial roadways or state highways. They extend for distances over two miles and are on roadways with overall higher speeds than Urban or Short Connector SBBLs.

Location

Broadway, 22nd, Speedway, Tucson, AZ

Coastal Highway 1, Rehoboth Beach, DE

Front Beach Rd, Panama City Beach, FL (proposed)

MD 528, Ocean City, MD

Aurora Avenue N, Shoreline, WA

Mineral Point Road, Madison, WI

\section{Condition}

Suburban arterial road

Highway and connector road for coastal city

Highway and connector road for coastal city

Highway and connector road for coastal city

Suburban arterial road

Suburban arterial road

\section{Operating Speeds}

Although the existing design of the roadway, available right-of-way, and classification of the roadway (functional and access management) will constrain the ability of the designer to change operating speeds on an SBBL, some change in speed can be expected because of changing the configuration of lanes, lane widths, and movement control. For example, if general traffic lanes are narrowed to enable an SBBL, this might tend to reduce traffic speed in those lanes (Schramm and Rakotonirainy 2009). A study was conducted by the City of Portland, in which traffic lanes were narrowed and new bicycle lanes were installed along North Ida Avenue. The study found that prior to the installation of the bike lanes, 41.7 percent of motorists drove below $31 \mathrm{mph}$. After the bike lanes were installed, 49.2 percent of motorists drove below $31 \mathrm{mph}$ (City of Portland Office of Transportation Planning n.d.). In addition, where design, context, and authorization permit, small changes in posted speed may be possible.

\section{SBBL Speed Limits}

Speed limits on roadways with SBBLs range between 25 and $45 \mathrm{mph}$ as shown in Table 4.4. The median speed among the examples surveyed is $30 \mathrm{mph}$ with the mean being $32 \mathrm{mph}$. Table 4.4 has been sorted by speed limit to make it easier to discern the range of speeds. Although the slower speed limits tend to be in denser urban areas, the planned SBBL design for Panama City Beach also proposes a lower speed limit, and some of the lanes with $35 \mathrm{mph}$ limits are not in downtown settings. 
Table 4.4 - Comparative SBBL Roadway Posted Speed Limits

\begin{tabular}{|l|l|c|c|}
\hline \multicolumn{1}{|c|}{ City } & \multicolumn{1}{|c|}{ Street } & $\begin{array}{c}\text { Speed Limit } \\
\text { (mph) }\end{array}$ & Width (feet) \\
\hline Eugene, OR & Kincaid Street & 20 & 15 \\
\hline Philadelphia, PA & Chestnut Street, Philadelphia, PA & 25 & 9 \\
\hline Boston, MA & Washington Street & 30 & 12 \\
\hline Chicago, IL & Milwaukee Avenue & 25 & 13 \\
\hline $\begin{array}{l}\text { Panama City Beach, FL } \\
\text { (proposed) }\end{array}$ & US 98 (Front Beach Road) (proposed) & $\begin{array}{c}25 \\
\text { (proposed) }\end{array}$ & $\begin{array}{c}11 \text { (proposed } \\
\text { bike/tram) }\end{array}$ \\
\hline Ft. Worth, TX & Throckmorton and Houston Streets & $25-30$ & 11 \\
\hline Denver, CO & Larimer Street & 30 & 12 \\
\hline Denver, CO & 19th Street & 30 & $12-18$ \\
\hline Washington, D.C. & 7th St NW, 9th St NW & 30 & $11-18^{\text {a }}$ \\
\hline Baltimore, MD & W Lombard Street and Pratt Street & 30 & $14-16$ \\
\hline Minneapolis, MN & Hennepin Ave & 30 & $13.5-18.5$ \\
\hline Portland, OR & Vancouver Avenue & 30 & $10-15$ \\
\hline Seattle, WA & Stewart Street & 30 & 12 \\
\hline Ft. Myers Beach, FL & State Road 865 (Mantanzas Pass & 35 & 12 \\
\hline Seattle, WA & Bridge) & 35 & $12-13$ \\
\hline Tucson, AZ & Elliot Ave W, 15 Ave W & $35-40$ & 9 - 12 \\
\hline Ocean City, MD & E Broadway Boulevard & $35-40$ & $11-12.5$ \\
\hline Madison, WI & MD 528 & $35-40$ & 13.5 \\
\hline Tucson, AZ & Mineral Point Road & 40 & $10-12$ \\
\hline Portland, OR & E 22nd Street & 40 & n/a \\
\hline Shoreline, WA & NE Glisan Street & & 12 \\
\hline Rehoboth Beach, DE & Aurora Avenue & Coastal Highway 1 & 12 \\
\hline $\begin{array}{l}\text { Source: Compiled List of Cities } \\
\text { a with SBBLs, see Appendix A }\end{array}$ & & \\
\hline Portions of 9th Street NW are separate but adjacent bicycle and bus lanes & 35 & \\
\hline & & 35 & 12 \\
\hline
\end{tabular}

Regarding safety and use of the SBBLs on higher-speed roads, survey respondents in Tucson report that the lanes are safe and do not seem to have had any effect on the number of bicycle crashes. The Maryland State Highway Administration of the Maryland Department of Transportation released summary crash data for MD 528 in Ocean City. However, these data are insufficient to determine whether the design and/or operation of the SBBL along MD 528 were contributing factors in any of these crashes. It would be useful to examine the individual crash reports as well as obtain bicycle traffic count data, if available, for MD 528 as well as for the surrounding street network to gauge exposure relative to other streets.

Similar data are not available for the other SBBLs having posted speed limits greater than $35 \mathrm{mph}$. The SBBL on Coastal Highway 1 in Rehoboth Beach, DE has the highest posted speed limit found among the examples of SBBLs. Correspondence and comments on a bicycle blog indicate that bicycling volumes have declined on Coastal Highway 1 after the SBBL was implemented (Bike Del blog 
2011). There is disagreement about whether this was because of the SBBL or because concurrent improvements for bicycling were made on nearby streets that allow bicyclists to bypass Coastal Highway 1.

\section{Speed Limit Guidance for Related Facilities}

While guidance for speed limits on SBBLs is sparse, several sources provide guidance for posted speed limits for facilities that include bicycle lanes.

- Albuquerque specifies five-foot bike lanes for posted speed limits of $40 \mathrm{mph}$ and over, and allows four-foot bike lanes for posted speeds $35 \mathrm{mph}$ and less (Alta Planning + Design and Gannett Fleming West 2010, Sec. 1.3 and 1.5).

- The AASHTO Guide uses $50 \mathrm{mph}$ and over as the dividing threshold for four- and five-foot lane widths (AASHTO 1999, 23).

- The Ottawa study suggested bus lanes for speeds over $60 \mathrm{~km} / \mathrm{h}(37 \mathrm{mph})$, and bus lanes, SBBLs, or mixed-traffic for speeds of $60 \mathrm{~km} / \mathrm{h}$ or less (Dillon Consulting 2009, 15).

- The Washington State DOT design manual recommends four-foot minimum width shoulders or shared-use paths for posted speed limits greater than $25 \mathrm{mph}$ and greater than 2000 ADT; shared roadway for local streets, collectors or minor arterials with speed or volume below this, and bike lanes or shared-use paths for major arterials in residential areas, school zones or streets in commercial or industrial areas (WSDOT 2010, Chap. 1520, p 3.).

The speed limit has been a consideration for the new "BICYCLES MAY USE FULL LANE" Sign (R4-11) in the MUTCD (FHWA 2009, 9B.06). This new sign is intended to communicate where travel lanes are too narrow for motor vehicles and bicyclists to operate side by side or where there are no bike lanes or shoulders suitable for bicycling. Prior to its adoption, there was concern expressed by reviewers that the sign should only be used on streets of posted speed limit less than $40 \mathrm{mph}$. However, the MUTCD ultimately did not specify a maximum speed limit for its use.

Speed has also been a consideration in the use of Shared Lane Markings. The purpose of the new Shared Lane Marking (FHWA 2009, 9C.07) often referred to as a "sharrow," is to reduce the number and severity of bicycle/motor vehicle crashes, particularly with opened doors of parked motor vehicles. The pavement marking indicates the appropriate bicyclist line of travel and cues motorists to pass with sufficient clearance. The MUTCD provides guidance that a Shared Lane Marking should not be used on a roadway with a posted speed limit greater than $35 \mathrm{mph}$, which reflects a concern for safety when bicyclists share lanes with faster-moving vehicles. Because it is common practice to allow SBBL use by right-turning general traffic, the 35-mph maximum speed for lanes with sharrows probably also should be regarded as a maximum speed for SBBLs. This guidance could be revised if justified by rigorous evaluation of the few SBBLs that operate at higher speeds.

In the U.K., speed on bus lanes also is regulated. With the exception of a few guided bus ways, bicyclists are allowed to use bus lanes in the U.K. unless otherwise signed. In residential areas, the default speed limit for buses is $30 \mathrm{mph}$, but with growing debate to create $20 \mathrm{mph}$ zones. In central London, average operating speed is much lower than $30 \mathrm{mph} .{ }^{17}$ Elsewhere in the U.K., the speed limit on most urban bus lanes is $30 \mathrm{mph}$, and sometimes $40 \mathrm{mph} .{ }^{18}$

The Florida Statutes provides standards for maximum speed limits for state, county and municipal roadways, as provided in Table 4.5 (Section 316.183(2), F.S., and Section 316.189(1), F.S.).

17 Iain Macbeth, Email communication, November 22, 2011.

18 Adrian Lord, Associate, Ove Arup \& Partners, Ltd., U.K., Email communication, November 22, 2011. 
Table 4.5 - Florida Statutes Standards for Maximum Speed Limits

\begin{tabular}{|c|c|c|}
\hline & $\begin{array}{l}\text { Business Districts and } \\
\text { Residential Districts }\end{array}$ & All Other Locations \\
\hline State roads & $30^{a}$ & 55 \\
\hline County roads & $30^{b}$ & 55 \\
\hline Municipal roads & $30^{c}$ & - \\
\hline \multicolumn{3}{|c|}{$\begin{array}{l}\text { a. With respect to state roads within a residential district in a county or municipality, the county or municipality can } \\
\text { set a } 20 \text { or } 25 \text { mph speed limit on these facilities after an investigation confirms the appropriateness of the speed } \\
\text { limit. } \\
\text { b. The Board of County Commissioners can set other speed limits after a study confirms the appropriateness of the } \\
\text { speed limit and that it conforms to FDOT criteria. } \\
\text { c. A different maximum speed limit can be set by a municipality after a study confirms the appropriateness of the } \\
\text { speed limit and that it conforms to FDOT criteria. }\end{array}$} \\
\hline
\end{tabular}

\section{Techniques to Reduce Speed}

Regarding techniques to consider for reducing speed on Transportation Design for Livable Communities (TDLC) projects on urban roadways of the State Highway System, lowering posted speed limits and providing speed humps/tables are both considered not appropriate. However, two techniques that are considered appropriate for evaluation relative to the context of the particular project include onstreet parking as a buffer for pedestrians and curb bulb-outs at ends of blocks (FDOT 2012b, Exhibit 21-B, 21-15). However, these two techniques likely would not be appropriate options for an SBBL, as on-street parking complicates the function of an SBBL by increasing the potential for conflict with bicycles and buses as motorists enter and leave parking spaces.

Regarding techniques to consider for encouraging multimodal travel on TDLC projects for urban roadways of the State Highway System, lowering speed limits again is considered not appropriate. However, bike lanes/paved shoulders, bicycle-friendly design, and bike parking are identified as appropriate techniques. Implementation of exclusive transit lanes is identified as a technique that may be appropriate and that must be evaluated relative to the context of the particular project (FDOT 2012b, Exhibit 21-B, 21-16). SBBLs are not identified as a potential technique to encourage multimodal travel in TDLC projects.

\section{Summary of Speeds}

Generally, an SBBL will be considered for implementation after a street or highway has been developed, when the functional class, access management class, and the design speed for the roadway are already fixed.

There is little formal guidance regarding appropriate speeds for SBBLs. Although the information collected for the SBBLs on higher-speed streets is incomplete, the limited information that is available does not indicate that designating the SBBLs on these streets has had increased or decreased bicycle crashes. Based on numerous sources, including the current guidance for Shared Lane Markings, the U.K. experience on SBBL speeds, and the maximum speed limit for state roads in business and residential districts, SBBLs appear to be reasonable options for streets with speeds of $30 \mathrm{mph}$ or less, if other conditions allow safe use of such lanes. If bus and other vehicle speeds are higher, then other design elements of the SBBL, such as lane width, would have to be considered with a greater emphasis on ensuring safety. Because the implementation of SBBLs is partly motivated by managing a limited right-of-way, there may be fewer opportunities to establish SBBLs on streets with favorable speed 
conditions. Researchers found no research to date measuring the relationships among crash rates, crash severity and SBBL speeds.

The information collected on existing SBBLs did not include any cases in which the maximum allowed speed for buses in the SBBL is lower than what is allowed in the adjacent general purpose lanes. When asked, several respondents surveyed for this study noted that buses in their SBBLs often operate below the posted speed limits. Reasons included frequent bus stops, but also right-turning traffic in the SBBL having to yield to heavy pedestrian volumes, use of the SBBL by unauthorized vehicles, such as roller bladers and joggers, and general violation of the SBBL by cars during special events.

\section{SBBL Lane Width}

\section{Lane Widths of Existing SBBLs}

This study found existing bike and bus lane facilities that might be categorized, for discussion purposes, into three types, based on widths. These three types include narrow width SBBLs, wide width SBBLs, and separate and adjacent bike and bus lanes. Table 4.6 summarizes examples by type and sorts them from narrow to wide widths to make it easier to perceive the range and frequency of different SBBL widths.

Table 4.6 - Example Cities by SBBL Type and Width

\begin{tabular}{|c|c|c|c|c|}
\hline City & Street & Width (feet) & Type & $\begin{array}{c}\text { Speed } \\
\text { Limit } \\
(\mathrm{mph})\end{array}$ \\
\hline $\begin{array}{l}\text { Philadelphia, } \\
\text { PA }\end{array}$ & Chestnut Street & 9 & Narrow SBBL & 25 \\
\hline Tucson, AZ & $\begin{array}{l}\text { Broadway } \\
\text { Boulevard }\end{array}$ & $9-12$ & Narrow SBBL & $35-40$ \\
\hline Tucson, AZ & E 22nd Street & $10-12$ & Narrow SBBL & 40 \\
\hline Portland, OR & Vancouver Avenue & $10-15$ & Narrow SBBL & 30 \\
\hline $\begin{array}{l}\text { Washington, } \\
\text { D.C. }\end{array}$ & $\begin{array}{l}\text { 7th Street NW, } \\
\text { 9th Street NW }\end{array}$ & 11 & Narrow SBBL & 30 \\
\hline Ft. Worth, TX & $\begin{array}{l}\text { Throckmorton, } \\
\text { Houston Streets }\end{array}$ & 11 & Narrow SBBL & $25-30$ \\
\hline $\begin{array}{l}\text { Panama City } \\
\text { Beach, FL }\end{array}$ & $\begin{array}{l}\text { US } 98 \text { (Front } \\
\text { Beach Road) } \\
\text { (proposed) }\end{array}$ & $\begin{array}{c}11 \text { (proposed } \\
\text { bike/tram) }\end{array}$ & $\begin{array}{l}\text { Narrow } \\
\text { bike/tram lanes }\end{array}$ & 25 \\
\hline Ocean City, MD & MD 528 & $11-12.5$ & Narrow SBBL & $35-40$ \\
\hline Tucson, AZ & E Speedway Blvd. & 12 & Narrow SBBL & $\mathrm{n} / \mathrm{a}$ \\
\hline Tucson, AZ & $\begin{array}{l}\text { E Tanque Verde } \\
\text { Road }\end{array}$ & 12 & Narrow SBBL & $\mathrm{n} / \mathrm{a}$ \\
\hline Shoreline, WA & Aurora Avenue & 12 & Narrow SBBL & $40-45$ \\
\hline Denver, CO & Larimer Street & 12 & Narrow SBBL & 30 \\
\hline $\begin{array}{l}\text { Rehoboth } \\
\text { Beach, DE }\end{array}$ & Coastal Highway 1 & 12 & Narrow SBBL & 45 \\
\hline $\begin{array}{l}\text { Ft. Myers } \\
\text { Beach, FL }\end{array}$ & State Road 865 & 12 & Narrow SBBL & 35 \\
\hline Boston, MA & Washington Street & 12 & Narrow SBBL & 30 \\
\hline Seattle, WA & Stewart Street & 12 & Narrow SBBL & 30 \\
\hline
\end{tabular}




\begin{tabular}{|l|l|l|l|c|}
\hline \multicolumn{1}{|c|}{ City } & \multicolumn{1}{|c|}{ Street } & Width (feet) & \multicolumn{1}{c|}{ Type } & $\begin{array}{c}\text { Speed } \\
\text { Limit } \\
\text { (mph) }\end{array}$ \\
\hline Seattle, WA & Elliot/15th Avenue & $12-13$ & Narrow SBBL & 35 \\
\hline Denver, CO & 19th Street & $12-18$ & Wide SBBL & 30 \\
\hline Chicago, IL & $\begin{array}{l}\text { N Milwaukee } \\
\text { Avenue }\end{array}$ & 13 & Narrow SBBL & 25 \\
\hline Madison, WI & Mineral Point Road & 13.5 & Narrow SBBL & $35-40$ \\
\hline $\begin{array}{l}\text { Minneapolis, } \\
\text { MN }\end{array}$ & Hennepin Avenue & $13.5-18.5$ & Wide SBBL & 30 \\
\hline Baltimore, MD & $\begin{array}{l}\text { W Lombard, Pratt } \\
\text { Streets }\end{array}$ & $\begin{array}{c}14-16 \\
\text { Kincaid Street }\end{array}$ & $\begin{array}{l}15 \\
\text { Wide SBBL }\end{array}$ & 30 \\
\hline Eugene, OR & Kincaid Street & $\begin{array}{l}\text { Wide SBBL } \\
\text { Eugene, OR }\end{array}$ & $\begin{array}{l}\text { Separate and } \\
\text { adjacent bike } \\
\text { and bus lane }\end{array}$ & $\mathrm{n} / \mathrm{a}$ \\
\hline $\begin{array}{l}\text { Washington, } \\
\text { D.C. }\end{array}$ & (portions) & $\begin{array}{l}\text { Separate and } \\
\text { adjacent bike } \\
\text { and bus lane }\end{array}$ & 30 \\
\hline $\begin{array}{l}\text { Minneapolis, } \\
\text { MN }\end{array}$ & Marquette Avenue & $\begin{array}{l}20 \\
(6 \text { bike } / 14 \text { bus })\end{array}$ & $\begin{array}{l}\text { Separate and } \\
\text { adjacent bike } \\
\text { and bus lane }\end{array}$ & 30 \\
\hline Madison, WI & University Avenue & $\begin{array}{l}\text { Separate and } \\
\text { adjacent bike } \\
\text { and bus lane }\end{array}$ & 25 \\
\hline
\end{tabular}

\section{Shared Bike/Bus Lane-Narrow Width Lane}

This type is a lane located adjacent to the curb and is also known as the curb or outside through lane. The lane is shared by both buses and bicycles, and is 13 feet wide or less. This SBBL type does not provide enough width for a bus to pass a bicyclist while staying within the lane, even in the U.K. which does not prescribe a minimum distance for passing, according to the Reid and Guthrie research from the U.K. Thirteen feet is also less than the 14-foot curb lane that is recommended by AASHTO for shared use by motorists and bicyclists and which Florida considers adequate for such shared use (AASHTO 1999, 17). The bus or the bicycle must enter the adjacent general purpose lane to the left in order to pass.

\section{Shared Bike/Bus Lane-Wide Width Lane}

This is similar to the narrow width lane except it describes facilities that do provide enough space for bicyclists and buses to pass each other while staying within the lane. The four examples of wide width lanes in Table 4.6 are 19th Street, Denver, CO, Hennepin Avenue, Minneapolis, MN, and Lombard and Pratt Streets, Baltimore, MD. These facilities have varying widths along the facilities but are at least 16 feet at their widest. All four of these facilities have posted speed limit of $30 \mathrm{mph}$.

\section{Separate and Adjacent Bicycle and Bus Lanes}

Separate and adjacent bicycle and bus lanes do not share the same space but instead allow each mode to operate in exclusive adjacent lanes. Identified examples of separate but adjacent lanes include some instances where the bicycle lane is to the left of the bus lane, and others where it is to the right. This facility type is included in this report because it was observed by one consultant 
who responded to the survey that where the bicycle lane is to the left of the bus lane, bicyclists often will ride in the bus portion of the parallel lanes, unless there is a bus present. This gives the bicyclists more separation from the general purpose vehicle lanes. The consultant noted that, in effect, the adjacent bicycle lane functions as a bus-passing lane. ${ }^{19}$

\section{SBBL Width Needed for Passing within the Lane}

The available width for the SBBL will determine whether buses will be able to pass a bicyclist while remaining within the SBBL. Staying in the lane to pass is not a necessary condition for an SBBL to operate in some settings. However, if this condition is important to maintain safety in a particular context, then Figure 4.2 illustrates the necessary width for an SBBL to allow passing within the lane.

This necessary width is estimated to be 16 feet, seven inches, where all the following conditions exist.

- Curb and gutter

- Posted speed limit $30 \mathrm{mph}$ or less, operating speed of buses is $30 \mathrm{mph}$ or less

- Lateral clearance of at least three feet between a bicyclist and a passing motor vehicle (required by state law in Florida and 19 other states (Bisbee 2012)

- Sufficient width for a public transit bus of standard width (eight feet, six inches) to pass a bicyclist while staying within the SBBL

This width includes a three feet, four inches of width of bicyclist operating space, per AASHTO guidelines $(1999,5)$, measured from the longitudinal joint of the gutter pan. Another three feet measured from the edge of the bicyclist operating space to the bus body is added per requirements of Florida State law (Section 316.083, F.S.). An additional eight feet, six inches represents the width of a standard public transit bus (TTI 1996, 37). ${ }^{20}$ An additional width of one foot, nine inches is added, measured from the left edge of the bus to the middle of the eight-inch-wide solid white stripe that separates the SBBL from the adjacent general traffic lane. This additional width was computed by positioning the bus in the center of 12 feet of operating space-the recommended width of a lane for public transit buses (Sando and Moses 2010, 44). These four widths, labeled in Figure 4.2, as A + B + $\mathrm{C}+\mathrm{D}$, added together, total 16 feet, seven inches.

\footnotetext{
19 Charlie Denny, Alta Planning + Design, Phone interview, July 21, 2011.

${ }^{20}$ At the present time, the bus passenger side mirrors can be below the height of the bicyclist. However, the bus width of interest in this calculation of needed lane width is $8^{\prime}-6^{\prime \prime}$ and not $10^{\prime}-2^{\prime \prime}$ (with protruding mirrors) because from the standpoint of safety and comfort of the bicyclist, the mass of the bus matters more. The passenger side mirror can protrude as far as 10". However, if the required lateral separation of $3^{\prime}$ between the side of the bus and the bicyclist is met, then the mirrors will not conflict. Mirror height on public transit buses is generally higher on the passenger side. Heights of mirrors vary greatly because they are adjustable by the bus operator. In many newer models of buses, mirrors are mounted higher and are smaller in size.
} 


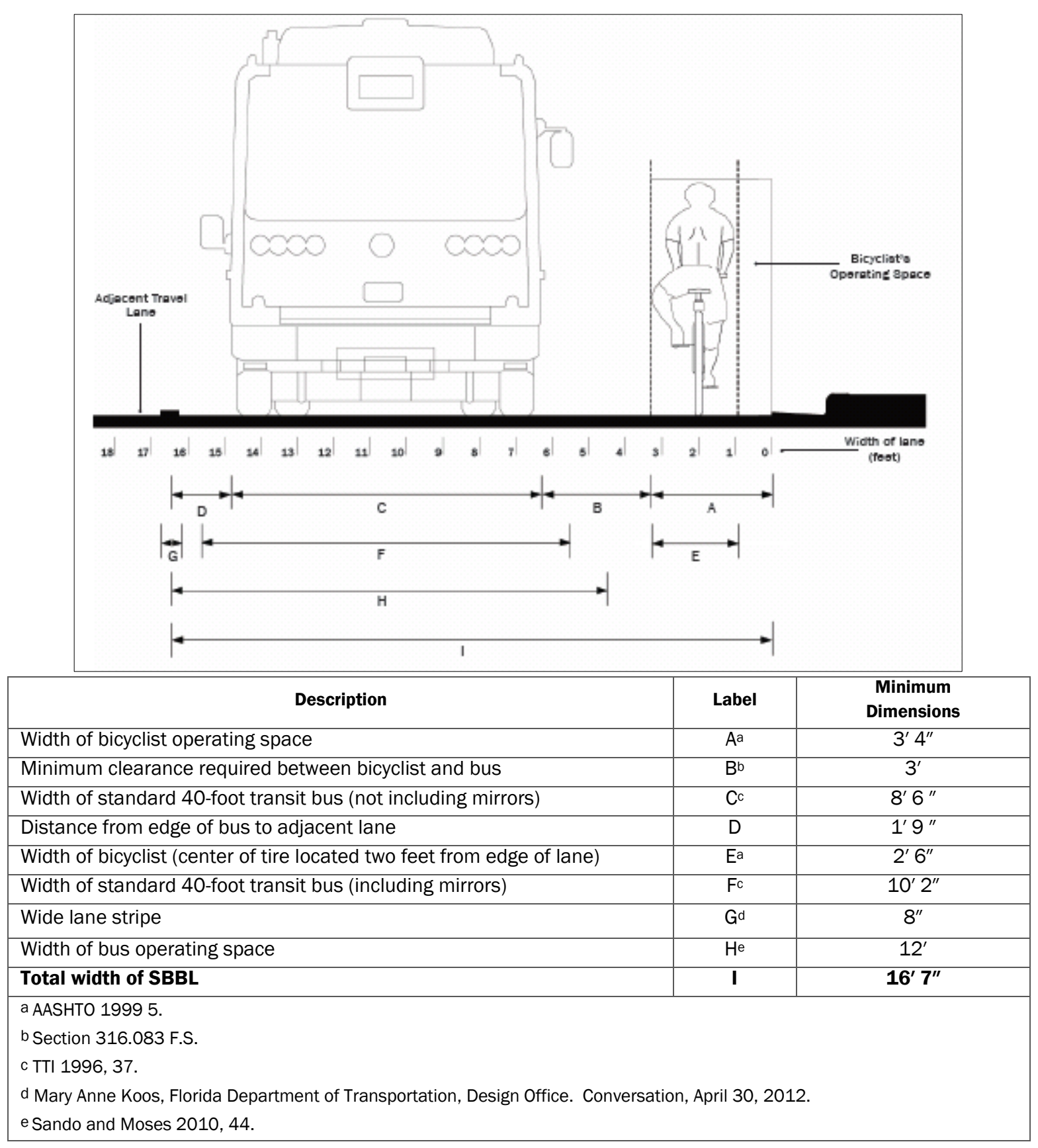

Figure 4.2 - Dimensions to accommodate passing within shared bike/bus lanes

\section{General Guidance on Lane Widths}

As with speeds, there is very little in the way of standards for lane widths of SBBLs. There are no standards or guidelines for SBBLs presently from the following sources.

- $\quad$ AASHTO Guide for the Development of Bicycle Facilities

- FHWA MUTCD

- FDOT Design Standards 
- FDOT Plans Preparation Manual (PPM)

- American Public Transportation Association

- Institute of Transportation Engineers

A publication of the Institute of Transportation Engineers (ITE), Innovative Bicycle Treatments, identified SBBLs as a design option and provided some discussion with regard to SBBL width. The objective of an SBBL is described by the ITE publication, "To provide a dedicated lane for bikes and buses in areas where it is not feasible to include both." The ITE publication describes the application of an SBBL "For use in bus corridors where there is not enough street width to provide separate bike and bus lanes or where bus counts are not high enough to justify separate lanes (Nabti and Ridgway, 2002, 17). While the AASHTO Guide is referenced for recommending a fivefoot bike lane, no lane widths are given for bus lanes. If one were to assume that the bus lane width is 12 feet, then the sum of 17 feet is the minimum value for sufficient width necessary for providing separate bicycle and bus lanes.

The ITE publication also provides some description that suggests design features of an SBBL, including a criterion for determining SBBL width. "The right-lane is stenciled as a diamond lane, with supporting signage and pavement legends that designate the lane for buses and bicycles only. In some locations the lane is painted or paved with colored asphalt to emphasize the lane designation. The lane should be wide enough to allow cyclists to pass a stopped bus" (Nabti and Ridgway 2002, 17). A value for the width of a lane that is wide enough for passing within the lane is not provided. The authors of the ITE publication found no evaluation studies of SBBLs.

Some municipalities provide SBBL guidelines (listed in Chapter 2, Table 2.1) that recommend minimum widths ranging between ten and 18 feet.

A study on the influence of lane width upon bus safety was conducted by researchers from the University of North Florida (UNF) and the Florida Agricultural and Mechanical University (FAMU)Florida State University (FSU) College of Engineering. This study is hereinafter referred to as the UNF study. A physical constraints analysis conducted as part of the UNF study found that where bicycles and buses operate in the same area of the street and are to pass each other within the lane, the outside lane width should be 17 feet, as measured from the face of the curb to the center of the stripe separating the shared lane from the adjacent general lane. For streets without curb and gutter, the UNF study recommends that the outside lane should be 16 feet in width, as measured from edge of pavement to the center of the stripe separating the shared lane from the adjacent general lane (Sando and Moses 2010, 37-42). These findings were based upon use of AASHTO's assumptions about the width of a bicyclist, 8.5 feet for the width of a bus, and the three feet of lateral separation required by state law between the bus and bicyclist. These findings are also based upon the assumption of allowing the bus mirrors to encroach into the three feet of clearance that state law requires when passing a bicyclist on the street. The study recommended that bus routes use widerlane major roadways at the perimeter of neighborhoods as a means to ensure safety (Sando and Moses 2010, Figures 8.3a and 8.3b).

\section{International Guidance on SBBL Widths}

The United Kingdom's Department for Transport (DfT) Cycle Infrastructure Design Guide (LTN 2/08) recommends a minimum clearance of $1.0 \mathrm{~m}$ (3.3 ft) between the cyclist's dynamic envelope (bicyclist

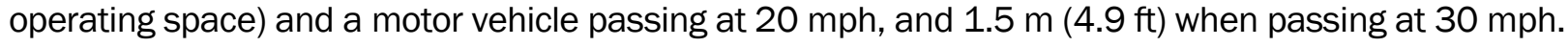

This clearance...added to the cyclist's dynamic envelope and the width of the motor vehicle, can be used to give ideal minimum widths for motor vehicles to pass cycles. 
These figures simply indicate ideal physical minimum width for motor vehicles to pass cyclists and do not necessarily form lane widths" (Cardiff Cycle Network 2011, 18).

Based upon these clearances from the Cycle Infrastructure Design Guide, the Cardiff Cycle Design

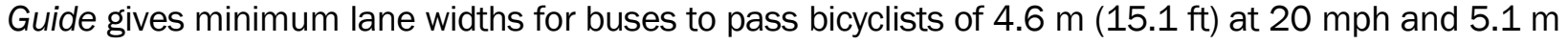
(16.7 ft) at $30 \mathrm{mph}$ (Cardiff Cycle Network 2011, 17-18). The Cardiff Guide treats $4.6 \mathrm{~m}$ as an ideal width. However, $4 \mathrm{~m}(13.1 \mathrm{ft})$ is the preferred minimum width where bus lanes (which bicyclists may use unless posted otherwise) may exist only in areas with limited right-of-way. Where necessary because of heavy bus volumes, upward slopes, or heavy bicycle traffic, the Guide recommends considering striping an advisory 1.5-m (4.9-ft) bicycle lane within the bus lane.

Research by the United Kingdom's Transport Research Laboratory recommended that lanes to be shared by bicycles and buses should be at least $4 \mathrm{~m}(13.1 \mathrm{ft})$ wide for bus speeds of $30 \mathrm{mph}$, and probably even wider for higher speeds (Reid and Guthrie 2004, 21).

\section{Florida and U.S. Guidance on Widths for Related Facilities}

\section{FDOT Plans Preparation Manual-General Use Lanes}

The FDOT PPM, Volume 1 sets forth geometric and other design criteria of the Florida Department of Transportation (FDOT) that represents requirements for the State Highway System. The PPM states that standard practice is to provide through lane widths as wide as practical, up to 12 feet. The width of through lanes on urban arterials is given as 12 feet; however, an 11-foot width is permitted if the right-of-way and existing conditions are found to be stringent controls, or if the facility operates on interrupted flow conditions, if the design speed is $40 \mathrm{mph}$ or less, or if truck volume is ten percent or less. Lane width for an urban collector is given as 11 feet (FDOT 2012b, Table 2.1.1).

As a Resurfacing, Restoration, and Rehabilitation (RRR) project for an urban multilane facility with curb and gutter, minimum through lane widths are ten feet, or 11 feet when trucks are greater than ten percent of Design Year Traffic or if the design speed is $40 \mathrm{mph}$ or greater (FDOT 2012b, Table 25.4.5.3). The PPM also states that "For existing sections that are currently without bicycle facilities and where no widening is planned, consideration shall be given to reducing lane widths to provide bicycle lanes, wide outside lanes or paved shoulders"(FDOT 2012b, 25-42). These new bicycle facilities must meet the criteria of PPM Chapter 8 , which are discussed below.

\section{FDOT Plans Preparation Manual-Bike Lanes}

In or within one mile of an urban area, bicycle lanes are to be provided for all new construction and reconstruction projects. For resurfacing, restoration, and rehabilitation projects, a bicycle lane or a wide curb lane may be appropriate (FDOT 2012b, Table 8.1.1). On urban arterials and urban collectors, bicycle lane widths are to be four feet, measured from the lip of the gutter, where there is curb and gutter, unless the bike lane is adjacent to guard rail or other barrier, a right turn lane or a bus bay (known as "keyhole" locations where there is potential for conflict between bicycles and turning vehicles), in which case the bike lane width should be five feet (FDOT 2012b, 8.4.2.1). Additionally, in new construction or reconstruction or traffic operations projects, where the five-foot bike lane is adjacent to on-street parking with high turnover (high not defined in the PPM), then an additional one to two feet should be added to the bike lane if right-of-way is adequate (adequate not defined in the PPM) (FDOT 2012b, Table 8.4.2.1). An SBBL marked with an advisory cycle lane might be considered to have keyhole locations where the bus moves to the right to stop. Illustrated later in 
Figure 4.6, an advisory cycle lane, as used in the U.K., is a bicycle lane marked by dashed lines in which other vehicles should not enter unless safe to do so.

Table 4.7 provides minimum lane widths for projects that qualify as TDLC. Bicycle lane widths are a minimum of four feet or a minimum of five feet where the bike lane is adjacent to on-street parking. Through lane widths are a minimum of 11 feet.21

Table 4.7 - Minimum Lane Widths for Transportation Design for Livable Communities Projects (Florida)

\begin{tabular}{|l|l|}
\hline Lane Types & Width \\
\hline Through Lanes & $\begin{array}{l}11 \text { feet; may be reduced to } 10^{\prime} \text { ' in highly restricted areas with design speeds } \\
\text { less than or equal to } 35 \mathrm{mph} \text { and having little or no truck traffic }\end{array}$ \\
\hline Turning Lanes & $\begin{array}{l}11 \text { feet; may be reduced to } 10^{\prime} \text { in highly restricted areas with design speeds } \\
\text { less than or equal to } 35 \mathrm{mph} \text { and having little or no truck traffic }\end{array}$ \\
\hline Parking Lanes (parallel) & $\begin{array}{l}\text { Eight feet; may be reduced to seven feet (measured from face of curb) in } \\
\text { residential areas }\end{array}$ \\
\hline Bicycle Lanes & Four feet; five feet adjacent to on-street parking \\
\hline Source: FDOT 2012b, Table 21.1. \\
\hline
\end{tabular}

\section{AASHTO-Wide Curb Lanes}

It is useful to examine guidance provided for general use lanes and bicycle lanes because these may provide a starting point for considering the minimum width for an SBBL. Although the 1999 AASHTO Guide for the Development of Bicycle Facilities does not address SBBLs, it does identify lane width as the most critical variable for bicycles and motor vehicles to share the roadway without compromising the level of service and safety for either $(1999,16)$. "On highway sections without designated bikeways, an outside or curb lane wider than $3.6 \mathrm{~m}$ (12 feet) can better accommodate both bicycles and motor vehicles in the same lane and thus is beneficial to both bicyclists and motorists. In many cases where there is a wide curb lane, motorists will not need to change lanes to pass a bicyclist" $(1999,17)$. Figure 4.3 illustrates an example of a wide curb lane.

${ }^{21}$ For more information on TDLC design, please refer to the FDOT PPM, Volume 1, Chapter 21. 


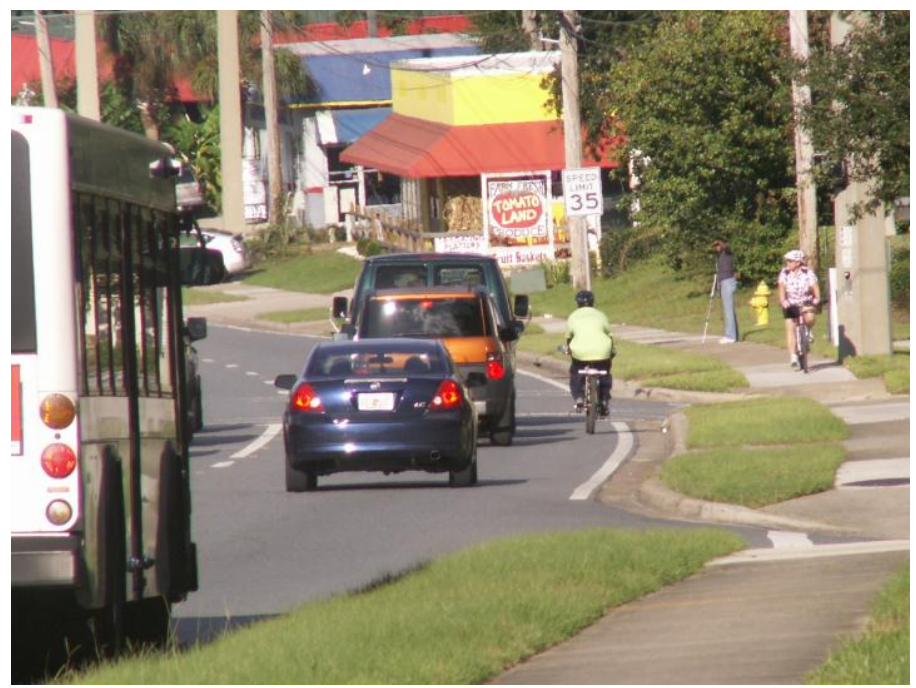

Figure 4.3 - Wide curb lane, SR 61/Thomasville Road, Tallahassee, FL

The Guide further states that, "In general, $4.2 \mathrm{~m}$ (14 feet) of usable lane width is the recommended width for shared use in a wide curb lane. Usable width normally would be from edge stripe to lane stripe or from the longitudinal joint of the gutter pan to lane stripe...widths greater than $4.2 \mathrm{~m}$ (14 feet) that extend continuously along a stretch of roadway may encourage the undesirable operation of two motor vehicles in one lane, especially in urban areas, and therefore are not recommended. In situations where more than $4.5 \mathrm{~m}$ (15 feet) of pavement width exists, consideration should be given to striping bike lanes or shoulders" $(1999,17)$. The Guide provides no references to modeling of the relationships among design variables.

In Florida, wide curb lanes can be used, in some conditions, such as RRR projects to provide facilities for bicyclists. Wide curb lanes provide a minimum of 14 feet in width that allows most motor vehicles to pass bicyclists while staying in the lane (FDOT 2012b, 8.20).

\section{USDOT/FHWA-Lane Width and Wind Draft of Heavy Motor Vehicles}

Because buses are very large vehicles, bicyclists in close proximity to buses may have to contend with loss of stability if caught in the draft of a passing bus. Figure 4.4 below illustrates how the force of the wind of a passing bus on a bicyclist depends upon bus speed and the distance between the bus and bicyclist. Where buses operate at speeds of $40 \mathrm{mph}$ or less, a three-foot separation should provide adequate protection; where buses operate between 40 and $50 \mathrm{mph}$, a four-foot separation is required (FHWA 1997, Figure B.1).

\section{NACTO-Shared Bike Lane/Right Turn Lane}

The NACTO Urban Bikeway Design Guide provides information on an experimental combined bike lane/right turn lane. In this case, a four-foot bicycle lane is marked by dashed lines within and on the left side of the right turn lane (2011, 181-190). FHWA considers this lane design experimental if the lane is marked with bicycle symbols, but allowable if the lane is marked with Shared Lane Markings.

\section{FDOT Accessing Transit-Bus Lane}

FDOT's publication, Accessing Transit, provides widths for designing bus facilities, originally listed in TTI (1996 37). These include eight feet, six inches for a 40-foot bus without allowance for mirrors, and 
ten feet, two inches to allow for them. Articulated buses are somewhat wider at ten feet, six inches with mirrors (Higgins and Audirac 2008, 44).

The UNF study cited earlier found a strong relationship between general lane width and bus vehicle safety (Sando and Moses 2010, 37-42). The study's analysis of crash results found that the narrower the lane width and the tighter the turning geometry, the higher the likelihood of sideswipe and mirror crashes. Lane widths of ten feet and less are overrepresented in the occurrences of sideswipe bus crashes. The study recommends that 12 -foot lanes be provided for roads along transit routes (Sando and Moses 2010, 44).

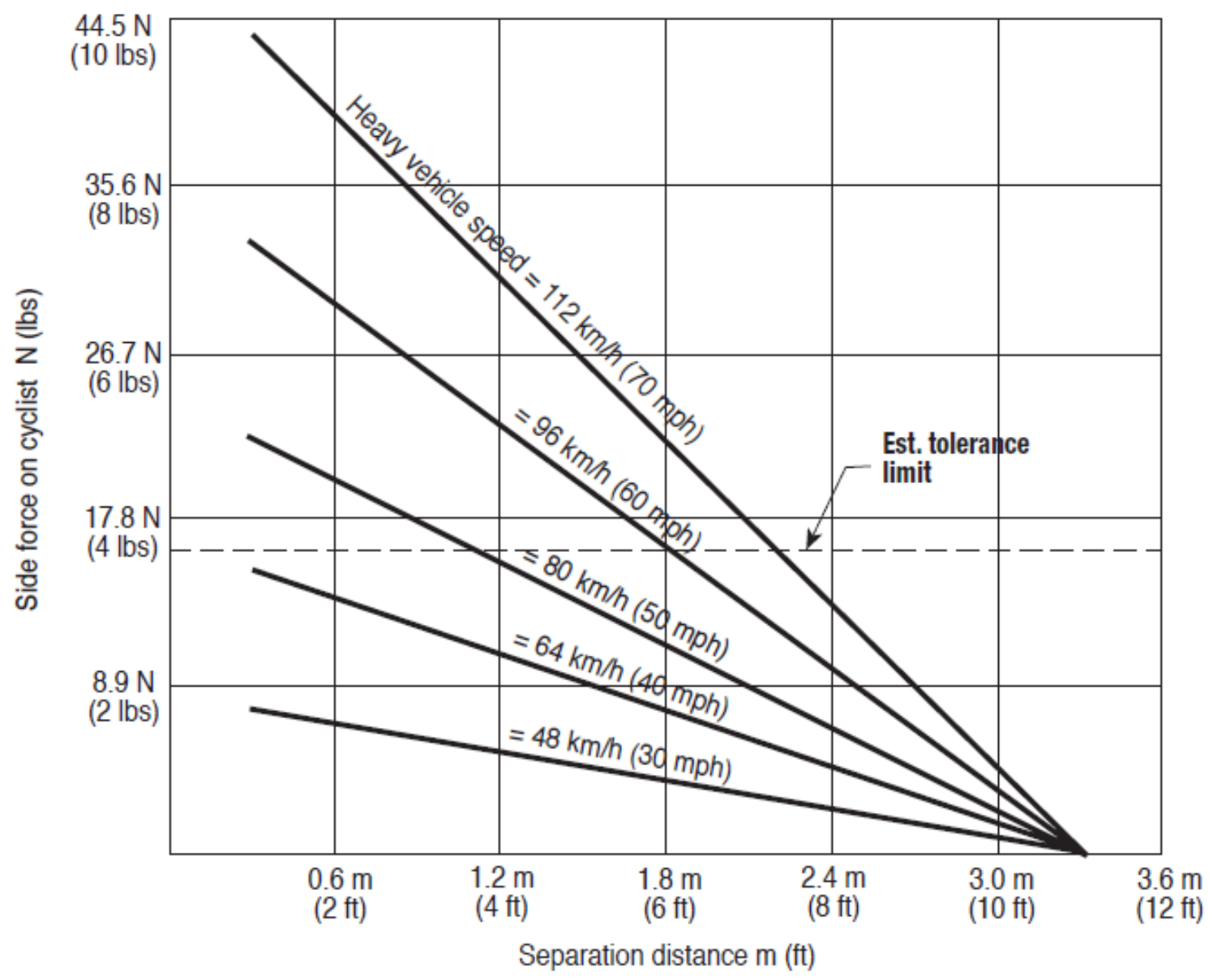

Figure 4.4 - Aerodynamic forces caused by heavy motor vehicles passing bicyclists

Summary of SBBL Widths

Table 4.8 summarizes SBBL widths that are from three types of sources. These include actual widths of existing facilities, recommended SBBL widths from studies, and SBBL widths included in official guidance documents. The guidance reflects a mix of physical requirements for safe operations, and what is needed for bicyclists to perceive that the SBBL is a safe and comfortable environment in which to ride. Figure 4.5 shows the combinations of lane speed and lane width identified among the existing SBBLs in the United States (speed and width data were not available for all of the 27 SBBLs in Appendix A). 
As noted above, there is little guidance explicitly for SBBLs, and little data and research on the actual safety of such lanes where they have been implemented. There is no clear evidence that they are safer, or less safe, than similar streets that have a mix of bicycle, bus, and general purpose traffic. Thus, it is striking from Table 4.8 and Figure 4.5 that the emerging guidance suggests that SBBLs should be wider than many of the existing ones. However, many of the narrow existing SBBLs were implemented before recent efforts to require that motor vehicles give at least three feet of clearance when passing a bicyclist. Although these older lanes do not provide enough space to give such clearance (for example, Figure 4.1.), they often exist only for short distances in settings where vehicle speeds are relatively low. This is especially true for the short urban connector type of SBBLs. The guidance does suggest that, all else being equal, SBBLs should be wider when the bus operating speeds are higher. Based on the results here, it might be prudent to presume that decisions to implement an SBBL narrower than 13 or 14 feet should require more justification than decisions to build one that is wider. Given the results of the analysis of Florida bus crashes by Sando and Moses referred to earlier, buses operating in lanes narrower than 12 feet face increased crash risk, so creating additional SBBLs narrower than this probably should be avoided for that reason.

Table 4.8 - Summary of Lane Width Recommendations from Studies or Official Guidance or Actual Widths

\begin{tabular}{|c|c|c|c|c|}
\hline Source & $\begin{array}{l}\text { Facility } \\
\text { Type }\end{array}$ & $\begin{array}{l}\text { Width } \\
\text { (feet) }\end{array}$ & Source Type & Conditions \\
\hline TRL study & SBBL & 13.1 & $\begin{array}{l}\text { Study } \\
\text { recommendations }\end{array}$ & $\begin{array}{l}\text { Minimum up to } 30 \mathrm{mph} \text {, bus encroaches } \\
\text { into adjacent lane to pass bike }\end{array}$ \\
\hline Cardiff Guide & SBBL & 13.1 & Official guide & $\begin{array}{l}\text { Minimum up to } 20 \mathrm{mph} \text {, bus encroaches } \\
\text { into adjacent lane to pass bike }\end{array}$ \\
\hline Cardiff Guide & SBBL & 15.1 & Official guide & $\begin{array}{l}\text { Ideal minimum up to } 20 \mathrm{mph} \text {, bus able to } \\
\text { pass bike within the same lane }\end{array}$ \\
\hline Cardiff Guide & SBBL & 16.7 & Official guide & $\begin{array}{l}\text { Up to } 30 \mathrm{mph} \text {, bus able to pass bike } \\
\text { within the same lane }\end{array}$ \\
\hline UNF & SBBL & 16 & $\begin{array}{l}\text { Study } \\
\text { recommendations }\end{array}$ & $\begin{array}{l}\text { Streets without curbs, based on physical } \\
\text { and legal constraints, bus passes bike } \\
\text { within the same lane }\end{array}$ \\
\hline UNF & SBBL & 17 & $\begin{array}{l}\text { Study } \\
\text { recommendations }\end{array}$ & $\begin{array}{l}\text { Streets with curbs, based on physical and } \\
\text { legal constraints, bus passes bike within } \\
\text { the same lane }\end{array}$ \\
\hline Various U.S. cities & SBBL & $\begin{array}{l}10- \\
18\end{array}$ & Official guide & Municipal guides \\
\hline FDOT PPM & $\begin{array}{l}\text { Wide curb } \\
\text { lane }\end{array}$ & 14 & $\begin{array}{l}\text { Design criteria per } \\
\text { state law }\end{array}$ & $\begin{array}{l}\text { Minimum width that allows most motor } \\
\text { vehicles to pass a bicycle while staying in } \\
\text { the same lane }\end{array}$ \\
\hline $\begin{array}{l}1999 \text { AASHTO } \\
\text { Guide for the } \\
\text { Development of } \\
\text { Bicycle Facilities }\end{array}$ & $\begin{array}{l}\text { Wide curb } \\
\text { lane }\end{array}$ & 14 & Official guide & National Recommendation \\
\hline U.S. SBBLS & SBBL & $9-16$ & Actual widths & See Table 4.6 \\
\hline $\begin{array}{l}\text { U.S. separate but } \\
\text { adjacent facilities }\end{array}$ & $\begin{array}{l}\text { separate } \\
\text { but } \\
\text { adjacent }\end{array}$ & $\begin{array}{l}15 \\
20\end{array}$ & Actual widths & $\begin{array}{l}\text { See Table } 4.6 \text {, sum is the total of both } \\
\text { lanes }\end{array}$ \\
\hline
\end{tabular}




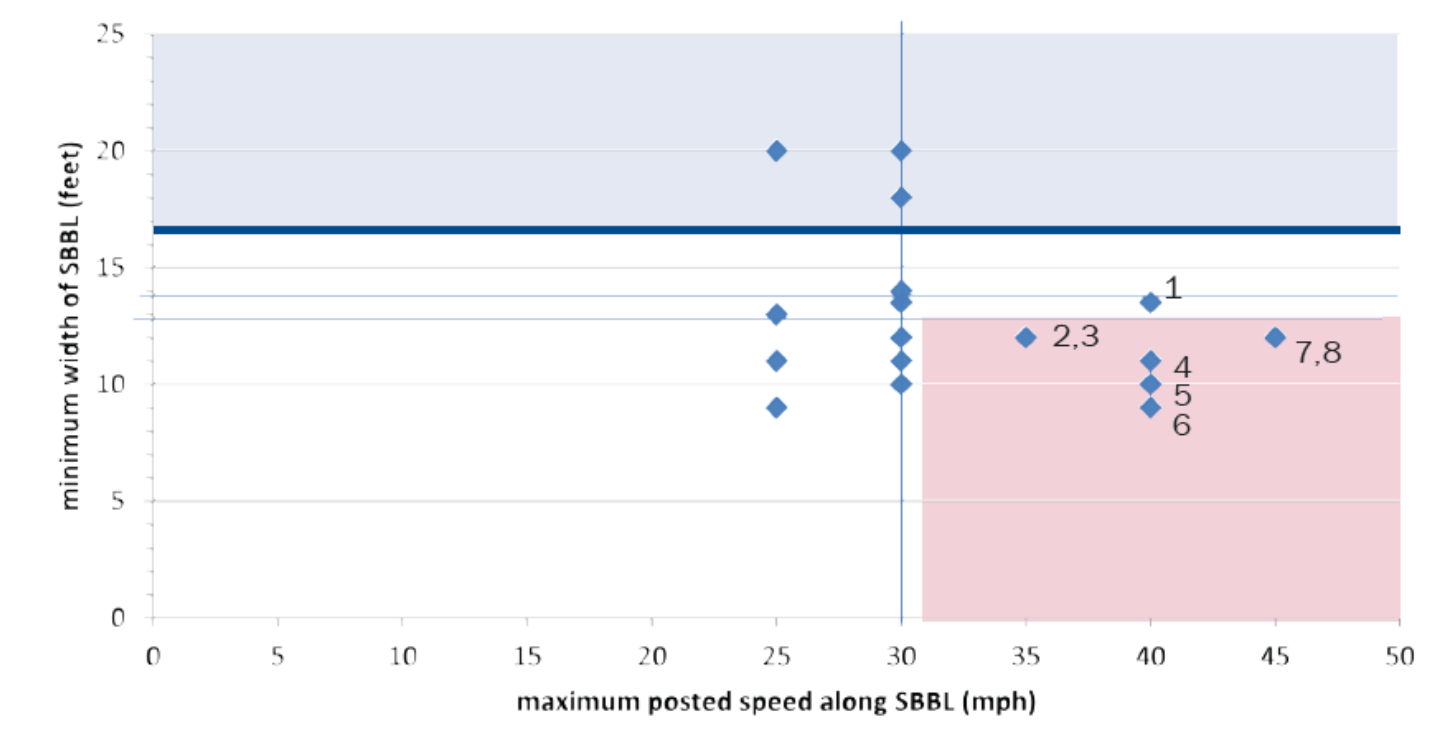

1 Mineral Point Road, Madison, WI

5 E 22nd Street, Tucson, AZ

2 County Highway 865, Ft Myers Beach, FL

3 Elliot Avenue, Seattle, WA

4 MD 528, Ocean City, MD

6 E Broadway Blvd, Tucson, AZ

7 Aurora Avenue N, Shoreline, WA

8 Coastal Highway 1, Rehoboth Beach, DE

SBBLs outside European standards

Minimum width to accommodate passing within a shared bike/bus lane

Figure 4.5 - Critical design values for existing U.S. SBBLS

\section{Parking}

Curbside parallel on-street parking next to an SBBL adds complexity to the operation of the SBBL. Known as a keyhole, motor vehicles can be expected to pass through the SBBL upon entering and exiting parking spaces, creating potential conflict and dangerous conditions for both bicyclists and buses. Additional operating space for bicycle lanes can be gained by marking narrower parking lanes because this decreases the incidence of cars parking farther than the legal22 limit of 12 inches from the curb (Furth et al. 2010). This might apply as well to an SBBL. Recent observational research about lateral positioning of bicyclists relative to parked cars indicates that “...The addition of a buffer space [painted diagonal lines] between the outer edge of the bicycle lane and the driver side of a parked car is the most effective way to ensure that bicyclists are removed from the door zone of parked motor vehicles" (Duthie et al. 2010, 42). Further guidance regarding the width of such a buffer zone is provided by the U.K. Traffic Signs Manual.

A clearance of 1.0 meter between the cyclist's dynamic envelope and the adjacent parked vehicle will allow for doors to be opened without conflicting with cyclists. (Department for Transport 2003, Chapter 5)

Several SBBLs (for example 19th Street in Denver, CO and Stewart Street in Seattle, WA) function as SBBLs during periods of peak travel demand, and as on-street parking lanes with bicycle traffic at the left side of the lane at other hours. This again creates the possibility for collisions between bicycles and car doors, and the need to enforce the vacation of parking spaces at times when the lane is to be open

22 Section 316.195, F.S. 
to buses as well as bicycles. Decisions about whether to retain or allow parking, and how to manage interaction with it, are elements of planning and designing an SBBL.

\section{Minor Modifications to ROW}

Although the overall right-of-way in the corridor may be regarded as a given condition that precludes widening of the street along its length, it may be possible to make "spot" adjustments to the right-ofway at some bus stops or intersections to improve safety or prevent them from constraining performance of the lane. Because of cost, it usually will be desirable to limit the number and extent of such changes. It may be possible to arrange for a public use easement with owners of some adjacent properties for minor bus stop modifications, such as installation of a partial bus bay that provides three to four additional feet to the left of the stopped bus in the SBBL for a bicyclist to pass. Another use of a minor addition of right-of-way may be those cases when the best option is to route a bicycle lane behind the bus stop shelter. These might be appropriate where there are large numbers of bicyclists and general traffic volumes and speeds are high. These options are described later in this chapter.

\section{Movement at Intersections}

Bus lanes are generally associated with a corridor, in which buses using the lane usually will be proceeding straight through intersections. Traffic control at intersections, such as signal priority for buses, improves function of the bus lane. With the addition of bicycles in the bus lane, intersection geometry, pavement markings, signage, and signalization should be reviewed to ensure safe accommodation of bicyclists desiring to travel straight, turn right, or turn left. This becomes especially important at intersections where buses turn onto other streets but where bicyclists may still have the option of continuing straight ahead.

Many SBBLs allow right-turning vehicles. Upon approaching an intersection, where the bicyclist desires to travel straight through, NACTO's Urban Bikeway Design Guide recommends that bicyclists ride within the left side of the right turn lane and describes an experimental combined bike lane/right turn lane that is marked with a four-foot bicycle placement area within and along the left side of the right turn lane (2011, 181-190).

Bike boxes are another possible feature for the intersection approach, to place bicyclists in front of stopped traffic. This improves visibility of the bicyclist to motorists, including bus operators, and allows the bicyclist to enter the intersection before motorists once the traffic signal turns green. Bike boxes do not help prevent right hook crashes with bicyclists if the traffic approaching the intersection is already moving; however, bike boxes are often designated with painted pavement. The painted area includes an ingress lane, calling attention to the possibility that a bicyclist could be approaching from the right side of a motor vehicle. The ingress lane potentially could be aligned with an advisory cycle lane striped within the SBBL. A "NO RIGHT TURN ON RED" sign prevents right-turning motorists from encroaching into the bike box. The NACTO Urban Bikeway Design Guide provides detailed guidance for the design of bike boxes (2011, 106-116). Presently, there are no standards or guidance for bike boxes contained within the AASHTO Guide for the Development of Bicycle Facilities or the MUTCD. However, bike boxes with advanced stop lines for motor vehicles and no-turn-on-red restrictions on the approach are currently experimental as designated by FHWA. If approved for implementation by FWHA, designation of bike boxes could be supported by a public education component to help motorists and bicyclists understand how they should operate their vehicles in relation to the bike box. 
TCRP Report 19 reports dimensions of standard buses and minimum turning radii for different combinations of street widths, both for approaching and entering street widths. When buses make right turns, the turning radius of the corner must accommodate bus dimensions, so that the left front wheel and overhang does not extend into oncoming approach lanes during turn execution and so that the right back wheel does not jump the curb. Wider than necessary turning radii can encourage traffic to take the turn faster. The required turning radius for an articulated bus is smaller than for a standard 40-foot bus (TTI 1996, 36-39). In this way, articulated buses provide one possible advantage in compatibility with bicycles by needing less clearance, thereby reducing turning speed of general traffic. At intersections, a curb extension may be used for improving pedestrian safety. It also appears to alter the turning radius for right-turning vehicles and may serve to slow them down. Depending upon the volumes of truck traffic and upon whether bus routes must turn right, this may be one way to slow right-turning vehicles (FDOT 2012b, 21.6.3).

\section{Distance between Bus Stops}

Bus stops are spaced according to characteristics of land use and density. In Central Business Districts (CBDs) and major employment centers, bus stops can be typically every 600 feet or approximately one-eighth mile. In suburban residential areas, bus stops typically may be as far apart as one half mile (TTI 1996, 18). These longer distances between bus stops provide a greater opportunity for buses to operate at the posted speed limit than where there is shorter spacing between stops, especially when buses have preferential use of the lane. Longer distances between bus stops can lead to greater speed differences between bicycles and buses in an SBBL and to consequences that are more serious for cyclists in the event of a collision. On the other hand, shorter distances between bus stops, such as those common in CBDs, may result in greater potential for bicyclists in an SBBL to overtake a bus, especially at stops.

Where the street has bus service but no dedicated bus lane, the spacing of bus stops should be considered as a variable in the initial design of the SBBL and adjusted as needed to improve safety and service, given the setting for the SBBL. For example, if the right-of-way is too narrow and there are too few gaps in general traffic to allow cyclists to pass stopped buses safely or comfortably, then increasing the spacing between stops is one alternative to reduce the number of conflicts. If the right-of-way is at least 16 feet, seven inches, as shown in Figure 4.2, then the existing stops could all be retained. The Minneapolis Bicycle Facilities Design Guidelines also suggests considering the placement and frequency of bus stops to minimize conflict (City of Minneapolis 2010a, 258-261). Where there is an existing dedicated bus lane, the spacing of bus stops may be more difficult to alter in the conversion to an SBBL, but it still could be considered as a design variable.

\section{Location of Bus Stops}

At intersections, according to Accessing Transit, far-side bus stops are considered better than nearside stops where (1) sufficient right-of-way allows other motorists to pass the bus, (2) intersections are complex with multiphase signals, and (3) the bus lane may serve as a right turn lane prior to the intersection. Far-side bus stops may provide better vehicle and pedestrian sight distance as people are encouraged to cross behind the bus at the crosswalk (Higgins and Audirac 2008, 49 and 51). Where buses begin to queue at the same bus stop location, transit agencies may need to move the bus stop farther away from the intersection to provide sufficient space for bus queuing to avoid blocking the intersection. Consideration will need to be given to whether buses should be allowed to pull out from behind another stopped bus or must stay in the lane and wait until the bus in front leaves. In the latter situation, bicyclists may be passing to the left of more than one bus, and conflict may occur with a departing bus. Section 316.0815(1), F.S., requires that vehicles must yield to buses that are 
reentering traffic. In the case of an SBBL, the yielding vehicle would not only be other motor vehicles but also bicyclists and other buses.

\section{Bus Stop Treatments}

Bus stops tend to have a range of potential conflicts between buses, bicycles, and other users of SBBLs. Figures 4.6, 4.8, 4.10, and 4.11 illustrate typical conflict points for different SBBL lane configurations including narrow width lanes, wide width lanes, bus stop islands, and partial bus bays. These potential conflicts result when different users want to use the same space at the same time, and one or another user is constrained in how to respond. Education and training of bus operators, bus passengers, and bicyclists can reduce these conflicts and make the behavior of each group at bus stops more predictable. The available training and education materials for bus operators provide clear recommendations on how to handle situations in which a bus overtakes a bicyclist, and this may be the best way to manage potential conflicts of this type. Attempts to manage the other major type of potential conflict, in which a bicyclist overtakes a bus at a stop, include some education but greater diversity in ways that physical design of the bus stop can reduce or eliminate it. The available right-ofway and budget may limit the use of some designs.

\section{Conflict points for narrow width lanes}

In cases where the SBBL width is less than 16 feet, seven inches and it is not possible to widen the SBBL, there appear to be two ways to manage conflicts at stops. First, a bicyclist can decide to stop behind the bus or second, to wait for an opportunity to move left into the adjacent general purpose lane and pass the bus. It is suspected that this is not safe unless the posted speed is $30 \mathrm{mph}$ or less and gaps in traffic are available. The sufficient number of gaps and the length of each gap that would provide a safe opportunity for a bicyclist to pass to the left of a bus are not known. Research would be necessary to determine the maximum safe posted speed limit and characteristics of gaps necessary to provide safe passing opportunities.

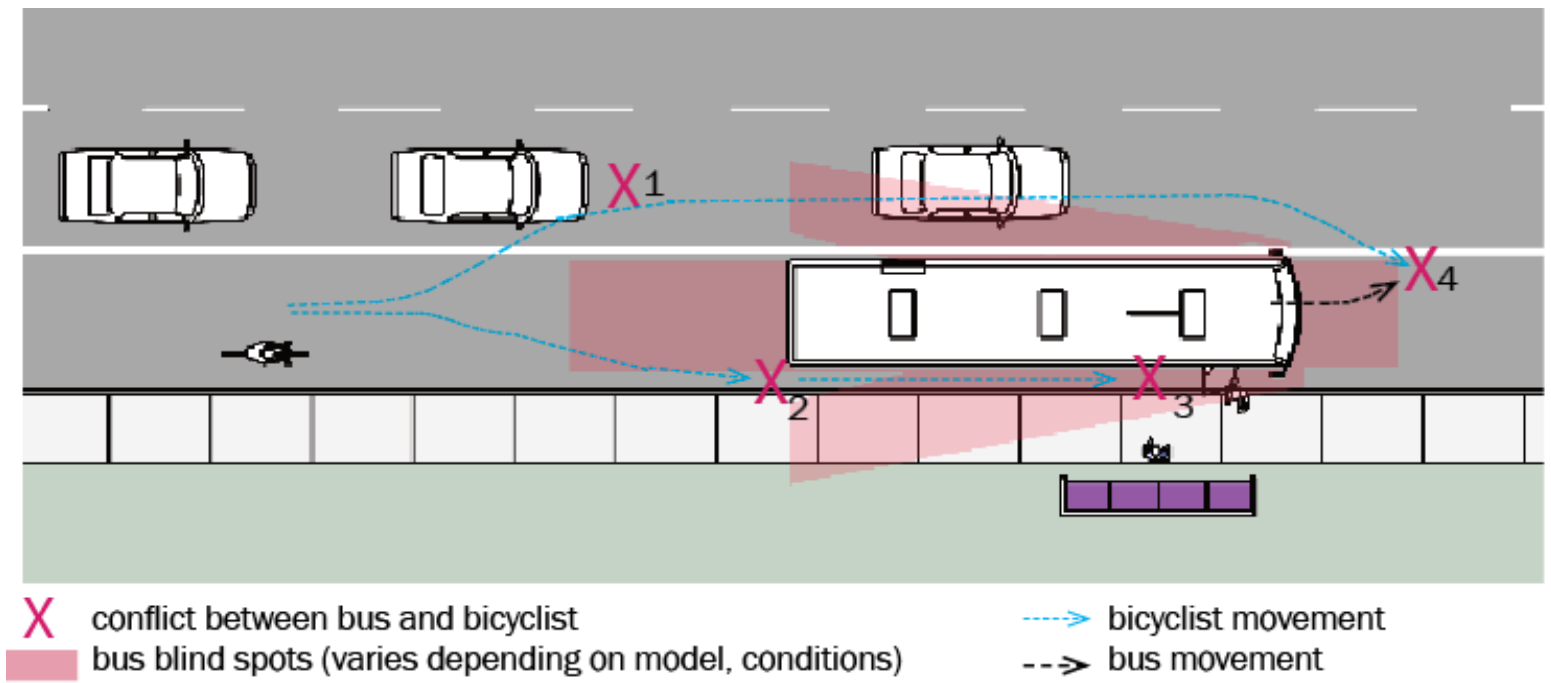

(figure not to scale)

Figure 4.6 - Conflict points for narrow width lanes ${ }^{23}$

${ }^{23}$ Reference regarding blind spots is Lin et al. 2010. 
Conflict 4.6.1: If a bicyclist moves to the left to pass a bus stopped at a bus stop, the bicyclist is approaching a bus blind spot. The bicyclist also risks moving into the line of travel of general traffic and being overtaken by faster moving motor vehicles in the adjacent lane.

Conflict 4.6.2: If a bicyclist begins to pass a bus stop at the same time as a bus is pulling into the bus stop, the bicyclist is in a bus blind spot and in danger of being squeezed by the bus. A bicyclist also can collide with bus passengers as they exit through the rear side door.

Conflict 4.6.3: If a bicyclist attempts to pass to the right side of a stopped bus, the bicyclist is in a bus blind spot and risks getting squeezed or overtaken by the bus as the bus begins to move forward. The bicyclist also risks colliding with bus passengers exiting through the front side door.

Conflict 4.6.4: A bicyclist who is passing to the left of a stopped bus is in a bus blind spot and may encounter a conflict if the bus begins to move forward as the bicyclist is merging rightward and back into the SBBL.

A variation of the narrow width bus stop is to mark an advisory cycle lane within the SBBL, along the right side of the lane, as illustrated in Figure 4.7. In some SBBL designs, an advisory cycle lane for bicyclists is marked with a solid white line along the inside right side of the SBBL (Ove Arup \& Partners 2008, 36). ${ }^{24}$ Figures 4.13 and 4.14 provide examples of a marked advisory cycle lane in the U.K. Bicycle advisory cycle lanes are commonly marked designated areas within bus lanes in the U.K. The U.K.'s National Cyclists' Organization (CTC), provides a position on advisory cycle lanes: “Full width advisory cycle lanes can be used on roads of any width, even the narrowest. Advisory cycle lanes should be thought of as indicators of the space cyclists need when they are being overtaken, not necessarily as exclusive space for cyclists" (CTC 2011).

One variation of this advisory cycle lane design is to provide a stop bar approaching the bus stop to indicate where the cyclist should stop if a bus is present, as shown in Figure 4.7. The stopping position should be placed outside of the blind spots of the bus operator. The advisory cycle lane can resume on the far side of the bus stop. Education will be needed to let bicyclists know that stopping is not required unless a bus is at the stop, and that they are permitted to use the adjacent general purpose lane when conditions permit this to be done safely.

\footnotetext{
${ }^{24}$ Note that in the U.K., motorists drive on the left side so the advisory cycle lane in the U.K. is actually on the inside
} left side of the SBBL. 


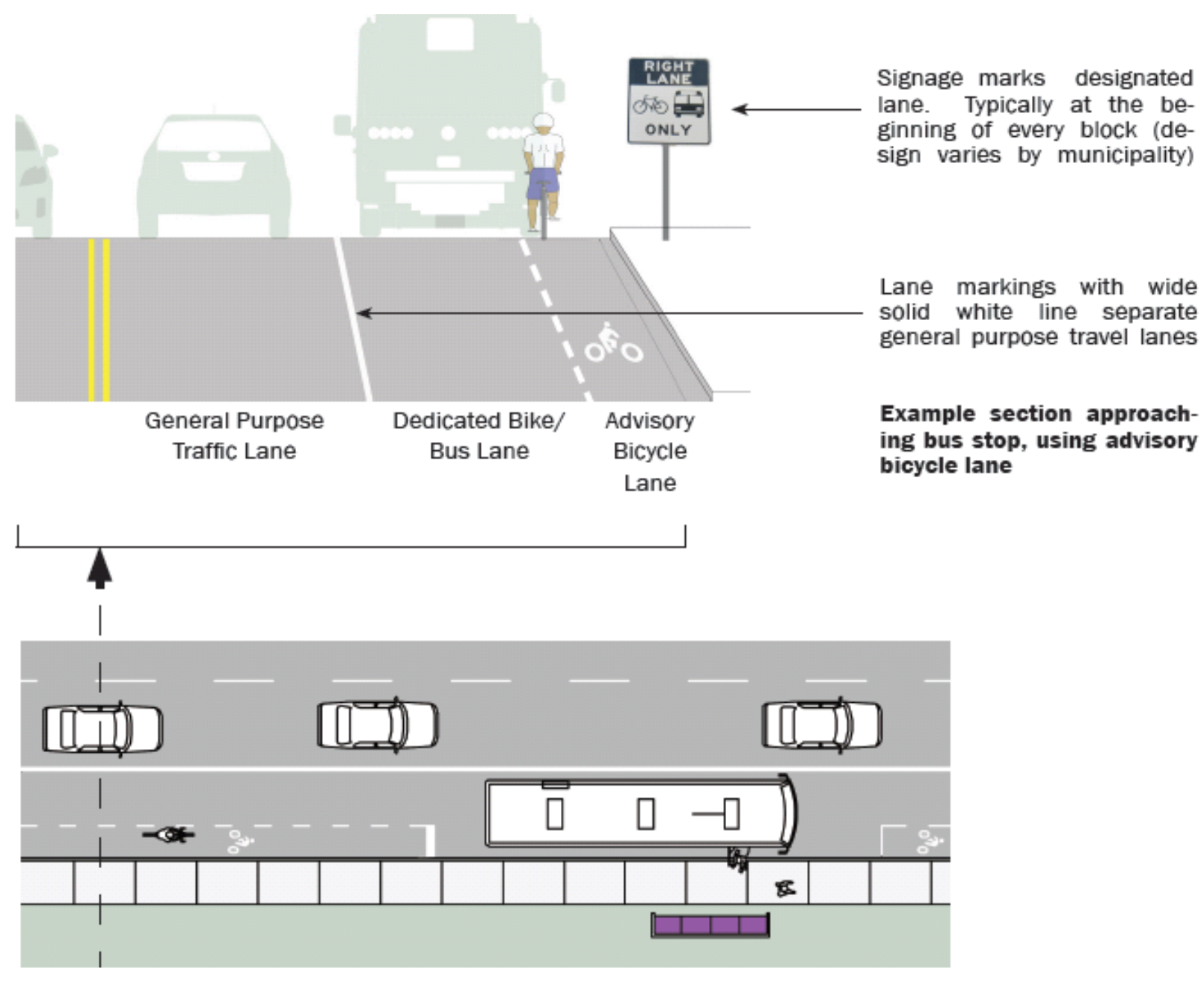

Figure 4.7 - Narrow width SBBL with advisory cycle lane and stop bar

Conflict points for wide width lanes

As shown in Figure 4.8, the bicyclist always has the option to stop behind the bus, wait, and then proceed after the bus leaves the bus stop. The bicyclist may choose to pass the bus to the left. If the SBBL is no less than 16 feet, seven inches, then the bicyclist can safely and comfortably pass a stopped bus while remaining within the SBBL. Bus operators would be trained to watch for overtaking bicyclists, and to pull close to the curb at the stop. This would discourage bicyclists from passing on the right and ensure adequate space for bicyclists to pass on the left. 

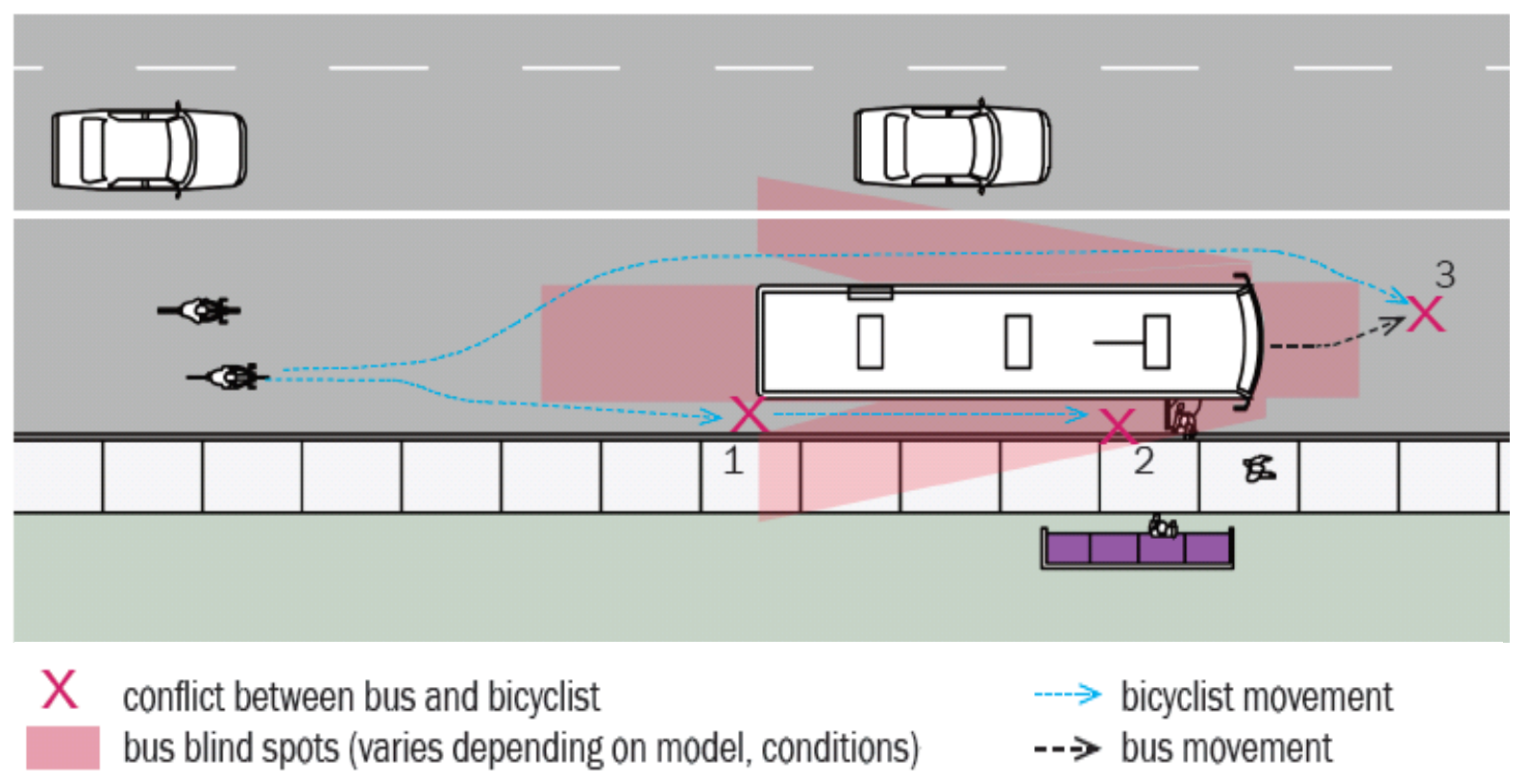

Figure 4.8 - Conflict points for wide width lanes ${ }^{25}$

Conflict 4.8.1: If a bicyclist begins to pass a bus stop at the same time as a bus is pulling into the bus stop, the bicyclist is in a bus blind spot and in danger of being squeezed by the bus. Bus operators sometimes miscalculate how fast a bicyclist is riding. A bicyclist also can collide with bus passengers as they exit through the rear side door. (Same as Conflict 4.6.2)

Conflict 4.8.2: If a bicyclist attempts to pass to the right side of a stopped bus, the bicyclist is in a bus blind spot and risks getting squeezed or overtaken by the bus as the bus begins to move forward. The bicyclist also risks colliding with bus passengers exiting through the front side door. (Same as Conflict 4.6.3)

Conflict 4.8.3: A bicyclist who is passing to the left of a stopped bus is in a bus blind spot and may encounter a conflict if the bus begins to move forward as the bicyclist is merging rightward and back into the SBBL. (Same as Conflict 4.6.4)

Where the right-of-way is wide enough to permit a bicycle to pass a bus within the SBBL, it is possible to make this passing option explicit, by marking an advisory passing lane within the SBBL, to the left of where the bus stops, as shown in Figures 4.9, 4.11, and 4.12. Education of the cyclists will be needed to let them know the purpose of the advisory cycle lane; the need to approach, move left toward it before reaching the bus operator's blind spot behind the bus; and the need to be alert to the possibility that the bus may begin moving away from the stop while the bicyclist is passing on the left.

25 Reference regarding blind spots is Lin et al. 2010. 


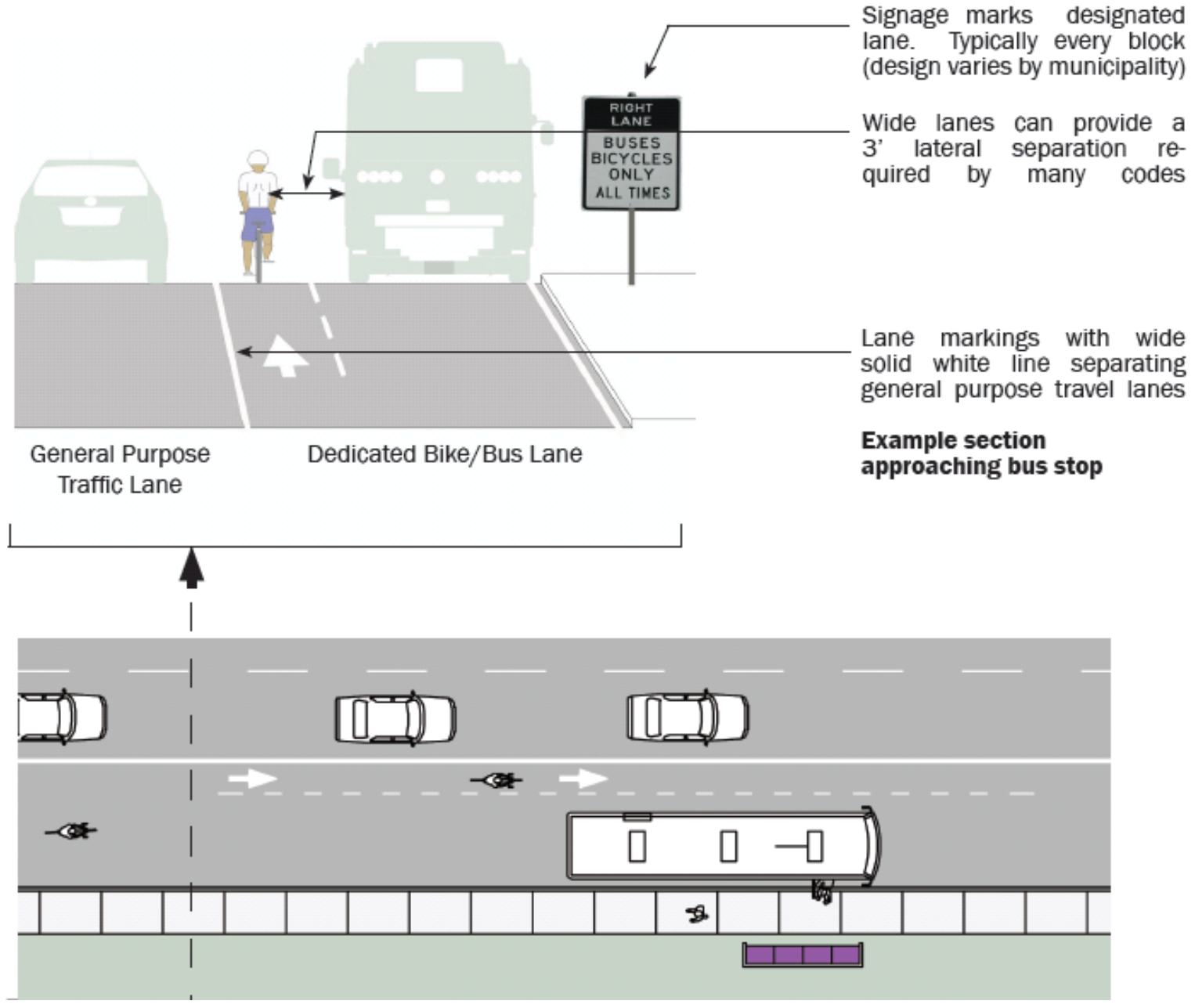

Figure 4.9 - Wide width SBBL with bicycle passing lane

Conflict points: bus stop island with advisory cycle lane

Other design options are possible for managing conflicts at bus stops when the planned SBBL cannot be made wide enough for a bicyclist and bus to pass side by side within the lane, but these depend on the available budget, details of the right-of-way, and sometimes political will. For example, where sidewalks are wide or where right-of-way is available to the right of the street, it may be possible to use some of this space to manage conflicts at the stop. One approach is to channel bicycle traffic from the right of the SBBL to the right of the bus stop, as shown in Figure 4.10. It runs behind the bus stop/shelter before reconnecting with the SBBL beyond the shelter. This allows maximum separation between bicyclists and general purpose traffic. This configuration creates potential bicycle conflicts with bus patrons. A short crosswalk across the channel can be marked to emphasize pedestrian priority. Markings or signs can be used, such as MUTCD R9-6, "BIKES YIELD TO PEDS", to give priority to bus patrons crossing the bicycle channel to get on or off the bus. Bicyclists would use the main SBBL to pass the stop when no bus is present. Figure 4.10 illustrates use of a bus stop island with an advisory cycle lane marked along the right side of a wide width SBBL. The bus stop island with a dedicated bike channel can also be applied to a narrow width SBBL. 


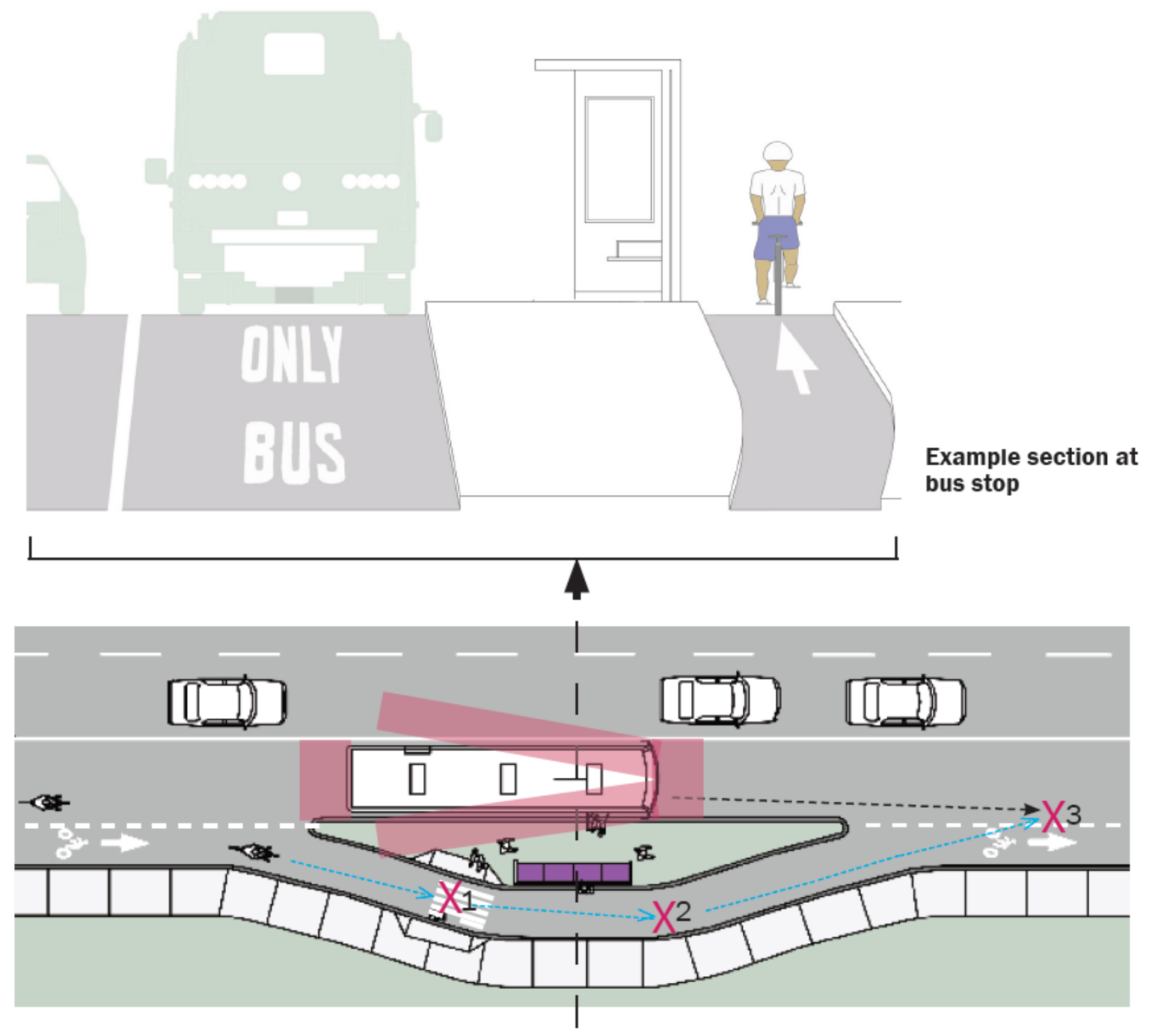

Figure 4.10 - Conflict points: bus stop island with advisory cycle lane ${ }^{26}$

Conflict 4.10.1 and 4.10.2: If there is a bicycle lane directed to the right of the bus stop, a bicyclist risks potential conflict with pedestrians who are crossing over the bike lane to and from the bus stop.

Conflict 4.10.3: As the bicyclist emerges from the bicycle lane and moves back into the SBBL, there is potential conflict with the bus as the bus begins to move away from the bus stop and the bus operator repositions the bus toward the center of the lane. In this case the bicyclist does not travel through the bus operator's blind spot and is more likely to be seen than in Figures 4.6 and 4.8 .

${ }^{26}$ Reference regarding blind spots is Lin et al. 2010. 
Figure 4.11 illustrates another alternative treatment. The bicyclist always has the option to stop behind the bus, wait, and then proceed after the bus leaves the bus stop. In the case where the SBBL is less than 16 feet, seven inches, another option is to provide partial bus bays at bus stops to provide the width necessary to allow cyclists to pass stopped buses without entering general purpose lanes to the left. This is done by shifting the bus stop a few feet to the right of the SBBL right-of-way, in a limited bus pull-out, to provide enough space for the bicyclist to pass on the left, as shown in Figures 4.11 and 4.12. This treatment appears to have the best potential of any of the treatments for reducing conflict at a bus stop. The shallow pull-out presents visual cues to an overtaking bicyclist. The cues discourage passing the bus on the right. This reduces the risks that a bicyclist may be squeezed between the bus and edge of the lane, and that a bicyclist may encounter or injure bus patrons entering or leaving the bus. At the same time, this design provides adequate space to pass on the left that can be reinforced, if necessary, with an advisory bicycle passing lane as in a wider SBBL. On the other hand, this treatment costs more than working within the existing curb-to-curb right-ofway.

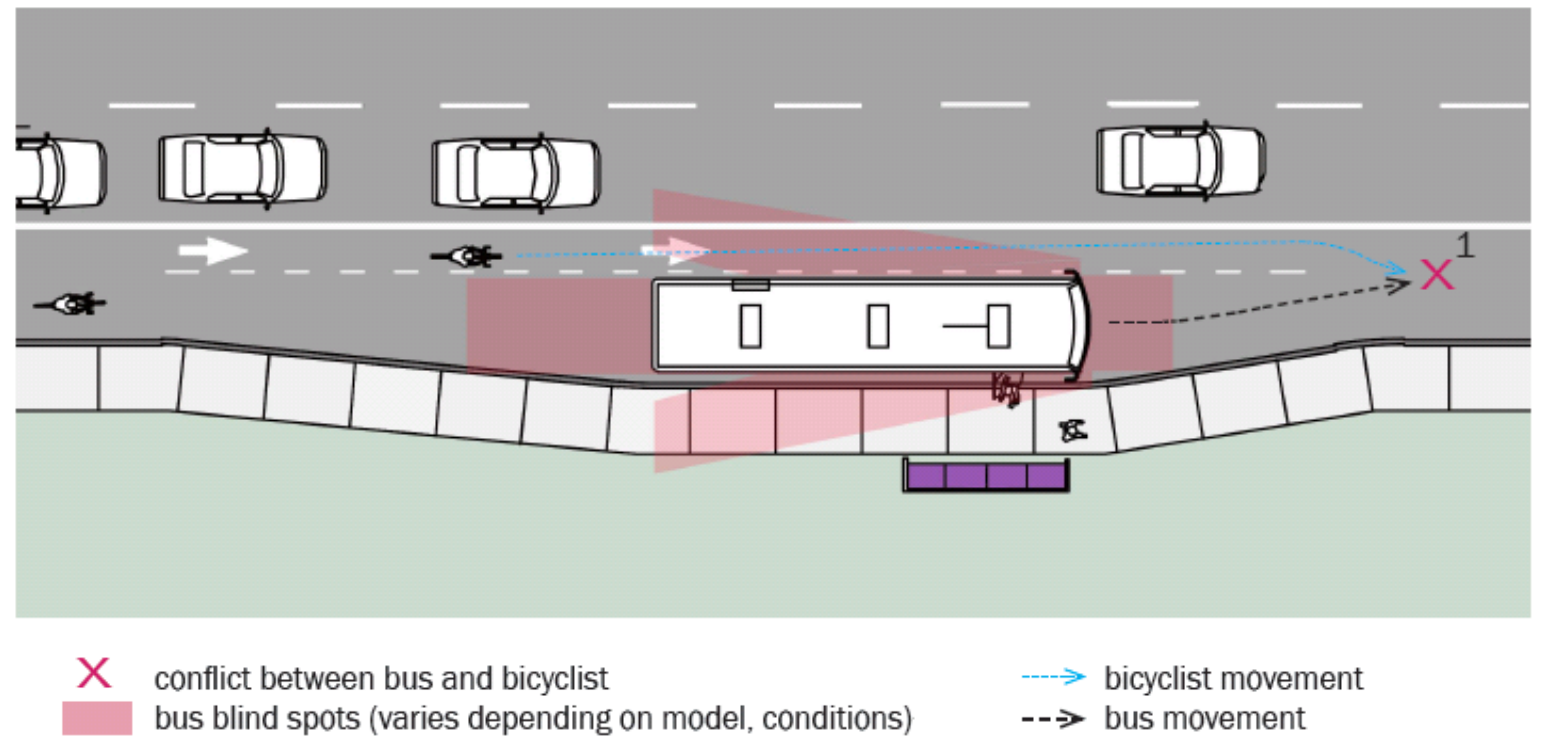

Figure 4.11 - Conflict points: partial bus bay with advisory cycle lane

Conflict 4.11.1: A bicyclist who is passing to the left of a stopped bus is in a bus blind spot and may encounter a conflict if the bus begins to move forward as the bicyclist is merging rightward and back into the SBBL. (Same as Conflict 4.6.4) 


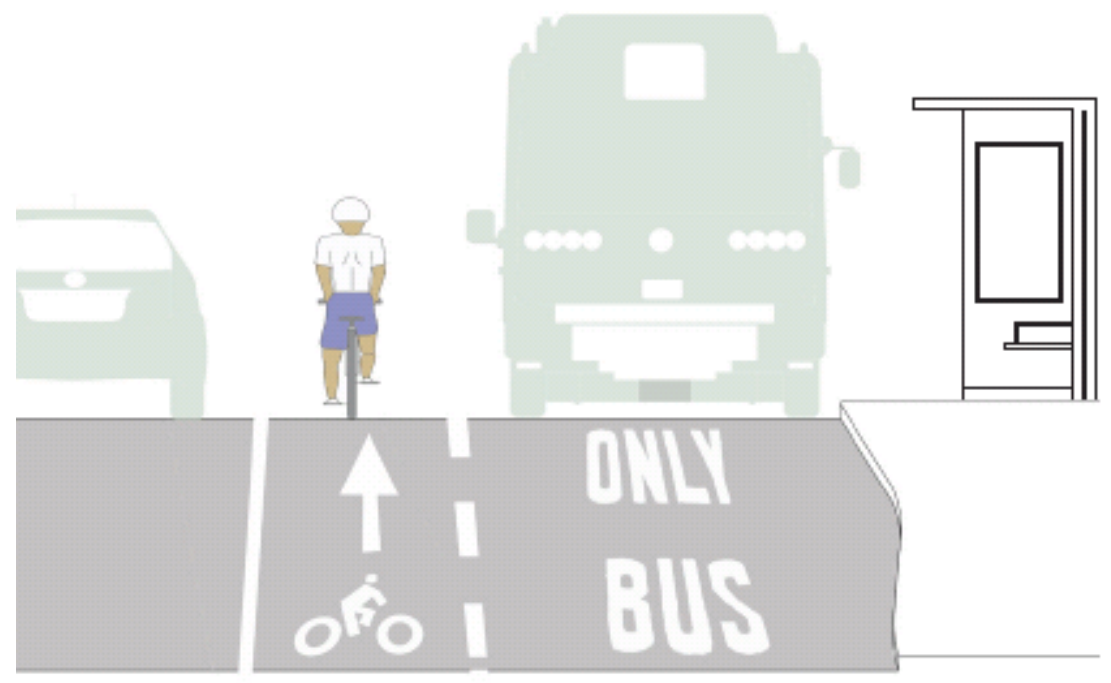

Example section at bus stop

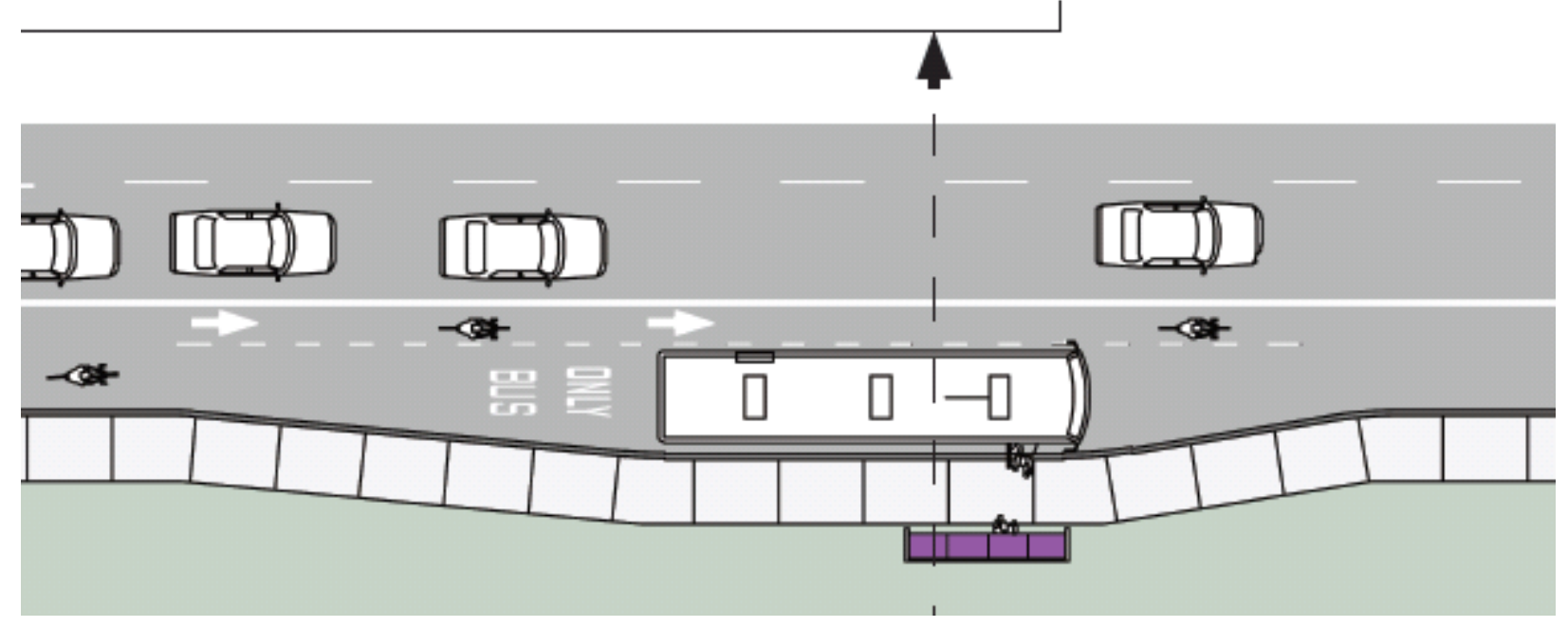

Figure 4.12 - Partial bus bay 


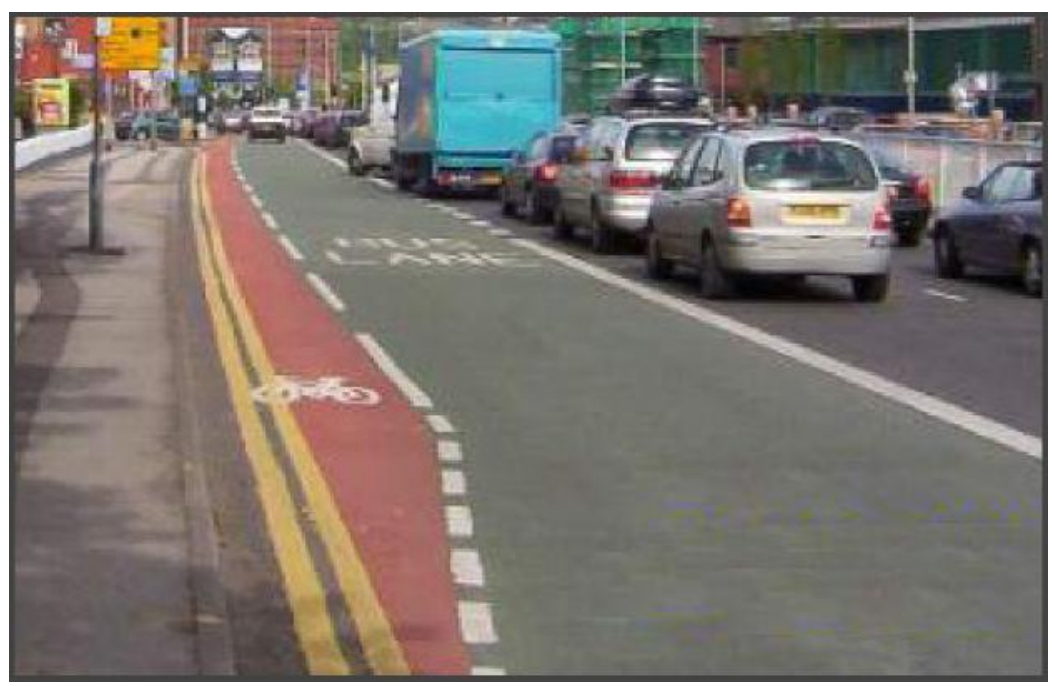

Figure 4.13 - Example of advisory cycle lane, United Kingdom

Credit: Cycling England Gallery

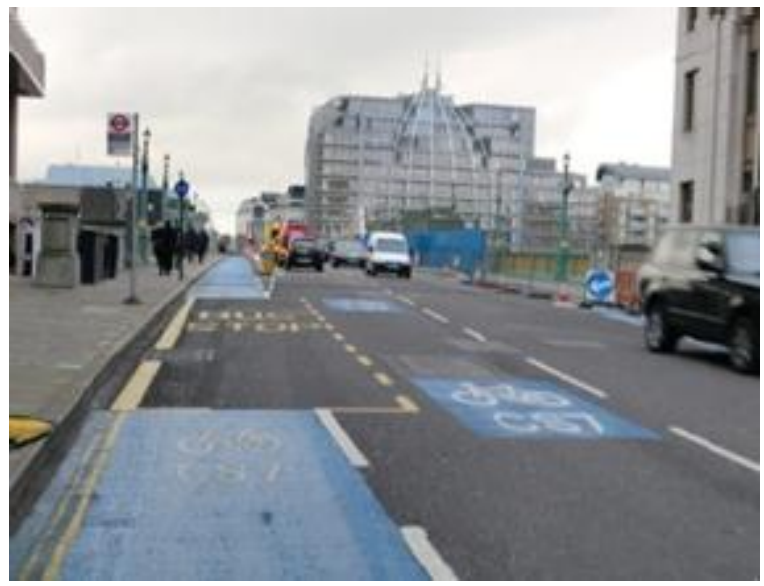

Figure 4.14 - Example of pavement markings around a bus stop, United Kingdom Credit: Cardiff Design Guide

\section{Pavement Marking}

Pavement marking guides the movement of vehicles within an SBBL, and assists enforcement by indicating who is permitted to use the lane. For example, in Pima County, AZ, painted lane markings on SBBLS, including a bicycle symbol and a "BUS ONLY" symbol are repeated every quarter mile and after every major signalized intersection (Pima DOT and Tucson DOT 2008, Sheet 6-1.1, Detail 2).

\section{Shared Lane Markings}

In Florida, pavement markings for bike lanes, as well as for Shared Lane Markings in shared lanes are guided by FDOT Design Standards, Indexes 17346 and 17347. Shared Lane Markings can be used only on roadways with a posted speed limit of $35 \mathrm{mph}$ or less (FHWA 2009, 9C.07). Shared Lane Markings provide bicyclists with guidance on lateral positioning in the lane, and especially on roadways with on-street parking or lanes too narrow for a bicyclist to ride side by side with a motor vehicle (FDOT 2012b, 8.4.5). 
Markings described as being similar to Shared Lane Markings were used in the Hennepin Avenue SBBL in Minneapolis, prior to the redesign of the SBBL in 2010. The review of these lanes prior to the redesign indicated that these markings may not have communicated with bicyclists and car drivers as clearly as expected, although it is unclear whether the difficulty was with the size, the design, or the placement of the markings. For the 2010 redesign, the city marked advisory cycle lanes within the SBBL and received permission to experiment with marking these with green pavement behind white Shared Lane Markings.

The CUTR study team requested clarification from FHWA about the appropriate marking for SBBLs. Based on the response received, there appear to be different ways to mark such a lane ${ }^{27}$ :

- The lane can be designated as "BUS/BIKE ONLY", plus right-turning at intersections (if this is an intended use of the lane), using pavement markings (FHWA 2009, Section 3D.01, paragraph 7), and/or signs. If so, then Shared Lane Markings may not be used within the lane without first applying to FHWA for permission to experiment.

- The lane can be marked as "BUS ONLY", plus right-turning at intersections (if this is intended) using pavement markings (FHWA 2009, Section 3D.01) and/or signs. Shared Lane Markings then can be used within the lane, along with signs, to communicate that bicyclists may use the lane. It may also be appropriate to use modified signs (MUTCD, Figure 9B-2, sign R4-4, or "BIKES MAY USE BUS LANE") to indicate this. Shared Lane Markings also can be positioned within the lane to guide cyclists where to ride. A bus lane marked in this way would function as an SBBL but would not be designated as one.

- The use of standard longitudinal bicycle lane symbols (solid stripes or dashed lines in rightturn lanes) is regarded as experimental, requiring permission from FHWA (FHWA 2012, Table). Thus, marking advisory cycle lanes within an SBBL used for right turns would require special application to FHWA.

- If the SBBL is designated as a bus/right-turn-only lane, then Shared Lane Markings can be used to guide bicycles to the left of buses at bus stops, or to the left side of the SBBL at intersections where buses and/or cars turn right. Standard "non-longitudinal" bike lane markings (bicycle or bicyclist, with arrow) could be used instead. Several SBBLs permit parking along the right side of the lane during off-peak hours, with bicyclists permitted to use the remainder of the lane at these times. This creates a risk of collision with an opening car door, and the MUTCD indicates that one use of Shared Lane Markings is to guide bicyclists to ride far enough from the parked vehicles to avoid this. The current restrictions on the use of Shared Lane Markings suggest that SBBLs where bicyclists would ride adjacent to on-street parking be designated as bus lanes and then be signed and marked as necessary to permit and guide bicycle use.

It is recommended that the MUTCD update process address traffic control in SBBLs and the appearance of conflict between markings for the three primary uses (bicyclists, buses, and rightturning general traffic) within a single preferential lane. The NACTO bicycle working group also should review the marking and signage needs of SBBLs. Additional research will be needed to evaluate the effectiveness and safety of alternative markings and signs.

\section{Lane Restriping}

The AASHTO Guide states that "Restriping to provide wide curb lanes may also be considered on some existing multilane facilities by making the remaining travel lanes and left-turn lanes narrower. This should only be considered after careful review of traffic characteristics along the corridor and

${ }_{27}$ Bruce Friedman, FHWA MUTCD team, personal communication, March 19, 2012 and March 22, 2012. 
supported by a documented engineering analysis based on applicable design criteria" $(1999,17)$. Taking into account the entire width of all lanes in one direction when determining the most appropriate width for a wide curb lane, recognizes that an operational relationship exists between the outside and inside lanes. Similarly for the implementation of an SBBL, the allocation of width among lanes should be considered.

A number of SBBLs in the U.S. were implemented using only changes in lane striping, the addition of lane markings and signage, and sometimes the use of public education to inform cyclists and motorists about the changes. Lane restriping has the advantage of being inexpensive and relatively quick to implement, once details of the design have been worked out and approval is given to proceed. New York City, which does not have SBBLs, has been creating many new bicycle and pedestrian facilities during the past several years. After carefully designing the facilities, city work crews frequently reconfigure intersections and short lengths of lane overnight or over a weekend, using paint, large planters, and street furniture (Wade and Quinn 2011). This approach allows not just rapid implementation, but flexibility in adjusting the installation, by moving or repainting elements of the facility, if unforeseen problems or uses emerge. Successful implementations can be made permanent by moving sidewalks, curbs, and other elements of the facility, when schedules and budgets permit.

The use of lane restriping to create an SBBL was recently completed in Fort Worth, Texas. Throckmorton and Houston Streets are paired one-way roadways in downtown Fort Worth. These streets have existing bus lanes located adjacent to the right curb. The city converted these lanes to permit cyclists to use them. Appendix D of this report contains the construction drawings (City of Ft. Worth and Kimley-Horn and Associates 2011). According to a senior planner for the City of Fort Worth, the changes were prompted after it was found that cyclists were already using the lanes illegally. ${ }^{28}$ The city's planning department initiated the project, working closely with the area's transit provider, the Fort Worth Transportation Authority (The T) that was amenable to the conversion. The Authority is working to inform bus operators to be aware of cyclists in the lanes.

Fort Worth downtown's relatively short blocks tend to reduce vehicle speeds. The city does not have heavy bus movements; even during the peak the volumes are relatively low. The existing lane widths are 12-13 feet depending on the block. Right turns are permitted every other block depending on the direction of the one-way cross street.

Fort Worth is using both signage and lane markings in the conversion. A 36-inch by 30-inch sign describing the restriction ("CURB LANE, BUSES AND BIKES ONLY") is located the beginning and end of every other block where right turns are not permitted. On blocks with right-turning vehicles, a 48inch by 54-inch overhead sign is located at the beginning of each block along with a sign, "RIGHT TURN ONLY, EXCEPT BUS AND BIKES". Lane markings alternate at each block depending on right turn permission and state "BUS BIKE LANE". Blocks with right-turning movements also include right turn arrows and "ONLY" marking the lane. The City recently amended local traffic ordinances thereby allowing bicycles to travel in the bus lane.

\section{Green Colored Pavement}

The FHWA has issued an Interim Approval for the use of green colored pavement in marked bicycle lanes and in extensions of bicycle lanes through intersections and other traffic conflict areas. FDOT has received permission from FHWA to use green pavement on locations on the State Highway System. Green pavement is to be used only where the path of bicyclists crosses the path of other road users

28 Julia McCleary, Senior Planner, City of Fort Worth, TX, Questionnaire completed on September 9, 2011. 
and where road users should yield to bicyclists. Green colored pavement may be used on the State Highway System where a keyhole exists and also where there is a demonstrated need for green pavement based upon crash history in the location or a study that has documented the prevalence of motorists failing to yield to bicyclists (FDOT 2012b, 8.4.2.2). The FDOT PPM provides illustrations how the green pavements can be used on the bike lane, where there is a separate right turn lane, a right turn drop lane, or a bus bay (FDOT 2012b, Figures 8.4.1, 8.4.2, and 8.4.5). It is possible that green colored pavement might have some applicability to an SBBL, if it is interpreted that a bus stopping at a bus stop in an SBBL is considered to be a keyhole location where the bus crosses into the path of a bicyclist.

\section{Pavement Management}

There are a number of considerations regarding pavement maintenance for joint use by both bicycles and buses. Bicycles are more vulnerable to imperfections in pavement surface. Potholes, ruts, and cracks can cause a bicyclist to lose balance. Closer attention to pavement maintenance, with a more frequent pavement inspection schedule, is recommended. Buses are heavy vehicles and where there are higher bus volumes, street pavement may be subject to rutting, especially in places where buses are braking as well as accelerating, such as prior to and beyond bus stops, respectively. Concrete is rigid and holds up best under heavy vehicle wear but concrete pavement also requires more expensive subgrade drainage, thickness and joint details. An alternative to concrete, polymer modified asphalt, PG 76-22, provides resistance to rutting from heavy vehicles (Higgins and Audirac 2008, 57).

Table 4.9 summarizes different types of paint used by municipalities that have painted SBBLs as part of lane markings. Other examples include Pima County and City of Tucson, AZ, where guidance provides that bike lane markings should be located 65 feet from the road intersection to avoid excessive wear by turning vehicles (Pima County DOT and Tucson DOT 2008, 6-1.1). Another example found in Philadelphia is blue pavement on bike lanes. It has been used to highlight only the conflict zones, such as where bike lanes shift leftward around right-turn lanes. Examples of this include the Walnut Street Bridge and 6th Street near Market Street (DVRPC and SEPTA 2009, 14).

Attention should be given to how pavement paint affects the ability to execute a controlled brake. It is recommended that if pavement paint is to be used for painting the entirety of the SBBL, that a prior test strip be painted to observe how well it wears before investing in paint for the entire facility. The pavement surface should drain well and be free of running water and puddles. The pavement surface should also be inspected and cleaned of oil stains, sand and debris that could cause a bicyclist to slip or lose control. 
Table 4.9 - Examples of Colored Lane Paint Options

\begin{tabular}{|c|c|c|c|}
\hline Type & Color & Sample Location & Notes \\
\hline $\begin{array}{l}\text { Standard Latex } \\
\text { Road Paint }\end{array}$ & Green & $\begin{array}{l}\text { Hennepin Ave, } \\
\text { Minneapolis, MN a }\end{array}$ & Barely visible after 9 months \\
\hline $\begin{array}{l}\text { Truffle Coating } \\
\text { Colored Epoxy }\end{array}$ & Green & New York City, NYb & $\begin{array}{l}\text { Developed for use on highways with heavy } \\
\text { traffic. Has a 5-10 year lifespan. }\end{array}$ \\
\hline $\begin{array}{l}\text { Asphacolor Integral } \\
\text { Color for Hot Mix }\end{array}$ & $\begin{array}{l}\text { Brick } \\
\text { Red }\end{array}$ & $\begin{array}{l}\text { Panama City Beachc } \\
\text { (proposed) }\end{array}$ & Proposed \\
\hline $\begin{array}{l}\text { Epoxy-modified, } \\
\text { acrylic, waterborne } \\
\text { coating }\end{array}$ & Green & Boston, MA & \\
\hline Thermoplastic & Green & $\begin{array}{l}\text { Portland, OR and } \\
\text { Austin, TX }\end{array}$ & $\begin{array}{l}\text { Quality of pavement is a contributing factor to } \\
\text { quick deterioration of thermoplastic }\end{array}$ \\
\hline $\begin{array}{l}\text { Truffle Coating } \\
\text { Colored Epoxy }\end{array}$ & Red & Philadelphia, PA & Barely visible \\
\hline $\begin{array}{l}\text { Thermoplastic and } \\
\text { Paint }\end{array}$ & Green & Los Angeles, CA & $\begin{array}{l}\text { Primary use of thermoplastic, while some } \\
\text { sections with poor pavement quality are } \\
\text { painted with standard latex road paint and then } \\
\text { thermoplastic is applied at a later date pending } \\
\text { roadway repairs }\end{array}$ \\
\hline \multicolumn{4}{|c|}{$\begin{array}{l}\text { a City of Minneapolis } 2011 . \\
\text { b Association of Pedestrian and Bicycle Professionals. Webinar: Bicycle and Pedestrian Facility Design within a } \\
\text { Constrained Right-of-Way. June 15, } 2011 . \\
\text { c HHI Design et al. } 2008 . \\
\text { dCharles Carmalt, Bicycle and Pedestrian Coordinator, Philadelphia Mayor's Office. Survey response, August 5, } 2011 .\end{array}$} \\
\hline
\end{tabular}

\section{Behavior of Bicyclists, Bus Operators, and Other Road Users}

The behaviors of travelers affect the safety of SBBLs. Its success depends on other motorists refraining from traveling on it or using it inappropriately. Examples of inappropriate use include general traffic that uses the SBBL as a through lane, or when skateboarders begin to use it, or when pedestrians wait in it to cross the general traffic lanes mid-block. Similarly, safety depends on travelers avoiding unnecessary conflict with other travelers and managing unavoidable conflicts.

\section{Leapfrogging}

While the incidence of leapfrogging is anticipated as a problem by those who are considering the implementation of SBBLs, few examples of leapfrogging problems were found during this study. The Bicycle and Pedestrian Planner for the City of Baltimore said, "The leapfrogging concept is overrated. Cyclists typically pass buses and quickly leave them in the wake." 29 This observation may be more apparent for downtown locations than for suburban locations where bus operating speeds can approach the speed limit because bus stops are spaced farther apart. The Ocean City case study is the only location identified where leapfrogging may have been a problem. While Ocean City did not do a study to determine the extent of leapfrogging, the decision by officials to keep the SBBLs as they were was made based upon a lack of evidence that the SBBLs were actually unsafe. Other studies contain documented observations of bike/bus interaction in places where there are high

29 Nate Evans, Bicycle and Pedestrian Planner, City of Baltimore, Interview, June 28, 2011. 
volumes of both bicyclists and buses, including the Hennepin Avenue Green Pavement Study in Minneapolis (City of Minneapolis 2011) and the TRL study in the U.K. (Reid and Guthrie 2004). These studies did not cite leapfrogging as a problem, per se, but instead focused upon conditions under which a bicyclist overtakes a bus a single time, and vice versa.

It is suspected that leapfrogging has not been identified as a problem because both bus operators and bicyclists want to avoid repeatedly passing each other and will adjust their speeds to minimize it. As a result, bike/bus interaction is generally low. For example, Table 1.1 in the introductory Chapter 1 of this report shows that over a 36-hour period of videotaping during the "Hennepin Avenue Green Pavement Study", there were just 21 instances where a bike overtook a bus or a bus overtook a bike, from observations at three locations along Hennepin Avenue, combined. More observational studies should be done to examine leapfrogging.

\section{Bus Operator Training}

In the cities contacted for case studies for this project, none of the agencies reported developing training for bus operators specifically targeted toward SBBL operations, although Washington, D.C. has been discussing this, and the training material for Ocean City, MD covers situations that apply in SBBLs. A number of the agencies contacted indicated that, because of increases in bicycle use or as the result of discussion with local bicycling organizations, they have been revising their training materials to pay greater attention to the topic of operating safely in the presence of bicycles.

Most case study contacts perceived that bicyclists have been using the SBBLs properly. However, in several instances, respondents indicated that bus operators think that SBBLs are less safe for bicyclists than are dedicated bicycle lanes. Buses have large blind spots, operators are trained to stay in their lane, and they perceive that bicyclists tend to stay in lanes marked for bicycle use when these are available. This helps the operator know where to look for bicyclists when it becomes necessary to change lanes or direction. In an SBBL, a bicyclist can be anywhere in the lane, which makes it more difficult for the operator to discern the location of the bicyclist before making the change. The training materials reviewed for bus operators in Chicago, Washington, D.C., Connecticut, and Delaware all stress the importance of checking carefully for bicyclists in any situation before changing the lateral position of the bus, whether bike lanes are present or not. The trainer in Washington, D.C. suggested that a diagram in their present training materials may be revised to encourage operators to give greater distance separation between buses and bicyclists.

The training materials reviewed for Chicago (http://www.chicagobikes.org/video) stressed that bus operators should do the following, which would apply to SBBLs as well.

- Always assume that there could be a bicyclist on their right, and check for this.

- Be alert when following or overtaking a bicyclist who is riding near parked cars that the bicyclist may need to swerve suddenly to avoid an opening car door.

- When passing a bicyclist, maintain steady speed, do not accelerate, and give the bicyclist at least three feet of space to the side-more if conditions allow. If conditions do not allow three feet of clearance when passing, then the bus operator must not pass the bicyclist, but instead follow or stop, depending on circumstances.

- Assume that bicyclists will not hear an overtaking bus before they see it passing them, because the engine is at the back of the bus, and many buses are quiet.

- Remember the bicyclists they pass, in case a passenger requests a stop just after the bus has passed a bicyclist.

- When overtaking, or being passed by a bicyclist in an area with potential conflicts, follow the bicyclist rather than trying to pass. 
- Bear in mind that bicycle lane markings end at intersections, and that bicyclists may change lanes in anticipation of where they need to turn or locate themselves on the other side of the intersection.

- Be aware that bicycle training advises bicyclists to be visible at intersections, including placing themselves fully in the lane, in front of stopped vehicles, to improve their safety.

- Be aware that the vehicles that bus operators must maneuver around when turning may block their view of bicyclists at the intersection.

- Be aware that a front-of-bus bicycle carrier changes the turning geometry of the bus.

- Check mirrors and slow if bicyclists are on the right, before pulling over.

- Adjust mirrors to ensure that a bicycle passing three feet from the bus will be visible in the mirrors.

- Check mirrors before changing lanes at intersections (Chicago Bike Program 2010).

Because the effectiveness of checking mirrors is limited by blind spots, identifying the presence of a bicyclist could be aided by equipping buses with a sideview video system or some other collision avoidance system. These include Lidar-based systems, radar-based systems, ultrasonic-based sensors, and computer vision systems. These could provide greater coverage and visibility than mirrors (Lin et al. 2010). These technologies could not only prevent crashes with bicyclists located in blind spots but prevent other crash types as well.

The Chicago materials also suggested the following for bicyclists:

- Never pass a bus on the right when it appears to be stopping.

- When passing a bus, allow the same three feet of clearance that the bus operator is expected to provide when passing a bicycle. This reduces the risk of being in the driver's blind spots.

- When a bus follows rather than passing, assume that the bus operator may be doing this to watch out for the bicyclist's safety; the bicyclist should remain visible and ride predictably.

- Refrain from lane splitting, and do not pass a stopped bus on the right. Be aware that a bus may need to veer to the left before making a right turn, and that this may give the initial impression that the bus is proceeding straight through the intersection while ignoring its right turn signal (Chicago Bike Program 2010).

Materials from the Delaware DOT (DelDOT Bicycle Program n.d.) and the Central Connecticut Bicycle Alliance (Central Connecticut Bicycle Alliance n.d.) focus on bus operators, not bicyclists. These materials cover much of the same information as Chicago, but offer some additional suggestions:

- Be aware that experienced cyclists can travel as fast as $25-30 \mathrm{mph}$, and in general be aware that bicyclists may be moving faster than perceived.

- Be aware that bicyclists are taught to ride toward the center of the lane when the lane is too narrow for bicycles and motor vehicles to pass safely within the lane.

- Do not pass a bicyclist and then turn right; in Connecticut, it is against state law to do this if it means that the bicyclist has to avoid the turning bus.

- Inspect brake and turn-signal lights daily, because bicyclists depend on these to determine how to operate safely near the bus.

- Delaware advises against using the bus horn to communicate with bicyclists.

The Washington Metro bus operator training materials instruct bus operators to give bicyclists four to five feet of lateral clearance, not just three feet, and to maintain at least one bus-length of distance when following bicyclists. When passing bicyclists, bus operators are instructed to merge at least partly into the adjacent lane at the left, to give clearance for the bicyclist in the restricted lane. Bus 
operators are advised to pull close to the curb at a stop, so as not to encourage bicyclists to pass the stopped bus on the right (WMATA 2011).

All of these materials place some emphasis on teaching bus operators what bicyclists are taught and explain bicyclist behavior. Transit agencies can make use of a variety of formats for instruction, including training manuals, videos, staff meetings, and bicycling classes. Bus operation on an SBBL could also be incorporated as part of the driving test in the Florida Bus Roadeo.

At least one transit agency (not identified by source) has used its bus simulator with mixed groups consisting of bicyclists and bus operators, to help each group better understand situations from the other's perspective (Maiello 2011). While this is impractical for teaching all bicyclists, it can be useful for teaching bicycle advocates and instructors who can then communicate safe riding practices to other bicyclists.

\section{Enforcement}

Several communities have experienced difficulties with enforcing the designated restrictions on the use of the SBBL lanes. The most common problem cited for this study is when drivers of other motor vehicles are allowed to make right turns from the lane, and some of them begin using the lane as a "through" lane rather than just as a turning lane. This has been a particular problem in Washington, D.C., Philadelphia, and Minneapolis. One of the respondents from Philadelphia reported that the original plan for the lanes did not permit right turns, but that the city council allowed right turns after political opposition to the original plan. In Minneapolis, the lanes were originally designated for rightturns only, but the "only" was removed from markings after local police determined that the volumes of traffic and turns made it impractical to enforce.

Other problems arose in Ocean City, MD, when skateboarders, roller bladers, or joggers use the lanes. In Philadelphia, delivery trucks blocked the SBBL when stopping to deliver goods. In Tucson, AZ, and in Ocean City, bicyclists rode in the lane against the designated flow of traffic. In Seattle, when parking was permitted in the lanes during off-peak hours, failure to remove the cars before the next peak was also a problem, although the respondent there did not consider this a serious problem.

There is agreement that frequent unpermitted use of SBBLs degrades their safety, performance, and intended benefits, and in extreme cases, this made the lanes no better than general purpose lanes. Several survey respondents suggested that, where possible, SBBLs should be designed and implemented in ways that do not require enforcement. However, they provided little guidance about such designs. A respondent in Washington, D.C., suggested that it might be easier to educate users about longer lanes. Where special rules applied only to a few blocks, this caused confusion. Another Washington, D.C., respondent believed that it would help enforcement to use colored pavement and place the SBBL against the curb rather than next to on-street parking. However, there was no evidence to support or refute the effectiveness of such designs in reducing the need for enforcement. One respondent suggested that enforcement is difficult in Washington, D.C., due to tourist unfamiliarity with SBBLs. However, a respondent in Ocean City, MD, observed that tourists who use the SBBLs rode with the flow of traffic more than did local commuters who bicycle. One respondent questioned whether SBBLs would be workable near universities with heavy bicycle traffic, expressing the opinion that university bicyclists are much less likely to follow traffic laws than are others.

SBBLs are not yet common in Florida or the rest of the U.S., and there has been little study of what design elements are more likely to support proper use. If compliance with traffic regulations is low in an area, then education and enforcement may become a large, recurring expense. Sustained 
enforcement of rules regarding the SBBL and a commitment to both public education and information campaigns would need to be made up front as part of the overall plan for establishing and operating the facility. In such cases, this may argue against developing an SBBL and for an option that requires less enforcement.

With regard to illegal SBBL users, where there are existing intersection enforcement issues, such as rolling stops, many local governments have installed cameras at intersections as part of electronic surveillance. These same recordings of intersection activity could also potentially pick up other infractions, such as motorists in SBBL/right turn lanes passing straight through the intersection.

With regard to not yielding right-of-way when required, public information and education may be the best way to address this. Many facility users may fail to yield right-of-way simply because they do not know the rules. It is recommended to develop and implement a public information campaign using a variety of media, such as brochures, Web sites, and signs on rear panels of buses. A few examples of education to help enforce proper use of SBBLs are provided here:

- Buses in Australia and Colorado, as reported in DVRPC and SEPTA (2009, 24), and in Florida, are equipped with rear panel signs reminding motorists to yield to buses that are reentering a traffic lane.

- The City of Minneapolis developed a Web site and a brochure (reproduced in this report as Appendix B) in advance of the opening of the two-way conversion of Hennepin Avenue and 1st Avenue. The information explained how motorists and bicyclists should use the SBBL. 30

- The City of Portland, OR used a combination of signage and colored lanes to remind motorists that they are crossing over bicycle lanes and that motorists must yield to bicyclists (as reported in DVRPC and SEPTA 2009 24-25).

- The Delaware Valley Regional Planning Commission in Pennsylvania recommended the adoption of a "yield/courtesy pyramid" policy to clarify right-of-way (DVRPC and SEPTA 2009, 28).

A number of other ideas to convey information to the public are included here:

- Public information about bicycle safety could be provided as inserts as part of annual mailed motor vehicle registration notices.

- Other information outlets might include the Web site of the Florida Department of Highway Safety and Motor Vehicles or the equivalent in other states.

- Bus operators and other motorists could be provided with information about common riding mistakes by bicyclists. This information is important to help bus operators and motorists anticipate and watch for unpredictable bicyclist behavior and locations.

- Bicycle safety information could also be conveyed through the Safe Routes to School Program that targets elementary and middle school students and their parents.

- Bicycle safety curricula could also be incorporated into public school physical education classes and developed as part of the curriculum in driver education classes.

Florida State bicycle law could be better emphasized as part of motor vehicle driver license testing. The law regarding bicycling in the 2012 Florida Driver's Handbook is easy to overlook (FL DHSMV 2012, 30-31). The Florida Driver's Handbook could include highlighted information about sharing the road with bicyclists. The driver license test requires that candidates for a license must correctly answer 15 out of 20 road rule questions. The test could include additional questions about

30 City of Minneapolis, "Hennepin and 1st Avenues Switch to Two-Way Traffic," Accessed at: http://www.minneapolismn.gov/bicycles/projects/Hennepin-Ave , (June 13, 2012). 
sharing the road with bicyclists. As more people begin to bicycle for transportation, there is more potential for conflicts with older drivers who took their licensing test years ago and have grown unfamiliar with the law regarding bicycling.

The Pima Association of Governments provides in its Regional Plan on Bicycling, recommended actions to keep law enforcement personnel up-to-date on best practices to enforce laws regarding bicycling (Pima Association of Governments 2009, 33-36):

- Action 1. Update or develop materials for use by law enforcement personnel to support their education and enforcement efforts.

- Action 2. Work with law enforcement to acquire or develop training materials for officers, to increase their understanding of and attention to legal and illegal bicycling and motorist behaviors.

- Action 3. Commit a defined portion of law enforcement time (both police bicycle patrols and motor vehicle patrols) to target specific research-based bicyclist and motorist offenses for focused enforcement.

- Action 4. Develop and implement a consistent, year-round traffic law education program for law enforcement personnel which focuses on teaching police officers a balanced education and enforcement program for improving motorist and bicyclist compliance with traffic laws.

- Action 5. Periodically review, and update as needed, national "best practices" in cyclist and motorist enforcement.

Bus operators who regularly drive SBBL routes could also assist in law enforcement by providing their observations about which locations, days, and times they see illegal use of the SBBL. Such a partnership between the transit agency and local enforcement could help reduce the enforcement costs. 


\section{Chapter 5: Need for Additional Research}

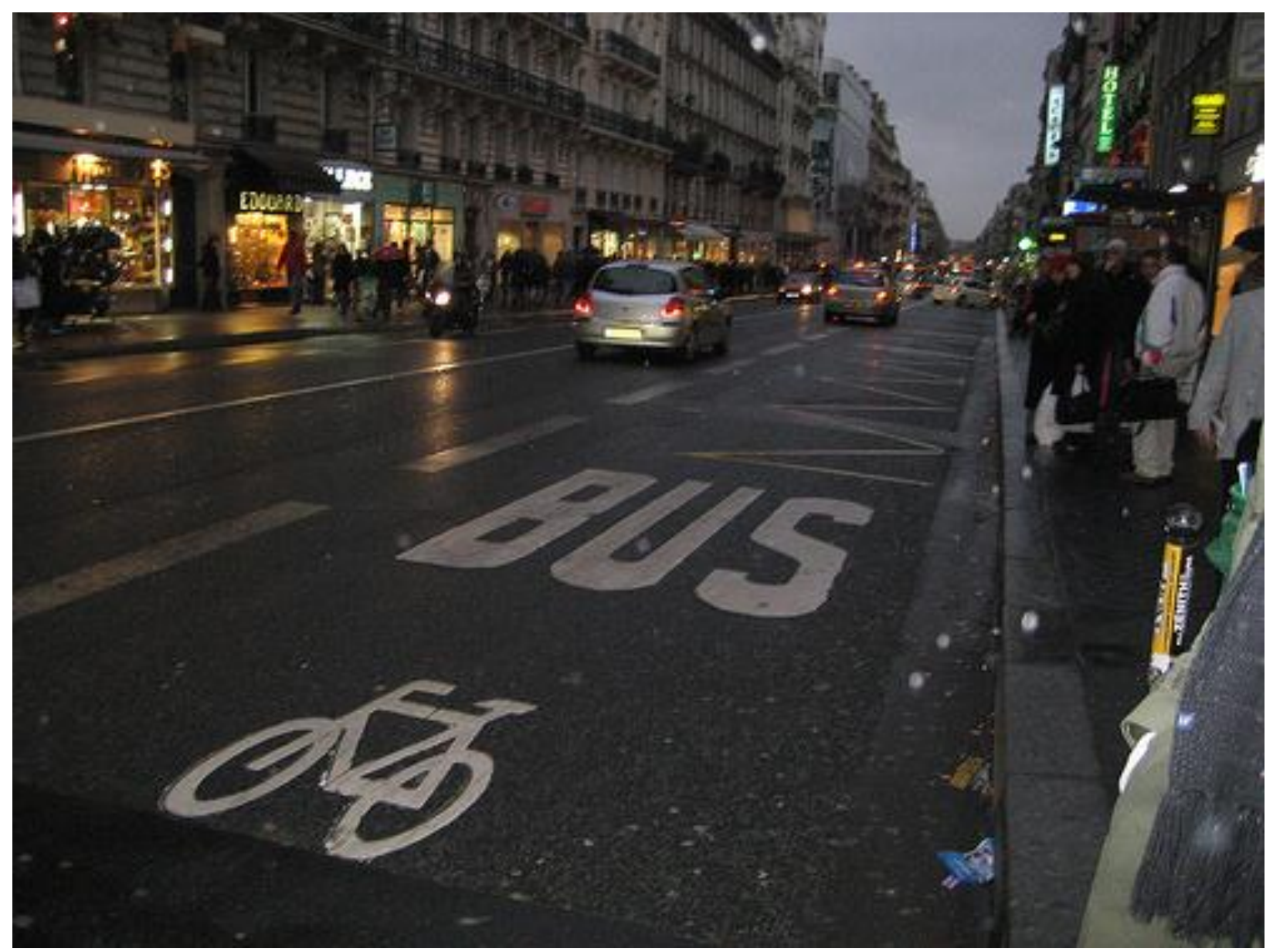

Figure 5.1 - Paris, France

Credit: John Ciccarelli

\section{Needs for Additional Research}

As noted throughout this report, very little research has focused specifically on SBBLs, and it has been necessary for the current study to examine research and guidance dealing with related topics, to infer what may be appropriate for SBBLs. 


\section{Effect of SBBLs on Encouraging Bicycling}

Additional research is needed to determine the extent to which SBBLs affect the amount of bicycling (do they induce more people to ride?) and the routes that bicyclists choose. Such research will need to count and survey bicyclists before and after the SBBL is implemented, both along he SBBL, and along comparable streets and nearby corridors, with attempts to control for bicycle infrastructure and improvements in the vicinity of the SBBL.

Little effort has been made to measure the effect that installing an SBBL has on bicycle use of the facility. Minneapolis appears to be the only case in which bicycle traffic volumes were measured before and after the installation of SBBLs, and the results there were not well controlled. Measurements there showed that bicycle volumes on the street decreased after the SBBL was put in place, but other improvements were made to bicycling infrastructure in the immediate vicinity, and bicyclists may have changed their routes to use these other facilities. A number of the persons interviewed and surveyed in other cities reported anecdotal increases in bicycle volumes on their SBBLs, but several of these also noted general increases in bicycling in their cities. Anecdotal reports of a decrease in bicycling on the Rehoboth Beach SBBL also mentioned improvements on an alternative route perceived to be safer. In addition, several of the current SBBLs in the U.S. were created from existing bus lanes that bicyclists were already using, and the new designation might have little effect on the number of bicyclists who use them.

\section{Better Ways to Collect Bicycle Traffic Count Data}

Data on numbers of buses is relatively easy to obtain, but data on numbers of bicyclists and of movements within the lanes remain expensive to collect, and therefore its coverage is spotty. For example, Minneapolis recorded three days' worth of video at each of four locations, and still did not have enough observations to achieve 95 percent confidence that right-turning motor vehicles were or were not giving bicyclists the three feet of clearance required by Minnesota state law.

Where SBBLs are implemented in downtown areas on streets with tall buildings, it may be practical to record video looking down on the street, rather than recording video at street level. Although research has been developing new technology to record bicycle numbers and movements in a corridor (Somasundaram, Morellas, and Papanikolopoulos 2012; Nordback et al. 2011), there is still a need for research and development on less expensive, easier-to-use methods for collecting this kind of data.

\section{Mobility Impacts of an SBBL upon All Modes}

Research is needed to estimate the mobility and level of service upon all modes using a street with an SBBL. This will require planning for such analysis and collecting data before the SBBL is implemented. Such analysis would include those streets targeted for SBBLs as well as nearby corridors.

This study identified no cases in which such as analysis has been done in the United States (the evaluation survey of bicyclists using Hennepin Avenue in Minneapolis did this for bicyclists, but with a design that did not permit separation of bicycle trips from trips that bicyclists make by other modes). Survey respondents in several cities commented that the SBBLs had or, in a few cases, had not improved transit or bicycle service, but it is not clear that these assessments are based on analysis of data. Aside from a study conducted by Genesis Group estimating level of service for a proposed SBBL in Tallahassee, no other instances have been identified in which the effects of existing SBBLs on general purpose traffic (capacity or delay) have been measured. 


\section{Bicycle Level of Service (LOS) Measurement Refinements}

a. The measures used for estimating bicycle LOS (prospectively, for planning) do not account for designated shared facilities, whether marked with Shared Lane Markings for use with general vehicle traffic, or designated as SBBLs. Research should be undertaken to refine bicycle LOS measures to include shared facilities.

b. Existing bicycle LOS measures focus upon arterial streets that often provide designated on-street facilities, such as bicycle lanes. However, many people are unwilling to ride on arterial streets, particularly where there are large volumes of faster-moving traffic. Research also should consider bicycle LOS measurement refinements that allow for consistent treatment of both arterials and minor streets that have lower volumes of traffic (where traffic volumes often are not recorded). This research should be undertaken in conjunction with c. below.

c. Because one of the objectives in implementing SBBLs is to encourage more bicycling, research should also focus upon bicycle LOS measurement refinements to account for bicyclists of varying skill levels, to relate those LOS measures to the proportion of the population that might be willing to ride when provided with different levels of service.

\section{Crash Analysis of SBBLs Compared to Other Bicycle Facility Types}

There is a need for additional research to compare the safety of SBBLs. Crash and use data should be collected before and after the establishment of an SBBL. This needs to be done for multiple SBBLs, and then the results should be compared to determine their safety relative to separate and adjacent bicycle lanes and other bicycle facility types such as lanes with Shared Lane Markings. The way that an SBBL is designated affects how it can be marked. Research is needed to determine whether SBBLs that are designated as such (and therefore cannot use Shared Lane Markings) are safer and more effective than lanes that are designated as bus-only lanes and are marked with Shared Lane Markings.

Except for the SBBLs in Minneapolis, there has not been solid comparison of crash frequency and severity before and after the lane was established. Even the Minneapolis data was collected over too short a period to rule out year-to-year fluctuations that are common in bicycle crash incidence. The reallocation of right-of-way on Nebraska Avenue in Tampa (part of a "road diet" that also included a bicycle lane shared with transit at bus stops) led to a 64 percent reduction in total crash rates per million vehicle miles traveled, and a 66 percent reduction in the average number of bicycle crashes per year (Chin 2011). However, the reduced crash rates may have resulted more from the reduction from four lanes to two plus a center left-turn-only lane. The reduced crash rates also may have resulted from a reduction in traffic volume of about 25 percent, than from the introduction of the bike lane that is shared with transit at bus stops. No data were reported on the incidence of crashes between bicycles and buses.

Perhaps more basic to the issue of crash analysis of SBBLs is the level of quality of the crash data. The data on crashes involving bicycles tends to be limited to the most severe crashes. Crashes that do not involve fatalities, serious injuries, or major property damage often are not reported. Thus, in an evaluation of safety, it is difficult to consider the less serious crashes that may be much more common. Research needs to be done on ways to reduce underreporting of bicycle crashes. DVRPC study authors noted that in their experience, non-motorized crash data is often mislabeled in the database, introducing some degree of uncertainty (DVRPC and SEPTA 2009, 5). 


\section{Crash Analysis of SBBLs of Different Designs}

Crash analyses should be conducted for SBBLs of different designs, both before and after their establishment. Elements of safety include the following.

- Impact of frequency and length of gaps in traffic in the adjacent lane to allow passing in a narrow SBBL.

- Volumes of right-turning traffic above which a bus lane or an SBBL is not advisable.

- Bus boarding volumes by stop location and time of day and its impact on SBBL function.

- Determination of the maximum safe posted speed limit for motor vehicles, relative to lane width and volumes of bicyclists, buses, and other motor vehicles, including right-turning vehicles.

- Frequency and characteristics of interactions among roadways users.

- Effect of Shared Lane Markings within an SBBL. MUTCD Section 9C.07 prohibits placement of Shared Lane Markings in designated bicycle lanes. In Minneapolis, green pavement was used to designate a bicycle advisory cycle lane within the Hennepin Avenue SBBL. This SBBL also contained Shared Lane Markings. The City of Minneapolis had received FHWA approval to test this treatment. Building upon the testing of the Hennepin Avenue SBBL, it is recommended that an application be made to FHWA to test the use of Shared Lane Markings within selected SBBLs. These experiments would ascertain what they communicate to motorists and bicyclists about the use of the SBBL.

- Effect of bicycle advisory cycle lanes within an SBBL. Research is needed to determine the actual relationship between advisory cycle lanes within an SBBL and crash rates. If advisory cycle lanes improve safety of SBBLs, then they should be made a regular part of SBBL design. If they have no effect on safety but make bicyclists feel safer, then they would be useful for improving perceived safety and encouraging more bicyclists to use SBBLs.

\section{Use of Intersection Red Light Cameras to Enforce SBBL Restrictions}

It would be useful to research whether technologies being developed and deployed for enforcement of other traffic laws (for example, cameras to help enforce stopping at traffic signals) might also be useful in helping to enforce restrictions on SBBL use, such as permitting use by right-turning general traffic but not through traffic, and enforcing the three-foot lateral clearance law.

\section{Evaluation of Alternative Bus Stop Treatments}

Alternatives for guiding bicyclist position at the left side of an SBBL, for overtaking at bus stops, need to be studied, to determine their effect on bicyclists' behavior, including when there is no bus at the bus stop. 


\section{References}

Alta Planning + Design, and Gannett Fleming West, Inc. 2010. “Innovative Design Treatments." In Albuquerque Bikeways and Trails Master Plan Update. Albuquerque, NM: City of Albuquerque. Accessed June 25, 2012 at http://www.cabqbikewaysandtrails.com/cabq/project-documents/.

Alta Planning + Design, and Parisi Associates. 2003. Supplemental Design Guidelines, City of San Francisco Bicycle Plan Update. San Francisco, CA: City of San Francisco, Department of Parking and Traffic. September Draft. Accessed June 25, 2012 at http://www.altaplanning.com/App Content/files/fp docs/SFDesignGuidelines 092903 sml.pdf.

AASHTO (American Association of State Highway and Transportation Officials). 1999. Guide for the Development of Bicycle Facilities. 3rd ed. Washington, D.C.: AASHTO.

Austroads. 2011. Cycling Aspects of Austroads Guides. Publication No. AP-G88/11. Sydney, Australia: Austroads.

Austroads. 2010. Guide to Road Design: Part 3: Geometric Design. Report AGRD03/09. Sydney, Australia: Austroads.

Bicycle Coalition of Greater Philadelphia. Last modified 2006-08 Comparison. "Fall 2008 Bike Counts at Broad and Chestnut." Accessed March 1, 2012 at http://www.bicyclecoalition.org/resources/statistics/2008_counts.

Bicycle Coalition of Greater Philadelphia. Last modified 2008. "Double Dutch: Bicycling Jumps in Philadelphia." Accessed September 13, 2011 at http://www.bicyclecoalition.org/files/Double Dutch-Bicycling Jumps in Philadelphia.pdf.

Bike Del blog. Comments originally accessed May 26, 2011. .Accessed June 25, 2012 at http://www.bikede.org/?s=rehoboth.

Birk, M., and R. Geller. 2006. "Bridging the Gaps: How the Quality and Quantity of a Connected Bikeway Network Correlates with Increasing Bicycle Use." 85th Annual Meeting, Washington, D.C.: Transportation Research Board of the National Academies.

Bisbee, Gene. 2012. "20 States Require Motorists Give 3 Feet or More when Passing Cyclists." Biking Bis Bicycle Touring Blog. Blog entry April 1. Accessed June 19, 2012 at http://www.bikingbis.com/2012/04/01/20-states-require-motorists-give-3-feet-or-more-whenpassing-cyclists/.

Capital Regional District. 2011. District Pedestrian and Cycling Master Plan Design Guidelines. British Columbia, Canada: Capital Regional District. Accessed September 12, 2011 at http://www.crd.bc.ca/regionalplanning/transportation/cyclingwalking/documents/PCMP Design Guidelines lowRes.pdf. 
Cardiff Cycle Network. 2011. Cardiff Cycle Design Guide. Cardiff, U.K.: Cardiff Council. Accessed December 7, 2011 at http://www.keepingcardiffmoving.co.uk/uploads/documents/37/original/Design_Guide_FINAL. pdf?1319638020.

Central Connecticut Bicycle Alliance. n.d. "Tips for Safe Bus Operation around Bicyclists." Accessed March 1, 2012 at http://connbikes.org/pdfs/bike_bus_share_road.pdf.

CROW (Centre for Research and Contract Standardization in Civil and Traffic Engineering). 2007. Engelstalige ontwerphandleiding voor fietsverkeer [Record 25: English design manual for bicycle traffic]. The Netherlands: CROW.

CROW (Centre for Research and Contract Standardization in Civil and Traffic Engineering). 1994. Record 10: Sign Up for the Bike: Design Manual for a Cycle-Friendly Infrastructure. The Netherlands: CROW.

Chicago Bike Program. 2010. "Share the Road: Buses and Bicycles." Video on website posted February 7. City of Chicago Department of Transportation. Accessed June 20, 2012 at http://www.chicagobikes.org/video/?loadVideo=buses_and_bicycles.

Chimba, Deo, Thobias Sando, and Valerian Kwigizile. 2010. "Effect of Bus Size and Operation to Crash Occurrences." Accident Analysis \& Prevention 42 (6): 2063-2067.

Chin, Ronald. 2011. "Nebraska Avenue (SR 45) between Kennedy Boulevard and Hillsborough Avenue." Association of Pedestrian and Bicycle Professionals webinar. PowerPoint presentation June 15.

City of Ft. Worth and Kimley-Horn and Associates. 2011. "Bicycle Facilities Pilot Program, Construction Drawings." Ft. Worth, City of Forth Worth.

City of Minneapolis. 2007. Access Minneapolis Downtown Action Plan, 10-Year Transportation Action Plan. Minneapolis, MN: City of Minneapolis. Accessed June 25, 2012 at http://www.ci.minneapolis.mn.us/publicworks/transplan/index.htm.

City of Minneapolis. 2010a. City of Minneapolis Bicycle Facility Design Guidelines. Minneapolis, MN: City of Minneapolis. Accessed June 25, 2012 at http://www.minneapolis.mn.gov/bicycles/projects/plan.

City of Minneapolis, Department of Public Works, Traffic \& Parking Services Division. 2010b. "Hennepin Avenue and 1st Avenue Two-Way Conversion Evaluation Report." Minneapolis, MN: City of Minneapolis. July.

City of Minneapolis, Department of Public Works, Traffic and Parking Services Division. 2011. "Hennepin Avenue Green Shared Lane Study." Minneapolis, MN: City of Minneapolis. Accessed at http://www.ci.minneapolis.mn.us/www/groups/public/@publicworks/documents/images/wcms1p085711.pdf

City of Panama City Beach. 2010. "Panama City Beach Community Redevelopment Area." City of Panama City Beach, FL: Community Redevelopment Agency. 
City of Portland Office of Transportation Planning, as reported in Nabti 2002, 99-103.

Cleveland, F. and F. Douma. 2008. The Impact of Bicycling Facilities on Commute Mode Share. Report MN/RC 2008-33. Minneapolis, MN: Minnesota Department of Transportation.

CTC (Cyclists' Touring Club) - The UK's National Cyclists' Organization. “Cycle Tracks and Lanes: CTC View," Accessed June 19, 2012 at http://www.ctc.org.uk/DesktopDefault.aspx?TabID=4703.

Danaher, Alan R. 2010. Bus and Rail Transit Preferential Treatments in Mixed Traffic: A Synthesis of Transit Practice. TCRP Synthesis 83. Washington, D.C.: Transportation Research Board of the National Academies. Accessed June 20, 2012 at http://onlinepubs.trb.org/onlinepubs/tcrp/tcrp_syn_83.pdf.

Danaher, Alan R., K. Blume, H. S. Levinson, and S. Zimmerman. 2007. TCRP Report 118: Bus Rapid Transit Practitioner's Guide. Washington, D.C.: Transportation Research Board of the National Academies.

DeIDOT Bicycle Program. n.d. "Information to Bus Operators on Bicycle Safety." Trifold brochure. Dover, DE: Delaware Department of Transportation, Statewide and Regional Planning. Accessed June 19,2012 at http://www.deldot.gov/information/community programs and services/bike/pdf/bus driver trainin g.pdf.

DVRPC (Delaware Valley Regional Planning Commission), and SEPTA (Southeastern Pennsylvania Transportation Authority). 2009. "Bicycle-Bus Conflict Area Study." Philadelphia, PA: DVRPC. Accessed August 19, 2011 at

ftp://ftp.dot.state.pa.us/public/pdf/BPR_PDF_FILES/Documents/Research/CompleteProjects/Reduc ing Fatalities/Bicycle Bus Area Conflict Study.pdf.

Department of the Environment, Transport and the Regions. 1997, "Keeping Buses Moving." Local Transport Note 1/97. London, U.K.: The Stationary Office.

Department for Transport. 2003. Traffic Signs Manual. London, U.K.: The Stationary Office.

Dillon Consulting. 2009. "Design Treatments for Bicycles and Buses on Arterial and Collector Roads: A Recommended Practice." Ottawa, Canada: City of Ottawa.

District of Columbia Office of Planning, and District Department of Transportation. 2010. "Mount Vernon Square District Design Project." Washington, D.C.: District Department of Transportation.

Dowling, Richard G., David B. Reinke, Aimee Flannery, Paul Ryus, Mark Vandehey, Theodore A. Petritsch, Bruce W. Landis, Nagui M. Rouphail and James S. Bonneson. 2008. "NCHRP Report 616: Multimodal Level of Service Analysis for Urban Streets." Washington, D.C.: Transportation Research Board of the National Academies. Accessed June 19, 2012 at http://onlinepubs.trb.org/onlinepubs/nchrp/nchrp_rpt_616.pdf.

Dublin Transportation Office. 1997. Cycle Track Design Guidelines Manual. Dublin, Ireland: 1997. Accessed March 1, 2012 at http://www.dto.ie/web2006/chapter5.pdf. 
Dutch Institute for Road Safety and Research (SWOV). 2010. "SWOV Fact Sheet: Functionality and Homogeneity." Leidschendam, The Netherlands: SWOV.

Duthie, Jennifer, John F. Brady, Alison F. Mills, and Randy B. Machemehl. 2010. "Effects of On-Street Bicycle Facility Configuration on Bicyclist and Motorist Behavior." Transportation Research Record: Journal of the Transportation Research Board, No. 2190. Washington, D.C.: Transportation Research Board of the National Academies. 33-44.

FHWA (Federal Highway Administration). 1977. "A Bikeway Criteria Digest: The ABCDs of Bikeways." FHWA-TS-77-201. Washington, D.C.: U.S. Department of Transportation.

FHWA (Federal Highway Administration). 2009. Manual on Uniform Traffic Control Devices for Streets and Highways (MUTCD). 2009 ed. Chapter 2G, Preferential and Managed Lane Signs; Chapter 3D, Markings for Preferential Lanes, and Part 9: Traffic Control for Bicycle Facilities. Washington, D.C.: U.S. Department of Transportation. Accessed March 1, 2012 at http:// mutcd.fhwa.dot.gov/kno_2009.htm.

FHWA (Federal Highway Administration). 2012. "Status in MUTCD of Different Bicycle-Related Treatments." Table. Washington, D.C.: U.S. Department of Transportation. Last modified January 9 , 2012. Accessed March 16, 2012 at http://www.fhwa.dot.gov/environment/bikeped/mutcd_bike.htm.

Florida Department of Highway Safety and Motor Vehicles (DHSMV). 2012. Florida Driver's Handbook. Tallahassee, FL: DHSMV. Accessed June 13, 2012 at http://www.flhsmv.gov/handbooks/EnglishDriverHandbook.pdf.

FDOT (Florida Department of Transportation). 2012a. "Design Standards FY 2012/2013, Index 17347, Bicycle Markings." Tallahassee, FL: FDOT. Last revision: January. Accessed June 20, 2012 at http://www.dot.state.fl.us/rddesign/DS/12/IDx/17347.pdf.

FDOT (Florida Department of Transportation). 2012b. Plans Preparation Manual. Volume 1, Topic 625-000-007. Tallahassee, FL: FDOT. January 1. Accessed June 20, 2012 at http://www.dot.state.fl.us/rddesign/PPMManual/2012/Volume1/2012Vol1.shtm.

FDOT (Florida Department of Transportation). 2009. Quality/Level of Service Handbook. Tallahassee, FL: Systems Planning Office. Accessed June 20, 2012 at http://www.dot.state.fl.us/planning/systems/sm/los/pdfs/2009FDOTQLOS_Handbook.pdf.

Furth, Peter G., Daniel M. Dulaski, Mapolo Buessing, and Parham Tavakolian. 2010. “Parking Lane Width and Bicycle Operating Space." Transportation Research Record: Journal of the Transportation Research Board, No. 2190. Washington, D.C.: Transportation Research Board of the National Academies. 45-50.

Gan, Albert, Allan Yue, Joan Shen, and Fang Zhao. 2002. "Development of Operational Performance Models for Bus Lane Preferential Treatments." Miami, FL: Florida International University, Lehman Center for Transportation Research. July.

Genesis Group. 2009. "West Tennessee Street (US90/SR10) Transit Corridor Study: LOS Analysis and Preliminary Concept Plan." Tallahassee, FL: City of Tallahassee Public Works. 
GRACQ (Les Cyclistes Quotidiens). 2002. “Bicycles and Public Transport: Towards Common Strategies \& Measures.” Brussels, Belgium: The European Cyclists' Federation.

HHI Design, DRMP, PBS\&J, and Rural Transit Consultants. 2008. Front Beach Road Streetscape Design Guidelines Manual. Panama City Beach, FL: City of Panama Beach, Community Redevelopment Agency.

Higgins, Harrison, and Ivonne Audirac. 2008. Accessing Transit: Design Handbook for Florida Bus Passenger Facilities. Version II. Tallahassee, FL: Florida Planning and Development Lab, Department of Urban and Regional Planning, Florida State University. Accessed June 19, 2012 at http://www.dot.state.fl.us/transit/Pages/2008 Transit Handbook.pdf.

HCM (Highway Capacity Manual). 2010. $5^{\text {th }}$ ed. Volume 3: Interrupted Flow. Chapter 17: Urban Street Segments. Washington, D.C.: Transportation Research Board of the National Academies.

Illinois Department of Transportation. 2011. Bureau of Design and Environment (BDE) Manual. Chapter 17, Bicycle and Pedestrian Accommodations. March 2011 update to the 2010 Edition. Accessed March 2, 2012 at http://www.dot.state.il.us/desenv/bdemanual.html.

Institution of Highways and Transportation, and Cyclists' Touring Club and Bicycle Association. 1996. Cycle-Friendly Infrastructure Guidelines for Planning and Design. London, U.K.: Department for Transport.

Jacobson, Mitchell, Mike Skene, Gavin Davidson, and David Rawsthorne. 2009. "An Overview of Shared Use Lane Pavement Markings for Cyclists." Paper prepared for presentation at the 2009 Annual Conference of the Transportation Association of Canada. Vancouver, British Columbia: Transportation Association of Canada. Accessed June 19, 2012 at http://www.tacatc.ca/english/resourcecentre/readingroom/conference/conf2009/pdf/jacobson.pdf.

Ker, lan, Steve Yapp, and Philip Moore, ARRB Group. 2005. "Bus-Bike Interaction within the Road Network." Research Report AP-R266/05. Sydney, Australia: Austroads.

Kittelson \& Associates, KFH Group, Parsons Brinckerhoff Quade \& Douglass, and Katherine HunterZaworski. 2003 Transit Capacity and Quality of Service Manual. $2^{\text {nd }}$ ed. TCRP Report 100. Part 4 Bus Transit Capacity, Chapter 2 Bus Preferential Treatments. Washington, D.C.: Transportation Research Board of the National Academies. Accessed June 20, 2012 at http://onlinepubs.trb.org/onlinepubs/tcrp/tcrp100/part\%200.pdf.

Lin, Pei-Sung, Chanyoung Lee, Achilleas Kourtellis, and Meeta Saxena. 2010. "Evaluation of Camerabased Systems to Reduce Transit Bus Side Collisions." Tampa, FL: University of South Florida Center for Urban Transportation Research. Accessed November 18, 2011 at http://www.nctr.usf.edu/pdf/77905.pdf.

London Cycle Network Steering Group. 1998. London Cycle Network-Design Manual. London, U.K.: Royal Borough of Kingston upon Thames. 
Maiello, Louie. 2012. "Bus Operators and Cyclists, Keeping an Eye on Each Other." Metro Magazine, July 11. Accessed June 13, 2012 at

http://www.metro-magazine.com/Blog/Transit-Dispatches/Story/2011/07/Bus-operators-and-

cyclists-keeping-an-eye-on-each-other.aspx.

MSHA (Maryland State Highway Administration). n.d. Maryland SHA Bicycle and Pedestrian Design Guidelines. Chapter 4, Other On-Road. Baltimore, MD: Maryland Department of Transportation. Accessed June 19, 2012 at http://www.sha.maryland.gov/Index.aspx?Pageld=25.

Nabti, Jumana, and Matthew Ridgway. 2002. "Innovative Bicycle Treatments: An Informational Report." Washington, D.C.: Washington, D.C.: ITE Pedestrian and Bicycle Council, Institute of Transportation Engineers.

NACTO (National Association of City Transportation Officials). 2011. Urban Bikeway Design Guide. New York, NY: NACTO. April Edition. Accessed July 15, 2011 at http://nacto.org/wp-content/uploads/2011/03/NACTO UrbanBikeway DesignGuide LRez.pdf.

National Committee on Uniform Traffic Laws and Ordinances. 2000. Uniform Vehicle Code.

National Transport Authority. 2010. National Cycle Manual. Republic of Ireland: National Transport Authority. Accessed March 2, 2012 at

http://www.cyclemanual.ie.

Nordback, Krista, Daniel Piatkowski, Brian Janson, Wesley Marshall, Kevin Krizek, and Deborah Main. 2011. "Using Inductive Loops to Count Bicycles in Mixed Traffic." Journal of Transportation of the Institute of Transportation Engineers 2 (1): 39-56. Accessed June 19, 2012 at http://carbon.ucdenver.edu/ kkrizek/pdfs/EcoCounterJOT1011.pdf.

Oldfield, R. H., P. H. Bly, and F. V. Webster. 1977. "With-Flow Bus Lanes: Economic Justification Using a Theoretical Model, TRRL Laboratory Report 809." Crowthorne, Berkshire, U.K.: Transport and Road Research Laboratory.

OECD (Organization for Economic Cooperation and Development) Road Research Group. 1977. "Bus Lanes and Busway Systems." Paris, France: OECD.

Ove Arup \& Partners. 2008. Cycle Infrastructure Design. Local Transport Note 2/08. London, U.K.: Department for Transport, The Stationary Office. Accessed March 2, 2012 at http://www2.dft.gov.uk/pgr/roads/tpm/Itnotes/ltn208.pdf.

Ove Arup \& Partners, and Sustrans. 1997. The National Cycle Network-Guidelines and Practical Details. Issue 2. Bristol, U.K.: Sustrans.

PBS\&. 2010. "Draft Preliminary Engineering Report, Front Beach Road (SR 30/US 98A) Improvements (From SR 79 to North Thomas Drive)." FPID 426391-1-28-01, FAP: N/A. Panama City Beach, FL: City of Panama City Beach. May.

Pima Association of Governments. 2009. Regional Plan for Bicycling. Tucson, AZ: Pima Association of Governments. Accessed June 17, 2011 at http://www.pagnet.org/documents/bicycle/RegionalBicyclePlan2009.pdf. 
Pima County Department of Transportation, and City of Tucson Department of Transportation. 2008. Pavement Marking Design Manual. 2nd ed. Tucson, AZ: City of Tucson. Accessed June 25, 2012 at http://dot.pima.gov/trafeng/DesignManual/PavementManual.pdf.

Polzin, Steven, Xuehao Chu, Rodney Bunner, Abdul Pinjari, and Martin Catala. 2011. “TBEST Model Enhancements-Parcel Level Demographic Data Capabilities and Exploration of Enhanced Trip Attraction Capabilities." Tampa, FL: University of South Florida Center for Urban Transportation Research. Accessed May, 22, 2012 at http://www.nctr.usf.edu/wp-content/uploads/2011/11/77801.pdf.

Reid, S., and N. Guthrie. 2004. "Cycling in Bus Lanes." Transport Research Laboratory Report TRL610. United Kingdom: Charging and Local Transport Division, Department for Transport.

Rosales, Jennifer. 2006. Road Diet Handbook: Setting Trends for Livable Streets. Parsons Brinckerhoff Monograph 20. Washington, D.C.: Institute of Transportation Engineers.

Sando, T., and R. Moses. 2010. Integrating Transit into Traditional Neighborhood Design Policies The Influence of Lane Width on Bus Safety. Jacksonville, FL: University of North Florida, and FAMUFSU College of Engineering. Accessed March 2, 2012 at http://www.dot.state.fl.us/transit/Pages/LaneWidthonBusSafety.pdf.

San Francisco Municipal Transportation Agency. 2009. San Francisco Bicycle Plan. San Francisco, CA: City of San Francisco. Accessed March 2, 2012 at

http://www.sfmta.com/cms/bproj/documents/San_Francisco_Bicycle_Plan_June_26_2009_002.pd f.

Schack, Daniel, and Jacob Mason. 2010. "Congestion Management Solutions for Dense Urban Corridors: A Plan for Center City.” Philadelphia, PA: City of Philadelphia.

Schramm, A., and A. Rakotonirainy. 2009. "The Effect of Road Lane Width on Cyclist Safety in Urban Areas." Sydney, New South Wales, Australia: 2009 Australasian Road Safety Research, Policing, and Education Conference, November 10-13. 419-427. Accessed June 20, 2012 at http://www.cyclingresourcecentre.org.au/images/uploads/post/attachment/RS094046.pdf.

Somasundaram, Guruprasad, Vassilios Morellas, and Nikolaos Papanikolopoulos. 2012, "Deployment of Practical Methods for Counting Bicycle and Pedestrian Use of a Transportation Facility." Report CTS 12-01. Minneapolis, MN: Center for Transportation Studies, University of Minnesota. Accessed June 20,2012 at http://www.cts.umn.edu/Publications/ResearchReports/pdfdownload.pl?id=1644.

SWOV (Dutch Institute for Road Safety and Research). 2010. “SWOV Fact Sheet: Functionality and Homogeneity." Leidschendam, The Netherlands: SWOV.

TII (Texas Transportation Institute) and Texas A\&M Research Foundation. 1996. "Guidelines for the Location and Design of Bus Stops." TCRP Report 19. Washington, D.C.: National Academy Press. Accessed June 20, 2012 at http://onlinepubs.trb.org/onlinepubs/tcrp/tcrp_rpt_19-b.pdf. 
Toole Design. 2005. Bicycle Facility Design Guide. Washington D.C.: District Department of Transportation. revised December. Accessed June 20, 2012 at http://www.tooledesign.com/DC\%20Bike\%20Design\%20Guide\%20for\%20toolkit.pdf.

Turnbull, Katherine F., and Donald G. Capelle. 1998. NCHRP Report 414: HOV Systems Manual. Washington, D.C.: National Cooperative Highway Research Program, Transportation Research Board, National Academy Press.

Vic Roads. 2007. “Cycle Notes No. 19: Providing for Cyclists within Bus Lanes.” Victoria, Australia: Victoria Department of Transport, April. Accessed March 5, 2012 at http://www.vicroads.vic.gov.au/NR/rdonlyres/3FAB30FE-B4B0-467C-8511C8BE5E3F68F6/0/vrpin01733.pdf.

Wade, Randy, and Sean Quinn. 2011. “Temporary Treatments: Efficient Change for Bustling Streets.” Association of Pedestrian and Bicycle Professionals webinar. PowerPoint presentation June 15.

WMATA (Washington Metropolitan Area Transit Authority). 2011. Street Smart: Pedestrian Awareness $\&$ Operator Alertness. Washington, D.C.: WMATA Bus Operator Candidate Training Program, June.

WSDOT (Washington State Department of Transportation). 2010. WSDOT Design Manual M22.01.07. Chap. 1520, Roadway Bicycle Facilities, Shared Roadway Bicycle Facility Design. July. Accessed June 24,2012 at http://www.wsdot.wa.gov/publications/manuals/fulltext/M22-01/1520.pdf.

Wilkinson, W.C., III, A. Clarke, B. Epperson, and R. Knoblauch. 1994. Selecting Roadway Design Treatments to Accommodate Bicycles. FHWA-RD-92-073. Washington, D.C.: Federal Highway Administration.

Zhou, Huaguo, and Stephanie Bromfield. 2007. "Moving the Bus Back into Traffic Safely: Signage and Lighting Configuration." Tampa, FL: University of South Florida Center for Urban Transportation Research. Accessed November 18, 2011 at http://www.nctr.usf.edu/pdf/77610.pdf. 


\section{Appendix A}

\section{Database of United States and International Cases of Shared Bike/Bus Lanes}

The database of United States and international examples was compiled from various sources, including websites, Google Earth maps, interviews, questionnaires, reports, and studies. The initial list was provided by John Ciccarelli, a transportation planner from California. The data from Mr. Ciccarelli's list was initially confirmed, and additional cases were located. Staff then added fields to the database as criteria were identified.

No U.S. cases were identified where an SBBL is separated from other lanes by a physically separated barrier, although information is not available for all examples. There was at least one case of a physically separated SBBL located in Europe. The data in several fields were estimated using Google Earth and/or responses from questionnaires: Average Width, Length, Speed Limit and Termini. Some examples did not completely fit the description of an SBBL. (SBBL is a term used in this report to describe a facility for shared use only by bicycles and buses, and which can be marked and signed in several ways. Depending upon how the SBBL is marked, it may fit the MUTCD description of a preferential lane.) These examples remain in the database because they were identified by local authorities or posted on responses to questionnaires. These examples were placed in a separate table with SBBLs that are currently proposed or that no longer exist. These include the following.

- Blanding Boulevard, Jacksonville, FL: used unofficially as an SBBL

- $\quad$ 4th Avenue S, St. Petersburg, FL: bus drop-off and bike lane

- Nebraska Avenue, Tampa, FL: bike lane that widens at bus stops

- $3 r d$ Avenue, Seattle, WA: allowed for use by passenger cars at certain times of day

- Marquette Avenue, Minneapolis, MN: bike lane located to the left of bus lane

The list of international examples is by no means complete. The identified cases serve as examples to compare certain criteria and characteristics to U.S. cases.

In tables of U.S. facilities, all facilities are listed alphabetically by state. In the table of international facilities, all facilities are listed alphabetically by country. 
Inventory of U.S. Cities with Shared Bike/Bus Lanes

\begin{tabular}{|c|c|c|c|c|c|c|c|c|c|c|c|c|c|c|}
\hline City & $\begin{array}{l}\text { Street } \\
\text { Segment }\end{array}$ & $\begin{array}{l}\text { Urban } \\
\text { Environment/ } \\
\text { Condition }\end{array}$ & Configuration & $\begin{array}{l}\text { Bus Stop } \\
\text { Spacing }\end{array}$ & $\begin{array}{l}\text { Average } \\
\text { Width(s) }\end{array}$ & Length & $\begin{array}{l}\text { Date } \\
\text { opened }\end{array}$ & \begin{tabular}{|l} 
Speed \\
Limit \\
on \\
Road
\end{tabular} & \begin{tabular}{|l|} 
Signage \\
and/or Lane \\
Markings
\end{tabular} & \begin{tabular}{|l} 
Number of \\
General \\
Purpose \\
Lanes not \\
including \\
SBBL(s)
\end{tabular} & Terminus 1 & Terminus 2 & $\begin{array}{l}\text { Lane } \\
\text { Color }\end{array}$ & $\begin{array}{l}\text { Adjacent } \\
\text { parking } \\
\text { lane }\end{array}$ \\
\hline Tucson, AZ & \begin{tabular}{|l|} 
E Broadway \\
Boulevard \\
N Columbus \\
Blvd. to N \\
Camino \\
Seco \\
(both sides \\
of the street)
\end{tabular} & $\begin{array}{l}\text { low density } \\
\text { urban } \\
\text { condition } \\
\text { (arterial } \\
\text { roadway) }\end{array}$ & $\begin{array}{l}\text { Shared } \\
\text { Bus/Bike/RTOL } \\
\text { lane sits on } \\
\text { roadway shoulder }\end{array}$ & & $9-12 \mathrm{ft}$ & $\begin{array}{l}5.5 \\
\text { miles }\end{array}$ & \begin{tabular}{|l} 
before \\
2002
\end{tabular} & $\begin{array}{l}35-40 \\
\mathrm{mph}\end{array}$ & \begin{tabular}{|l|} 
Some \\
signage. \\
Lane striped, \\
occasional \\
lane \\
markings \\
(near \\
intersections)
\end{tabular} & $\begin{array}{l}6 \text { lane divided } \\
\text { highway with } \\
\text { dedicated } \\
\text { bus/bike lanes } \\
\text { on either side. }\end{array}$ & \begin{tabular}{|l|} 
Columbus \\
Blvd: Bike \\
lane + right \\
turn lane \\
(both sides of \\
the street)
\end{tabular} & $\begin{array}{l}\text { Camino } \\
\text { Seco: } \\
\text { Right turn } \\
\text { lanes } \\
\text { (both sides } \\
\text { of the } \\
\text { street) }\end{array}$ & no & no \\
\hline Tucson, AZ & \begin{tabular}{|l} 
E 22nd \\
Street \\
S Country \\
Club Road to \\
S Craycroft \\
Road \\
(both sides \\
of the street)
\end{tabular} & $\begin{array}{l}\text { low density } \\
\text { urban } \\
\text { condition } \\
\text { (arterial } \\
\text { roadway) }\end{array}$ & $\begin{array}{l}\text { Shared } \\
\text { Bus/Bike/RTOL } \\
\text { lane sits on } \\
\text { roadway shoulder }\end{array}$ & & $\begin{array}{l}10-12 \mathrm{ft} \\
\text { portions of the } \\
\text { lane are not } \\
\text { contiguous }\end{array}$ & $\begin{array}{l}1.52 \\
\text { miles }\end{array}$ & $\begin{array}{l}\text { before } \\
2002\end{array}$ & $40 \mathrm{mph}$ & \begin{tabular}{|l} 
Some \\
signage. \\
Lane striped, \\
occasional \\
lane \\
markings
\end{tabular} & $\begin{array}{l}6 \text { lane divided } \\
\text { highway with } \\
\text { dedicated } \\
\text { bus/bike lanes } \\
\text { on either side. }\end{array}$ & $\begin{array}{l}\text { Country Club } \\
\text { Rd: EB: } \\
\text { nothing WB: } \\
\text { extra wide } \\
\text { lane }\end{array}$ & $\begin{array}{l}\text { Craycroft } \\
\text { Rd: } \\
\text { EB: Bike } \\
\text { lane + right } \\
\text { turn lane } \\
\text { WB: } \\
\text { nothing }\end{array}$ & no & no \\
\hline Tucson, AZ & \begin{tabular}{|l|} 
E \\
Speedway \\
Blvd \\
N Kolb Rd to \\
N Pantano \\
Rd \\
\end{tabular} & $\begin{array}{l}\text { low density } \\
\text { urban } \\
\text { condition } \\
\text { (arterial } \\
\text { roadway) }\end{array}$ & \begin{tabular}{|l} 
Shared \\
Bus/Bike/RTOL \\
lane sits on \\
roadway shoulder
\end{tabular} & & $12 \mathrm{ft}$ & $\begin{array}{l}0.47 \\
\text { miles }\end{array}$ & & & & & & & & \\
\hline Tucson, AZ & \begin{tabular}{|l|} 
E Tanque \\
Verde Rd \\
E Pima St to \\
E Grant Rd
\end{tabular} & $\begin{array}{l}\text { low density } \\
\text { urban } \\
\text { condition } \\
\text { (arterial } \\
\text { roadway) }\end{array}$ & \begin{tabular}{|l} 
Shared \\
Bus/Bike/RTOL \\
lane sits on \\
roadway shoulder
\end{tabular} & & $12 \mathrm{ft}$ & $\begin{array}{l}0.34 \\
\text { miles }\end{array}$ & & & & & & & & \\
\hline Denver, CO & \begin{tabular}{|l|} 
Larimer \\
Street \\
N Speer Blvd \\
to 14th St
\end{tabular} & $\begin{array}{l}\text { Central } \\
\text { Business } \\
\text { District }\end{array}$ & $\begin{array}{l}\text { Shared Bus/Bike } \\
\text { lane }\end{array}$ & $\begin{array}{l}\text { No stops } \\
\text { within the } \\
\text { SBBL section }\end{array}$ & $12 \mathrm{ft}$ & \begin{tabular}{|l|}
600 \\
(2 city \\
blocks)
\end{tabular} & & $\begin{array}{l}\text { Down- } \\
\text { town } \\
\text { speeds }\end{array}$ & & $\begin{array}{l}2 \text { (in opposite } \\
\text { direction) + } \\
\text { Additional Bus } \\
\text { only lane in } \\
\text { opp. direction }\end{array}$ & \begin{tabular}{|l|} 
Speer Blvd: \\
private road \\
(Speer is a \\
large dvd hwy \\
that buses \\
loop around)
\end{tabular} & $\begin{array}{l}14 \text { St: } 3 \\
\text { lane one } \\
\text { way street } \\
\text { with parking }\end{array}$ & no & $\begin{array}{l}\text { no, } \\
\text { portions } \\
\text { of street }\end{array}$ \\
\hline
\end{tabular}




\begin{tabular}{|c|c|c|c|c|c|c|c|c|c|c|c|c|c|c|}
\hline City & $\begin{array}{l}\text { Street } \\
\text { Segment }\end{array}$ & $\begin{array}{l}\text { Urban } \\
\text { Environment/ } \\
\text { Condition }\end{array}$ & Configuration & $\begin{array}{l}\text { Bus Stop } \\
\text { Spacing }\end{array}$ & $\begin{array}{l}\text { Average } \\
\text { Width(s) }\end{array}$ & Length & $\begin{array}{l}\text { Date } \\
\text { opened }\end{array}$ & $\begin{array}{l}\text { Speed } \\
\text { Limit } \\
\text { on } \\
\text { Road }\end{array}$ & \begin{tabular}{|l|} 
Signage \\
and/or Lane \\
Markings
\end{tabular} & \begin{tabular}{|l} 
Number of \\
General \\
Purpose \\
Lanes not \\
including \\
SBBL(s)
\end{tabular} & Terminus 1 & Terminus 2 & $\begin{array}{l}\text { Lane } \\
\text { Color }\end{array}$ & $\begin{array}{l}\text { Adjacent } \\
\text { parking } \\
\text { lane }\end{array}$ \\
\hline Denver, CO & $\begin{array}{l}\text { 19th Street } \\
\text { Wynkoop St } \\
\text { to Arapahoe } \\
\text { St }\end{array}$ & $\begin{array}{l}\text { Central } \\
\text { Business } \\
\text { District }\end{array}$ & $\begin{array}{l}\text { Shared } \\
\text { Bus/HOV/Bike } \\
\text { lane (restricted M- } \\
\text { F 5-9am). Parking } \\
\text { allowed in portions } \\
\text { during non- } \\
\text { restricted hours }\end{array}$ & $\begin{array}{l}\text { Approximately } \\
\text { every other } \\
\text { block. Busy } \\
\text { bus connector } \\
\text { with Highway } \\
\text { HOV }\end{array}$ & $12-15 \mathrm{ft}$ & $\begin{array}{l}0.40 \\
\text { miles } \\
(6 \text { city } \\
\text { blocks })\end{array}$ & 1994 & $\begin{array}{l}\text { Down- } \\
\text { town } \\
\text { speeds }\end{array}$ & \begin{tabular}{|l|} 
solid white \\
line, no add'l \\
pavement \\
markings, \\
signage \\
every block
\end{tabular} & \begin{tabular}{|l|}
3 lanes. \\
Changes from \\
bidirectional to \\
one direction. \\
Restricted \\
parallel \\
parking on \\
opp. side.
\end{tabular} & $\begin{array}{l}\text { Arapahoe St: } \\
\text { wide sharrow. } \\
\text { Adjacent } \\
\text { streets have } \\
\text { bike lanes } \\
\text { (approaching } \\
\text { street car } \\
\text { lane) }\end{array}$ & \begin{tabular}{|l|} 
Wynkoop: \\
Highway \\
intersection \\
with Bus \\
HOV ramp. \\
Adjacent \\
streets \\
have bike \\
lanes
\end{tabular} & no & no \\
\hline $\begin{array}{l}\text { Rehoboth } \\
\text { Beach, DE }\end{array}$ & \begin{tabular}{|l|} 
Coastal \\
Highway 1 \\
Rd 273A \\
(Rehoboth \\
Canal) to \\
Lewes \\
Georgetown \\
Hwy
\end{tabular} & $\begin{array}{l}\text { Low density } \\
\text { suburban } \\
\text { highway } \\
\text { condition }\end{array}$ & $\begin{array}{l}\text { Shared } \\
\text { Bus/Bike/RTOL on } \\
\text { both sides of the } \\
\text { street }\end{array}$ & & $12 \mathrm{ft}$ & $\begin{array}{l}5.35 \\
\text { miles }\end{array}$ & & $45 \mathrm{mph}$ & \begin{tabular}{|l|} 
Lane \\
markings \\
every 375'. \\
Sign at every \\
other lane \\
marking \\
(every 700')
\end{tabular} & \begin{tabular}{|l}
6 lane divided \\
highway with \\
dedicated \\
bus/bike/RTOL \\
lanes on either \\
side. Many \\
center left turn \\
lanes
\end{tabular} & $\begin{array}{l}\text { Rd 273A: } \\
\text { right turn lane } \\
\text { and bike lane }\end{array}$ & $\begin{array}{l}\text { Lewes } \\
\text { George- } \\
\text { town Hwy: } \\
\text { Right turn } \\
\text { lanes }\end{array}$ & no & no \\
\hline \begin{tabular}{|l|} 
Washington, \\
DC \\
(paired \\
street)
\end{tabular} & \begin{tabular}{|l|} 
7th Street \\
NW \\
Massachu- \\
setts Ave to \\
Pennsylvania \\
Ave.
\end{tabular} & \begin{tabular}{|l} 
Central \\
Business \\
District/ \\
Theatre \\
district \\
near federal \\
buildings. \\
High \\
north/south \\
bus volumes
\end{tabular} & $\begin{array}{l}\text { Shared Bus/Bike } \\
\text { laneradjacent } \\
\text { on-street parking } \\
\text { lane }\end{array}$ & Every block. & $11 \mathrm{ft}$ & \begin{tabular}{|l|}
0.6 \\
miles
\end{tabular} & 2003 & $30 \mathrm{mph}$ & \begin{tabular}{|l|} 
Heavily \\
marked with \\
both signage \\
and lane \\
markings. \\
Lane \\
markings \\
were \\
removed on \\
a portion of \\
the street as \\
part of a \\
road \\
construction \\
project.
\end{tabular} & \begin{tabular}{|l|}
2 lanes +2 \\
on-street \\
parking lanes \\
2 way traffic
\end{tabular} & & & no & $\begin{array}{l}\text { Yes. } \\
\text { Parking } \\
\text { on both } \\
\text { sides of } \\
\text { the street }\end{array}$ \\
\hline
\end{tabular}




\begin{tabular}{|c|c|c|c|c|c|c|c|c|c|c|c|c|c|c|}
\hline City & $\begin{array}{l}\text { Street } \\
\text { Segment }\end{array}$ & $\begin{array}{l}\text { Urban } \\
\text { Environment/ } \\
\text { Condition }\end{array}$ & Configuration & $\begin{array}{l}\text { Bus Stop } \\
\text { Spacing }\end{array}$ & $\begin{array}{l}\text { Average } \\
\text { Width(s) }\end{array}$ & Length & $\begin{array}{l}\text { Date } \\
\text { opened }\end{array}$ & $\begin{array}{l}\text { Speed } \\
\text { Limit } \\
\text { on } \\
\text { Road }\end{array}$ & \begin{tabular}{|l|} 
Signage \\
and/or Lane \\
Markings
\end{tabular} & \begin{tabular}{|l} 
Number of \\
General \\
Purpose \\
Lanes not \\
including \\
SBBL(s)
\end{tabular} & Terminus 1 & Terminus 2 & \begin{tabular}{|l} 
Lane \\
Color
\end{tabular} & $\begin{array}{l}\text { Adjacent } \\
\text { parking } \\
\text { lane }\end{array}$ \\
\hline $\begin{array}{l}\text { Washington, } \\
\text { DC } \\
\text { (paired } \\
\text { street) }\end{array}$ & $\begin{array}{l}\text { 9th Street } \\
\text { NW } \\
\text { E Street NW } \\
\text { to K Street } \\
\text { NW }\end{array}$ & $\begin{array}{l}\text { Central } \\
\text { Business } \\
\text { District near } \\
\text { federal } \\
\text { buildings }\end{array}$ & $\begin{array}{l}\text { Lane switches } \\
\text { between SBBL } \\
\text { adjacent to } \\
\text { parking and bike } \\
\text { lane to the left of } \\
\text { bus lane } \\
\text { (separate). }\end{array}$ & Every block & $\begin{array}{l}11 \mathrm{ft} \text { SBBL, } \\
18 \mathrm{ft} \text { separate } \\
\text { lanes }\end{array}$ & $\begin{array}{l}0.4 \\
\text { miles }\end{array}$ & 2003 & $30 \mathrm{mph}$ & \begin{tabular}{|l|} 
Heavily \\
marked with \\
both signage \\
and lane \\
markings
\end{tabular} & $\begin{array}{l}2 \text { lanes + 1-2 } \\
\text { on-street } \\
\text { parking lanes } \\
\text { one-way } \\
\text { southbound }\end{array}$ & & & no & Yes \\
\hline $\begin{array}{l}\text { Ft. Myers } \\
\text { Beach, FL }\end{array}$ & \begin{tabular}{|l|} 
State Road \\
865 \\
Matanzas \\
Pass Bridge \\
to Ft. Myers \\
Beach
\end{tabular} & \begin{tabular}{|l|} 
Primary \\
bridge to \\
tourist beach \\
area. Heavily \\
traveled \\
during spring \\
break
\end{tabular} & $\begin{array}{l}\text { Shared Rubber } \\
\text { Wheel Trolley/Bike } \\
\text { Lane } \\
\text { begins and ends } \\
\text { as a right turn only } \\
\text { lane }\end{array}$ & $\begin{array}{l}\text { No stops } \\
\text { within the } \\
\text { SBBL section }\end{array}$ & $12 \mathrm{ft}$ & $\begin{array}{l}0.53 \\
\text { miles }\end{array}$ & \begin{tabular}{|l|} 
Began as \\
a pilot \\
project. \\
Now \\
Under \\
construct- \\
ion in \\
2011 to \\
become \\
a perma- \\
nent \\
facility \\
\end{tabular} & $35 \mathrm{mph}$ & \begin{tabular}{|l|} 
Limited to no \\
signage. \\
Pavement \\
Markings \\
every 1/4 \\
mile
\end{tabular} & $\begin{array}{l}2 \text { lane bridge } \\
\text { plus } \\
\text { pedestrian } \\
\text { walkway on } \\
\text { opposite side } \\
\text { of trolley/bike } \\
\text { lane }\end{array}$ & $\begin{array}{l}\text { Right Turn } \\
\text { lane }\end{array}$ & $\begin{array}{l}\text { Right Turn } \\
\text { lane }\end{array}$ & no & no \\
\hline Chicago, IL & \begin{tabular}{|l|}
$\mathrm{N}$ \\
Milwaukee \\
Avenue \\
W Erie Street \\
to W Grand \\
Ave \\
(640 N \\
Milwaukee \\
Avenue - \\
nearby \\
address)
\end{tabular} & $\begin{array}{l}\text { Urban } \\
\text { Neighborhood } \\
\text { One mile } \\
\text { northwest of } \\
\text { the CBD. } \\
\text { Highway } \\
\text { overpass. } \\
\text { Shared lanes } \\
\text { return to } \\
\text { bike/parking } \\
\text { lanes at either } \\
\text { end. }\end{array}$ & $\begin{array}{l}\text { Shared } \\
\text { Bus/Bike/RTOL }\end{array}$ & $\begin{array}{l}\text { No stops } \\
\text { within the } \\
\text { SBBL section }\end{array}$ & $13 \mathrm{ft}$ & \begin{tabular}{|l|}
0.2 \\
miles \\
highway \\
over- \\
pass
\end{tabular} & & & & $\begin{array}{l}2 \text { lanes } \\
\text { (bidirectional) } \\
+ \text { bike lane } \\
\text { and parking } \\
\text { lane on } \\
\text { opposite side } \\
\text { of shared } \\
\text { bus/bike lane }\end{array}$ & & & no & no \\
\hline
\end{tabular}




\begin{tabular}{|c|c|c|c|c|c|c|c|c|c|c|c|c|c|c|}
\hline City & $\begin{array}{l}\text { Street } \\
\text { Segment }\end{array}$ & $\begin{array}{l}\text { Urban } \\
\text { Environment/ } \\
\text { Condition }\end{array}$ & Configuration & $\begin{array}{l}\text { Bus Stop } \\
\text { Spacing }\end{array}$ & $\begin{array}{l}\text { Average } \\
\text { Width(s) }\end{array}$ & Length & $\begin{array}{l}\text { Date } \\
\text { opened }\end{array}$ & \begin{tabular}{|l|} 
Speed \\
Limit \\
on \\
Road
\end{tabular} & \begin{tabular}{|l|} 
Signage \\
and/or Lane \\
Markings
\end{tabular} & \begin{tabular}{|l} 
Number of \\
General \\
Purpose \\
Lanes not \\
including \\
SBBL(s)
\end{tabular} & Terminus 1 & Terminus 2 & \begin{tabular}{|l|} 
Lane \\
Color
\end{tabular} & $\begin{array}{l}\text { Adjacent } \\
\text { parking } \\
\text { lane }\end{array}$ \\
\hline Boston, MA & $\begin{array}{l}\text { Washington } \\
\text { Street } \\
\text { Melnea Cass } \\
\text { Blvd to } \\
\text { Herald St } \\
\text { /Massa- } \\
\text { chusetts } \\
\text { Turnpike }\end{array}$ & $\begin{array}{l}\text { South End of } \\
\text { Boston }\end{array}$ & $\begin{array}{l}\text { Shared } \\
\text { Bus/Bike/RTOL on } \\
\text { both sides of the } \\
\text { street }\end{array}$ & $\begin{array}{l}\text { Every other } \\
\text { Block (varies) }\end{array}$ & $\begin{array}{l}12 \mathrm{ft} \\
\text { (varies at } \\
\text { intersections) }\end{array}$ & $\begin{array}{l}1.32 \\
\text { miles }\end{array}$ & 2008 & \begin{tabular}{|l|}
$30 \mathrm{mph}$ \\
Includes \\
School \\
zone \\
$(20$ \\
mph)
\end{tabular} & \begin{tabular}{|l|} 
Lanes \\
marked with \\
bicycle \\
markings. \\
Signage \\
indicates \\
Bus/RTOL \\
only
\end{tabular} & $\begin{array}{l}2 \text { lanes plus } \\
\text { occasional } \\
\text { center left } \\
\text { turn. Bus } \\
\text { lanes on both } \\
\text { sides (portion } \\
\text { of street near } \\
\text { Herald has } \\
\text { only } 1 \text { lane for } \\
\text { bus and } \\
\text { bicyclists. } \\
\text { Vehicles cross } \\
\text { this to make } \\
\text { left turns. }\end{array}$ & & & no & $\begin{array}{l}\text { Yes. } \\
\text { Parking } \\
\text { on both } \\
\text { sides of } \\
\text { the street }\end{array}$ \\
\hline $\begin{array}{l}\text { Baltimore, } \\
\text { MD } \\
\text { (paired } \\
\text { Street) }\end{array}$ & $\begin{array}{l}\text { W Lombard } \\
\text { Street } \\
\text { Martin Luther } \\
\text { King Jr. Blvd } \\
\text { to President } \\
\text { Street }\end{array}$ & \begin{tabular}{|l} 
Central \\
Business \\
District near \\
baseball \\
stadium and \\
light rail
\end{tabular} & $\begin{array}{l}\text { Shared } \\
\text { Bus/Bike/RTOL }\end{array}$ & \begin{tabular}{|l} 
Every inter- \\
section
\end{tabular} & $14-16 \mathrm{ft}$ & $\begin{array}{l}1.2 \\
\text { miles }\end{array}$ & 2009 & $30 \mathrm{mph}$ & \begin{tabular}{|l|} 
Minimal \\
markings \\
indicating \\
shared \\
bike/bus lane
\end{tabular} & $\begin{array}{l}3 \text { lanes one } \\
\text { direction } \\
\text { (varies) }\end{array}$ & $\begin{array}{l}\text { proposed 5' } \\
\text { bike lane on } \\
\text { Lombard St }\end{array}$ & $\begin{array}{l}\text { 5' bike lane } \\
\text { on adjacent } \\
\text { President } \\
\text { St }\end{array}$ & no & $\begin{array}{l}\text { no } \\
\text { (removed } \\
\text { in order } \\
\text { for the } \\
\text { lane to } \\
\text { operate } \\
\text { better) }\end{array}$ \\
\hline $\begin{array}{l}\text { Baltimore, } \\
\text { MD } \\
\text { (paired } \\
\text { street) }\end{array}$ & $\begin{array}{l}\text { Pratt Street } \\
\text { Martin Luther } \\
\text { King Jr. Blvd } \\
\text { to President } \\
\text { Street }\end{array}$ & $\begin{array}{l}\text { Central } \\
\text { Business } \\
\text { District near } \\
\text { baseball } \\
\text { stadium and } \\
\text { light rail }\end{array}$ & $\begin{array}{l}\text { Shared } \\
\text { Bus/Bike/RTOL }\end{array}$ & $\begin{array}{l}\text { Every inter- } \\
\text { section }\end{array}$ & $14-16 \mathrm{ft}$ & $\begin{array}{l}1.2 \\
\text { miles }\end{array}$ & 2009 & $30 \mathrm{mph}$ & \begin{tabular}{|l|} 
Minimal \\
markings \\
indicating \\
shared \\
bike/bus lane
\end{tabular} & $\begin{array}{l}3 \text { lanes one } \\
\text { direction } \\
\text { (varies) }\end{array}$ & $\begin{array}{l}\text { proposed 5' } \\
\text { bike lane on } \\
\text { Lombard St }\end{array}$ & \begin{tabular}{|l|} 
Share The \\
Road signs \\
on Pratt St.
\end{tabular} & no & $\begin{array}{l}\text { no } \\
\text { (removed } \\
\text { in order } \\
\text { for the } \\
\text { lane to } \\
\text { operate } \\
\text { better) }\end{array}$ \\
\hline
\end{tabular}




\begin{tabular}{|c|c|c|c|c|c|c|c|c|c|c|c|c|c|c|}
\hline City & $\begin{array}{l}\text { Street } \\
\text { Segment }\end{array}$ & $\begin{array}{l}\text { Urban } \\
\text { Environment/ } \\
\text { Condition }\end{array}$ & Configuration & $\begin{array}{l}\text { Bus Stop } \\
\text { Spacing }\end{array}$ & $\begin{array}{l}\text { Average } \\
\text { Width(s) }\end{array}$ & Length & $\begin{array}{l}\text { Date } \\
\text { opened }\end{array}$ & \begin{tabular}{|l} 
Speed \\
Limit \\
on \\
Road
\end{tabular} & \begin{tabular}{|l|} 
Signage \\
and/or Lane \\
Markings
\end{tabular} & \begin{tabular}{|l} 
Number of \\
General \\
Purpose \\
Lanes not \\
including \\
SBBL(s)
\end{tabular} & Terminus 1 & Terminus 2 & $\begin{array}{l}\text { Lane } \\
\text { Color }\end{array}$ & $\begin{array}{l}\text { Adjacent } \\
\text { parking } \\
\text { lane }\end{array}$ \\
\hline $\begin{array}{l}\text { Ocean City, } \\
\text { MD } \\
\text { (seasonal } \\
\text { community) }\end{array}$ & \begin{tabular}{|l|} 
MD 528 \\
17 th Street \\
to East 145th \\
Street \\
(both sides \\
of the street) \\
northbound \\
SBBL is \\
interrupted \\
from 59th to \\
64th street
\end{tabular} & $\begin{array}{l}\text { On barrier } \\
\text { Islands } \\
\text { (tourist } \\
\text { destination). } \\
\text { Portion of } \\
\text { street with } \\
\text { shared lane is } \\
\text { located within } \\
\text { a more } \\
\text { densely } \\
\text { developed } \\
\text { area. }\end{array}$ & $\begin{array}{l}\text { Shared Bus/Bike } \\
\text { lane/RTOL } \\
\text { Converts to bike } \\
\text { lane at north end. } \\
\text { Bicyclists use } \\
\text { frequently. } \\
\text { (scooters under } \\
\text { 49cc can use) }\end{array}$ & \begin{tabular}{|l} 
Every other \\
Block $\left(1200^{\prime}\right)$ \\
varies \\
depend-ing \\
on adjacent \\
land uses
\end{tabular} & $11-12.5 \mathrm{ft}$ & $\begin{array}{l}7.36 \\
\text { miles }\end{array}$ & $\begin{array}{l}\text { late } \\
1980 \text { s }\end{array}$ & $\begin{array}{l}35-40 \\
\mathrm{mph}\end{array}$ & & $\begin{array}{l}\text { 6-lane divided } \\
\text { highway with } \\
\text { dedicated } \\
\text { bus/bike lanes } \\
\text { on either side. }\end{array}$ & $\begin{array}{l}\text { 17th: parking } \\
\text { lane. Bike } \\
\text { lane on } \\
\text { adjacent } \\
\text { street (right) }\end{array}$ & $\begin{array}{l}\text { 145th: Turn } \\
\text { lane and } \\
\text { then bike } \\
\text { lane }\end{array}$ & no & no \\
\hline $\begin{array}{l}\text { Minneapolis, } \\
\text { MN }\end{array}$ & \begin{tabular}{|l|} 
Hennepin \\
Avenue \\
11th Street N \\
to 2nd Street \\
$\mathrm{N}$
\end{tabular} & \begin{tabular}{|l|} 
Central \\
Business \\
District. \\
Med/heavy \\
bicycle traffic \\
volumes.
\end{tabular} & \begin{tabular}{|l|} 
Shared \\
Bus/Bike/RTOL \\
RTOL every other \\
block
\end{tabular} & $\begin{array}{l}\text { Every other } \\
\text { Block }\left(800^{\prime}\right)\end{array}$ & \begin{tabular}{|l|} 
Alternates \\
every other \\
block $13.5 \mathrm{ft}$ \\
or $18.5 \mathrm{ft}$ \\
depending on \\
CLTL
\end{tabular} & $\begin{array}{l}(10 \text { city } \\
\text { blocks })\end{array}$ & $\begin{array}{l}\text { October, } \\
2009, \\
\text { with } \\
\text { revisions } \\
\text { in } 2010\end{array}$ & $30 \mathrm{mph}$ & \begin{tabular}{|l} 
Signage, \\
lane \\
markings \\
and plastic \\
delineator \\
posts (red)
\end{tabular} & \begin{tabular}{|l|}
2 lanes in \\
each direction. \\
Every other \\
block has a \\
CLTL
\end{tabular} & & & \begin{tabular}{|l|} 
yes. $4 \mathrm{ft}$ \\
wide \\
painted \\
green \\
stripe in \\
2010 as \\
a part of \\
a study. \\
Now \\
worn off \\
com- \\
pletely
\end{tabular} & $\begin{array}{l}\text { no. One } \\
\text { block } \\
\text { includes } \\
\text { adjacent } \\
\text { parking }\end{array}$ \\
\hline \begin{tabular}{|l|} 
Eugene, OR \\
(university \\
edge)
\end{tabular} & $\begin{array}{l}\text { Kincaid } \\
\text { Street } \\
\text { 11th Ave to } \\
\text { 13th Ave }\end{array}$ & \begin{tabular}{|l} 
University of \\
Oregon- \\
Eugene. \\
Along western \\
edge of \\
campus. Bike \\
lane preceded \\
by angled on- \\
street parking. \\
Limited \\
vehicle traffic
\end{tabular} & \begin{tabular}{|l|} 
Varies between \\
bike lane to left of \\
bus lane, shared \\
bus/bike lane, \\
shared \\
bus/bike/RTOL
\end{tabular} & & $15 \mathrm{ft}$ & \begin{tabular}{|l|}
$800 \mathrm{ft}$ \\
$(2$ \\
blocks $)$
\end{tabular} & \begin{tabular}{|l} 
prior to \\
2006
\end{tabular} & $20 \mathrm{mph}$ & \begin{tabular}{|l} 
Lane \\
Markings
\end{tabular} & \begin{tabular}{|l|}
1 lane \\
(northbound) \\
with on-street \\
parking \\
(opposite side \\
of street)
\end{tabular} & & & no & \\
\hline
\end{tabular}




\begin{tabular}{|c|c|c|c|c|c|c|c|c|c|c|c|c|c|c|}
\hline City & $\begin{array}{l}\text { Street } \\
\text { Segment }\end{array}$ & $\begin{array}{l}\text { Urban } \\
\text { Environment/ } \\
\text { Condition }\end{array}$ & Configuration & $\begin{array}{l}\text { Bus Stop } \\
\text { Spacing }\end{array}$ & $\begin{array}{l}\text { Average } \\
\text { Width(s) }\end{array}$ & Length & \begin{tabular}{|l} 
Date \\
opened
\end{tabular} & $\begin{array}{l}\text { Speed } \\
\text { Limit } \\
\text { on } \\
\text { Road }\end{array}$ & \begin{tabular}{|l|} 
Signage \\
and/or Lane \\
Markings
\end{tabular} & $\begin{array}{l}\text { Number of } \\
\text { General } \\
\text { Purpose } \\
\text { Lanes not } \\
\text { including } \\
\text { SBBL(s) }\end{array}$ & Terminus 1 & Terminus 2 & \begin{tabular}{|l} 
Lane \\
Color
\end{tabular} & $\begin{array}{l}\text { Adjacent } \\
\text { parking } \\
\text { lane }\end{array}$ \\
\hline Portland, OR & \begin{tabular}{|l|} 
NE Glisan \\
Street \\
near $15^{\text {th }}$ and \\
I-405
\end{tabular} & & & & & & & $40 \mathrm{mph}$ & & & & & no & \\
\hline Portland, OR & $\begin{array}{l}\text { SW 5th } \\
\text { Avenue } \\
\text { Over l-405 }\end{array}$ & $\begin{array}{l}\text { Edge of } \\
\text { downtown } \\
\text { CBD. Part of } \\
\text { highway } \\
\text { overpass. }\end{array}$ & $\begin{array}{l}\text { Shared } \\
\text { Bus/Bike/RTOL } \\
\text { Returns to bike } \\
\text { lane entering } \\
\text { downtown }\end{array}$ & $\begin{array}{l}\text { No stops } \\
\text { within the } \\
\text { SBBL section }\end{array}$ & & \begin{tabular}{|l|}
0.2 \\
miles \\
highway \\
over- \\
pass \\
\end{tabular} & $\begin{array}{l}\text { Installed } \\
\text { in 2008- } \\
09\end{array}$ & & & & & & no & \\
\hline Portland, OR & $\begin{array}{l}\text { Vancouver } \\
\text { Avenue } \\
\text { Intersection } \\
\text { of N. } \\
\text { Broadway }\end{array}$ & $\begin{array}{l}\text { Surrounded } \\
\text { by residential } \\
\text { neighbor- } \\
\text { hoods. } \\
\text { Specific } \\
\text { condition is a } \\
\text { major } \\
\text { intersection } \\
\text { above } 15 \\
\text { Highway. } \\
\end{array}$ & $\begin{array}{l}\text { Shared Bus/Bike } \\
\text { lane through } \\
\text { intersection. } \\
\star \star \star \star N o \text { turns } \\
\text { allowed for cars in } \\
\text { adjacent lanes to } \\
\text { Bus/Bike lane. }\end{array}$ & $\begin{array}{l}\text { one stop at } \\
\text { this intersec- } \\
\text { tion }\end{array}$ & $\begin{array}{l}\text { varies } \\
10-15 \mathrm{ft}\end{array}$ & $600 \mathrm{ft}$ & & $30 \mathrm{mph}$ & $\begin{array}{l}\text { Signs (both } \\
\text { yellow and } \\
\text { BM), lane } \\
\text { markings, } \\
\text { dashed and } \\
\text { striped }\end{array}$ & $\begin{array}{l}2 \text { lanes one } \\
\text { direction. Two } \\
\text { additional } \\
\text { lanes entering } \\
\text { intersection } \\
\text { from same } \\
\text { direction }\end{array}$ & & & no & \\
\hline \begin{tabular}{|l|} 
Philadelphia, \\
PA
\end{tabular} & \begin{tabular}{|l|} 
Chestnut \\
Street \\
18th Street \\
to 6th Street
\end{tabular} & $\begin{array}{l}\text { Downtown } \\
\text { CBD } \\
\text { (bus lines 9, } \\
21,42 \text { ) }\end{array}$ & $\begin{array}{l}\text { Shared } \\
\text { Bus/Bike/RTOL }\end{array}$ & $\begin{array}{l}\text { Every block } \\
\left(400^{\prime}\right)\end{array}$ & $9 \mathrm{ft}$ & $\begin{array}{l}1.06 \\
\text { miles }\end{array}$ & 1990s. & $25 \mathrm{mph}$ & & \begin{tabular}{|l}
1 one-way \\
lane +1 on- \\
street parking \\
lane (not \\
adjacent to \\
bus/bike lane)
\end{tabular} & & & $\begin{array}{l}\text { yes } \\
\text { (mostly } \\
\text { faded) }\end{array}$ & $\begin{array}{l}\text { no } \\
\text { (parking } \\
\text { on } \\
\text { opposite } \\
\text { side) }\end{array}$ \\
\hline $\begin{array}{l}\text { Ft. Worth, } \\
\text { TX } \\
\text { (paired } \\
\text { street) }\end{array}$ & $\begin{array}{l}\text { Throckmor- } \\
\text { ton Street }\end{array}$ & $\begin{array}{l}\text { Downtown } \\
\text { CBD. Pair of } \\
\text { one-way } \\
\text { streets }\end{array}$ & $\begin{array}{l}\text { Conversion from } \\
\text { Bus/RTOL to } \\
\text { Bus/Bike/RTOL }\end{array}$ & & $11 \mathrm{ft}$ & & Late 2011 & $\begin{array}{l}25-35 \\
\mathrm{mph}\end{array}$ & & $\begin{array}{l}\text { 2-3 lanes one } \\
\text { direction }\end{array}$ & & & & \\
\hline $\begin{array}{l}\text { Ft. Worth, } \\
\text { TX } \\
\text { (paired } \\
\text { street) }\end{array}$ & $\begin{array}{l}\text { Houston } \\
\text { Street }\end{array}$ & $\begin{array}{l}\text { Downtown } \\
\text { CBD. Pair of } \\
\text { one-way } \\
\text { streets }\end{array}$ & $\begin{array}{l}\text { Conversion from } \\
\text { Bus/RTOL to } \\
\text { Bus/Bike/RTOL }\end{array}$ & & $11 \mathrm{ft}$ & & Late 2011 & $\begin{array}{l}25-35 \\
\mathrm{mph}\end{array}$ & & $\begin{array}{l}\text { 2-3 lanes one } \\
\text { direction }\end{array}$ & & & & \\
\hline
\end{tabular}




\begin{tabular}{|c|c|c|c|c|c|c|c|c|c|c|c|c|c|c|}
\hline City & $\begin{array}{l}\text { Street } \\
\text { Segment }\end{array}$ & $\begin{array}{l}\text { Urban } \\
\text { Environment/ } \\
\text { Condition }\end{array}$ & Configuration & $\begin{array}{l}\text { Bus Stop } \\
\text { Spacing }\end{array}$ & $\begin{array}{l}\text { Average } \\
\text { Width(s) }\end{array}$ & Length & $\begin{array}{l}\text { Date } \\
\text { opened }\end{array}$ & $\begin{array}{l}\text { Speed } \\
\text { Limit } \\
\text { on } \\
\text { Road }\end{array}$ & \begin{tabular}{|l|} 
Signage \\
and/or Lane \\
Markings
\end{tabular} & \begin{tabular}{|l} 
Number of \\
General \\
Purpose \\
Lanes not \\
including \\
SBBL(s) \\
\end{tabular} & Terminus 1 & Terminus 2 & \begin{tabular}{|l|} 
Lane \\
Color
\end{tabular} & $\begin{array}{l}\text { Adjacent } \\
\text { parking } \\
\text { lane }\end{array}$ \\
\hline Seattle, WA & $\begin{array}{l}\text { Stewart } \\
\text { Street } \\
\text { Denny Way } \\
\text { to 2nd Ave }\end{array}$ & $\begin{array}{l}\text { Downtown } \\
\text { outside CBD }\end{array}$ & $\begin{array}{l}\text { right side } \\
\text { Bus/Bike/RTOL/ } \\
\text { parking during off } \\
\text { peak hours Left } \\
\text { side contains } \\
\text { Shared Lane } \\
\text { Markings } \\
\text { (sometimes LTOL) } \\
\text { Buses serve } \\
\text { mostly } \\
\text { commuters (Grey- } \\
\text { hound station on } \\
\text { street) } \\
\text { High buses per } \\
\text { hour }\end{array}$ & & $12 \mathrm{ft}$ & $\begin{array}{l}0.69 \\
\text { miles }\end{array}$ & 2009 & $30 \mathrm{mph}$ & $\begin{array}{l}\text { lane } \\
\text { markings, } \\
\text { cannot } \\
\text { confirm } \\
\text { signage. }\end{array}$ & $\begin{array}{l}3 \text { lanes one } \\
\text { direction } \\
\text { (includes left } \\
\text { lane with } \\
\text { Shared Lane } \\
\text { Markings. Off } \\
\text { peak parking } \\
\text { on both sides }\end{array}$ & \begin{tabular}{|l|} 
2nd Ave - all \\
buses merge \\
and turn left \\
onto 2nd Ave, \\
where they \\
enter a \\
similar \\
bus/RTOL/off- \\
peak parking \\
lane. \\
Bicyclists: \\
merge to the \\
next general \\
purpose lane, \\
or turn left \\
onto 2nd Ave \\
(bicycle lane \\
on the left \\
side of a one- \\
way)
\end{tabular} & $\begin{array}{l}\text { N/A, } \\
\text { Stewart St } \\
\text { is one-way } \\
\text { westbound }\end{array}$ & \begin{tabular}{|l} 
no, \\
painted \\
bus \\
zone \\
curbs - \\
con- \\
tinuous \\
red and \\
yellow \\
pattern \\
to \\
prohibit \\
parking/ \\
stopping
\end{tabular} & $\begin{array}{l}\text { no } \\
\text { (becomes } \\
\text { parking } \\
\text { off-peak) }\end{array}$ \\
\hline Seattle, WA & $\begin{array}{l}\text { Elliot Ave W } \\
\text { 15th Ave W } \\
\text { W Harrison } \\
\text { St to W } \\
\text { Dravus St } \\
\text { (both sides } \\
\text { of the street) }\end{array}$ & \begin{tabular}{|l|} 
Approx 1 mile \\
Northwest of \\
CBD. \\
Collector road \\
into medium \\
density \\
suburbs. \\
(adjacent to \\
Puget Sound)
\end{tabular} & $\begin{array}{l}\text { Shared } \\
\text { Bus/Bike/RTOL/ } \\
\text { parking during off } \\
\text { peak hours } \\
\text { (restricted } \\
\text { days/hours) }\end{array}$ & \begin{tabular}{|l} 
Every 1000' \\
(varies)
\end{tabular} & $12-13 \mathrm{ft}$ & $\begin{array}{l}2.06 \\
\text { miles }\end{array}$ & 2008 & $35 \mathrm{mph}$ & \begin{tabular}{|l|} 
lane \\
markings \\
and signage
\end{tabular} & $\begin{array}{l}4 \text { lanes two } \\
\text { directions. } \\
\text { CLTL (no } \\
\text { median) }\end{array}$ & \begin{tabular}{|l} 
Becomes a \\
general \\
purpose \\
travel lane \\
with no \\
parking
\end{tabular} & \begin{tabular}{|l|} 
Becomes a \\
general \\
purpose \\
travel lane \\
with no \\
parking
\end{tabular} & \begin{tabular}{|l} 
no, \\
painted \\
bus \\
zone \\
curbs - \\
dashed \\
red/ \\
yellow/ \\
red to \\
prohibit \\
parking \\
(3 ft red, \\
$4 \mathrm{ft}$ \\
yellow, \\
$3 \mathrm{ft}$ red, \\
$10 \mathrm{ft}$ \\
gap)
\end{tabular} & \begin{tabular}{|l} 
no \\
(becomes \\
parking \\
lane \\
during off \\
peak \\
hours)
\end{tabular} \\
\hline
\end{tabular}




\begin{tabular}{|c|c|c|c|c|c|c|c|c|c|c|c|c|c|c|}
\hline City & $\begin{array}{l}\text { Street } \\
\text { Segment }\end{array}$ & \begin{tabular}{|l|} 
Urban \\
Environment/ \\
Condition
\end{tabular} & Configuration & $\begin{array}{l}\text { Bus Stop } \\
\text { Spacing }\end{array}$ & $\begin{array}{l}\text { Average } \\
\text { Width(s) }\end{array}$ & Length & $\begin{array}{l}\text { Date } \\
\text { opened }\end{array}$ & \begin{tabular}{|l} 
Speed \\
Limit \\
on \\
Road
\end{tabular} & \begin{tabular}{|l|} 
Signage \\
and/or Lane \\
Markings
\end{tabular} & \begin{tabular}{|l} 
Number of \\
General \\
Purpose \\
Lanes not \\
including \\
SBBL(s)
\end{tabular} & Terminus 1 & Terminus 2 & $\begin{array}{l}\text { Lane } \\
\text { Color }\end{array}$ & \begin{tabular}{|l|} 
Adjacent \\
parking \\
lane
\end{tabular} \\
\hline $\begin{array}{l}\text { Shoreline, } \\
\text { WA }\end{array}$ & $\begin{array}{l}\text { Aurora } \\
\text { Avenue N } \\
\text { N115th St to } \\
\text { N165th } \\
\text { (both sides } \\
\text { of the street) }\end{array}$ & \begin{tabular}{|l|} 
Suburban \\
Arterial \\
Condition
\end{tabular} & \begin{tabular}{|l|} 
Bus/RTOL \\
Bicyclists \\
permitted although \\
no markings/ \\
signage
\end{tabular} & & $12 \mathrm{ft}$ & \begin{tabular}{|l|}
2.7 \\
miles \\
north- \\
bound \\
1.0 \\
miles \\
south- \\
bound
\end{tabular} & & $\begin{array}{l}40-45 \\
\text { mph }\end{array}$ & \begin{tabular}{|l|} 
Lanes \\
marked with \\
solid and \\
dashed white \\
lines. RTOL \\
markings \\
prevalent. \\
Bus only \\
signage. No \\
bicycle signs
\end{tabular} & $\begin{array}{l}4 \text { lane divided } \\
\text { roadway with } \\
\text { many turn } \\
\text { lanes }\end{array}$ & & & no & no \\
\hline $\begin{array}{l}\text { Madison, WI } \\
\text { (both sides } \\
\text { of the street) }\end{array}$ & \begin{tabular}{|l} 
Mineral \\
Point Road \\
aka County \\
Road "S" \\
near James \\
Madison \\
Memorial \\
High School, \\
on the \\
southwest \\
side of \\
Madison. \\
Gammon \\
Road and \\
the Beltline \\
(Highways \\
12 and 14)
\end{tabular} & \begin{tabular}{|l|} 
Suburban \\
Arterial Road \\
about 5 miles \\
outside of \\
downtown \\
Madison
\end{tabular} & SBBL & & $13.5 \mathrm{ft}$ & & & $\begin{array}{l}35-40 \\
\text { mph }\end{array}$ & & & & & & \\
\hline
\end{tabular}


Examples of Facilities: Proposed, Removed, or Uncommon Design/Operation

\begin{tabular}{|c|c|c|c|c|c|c|c|c|c|c|c|c|c|c|}
\hline City & $\begin{array}{l}\text { Street } \\
\text { Segment }\end{array}$ & \begin{tabular}{|l|} 
Urban \\
Environment/ \\
Condition
\end{tabular} & Configuration & $\begin{array}{l}\text { Bus Stop } \\
\text { Spacing }\end{array}$ & $\begin{array}{l}\text { Average } \\
\text { Width(s) }\end{array}$ & Length & \begin{tabular}{|l|} 
Date \\
opened
\end{tabular} & \begin{tabular}{|l|} 
Speed \\
Limit on \\
Road
\end{tabular} & \begin{tabular}{|l} 
Signage \\
and/or Lane \\
Markings
\end{tabular} & \begin{tabular}{|l|} 
Number of \\
General \\
Purpose \\
Lanes not \\
including \\
SBBL(s)
\end{tabular} & \begin{tabular}{|l} 
Terminus \\
1
\end{tabular} & $\begin{array}{l}\text { Terminus } \\
2\end{array}$ & $\begin{array}{l}\text { Lane } \\
\text { Color }\end{array}$ & $\begin{array}{l}\text { Adjacent } \\
\text { parking } \\
\text { lane }\end{array}$ \\
\hline $\begin{array}{l}\text { Jacksonville, FL } \\
\text { (unofficial) }\end{array}$ & \begin{tabular}{|l|} 
Blanding \\
Boulevard \\
Morse Ave to \\
103rd St
\end{tabular} & & $\begin{array}{l}\text { officially Bus/RTOL } \\
\text { lanes in both } \\
\text { directions. } \\
\text { Sometimes used by } \\
\text { bicyclists due to lack } \\
\text { of bicycle lanes in } \\
\text { area }\end{array}$ & & $10 \mathrm{ft}$ & $\begin{array}{l}1.6 \\
\text { miles }\end{array}$ & & $45 \mathrm{mph}$ & $\begin{array}{l}\text { dashed line } \\
\text { indicating lane } \\
\text { and bus lane } \\
\text { road markings }\end{array}$ & $\begin{array}{l}\text { 4-lane } \\
\text { divided } \\
\text { highway plus } \\
\text { occasional } \\
\text { center left } \\
\text { turn (bus } \\
\text { lane on } \\
\text { either side) }\end{array}$ & & & no & no \\
\hline $\begin{array}{l}\text { Panama City } \\
\text { Beach } \\
\text { (Proposed) }\end{array}$ & \begin{tabular}{|l|} 
US 98 \\
(Front Beach \\
Road, SR30) \\
South \\
Thomas \\
Drive to De \\
Luna Place
\end{tabular} & $\begin{array}{l}\text { Beach/Sea- } \\
\text { sonal } \\
\text { Community }\end{array}$ & $\begin{array}{l}\text { Proposed Shared } \\
\text { Tram/Bike Lane on } \\
\text { both sides of the } \\
\text { street }\end{array}$ & \begin{tabular}{|l|} 
Tram \\
stops \\
every \\
approx. \\
every \\
1100 ' or \\
40 stops \\
over 8.35 \\
miles. \\
Two \\
transit \\
routes: \\
west \\
route - De \\
Luna PI to \\
Pier Park \\
(2.85 \\
miles w/ \\
15 stops) \\
East \\
Route - S \\
Thomas \\
Dr to Pier \\
Park (5.5 \\
miles w/ \\
25 stops) \\
\end{tabular} & $11 \mathrm{ft}$ & $\begin{array}{l}8.35 \\
\text { miles }\end{array}$ & $\begin{array}{l}\text { proposed } \\
2006- \\
2008\end{array}$ & $\begin{array}{l}\text { Current } \\
35 \mathrm{mph} \text {, } \\
\text { pro- } \\
\text { posed } \\
25 \mathrm{mph} \\
\text { (buses } \\
\text { may be } \\
\text { required } \\
\text { to move } \\
\text { slower) }\end{array}$ & & \begin{tabular}{|l} 
Proposed \\
one lane in \\
each \\
direction with \\
a center-left \\
turn lane
\end{tabular} & & & Yes (red) & no \\
\hline
\end{tabular}




\begin{tabular}{|c|c|c|c|c|c|c|c|c|c|c|c|c|c|c|}
\hline City & $\begin{array}{l}\text { Street } \\
\text { Segment }\end{array}$ & $\begin{array}{l}\text { Urban } \\
\text { Environment/ } \\
\text { Condition }\end{array}$ & Configuration & $\begin{array}{l}\text { Bus Stop } \\
\text { Spacing }\end{array}$ & $\begin{array}{l}\text { Average } \\
\text { Width(s) }\end{array}$ & Length & $\begin{array}{l}\text { Date } \\
\text { opened }\end{array}$ & $\begin{array}{l}\text { Speed } \\
\text { Limit on } \\
\text { Road }\end{array}$ & \begin{tabular}{|l} 
Signage \\
and/or Lane \\
Markings
\end{tabular} & \begin{tabular}{|l} 
Number of \\
General \\
Purpose \\
Lanes not \\
including \\
SBBL(s)
\end{tabular} & $\begin{array}{l}\text { Terminus } \\
1\end{array}$ & $\begin{array}{l}\text { Terminus } \\
2\end{array}$ & $\begin{array}{l}\text { Lane } \\
\text { Color }\end{array}$ & $\begin{array}{l}\text { Adjacent } \\
\text { parking } \\
\text { lane }\end{array}$ \\
\hline $\begin{array}{l}\text { St. Petersburg, } \\
\text { FL (bus drop-off } \\
\text { lane) }\end{array}$ & $\begin{array}{l}\text { 4th Ave S } \\
\text { (Stadium } \\
\text { Drive) } \\
\text { 16th Street S } \\
\text { to Dr Martin } \\
\text { Luther King } \\
\text { Jr Street S }\end{array}$ & $\begin{array}{l}\text { Adjacent to } \\
\text { the south side } \\
\text { of Tropicana } \\
\text { Field }\end{array}$ & $\begin{array}{l}\text { Bus drop off and } \\
\text { bicycle lane }\end{array}$ & & $9 \mathrm{ft}$ & $\begin{array}{l}0.5 \\
\text { miles }\end{array}$ & recent & $30 \mathrm{mph}$ & $\begin{array}{l}\text { Bike lane } \\
\text { markings, bus } \\
\text { drop off signs }\end{array}$ & $\begin{array}{l}1 \text { westbound } \\
\text { lane }\end{array}$ & & & no & no \\
\hline $\begin{array}{l}\text { Tallahassee, FL } \\
\text { University edge } \\
\text { (feasibility study) }\end{array}$ & \begin{tabular}{|l} 
W \\
Tennessee \\
Street \\
Ocala Road \\
to Monroe \\
Street
\end{tabular} & $\begin{array}{l}\text { Principal } \\
\text { Arterial } \\
\text { Roadway } \\
\text { adjacent to } \\
\text { the north edge } \\
\text { of the Florida } \\
\text { State } \\
\text { University } \\
\text { Campus. } \\
\text { Opposite side } \\
\text { of the street } \\
\text { are many off- } \\
\text { campus } \\
\text { activity } \\
\text { locations } \\
\text { yielding many } \\
\text { pedestrian } \\
\text { crossings. }\end{array}$ & $\begin{array}{l}\text { Concept for a Shared } \\
\text { Bike/Bus/RTOL lane }\end{array}$ & & $\begin{array}{l}10 \mathrm{ft} \\
\text { existing } \\
\text { and } \\
\text { proposed } \\
\text { curb-to- } \\
\text { curb width } \\
\text { is } 86 \mathrm{ft} \text { but } \\
\text { may vary. }\end{array}$ & $\begin{array}{l}2.3 \\
\text { miles }\end{array}$ & $\begin{array}{l}\text { Feasibility } \\
\text { study only }\end{array}$ & $\begin{array}{l}35 \text { mph } \\
\text { (current) } \\
\text { WB from } \\
\text { Dewey, } \\
30 \text { mph }\end{array}$ & & $\begin{array}{l}6 \text { lanes with } \\
\text { median and } \\
\text { CLTL } \\
\text { (current) } 4 \\
\text { lanes } \\
\text { (proposed) }\end{array}$ & & & no & no \\
\hline Tampa, FL & \begin{tabular}{|l} 
Nebraska \\
Avenue \\
E Palm Ave \\
to E \\
Hillsborough \\
Ave.
\end{tabular} & $\begin{array}{l}\text { Urban } \\
\text { Neighborhood } \\
\text { northeast of } \\
\text { the CBD }\end{array}$ & $\begin{array}{l}\text { Bicycle lane widens } \\
\text { at bus stop locations }\end{array}$ & $\begin{array}{l}\text { Approxi- } \\
\text { mately } \\
\text { every } \\
\text { other } \\
\text { block }\end{array}$ & $8 \mathrm{ft}$ & $\begin{array}{l}2.3 \\
\text { miles }\end{array}$ & 2007 & $\begin{array}{l}35 \mathrm{mph} \\
\mathrm{NB} \text { at } \\
\text { south } \\
\text { end }\end{array}$ & Lane Markings & $\begin{array}{l}2 \text { lanes plus } \\
\text { occasional } \\
\text { center left } \\
\text { turn }\end{array}$ & & & no & no \\
\hline
\end{tabular}




\begin{tabular}{|c|c|c|c|c|c|c|c|c|c|c|c|c|c|c|}
\hline City & $\begin{array}{l}\text { Street } \\
\text { Segment }\end{array}$ & $\begin{array}{l}\text { Urban } \\
\text { Environment/ } \\
\text { Condition }\end{array}$ & Configuration & $\begin{array}{l}\text { Bus Stop } \\
\text { Spacing }\end{array}$ & $\begin{array}{l}\text { Average } \\
\text { Width(s) }\end{array}$ & Length & $\begin{array}{l}\text { Date } \\
\text { opened }\end{array}$ & $\begin{array}{l}\text { Speed } \\
\text { Limit on } \\
\text { Road }\end{array}$ & \begin{tabular}{|l} 
Signage \\
and/or Lane \\
Markings
\end{tabular} & $\begin{array}{l}\text { Number of } \\
\text { General } \\
\text { Purpose } \\
\text { Lanes not } \\
\text { including } \\
\text { SBBL(s) }\end{array}$ & \begin{tabular}{|l} 
Terminus \\
1
\end{tabular} & $\begin{array}{l}\text { Terminus } \\
2\end{array}$ & $\begin{array}{l}\text { Lane } \\
\text { Color }\end{array}$ & $\begin{array}{l}\text { Adjacent } \\
\text { parking } \\
\text { lane }\end{array}$ \\
\hline $\begin{array}{l}\text { Chicago, IL } \\
\text { (proposed) }\end{array}$ & $\begin{array}{l}\text { Randolph } \\
\text { Street }\end{array}$ & $\begin{array}{l}\text { Major divided } \\
\text { roadway just } \\
\text { west of } \\
\text { downtown } \\
\text { CBD }\end{array}$ & $\begin{array}{l}\text { Shared BRT/Bicycle } \\
\text { Lane }\end{array}$ & & & & $\begin{array}{l}\text { proposed } \\
\text { in } 2010\end{array}$ & & & \begin{tabular}{|l|}
2 lane \\
boulevard \\
with divided \\
local lanes \\
on either \\
side. Angled \\
parking on \\
both sides
\end{tabular} & & & & \\
\hline Minneapolis, MN & $\begin{array}{l}\text { Marquette } \\
\text { Avenue } \\
\text { 1st Street S } \\
\text { to S 12th } \\
\text { Street }\end{array}$ & \begin{tabular}{|l} 
Central \\
Business \\
District. Light \\
bicycle traffic
\end{tabular} & $\begin{array}{l}\text { Bike lane to left of } \\
\text { bus lane }\end{array}$ & & $\begin{array}{l}20 \mathrm{ft} \\
\text { total incl } \\
\text { bus lane. } \\
6 \mathrm{ft} \text { bike } \\
\text { lane only }\end{array}$ & $\begin{array}{l}0.75 \\
\text { miles }\end{array}$ & \begin{tabular}{|l|} 
Portions \\
under \\
construc- \\
tion in \\
2009 \\
(GE)
\end{tabular} & $30 \mathrm{mph}$ & $\begin{array}{l}\text { Lane markings. } \\
\text { Very minimal } \\
\text { signage }\end{array}$ & \begin{tabular}{|l|}
2 lanes one \\
direction + \\
parking lane \\
(on opposite \\
side of \\
bus/bike \\
lanes)
\end{tabular} & & & & \\
\hline \begin{tabular}{|l|} 
Portland, OR \\
(SBBL no longer \\
exists)
\end{tabular} & \begin{tabular}{|l|} 
E Burnside \\
Street \\
Approaching \\
the Burnside \\
Bridge
\end{tabular} & \begin{tabular}{|l} 
Near \\
Williamette \\
River. Part of \\
medium \\
density urban \\
core.
\end{tabular} & $\begin{array}{l}\text { Shared } \\
\text { Bus/Bike/RTOL } \\
\text { removed }\end{array}$ & & $14 \mathrm{ft}$ & $\begin{array}{l}800 \mathrm{ft} \\
(3 \\
\text { blocks })\end{array}$ & \begin{tabular}{|l|} 
Installed \\
in 2009, \\
removed \\
in 2010
\end{tabular} & $35 \mathrm{mph}$ & \begin{tabular}{|l} 
Sign and lane \\
markings \\
include solid \\
white line
\end{tabular} & $\begin{array}{l}5 \text { lanes, no } \\
\text { parking } \\
\text { (replaced } \\
\text { with parking } \\
\text { lane) }\end{array}$ & & & no & \\
\hline Seattle, WA & \begin{tabular}{|l|} 
3rd Avenue \\
(bus street) \\
not designed \\
for bikes but \\
is now shared \\
with them
\end{tabular} & $\begin{array}{l}\text { Downtown } \\
\text { CBD }\end{array}$ & $\begin{array}{l}\text { Bus Street with } \\
\text { automobiles limited } \\
\text { at certain times of the } \\
\text { day. Bicycles } \\
\text { permitted }\end{array}$ & & & $\begin{array}{l}0.53 \\
\text { miles }\end{array}$ & & & $\begin{array}{l}\text { unmarked for } \\
\text { bicycles }\end{array}$ & 4 lanes & & & no & \\
\hline \begin{tabular}{|l|} 
Madison, WI \\
University edge \\
(SBBL no longer \\
exists)
\end{tabular} & $\begin{array}{l}\text { University } \\
\text { Avenue } \\
\text { N Randall } \\
\text { Ave }\end{array}$ & $\begin{array}{l}\text { University of } \\
\text { Wisconsin at } \\
\text { Madison. } \\
\text { Street is } \\
\text { located along } \\
\text { south edge of } \\
\text { campus. } \\
\text { Heavily } \\
\text { traveled by } \\
\text { bicyclists. }\end{array}$ & $\begin{array}{l}\text { SBBL replaced with } \\
\text { bike lane to left of } \\
\text { bus lane }+ \\
\text { Contraflow bike lane } \\
\text { on opposite side } \\
\text { (converted from a } \\
\text { bus lane) with a } \\
\text { concrete median. }\end{array}$ & & $\begin{array}{l}12 \mathrm{ft} \mathrm{bus} \\
\text { lane }+8 \\
\mathrm{ft} \text { bike } \\
\text { lane }=20 \\
\mathrm{ft} \text { total }\end{array}$ & $\begin{array}{l}0.85 \\
\text { miles }\end{array}$ & \begin{tabular}{|l|} 
before \\
late 2001
\end{tabular} & $25 \mathrm{mph}$ & & $\begin{array}{l}3 \text { lanes one } \\
\text { direction + } \\
\text { contraflow } \\
\text { bike lane in } \\
\text { opposite } \\
\text { direction }\end{array}$ & & & no & no \\
\hline
\end{tabular}


The table below contains information regarding SBBLs in other countries. Anecdotal evidence also exists that there are SBBLs in Queensland, Australia; Brussels, Belgium; Edmonton, Alberta, Canada; Erlangen, Germany; and Copenhagen, Denmark; but no specific information could be found about these facilities.

\section{Inventory of International Cities with Shared Bike/Bus Lanes}

\begin{tabular}{|c|c|c|c|c|c|c|c|c|c|c|c|c|c|}
\hline City/Country & Street & $\begin{array}{l}\text { Urban } \\
\text { Environment / } \\
\text { Condition }\end{array}$ & Configuration & \begin{tabular}{|l} 
Width(s) \\
(GE)
\end{tabular} & $\begin{array}{l}\text { Length } \\
\text { (GE) }\end{array}$ & $\begin{array}{l}\text { Date } \\
\text { opened }\end{array}$ & $\begin{array}{l}\text { Speed } \\
\text { Limit on } \\
\text { Road }\end{array}$ & \begin{tabular}{|l|} 
Signage \\
and/or Lane \\
Markings
\end{tabular} & $\begin{array}{l}\text { Number of } \\
\text { General } \\
\text { Purpose } \\
\text { Lanes }\end{array}$ & Termini & $\begin{array}{l}\text { Lane } \\
\text { Color }\end{array}$ & $\begin{array}{l}\text { Physically } \\
\text { Separated }\end{array}$ & $\begin{array}{l}\text { Adjacent } \\
\text { parking } \\
\text { lane }\end{array}$ \\
\hline $\begin{array}{l}\text { Vienna, } \\
\text { Austria }\end{array}$ & $\begin{array}{l}\text { reference in } \\
\text { blog to one } \\
\text { outside the } \\
\text { core area, } \\
\text { no other } \\
\text { info } \\
\end{array}$ & & & & & & & & & & & & \\
\hline $\begin{array}{l}\text { Ghent, } \\
\text { Belgium }\end{array}$ & & & $\begin{array}{l}\text { may include contraflow } \\
\text { bike lane }\end{array}$ & & & 1992 & & & & & & & \\
\hline $\begin{array}{l}\text { Ottawa, } \\
\text { Canada }\end{array}$ & $\begin{array}{l}\text { Woodroffe } \\
\text { Avenue } \\
\text { Norice St to } \\
\text { David Dr }\end{array}$ & $\begin{array}{l}\text { Low density } \\
\text { suburban arterial } \\
\text { road }\end{array}$ & $\begin{array}{l}\text { Shared Bike/Bus lane } \\
\text { Northbound with } \\
\text { dedicated Bike and Bus } \\
\text { lanes before and after. } \\
\text { RTOL to the right of } \\
\text { shared lane }\end{array}$ & $11 \mathrm{ft}$ & $\begin{array}{l}0.38 \\
\text { miles }\end{array}$ & $\begin{array}{l}\text { prior to } \\
2004 ?\end{array}$ & $60 \mathrm{~km} / \mathrm{h}$ & $\begin{array}{l}\text { Overhead } \\
\text { Signage and } \\
\text { lane } \\
\text { markings } \\
\text { (signage } \\
\text { includes fine } \\
\text { amount for } \\
\text { non- } \\
\text { compliance). }\end{array}$ & $\begin{array}{l}4 \text { plus LCTL, } \\
\text { RTOL, and } \\
\text { center } \\
\text { median }\end{array}$ & & no & & \\
\hline \begin{tabular}{|l} 
Toronto, \\
Canada \\
(University of \\
Toronto) \\
(shared lane \\
on both \\
sides of the \\
street)
\end{tabular} & $\begin{array}{l}\text { Bay Street } \\
\text { Cumberland } \\
\text { Street to } \\
\text { Front Street } \\
\text { West }\end{array}$ & $\begin{array}{l}\text { Downtown CBD } \\
\text { and University } \\
\text { edge }\end{array}$ & $\begin{array}{l}\text { Shared } \\
\text { Bike/Bus/Taxi/RTOL } \\
\text { Operates from 7am to } \\
\text { 7pm M-F. (no left turns } \\
\text { allowed on portion of } \\
\text { street) (Portion of street } \\
\text { includes light rail) }\end{array}$ & $11-15 \mathrm{ft}$ & $\begin{array}{l}1.78 \\
\text { miles }\end{array}$ & $\begin{array}{l}\text { prior to } \\
2007 ?\end{array}$ & $\begin{array}{l}\text { downtown } \\
\text { speeds }\end{array}$ & \begin{tabular}{|l} 
Overhead \\
Signage and \\
lane \\
markings
\end{tabular} & $\begin{array}{l}2 \text { lanes } \\
\text { bidirectional } \\
\text { occasional } \\
\text { CLTL or light } \\
\text { rail lines }\end{array}$ & & no & & \\
\hline
\end{tabular}




\begin{tabular}{|c|c|c|c|c|c|c|c|c|c|c|c|c|c|}
\hline City/Country & Street & $\begin{array}{l}\text { Urban } \\
\text { Environment / } \\
\text { Condition }\end{array}$ & Configuration & $\begin{array}{l}\text { Width(s) } \\
\text { (GE) }\end{array}$ & $\begin{array}{l}\text { Length } \\
\text { (GE) }\end{array}$ & $\begin{array}{l}\text { Date } \\
\text { opened }\end{array}$ & $\begin{array}{l}\text { Speed } \\
\text { Limit on } \\
\text { Road }\end{array}$ & \begin{tabular}{|l|} 
Signage \\
and/or Lane \\
Markings
\end{tabular} & $\begin{array}{l}\text { Number of } \\
\text { General } \\
\text { Purpose } \\
\text { Lanes }\end{array}$ & Termini & \begin{tabular}{|l|} 
Lane \\
Color
\end{tabular} & $\begin{array}{l}\text { Physically } \\
\text { Separated }\end{array}$ & $\begin{array}{l}\text { Adjacent } \\
\text { parking } \\
\text { lane }\end{array}$ \\
\hline $\begin{array}{l}\text { Vancouver } \\
\text { BC, Canada }\end{array}$ & \begin{tabular}{|l|} 
W Pender \\
Street \\
Granville St \\
to Beatty St
\end{tabular} & $\begin{array}{l}\text { Downtown CBD. } \\
\text { Buses every +/-5 } \\
\text { minutes }\end{array}$ & \begin{tabular}{|l} 
Shared Electric \\
Bus/Bike/RTOL \\
Returns to bike lane \\
(south) becomes a \\
sharrow lane (north) bus \\
lanes disappear
\end{tabular} & $11 \mathrm{ft}$ & $\begin{array}{l}0.32 \\
\text { miles }\end{array}$ & & & \begin{tabular}{|l|} 
Left turns \\
are \\
restricted \\
certain times \\
of the \\
day/week.
\end{tabular} & 2 GP lanes & & no & & \\
\hline \begin{tabular}{|l|} 
Vancouver \\
BC, Canada \\
\end{tabular} & \begin{tabular}{l|} 
East on W. \\
Hastings St. \\
\end{tabular} & & bike/bus lane & & & & & & & & & & \\
\hline $\begin{array}{l}\text { Paris, France } \\
\text { (Extensive } \\
\text { network of } \\
\text { bike-bus } \\
\text { lanes) }\end{array}$ & $\begin{array}{l}\text { Rue de } \\
\text { Rivoli } \\
\text { Rue de } \\
\text { l'Echelle to } \\
\text { Rue de } \\
\text { Birague }\end{array}$ & $\begin{array}{l}\text { Downtown Historic } \\
\text { Core, adjacent to } \\
\text { museums, plazas }\end{array}$ & $\begin{array}{l}\text { Shared } \\
\text { Bus/Bike/Taxi/Private Bus } \\
\text { lane }\end{array}$ & $\begin{array}{l}3.5-5 \mathrm{~m} \\
\text { (not } \\
\text { including } \\
\text { barrier) }\end{array}$ & $\begin{array}{l}1.57 \\
\text { miles }\end{array}$ & $\begin{array}{l}\text { prior to } \\
2002 ?\end{array}$ & & & $\begin{array}{l}2 \text { (far lane is } \\
\text { wider) plus } \\
\text { bus/bike lane }\end{array}$ & $\begin{array}{l}\text { l'Echelle: } \\
\text { Continues } \\
\text { as a } \\
\text { physically } \\
\text { separated } \\
\text { bike lane } \\
\text { with on- } \\
\text { street } \\
\text { parking to } \\
\text { the left of } \\
\text { the bike } \\
\text { lane } \\
\text { barrier }\end{array}$ & No & yes & $\begin{array}{l}\text { yes to } \\
\text { the left of } \\
\text { the } \\
\text { lane/left } \\
\text { of a } \\
\text { barrier }\end{array}$ \\
\hline Germany & & & $\begin{array}{l}\text { Bus lane with } \\
\text { "Open to bicyclists" sign }\end{array}$ & & & & & & & & & & \\
\hline $\begin{array}{l}\text { Geneva, } \\
\text { Switzerland }\end{array}$ & & & Bus/Bike lane along curb & & & & & & & & & & \\
\hline $\begin{array}{l}\text { Edinburgh, } \\
\text { U.K. }\end{array}$ & & & Bus/Bike lane & & & & & & & & & & \\
\hline
\end{tabular}




\begin{tabular}{|c|c|c|c|c|c|c|c|c|c|c|c|c|c|}
\hline City/Country & Street & $\begin{array}{l}\text { Urban } \\
\text { Environment / } \\
\text { Condition }\end{array}$ & Configuration & \begin{tabular}{|l|} 
Width(s) \\
(GE)
\end{tabular} & $\begin{array}{l}\text { Length } \\
\text { (GE) }\end{array}$ & \begin{tabular}{|l|} 
Date \\
opened
\end{tabular} & $\begin{array}{l}\text { Speed } \\
\text { Limit on } \\
\text { Road }\end{array}$ & \begin{tabular}{|l|} 
Signage \\
and/or Lane \\
Markings
\end{tabular} & $\begin{array}{l}\text { Number of } \\
\text { General } \\
\text { Purpose } \\
\text { Lanes }\end{array}$ & Termini & $\begin{array}{l}\text { Lane } \\
\text { Color }\end{array}$ & $\begin{array}{l}\text { Physically } \\
\text { Separated }\end{array}$ & \begin{tabular}{|l|} 
Adjacent \\
parking \\
lane
\end{tabular} \\
\hline $\begin{array}{l}\text { London, U.K. } \\
\text { (Extensive } \\
\text { network of } \\
\text { bike-bus } \\
\text { lanes) }\end{array}$ & $\begin{array}{l}\text { Charing } \\
\text { Cross } \\
\text { Road/ } \\
\text { Tottenham } \\
\text { Court Road } \\
\text { Torrington } \\
\text { Place to } \\
\text { Shaftesbury } \\
\text { Avenue }\end{array}$ & Downtown CBD & $\begin{array}{l}\text { Bus/Bike/Taxi/Motorcycle/ } \\
\text { Queue jump lane } \\
\text { (restricted hours M-Sat } \\
\text { 11am-10pm) } \\
\text { (briefly interrupted in } \\
\text { spots) (portion of } \\
\text { street is a contraflow bus } \\
\text { lane) }\end{array}$ & $11.3 \mathrm{ft}$ & $\begin{array}{l}0.63 \\
\text { miles }\end{array}$ & $\begin{array}{l}\text { prior to } \\
1999\end{array}$ & & \begin{tabular}{|l|} 
Frequent \\
signage and \\
lane \\
markings.
\end{tabular} & $\begin{array}{l}2 \text { lanes one- } \\
\text { way }\end{array}$ & $\begin{array}{l}\text { Torrington: } \\
\text { Continues } \\
\text { as a green } \\
\text { colored, } \\
\text { narrow } \\
\text { bike lane. } \\
\text { Also a } \\
\text { green } \\
\text { queue } \\
\text { jump with } \\
\text { signal to } \\
\text { turn } \\
\text { across } \\
\text { onto } \\
\text { Torrington } \\
\text { Place }\end{array}$ & yes & $\begin{array}{l}\text { yes, only at } \\
\text { intersections }\end{array}$ & \begin{tabular}{|l} 
No, two \\
instances \\
of \\
loading \\
zonings \\
for \\
private \\
vehicles
\end{tabular} \\
\hline
\end{tabular}




\section{Appendix B}

\section{Minneapolis, MN, Educational Brochure of Lane Changes on Hennepin and First Avenues}

Appendix B illustrates a brochure that was distributed by Minneapolis Public Works on their website to educate drivers and bicyclists how to safely adjust to new road conversions, offset parking, bicycle lanes, bike boxes, and SBBLs. 


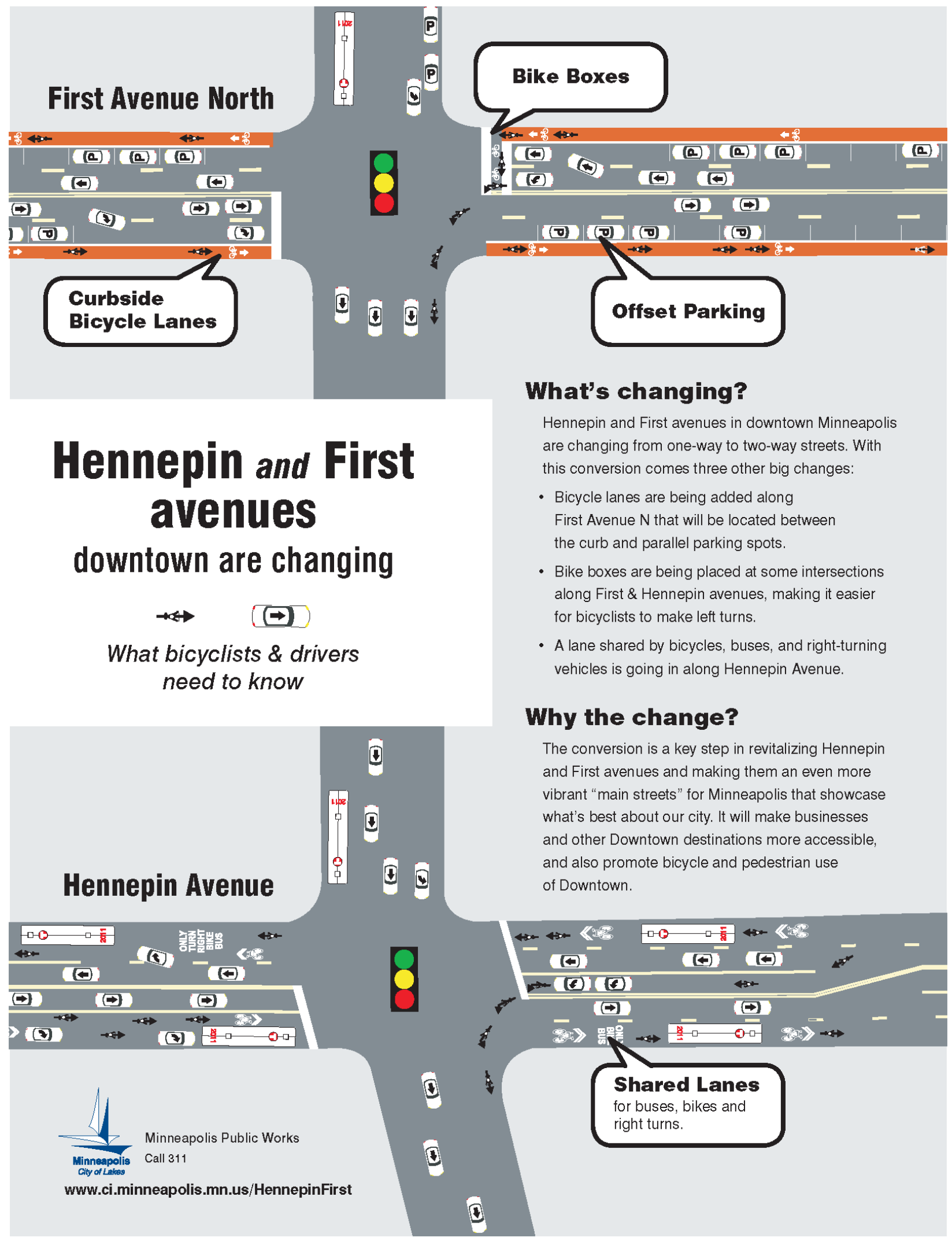




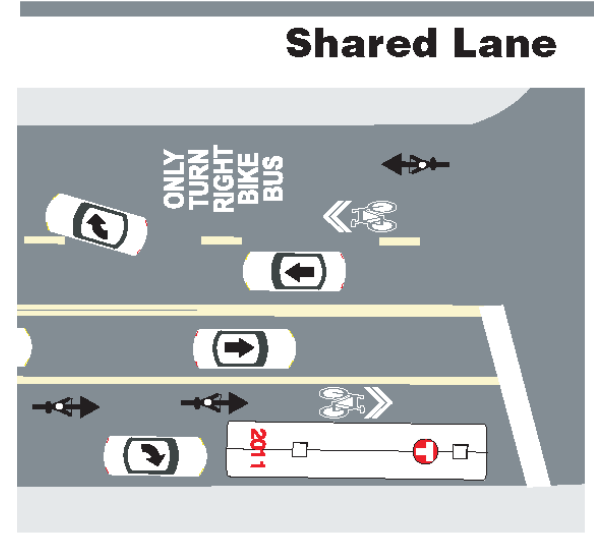

Shared lanes on Hennepin Avenue are lanes that bicycles, buses, and right-turning vehicles need to share. They are marked with a "sharrow" (see image on right). While bicyclists are encouraged to use the shared lane, they may still use other lanes for moving, passing, and turning.

\section{what DRIVERS need to know}

- If you are making a right turn in the combined bus, bicycle, and right-turn lane, expect to see a bicyclist using the entire lane. Be patient and do not pass bicycles unless you can give at least a three-foot clearance (required by Minnesota law).

\section{what BICYCLISTS need to know}

- Other vehicles may occupy the shared lane, so exercise patience and wait if there is not enough space to safely pass a stopped vehicle ahead of you. Use heightened awareness around buses.

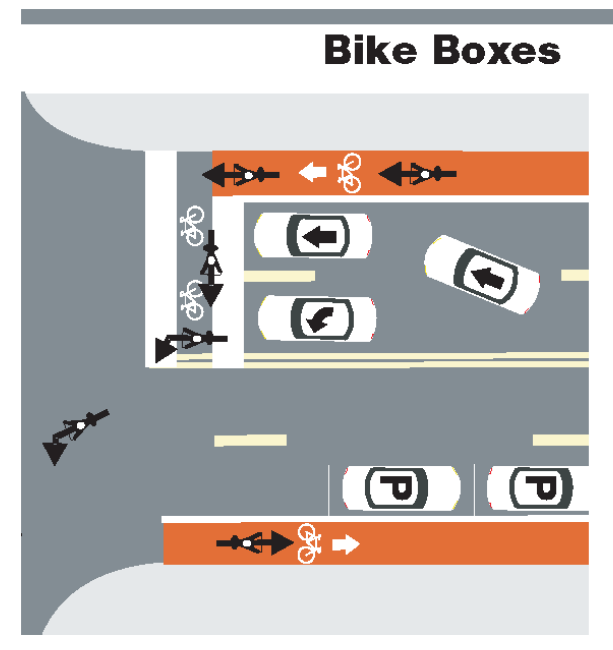

At some intersections along Hennepin and First avenues, there will be 10 foot deep bike boxes between crosswalks and the lines drivers need to stop at when the lights are red. Left-turning bicycles can pull ahead of stopped traffic and wait in the bike boxes for the light to turn green. Drivers are not allowed in bike boxes during yellow and red stoplight phases.

\section{what DRIVERS need to know}

- Do not stop in the bike box when lights are yellow or red. Always stop at the stop line. When the light turns green, you can enter the bike box only after bicyclists in your lane have made their left turns. Wait behind them until they have safely cleared your lane.

\section{what BICYCLISTS need to know}

- Instead of having to merge across lanes of traffic in advance of a left turn, you can enter a bike box when the traffic signal is yellow or red. Make sure drivers have stopped before you enter the bike box. Move toward the center line and signal your turn. Make your left as soon as the traffic signal turns green and oncoming traffic clears. If the intersection you're approaching has a green light, enter the left lane only after yielding to vehicles and then make your left turn.

\section{Curbside Bicycle Lane \& Offset Parking}
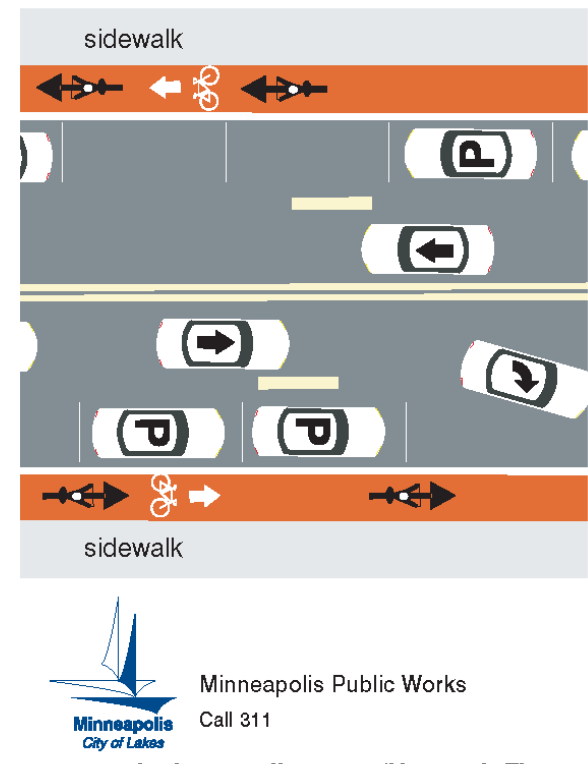

www.ci.minneapolis.mn.us/HennepinFirst
Instead of having parallel parking next to the curb along First Avenue, there will be a bike lane between the curb and parked cars. This is a unique way of providing on-street parking that can serve as a driving lane during rush hour and other peak traffic times. During non-peak traffic hours, parked cars will serve as a buffer between drivers and bicyclists.

\section{what DRIVERS need to know}

- Do not stop or park along the curb on First Avenue. You can be towed immediately for blocking the bike lane.

- Passengers in your parked vehicle can only open their doors if no bicyclists are approaching in the bike lane (this is required by Minnesota law).

- When making right turns at intersections, yield to bicyclists in the bike lane just as you would yield to pedestrians in a crosswalk (also required by Minnesota law).

- Do not park along First Avenue downtown 7 - 9 a.m. and 4 - 6 p.m. Monday through Friday, and 10 p.m. to 6 a.m. Friday and Saturday nights.

\section{what BICYCLISTS need to know}

- Watch for side doors on parked cars opening in your path. Keep a reasonable speed in the curbside bike lanes in case you need to stop quickly.

- Keep your eyes open for right-turning vehicles at intersections. Make sure they are yielding the right-of-way before proceeding through and be prepared to stop if a vehicle turns in front of you.

- When making a left turn where bike boxes are not provided, you may 1) Exit the bike lane at the previous intersection,

ride in the general traffic lane, and make your turn as a car would; or 2) Dismount in the bike lane and use the crosswalk. 


\title{
Appendix C
}

\section{Questionnaire Forms}

\section{A Guide to Design, Policies and Operational Characteristics for Shared Bicycle/Bus Lanes}

\author{
Planning Agency and Transit Authority \\ Questionnaire
}

\begin{abstract}
Objective - The objectives of the guide are three-fold: (1) identify and describe the state of art and practice in the design, implementation, operation, and use of shared bicycle/bus lane, (2) evaluate the benefits and barriers to implementing these types of shared bicycle/bus lanes, and (3) develop recommendations to consider the use of shared bicycle/bus lanes on state highway systems.
\end{abstract}

Survey - The purpose of this survey is to obtain information about jurisdictions that have constructed shared bicycle/bus lanes, along with positive and negative experiences.

Definition - For this survey a Shared Bicycle/Bus Lane is defined as a lane of a traveled way that is dedicated for bicycle travel and bus transit use where bicycles and buses share the lane space together. These lanes may also include permitted use by other high-occupancy vehicles, right turning vehicles, taxis, and/or vehicles during off-peak periods. They may be located on one or both sides of the street and are often terminated with dedicated bicycle lanes or shared roadways.

If your jurisdiction has more than one street with a shared lane configuration, please complete a separate questionnaire for each. The final guide that incorporates the results of this survey will be shared with all participants.

Initial research located the following roadway in your jurisdiction which includes a shared bicycle/bus configuration:

Street: (list street location)

Shared lane configuration located: (list portion of street with facility)

\section{General Information on the DOT, transit agency or planning organization:}

Department/Agency Name:

Address:

City: State/Province: Postal Code:

Contact Name/Title:

Telephone: email: Date:

1. What role does your department/agency play in the process of planning for dedicated bus lanes or shared use bicycle/bus lanes? Is your department/agency involved in initiating projects? If so, how do you decide where they will go? 
2. Are you aware of any shared bicycle/bus lane projects currently under review?

( ) Yes ( ) No If yes, specify location(s) (street and termini):

3. What conditions prompted the installation of the shared bicycle/bus lane?

4. What year was the lane constructed?

5. Has the lane been modified from its initial constructed design or is there intent to modify the lane in the future? This includes a constructed lane that was subsequently removed?

( ) Yes ( ) No If yes, please explain why the lane was changed and what year those changes took place.

\section{LANE CONFIGURATION}

- $\quad$ Shared lane width: (please note if this includes adjacent parking)

- Which vehicle types are permitted in the shared lane?

() Bus () Bicycle () Right-turn-only vehicles ( ) Taxis () Other high-occupancy vehicles ( ) Moving vehicles during off-peak periods ( ) Parked vehicles during off-peak hours

- Are their special restrictions on the use of the lane? (i.e. dedicated lane for certain days/hours only)

- What is the speed limit on the street?

- How does the lane terminate at either end? (example: returns to a 5-foot bicycle lane)

North or West end:

South or East end:

7. Were any restrictions placed on the street in order for the shared lane to operate more efficiently or safely such as no left turns during peak periods? ( ) Yes ( ) No. If yes, please describe

8. What is the level of use by bicyclists? Has use by bicyclists increased or decreased since the shared lane was installed?

9. What is the frequency of buses during:

Peak periods:

Off-peak periods:

Weekends:

10. To what degree were signage and lane markings important factors in the design of the shared lane? 
11. What has been the impact on the level of transit service? What has been the impact on level of service for other motorized vehicles? Has the shared lane made transit service better, worse, or no change?

12. Are bus operators complaining about shared lanes? Does the department/agency hear about complaints from others?

13. Has additional training been required or specific training manuals developed for bus operators to use shared lanes?

14. Provide a general description of traffic volume on the street and on the shared use lane. Are you aware of any changes to the traffic volume on the street or the lane since the lane was installed?

15. Since the lane was put into operation, has there been an increase or decrease in crashes/near misses? Is there any indication of why there was change in incident rates? Was subsequent bus operator training added resulting from a change in incident rates?

16. In discussions with various cycling organizations, there is general consensus that enforcement (of non-transit vehicles) in shared lanes yields a safer experience for bicyclists. To what degree has this been an issue in your jurisdiction?

17. Generally, are bicyclists using the shared lane correctly? ( ) Yes ( ) No

18. What concerns do you have regarding the design and/or operation of the shared bicycle/bus lane concept?

19. In planning future shared bicycle/bus lanes, what if anything, would you do differently? What lessons can we learn from?

20. Suggested contacts at agencies involved with the design, operation, and/or review of your shared use bicycle/bus lane (DOT, Bus Operator, bicycle advocates etc.)

\section{Additional comments}




\section{Report Materials:}

If graphics/drawings, reports, crash data, or photographs are available they would be appreciated.

Please include with questionnaire and include credits that should be used if they are republished as part of this guide. Materials will be returned after review.

Thank you in advance for assisting us with the project. Should you have any questions, please contact me at the address below.

\section{Please return this questionnaire to: \\ JoAnne Fiebe \\ Center for Urban Transportation Research \\ 4202 East Fowler Avenue, CUT 100 \\ Tampa, FL 33620 \\ (727) 243.5404 \\ joannefiebe@cutr.usf.edu}




\title{
A Guide to Design, Policies and Operational Characteristics for Shared Bicycle/Bus Lanes
}

\section{Questionnaire for cyclists and cycling organizations}

\begin{abstract}
Objective - The objectives of the guide are three-fold: (1) identify and describe the state of art and practice in the design, implementation, operation, and use of shared bicycle/bus lane, (2) evaluate the benefits and barriers to implementing these types of shared bicycle/bus lanes, and (3) develop recommendations to consider the use of shared bicycle/bus lanes.
\end{abstract}

Survey - The purpose of this survey is to obtain information about shared bicycle/bus lanes, including positive and negative experiences from cyclists.

Definition - For this survey a Shared Bicycle/Bus Lane is defined as a lane of a traveled way that is dedicated for bicycle travel and bus transit use where bicycles and buses share the lane space together. These lanes may also include permitted use by other highoccupancy vehicles, right turning vehicles, taxis, and/or vehicles during off-peak periods. They may be located on one or both sides of the street and are often terminated by dedicated bicycle lanes or shared roadways.

The final guide that incorporates the results of this survey will be shared with all participants.

Initial research identified the following roadway in your area which includes a shared bicycle/bus configuration:

Streets:

Shared lane configuration located:

Date:

Name of bicycle organization:

Name and Title of person completing questionnaire:

Address:

Phone Number: ( )______ Email:

\section{Planning}

1. What are your impressions of the shared bike/bus lane? How well is the lane operating?

2. From your perspective, is there an encroachment or enforcement issue from vehicles who are not permitted to use the lane?

3. When approaching a bus, is the lane wide enough for you to ride around it without having to move out of the lane, or do you frequently have to move into adjacent travel lanes? 
4. Do bicyclists have problems interacting with the buses? Do the bus drivers pay attention? Are bus operators adequately trained to drive in the shared lane and interact with cyclists? Are there specific items that should be added to bus training curriculum or manuals?

5. Is LEAPFROGGING (where buses overtake cyclists between bus stops and cyclists catch up and overtake buses at bus stops) a serious issue when sharing a lane with buses?

6. What is the perception of safety in the shared bike/bus lane? Do cyclists avoid the lane and opt to use bike-only lanes or other streets, or do they prefer the lane?

The following question is for bicycle organizations/individuals who were involved in the planning process of the shared lane

7. During the planning of the shared lane, were you or your organization reached out to from the city, transit agency or other planning authority? If so, to what extent were you listened to? If you or your organization expressed concerns about the lane, did the agencies involved act to correct design problems? Did the problems you were concerned about materialize once the lane was implemented?

\section{Operation and Experience}

8. Do you observe bicyclists doing unsafe things in the lanes such as: going the wrong way in the lane or passing a stopped bus on the right? Yes ( ) No ( )

9. Does the shared lane encourage unsafe behavior by either bicyclists or bus operators? If so, please describe this. Yes ( ) No ( )

10. What concerns do you have regarding the design and/or operation of the shared bicycle/bus lane concept? What improvements could be made to your local shared bike/bus lane? 
11. Do you have any suggested contacts at agencies involved with the design or operation of your shared use bicycle/bus lane?

12. Additional comments?

\title{
Additional Materials
}

If reports or photographs are available they would be appreciated. Please include with questionnaire and include credits that should be used if they are republished as part of this guide. Materials will be returned after review.

Thank you in advance for assisting us with the project. Should you have any questions, please contact me at the address below.

\author{
Please complete and return this questionnaire to: \\ JoAnne Fiebe \\ Center for Urban Transportation Research \\ 4202 East Fowler Avenue, CUT 100 \\ Tampa, FL 33620 \\ (727) 243.5404 \\ joannefiebe@cutr.usf.edu
}




\section{Appendix D}

\section{Pavement Marking Construction Details}

Pima County Department of Transportation and City of Tucson Department of Transportation, Pavement Marking Design Manual. 2nd Edition. Tucson, AZ. August 2008. Sheet 6-1.1. Accessed June 25, 2012 at http://dot.pima.gov/trafeng/DesignManual/PavementManual.pdf

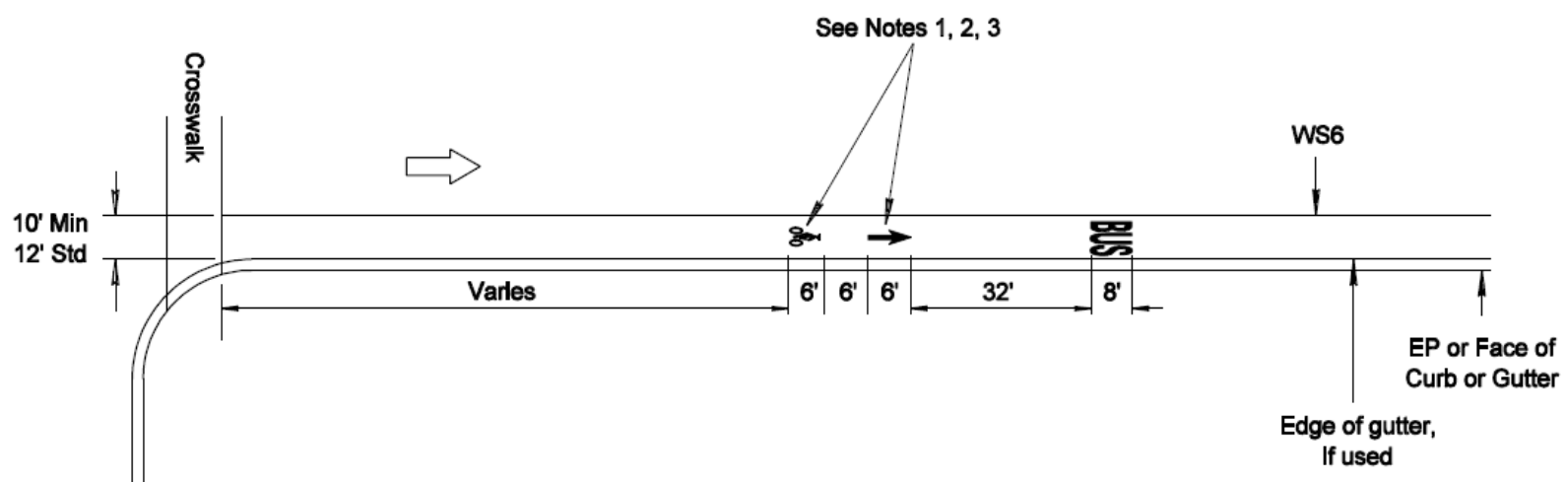

DETAIL 2 - BUS / BIKE LANE

NOTES:

1. Use of bike lane symbols is optional.

2. The bike lane symbol may be installed on designated bike routes at the discretion of the Engineer.

\section{LEGEND}

3. If used, the bike lane symbol shall be placed approximately $65 \mathrm{ft}$ (from crosswalk) from the crossroad, or other locations as needed. The frequency of the symbol is every half mile (City of Tucson) or quarter mile (Pima County) and after every major signalized intersection.

4. $65 \mathrm{ft}$ ensures that turning vehicles do not damage the legends. Distance from intersection should take into consideration the presence of driveways and bus stops. Avoid placing legends where buses stop and dwell. 
City of Ft. Worth and Kimley-Horn and Associates, Inc. Bicycle Facilities Pilot Program. Construction Drawings, April, 2011. Sheets 9, 10, 14.

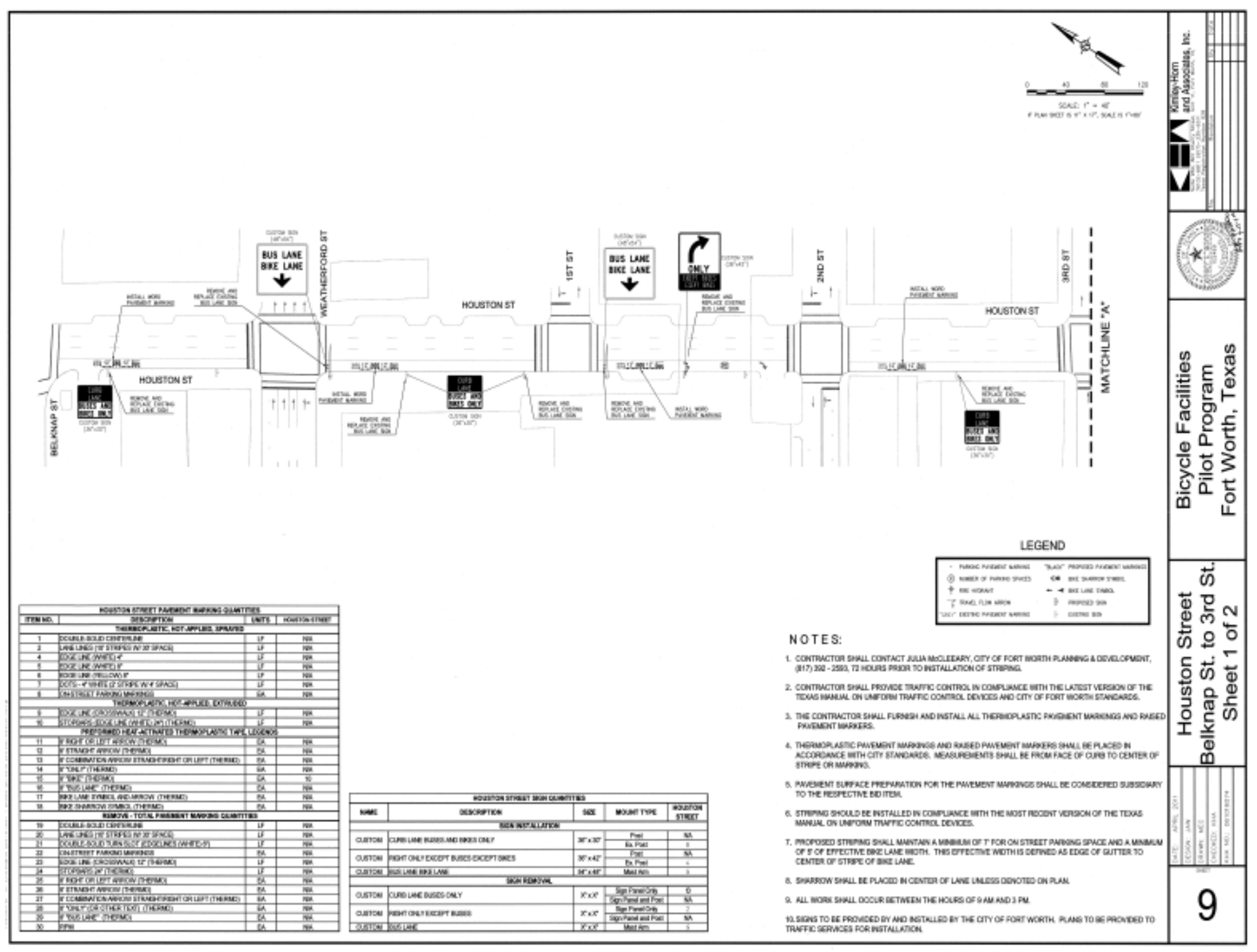




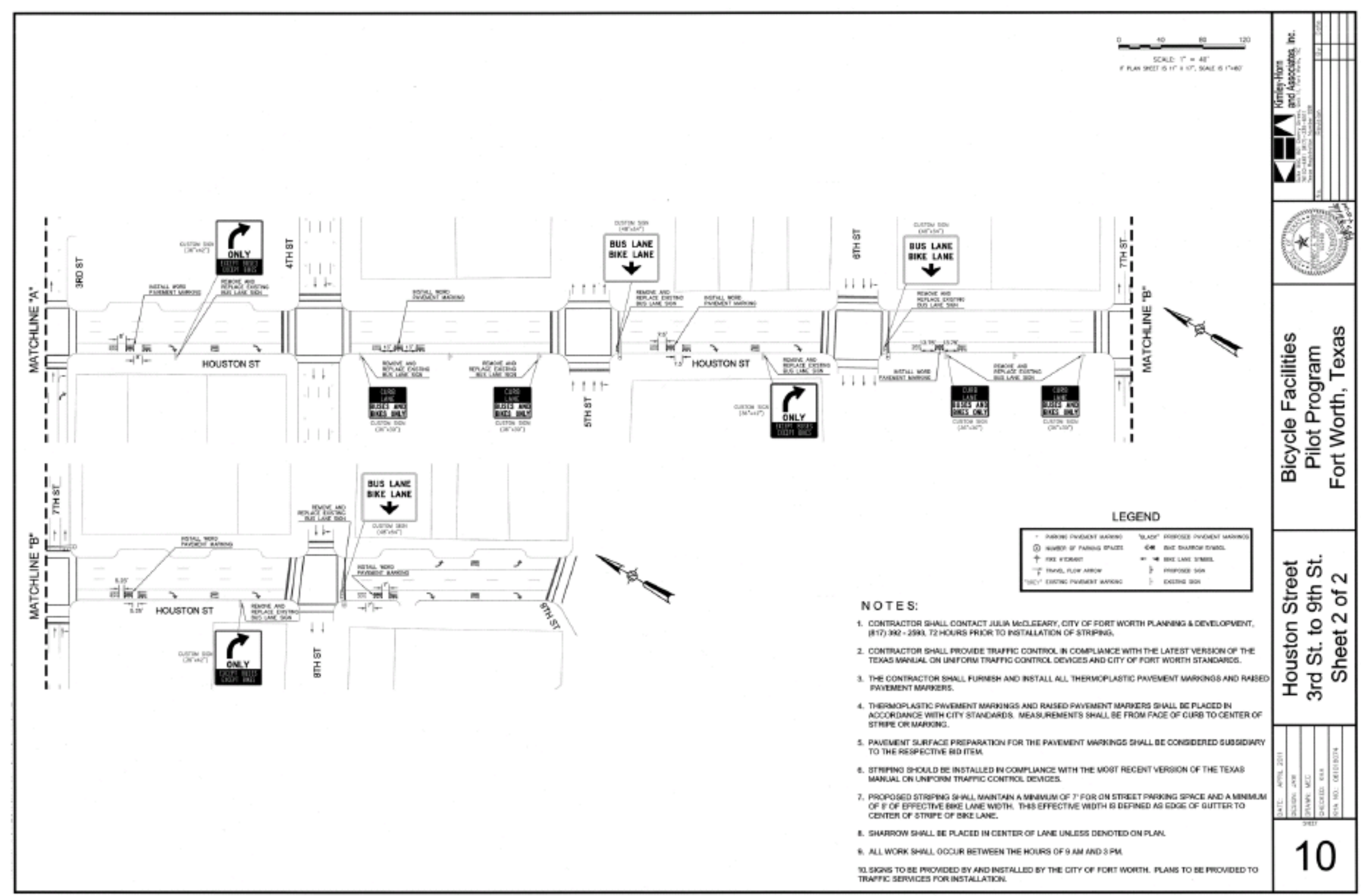




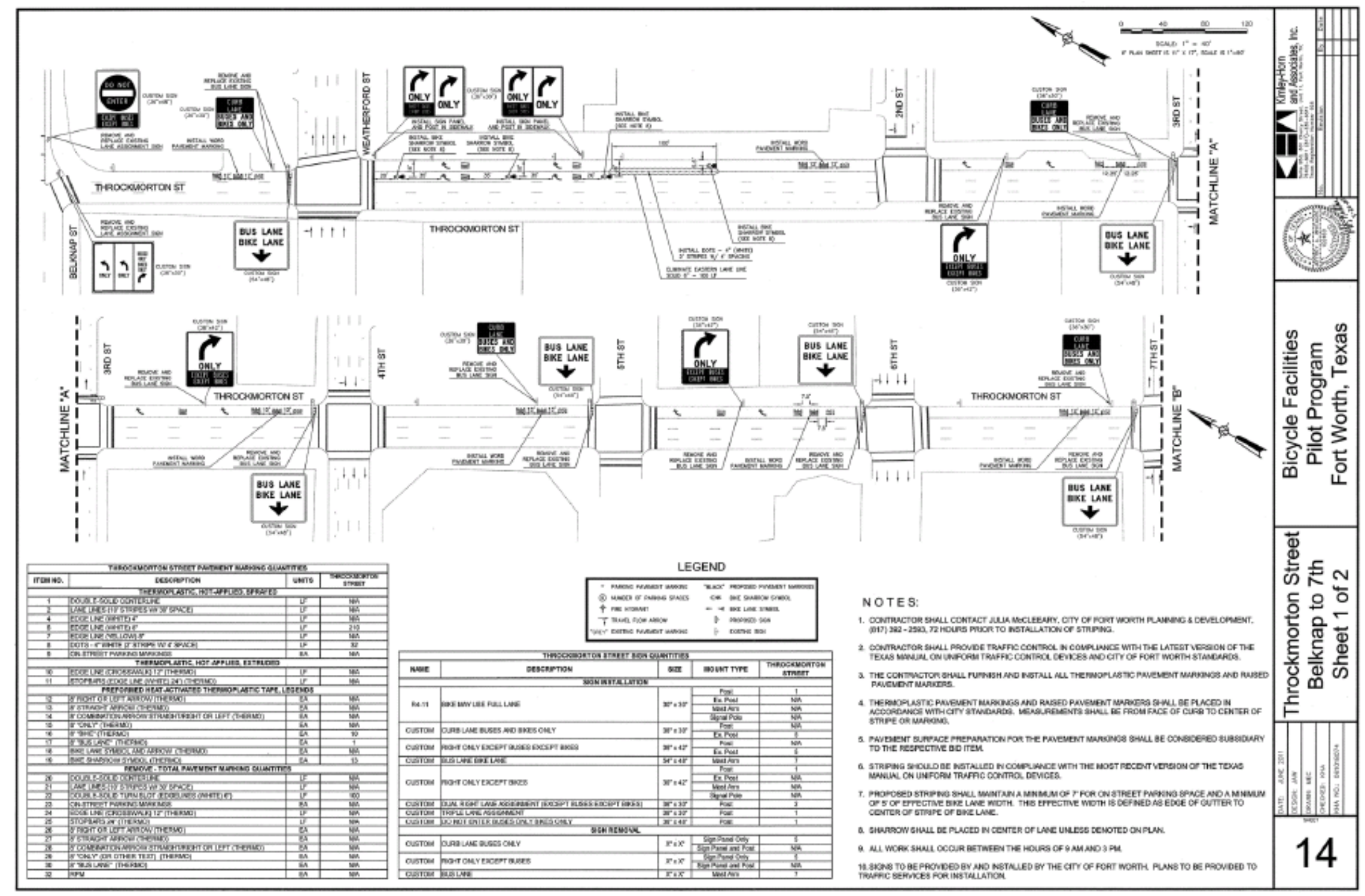




\section{Glossary}

Advisory Cycle Lane: guides bicyclists where they should be riding. A term used in the United Kingdom to mean a bicycle lane marked by dashed lines in which other vehicles should not enter unless safe to do so. These are in contrast with a mandatory cycle lane that is bounded by a solid white line and where other traffic is excluded. (Ove Arup \& Partners, Ltd. Cycle Infrastructure Design, p. 36.)

Bicycle: Section 316.003(2), F.S., defines a bicycle as "Every vehicle propelled solely by human power, and every motorized bicycle propelled by a combination of human power and an electric helper motor capable of propelling the vehicle at a speed of not more than 20 miles per hour on level ground upon which an person may ride, having two tandem wheels, and including any device generally recognized as a bicycle though equipped with two front or two rear wheels. The term does not include such a vehicle with a seat height of no more than 25 inches from the ground when the seat is adjusted to its highest position or a scooter or similar device. No person under the age of 16 may operate or ride upon a motorized bicycle."

Bicycle Lane: a portion of the roadway that has been designated for preferential or exclusive use by bicyclists by pavement markings and, if used, signs. (MUTCD, 2009, Section 1A.13, p. 11.)

Bus: Section 316.003(3), F.S., defines a bus as "Any motor vehicle designed for carrying more than 10 passengers and used for the transportation of persons and any motor vehicle, other than a taxicab, designed and used for the transportation of persons for compensation."

CTC: acronym for the Cyclists' Touring Club in the U.K. This is the U.K.'s National Cyclists' Organization. The group appears to use "CTC" rather than the full name.

Dynamic Envelope: The amount of additional width a bicyclist needs while moving to compensate for wobbling or deviating from a straight line of travel. Also referred to as "Bicyclist Operating Space" in the AASHTO Guide for the Development of Bicycle Facilities, 1999, p. 5. A term used in the United Kingdom to mean the functional width of a bicyclist. The dynamic envelope is generally considered to be one meter wide (3.28 feet). (Ove Arup \& Partners, Ltd. Cycle Infrastructure Design, p. 16.)

Leapfrog: repetitive alternating overtaking between two vehicles. There is no standard definition found but Vic Roads offers one description: "Generally, buses will overtake cyclists between bus stops and cyclists will catch up and overtake buses at bus stops. This process can lead to "leapfrogging" along the bus lane." (Cycle Notes, "Providing for Cyclists Within Bus Lanes," No. 19, Vic Roads, Victoria, Australia, April 2007.)

Outside Lane: Also referred to as curb lane.

Parallel Bike and Bus Lanes: also referred to as separate bicycle and bus lanes.

Preferential Lanes: a highway lane reserved for the exclusive use of one or more specific types of vehicles or vehicles with at least a specific number of occupants. (MUTCD 2009, Section 1A.13, Definitions of Headings, Words, and Phrases in this Manual, p. 18). Examples of preferential lanes are also listed in Sections 3D.01 and 2G.01 as lanes designated for special traffic uses, including but not 
limited to high-occupancy vehicles (HOVs), bicycles only, and buses only.

Shared Bike/Bus Lane: a term used in this report to describe a facility for shared use only by bicycles and buses, and which can be marked and signed in several ways. For brevity, this report uses the abbreviation, "SBBL". Depending upon how the SBBL is marked, it may fit the MUTCD description of a preferential lane.

Shared Roadway: a roadway that is officially designated and marked as a bicycle route, but which is open to motor vehicle travel and upon which no bicycle lane is designated. (MUTCD 2009, Section 1A.13, p. 20). The AASHTO Guide for the Development of Bicycle Facilities, 1999, also provides that signed shared roadways are those that have been identified by signed and preferred bike routes (p.19).

Substandard Width Lane: a "lane that is too narrow for a bicycle and a vehicle to travel safely side by side within the same lane." (National Committee on Uniform Traffic Laws and Ordinances 2000, §111205, 165).

Definition provided by Rule 14-96.002 State Highway System Connection Permits:

(8) Controlled Access Facility: a transportation facility to which access is regulated through the use of a permitting process by the Florida Department of Transportation.

Definitions provided by Rule 14-94.002, F.A.C. Statewide Minimum Level of Service Standards:

(2) Controlled Access Facilities: non-limited access arterial facilities where access connections, median openings, and traffic signals are highly regulated.

(3) Exclusive Through Lanes: roadway lanes exclusively designated for intrastate travel, which are physically separated from general use lanes, and to which access is highly regulated. These lanes may be used for high occupancy vehicles and express buses during peak hours if the level of service standards can be maintained.

(5) General Use Lanes: roadway lanes not exclusively designated for long distance high speed travel. In urbanized areas general use lanes include high occupancy vehicle lanes not physically separated from other travel lanes.

(7) Limited Access Facilities: multilane divided highways having a minimum of two lanes for exclusive use of traffic in each direction and full control of ingress and egress; this includes freeways and all fully controlled access roadways.

(12) Roadways Parallel to Exclusive Transit Facilities: roads that generally run parallel to and within one-half mile of exclusive transit facilities, which are physically separated rail or roadway lanes reserved for multi-passenger use by rail cars or buses serving large volumes of home/work trips during peak travel hours. Exclusive transit facilities do not include downtown people-movers, or high occupancy vehicle lanes unless physically separated from other travel lanes. 